\title{
Exotic reptiles in the pet trade: Are they a threat to New Zealand?
}

\author{
Kristina Heidy Kikillus
}

A thesis submitted to

Victoria University of Wellington

in fulfilment of the requirements for the degree of Doctor of Philosophy in Ecology and Biodiversity

Victoria University of Wellington

Te Whare Wānanga o te Ūpoko o te Ika a Māui

2010 


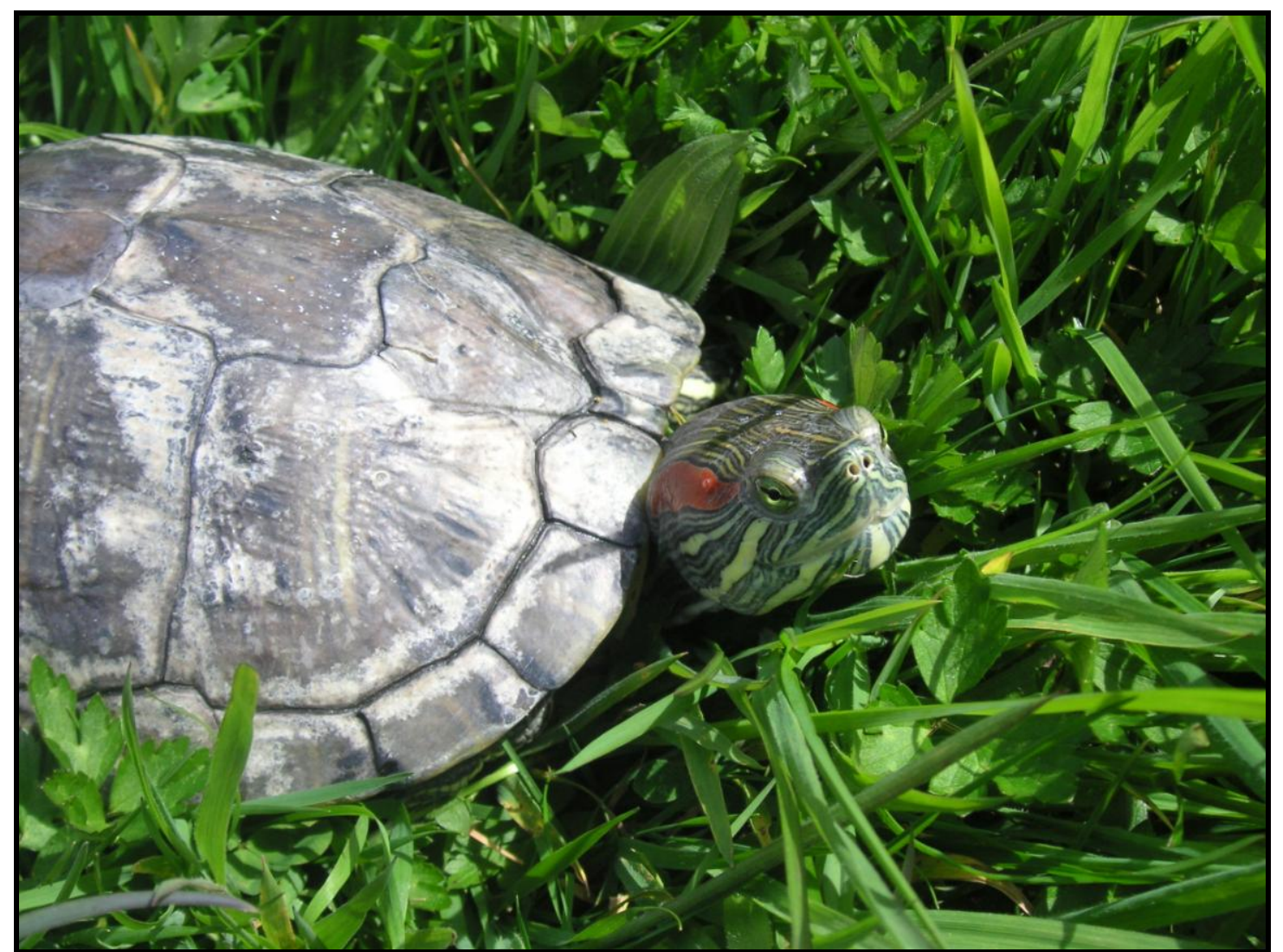

Red-eared slider turtle (Trachemys scripta elegans): The most popular species of exotic reptile found in the New Zealand pet trade. 


\section{"If you love something, set it free..."}

This phrase is no longer relevant in today's day and age. If you love your pet, but it has become an inconvenience, for goodness sake, DO NOT let it go.

It will either die a horrible death or establish an invasive population. 


\section{Abstract}

Worldwide, invasive species are associated with severe ecological and economic impacts. As a group, reptiles are very successful invaders and in some areas where they have established they are responsible for the decline of native fauna and economic disruptions, whilst also posing a threat to human health. Due to its biogeographical isolation and unique evolutionary history, New Zealand is highly susceptible to invasive species. Importation of reptiles into New Zealand is illegal, however over a dozen species of exotic reptile are legally present in captivity and their risk of establishment is unknown. This study investigates their establishment potential and possible impacts by considering 1) the amount of trade and propagule pressure of species, 2) the degree of climate match between their native range and New Zealand, 3) areas that may be suitable for establishment based on physiological models of incubation and development, 4) their ability to transfer pathogens to native fauna and humans, and 5) overall establishment risk.

The red-eared slider (Trachemys scripta elegans; RES) is the most common and easily obtained exotic reptile pet in New Zealand, with over 800 sales per annum. The RES is also the species most regularly released into the wild. Climate matching models in this study were developed to minimise false-negative predictions, to generate a suitability score irrespective of the prevalence of species records (allowing species to be easily compared to one another), and incorporated a weighted multimodel average prediction based on the relative importance of climatic variables to each species. These correlative models indicated that the blotched blue-tongue skink (Tiliqua nigrolutea) had the highest degree of climate match with parts of New Zealand, while the common blue-tongue skink (T. scincoides) had the highest proportion of land area predicted to be suitable for establishment. The other 10 species generally had both low climate match scores and limited areas within New Zealand predicted to be suitable.

Mechanistic models focus upon environmental influences on physiological processes of a species, such as development and growth. Degree-day models, combined with soil measurements in potential reptile nesting sites in New Zealand, were utilised to determine if environmental conditions were suitable for the successful reproduction of oviparous exotic reptiles. These models predicted that the 
New Zealand environment meets the minimum thermal requirements for the incubation of eggs of RES, snake-neck turtles (Chelodina longicollis), and Reeves turtles (Chinemys reevesii).

While prevalence of Salmonella in exotic reptiles is higher than that of native reptiles, it is considerably lower than that of exotic reptiles overseas. All serovars identified in this study had been previously reported both in humans and reptiles in New Zealand.

The overall risk assessment for 12 species of exotic reptile kept in captivity in New Zealand indicates that blotched blue-tongue skinks and RES pose the highest establishment risk. Blotched blue-tongue skinks are allegedly only present in zoos. Therefore, based on propagule pressure, RES pose the highest establishment risk and efforts should focus on minimising release events and removing feral individuals from the New Zealand environment.

In summary, at least eight species of exotic reptile legally traded within New Zealand are predicted to be capable of surviving in a portion of the New Zealand environment and at least three species have the potential to successfully breed in warmer microclimates. However, further research involving climatic tolerances and breeding potential (i.e., soil moisture content, juvenile survival, sex ratio, and predicted climate change) is recommended. Public education and possible regulations imposed on the New Zealand exotic reptile trade may prevent introductions of these species into the local environment and still allow selected species to be enjoyed by the New Zealand public.

The methods developed in this study may be easily applied to other species and other geographic regions, allowing investigation into the establishment risk of alien species. This may help guide control and management efforts and help stem the tide of the growing problem of invasive species. 


\section{Acknowledgements}

Both Murray Williams and Kelly Hare were very inspirational in my decision to pursue a $\mathrm{PhD}$, although admittedly, some days I was more thankful than others. Thanks to my supervisors: Stephen Hartley, Kelly Hare, and Brett Gartrell for their guidance. Funding was generously provided by Victoria University of Wellington (VUW), a Helen Stewart Royle Postgraduate Scholarship, a Kathleen Stewart Postgraduate Scholarship, the New Zealand Biosecurity Institute, the Society for Research on Amphibians and Reptiles in New Zealand, Education NZ, the New Zealand Wildlife Health Centre, the Ian Swingland Scholarship Fund, and the Centre for Biodiversity and Restoration Ecology.

Paul Pendlebury of Reptrans UK was very helpful in suggesting factors to incorporate when choosing datalogger deployment sites. Thanks to Greg Hoskins, Andrew Stein, Mark Mitchell, Miranda Bennett, and Jack Craw of the Auckland Regional Council (ARC) for assistance in identifying suitable study sites and for not laughing too much when my gumboots got stuck in the mud at the edge of Henderson Creek. Also thanks to the other folks that allowed me to bury dataloggers at their institutions: Lana Judd, Lou Parker, and Mike and Alex Chillingworth of Auckland Zoo, Kara Goddard of Hamilton Zoo, and Raewynn Empson of Zealandia.

Thanks to Andrew Smith, Monica Awasthy, Gesine Pufal, and Leon Briggs for fieldwork assistance, especially datalogger deployment and retrieval. It was challenging wandering around parks and botanic gardens, etc. with a shovel and gardening spade while trying to not appear "dodgy" to concerned members of the public. At one site in Waitakere, it was particularly difficult to locate a buried datalogger; ARC, VUW colleagues, and I spent over an hour turning up turf trying to find it. Luckily it was an isolated area, as if anyone had spotted us, it's possible they may have thought we were trying to bury a body. Thanks to Andy Stein for finding the elusive logger a year later with the help of a metal detector.

Thanks to the many owners of exotic reptiles in New Zealand that allowed me to sample their collections, some of which, such as Tony and Viv Whitaker, even generously housed and fed me while I collected samples! Sample collection procedures were approved by the Victoria University of Wellington (VUW) Animal Ethics Committee (\#2006R18) and Salmonella cultures were carried out by New Zealand Veterinary Pathology.

Thanks to the late Steve Irwin for educating me in the handling procedures of unruly reptiles. Upon my first pet shop visit of this study, I was directed to a large walk-in enclosure housing adult waterdragons. Not wanting to admit I'd never handled one of these animals before, I thought back to the Crocodile Hunter TV shows I'd seen, and launched myself across the exhibit, landing on a huge waterdragon and securing it in one seamless motion. I surprised not only myself, but apparently the entire pet store staff, who had congregated at the exhibit entrance with their mouths hanging wide open. When I asked how they usually captured the animals, their response was "We never have. We're afraid of them".

It was great to meet other folks involved in similar work as myself at the $6^{\text {th }}$ World Congress of Herpetology in Brazil. Thanks to Fred Kraus and Bob Reed for organising the Invasive Herpetofauna symposium and the invitation to present. Also thanks to Earl Kraus, Ernst Baard, Nicola van Wilgen, Gordon Rodda, Jim Foster, Gad Perry, Michelle Christy, Joshua Ream, Weiguo Du, Phil Bishop, Nate Hawley, James Stanford, Toby Hibbits, Bryan Maritz, and Francesco Ficetola. Also thanks to 
Haitao Shi for lengthy discussions regarding red-eared slider turtles in China (for which we had plenty of time for as our post-conference fieldtrip resulted in a brokendown houseboat, leaving us stranded in the middle of the Amazon for days).

The VUW Herpetological Hatchet group, Bug Club, and Terrestrial Vertebrate group were extremely helpful in providing constructive criticisms on drafts. Special thanks to Duncan Wright, Elizabeth Heeg, Andy Douglas, Danielle Middleton, Catherine Duthie, Allan Burne, Rosalyn Anderson-Lederer, Ilse Corkery, Bionda Morelissen, Nicky Nelson, Ben Bell, Alison Cree, Beaux Berkeley, Laura Warman, Dan Logan, Pip Tronc, Rochelle Hawthorn, Robyn and Jan Lutzenberger, Darren Reddiex, Gabby O'Brien, and my San Diego Zoo mates. Also thanks to Dr. Mark Feldman for discussions regarding red-eared sliders in New Zealand. Life would have been much more difficult without Sue D'Ath of the VUW library. Her prompt and concise responses to my many EndNote queries were much appreciated. Also thanks to Patricia Stein, Mary Murray, and Sandra Taylor for always having an answer for my administrative questions, for providing me with an awesome office, and for participating in our delicious weekly "Healthy Lunch" club. Also thanks to the regular Karori quiz team, who shared my feeling of bewilderment that a table full of postgrads could not consistently achieve a high score. Special thanks to Jeff Shima, Dianne Brunton, and Bob Reed for providing comments to greatly improve this thesis.

Thanks to my landlord for deciding to sell my flat the week before I handed-in; it allowed me to discover innovative time-management and stress-relief techniques. Special thanks to Leon Briggs for his unconditional support, encouragement, Microsoft Office tips, and for cheerfully tolerating my PhD-induced mood swings without a single complaint. You are one-of-a-kind. Most of all, thank you to my wonderful parents who supported me whole-heartedly, even though they didn't always fully understand what I was doing. They even took me with them on a trip to Hawaii and a Mexican cruise, where I was able to simultaneously work on my thesis and my tan. Also, thanks to them for taking such good care of Harley. I wish he could have held on until I finished; but I know my Pumpkin was in the best of hands. Thanks again everyone; I owe you all a margarita at the very least! 


\section{Table of Contents}

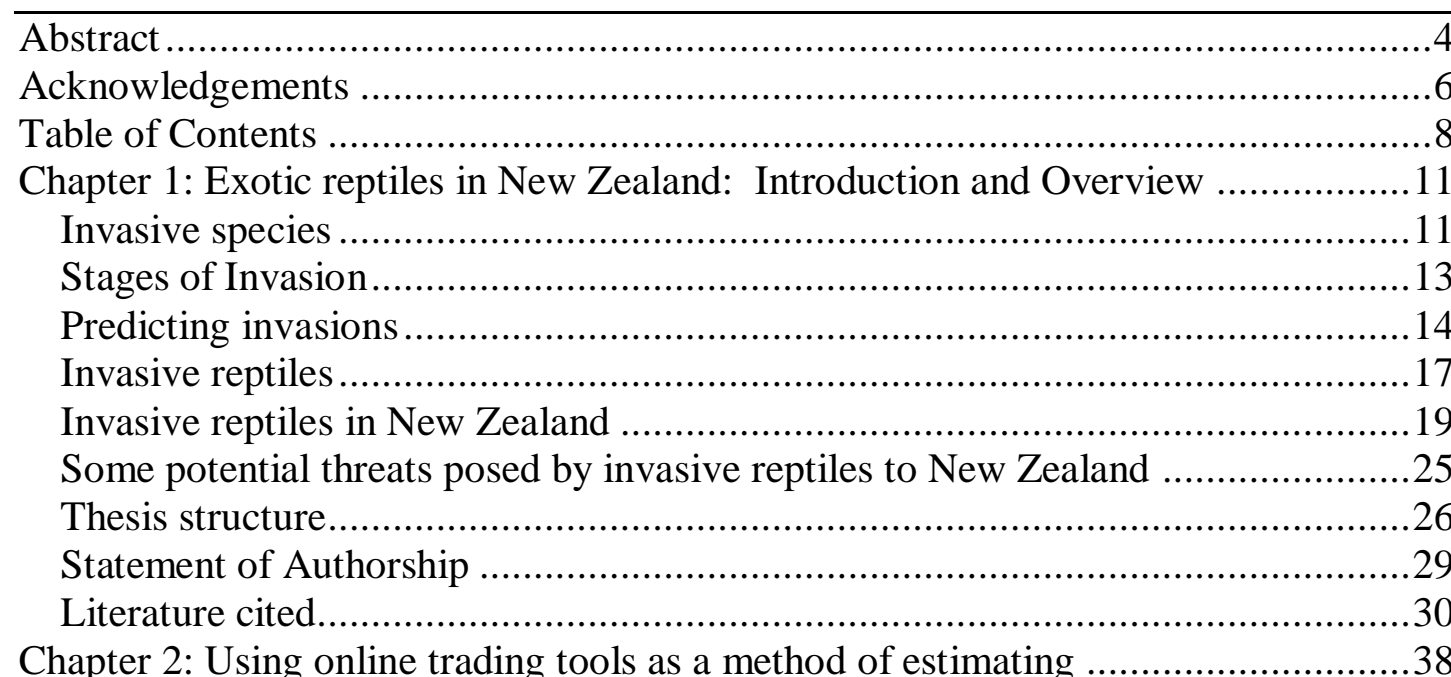

propagule pressure of an invasive species: A case study using red-eared slider turtles

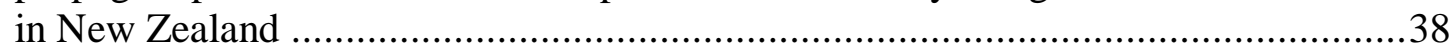

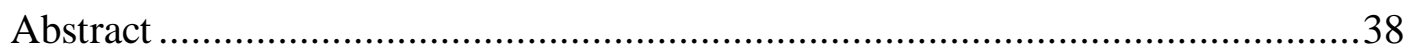

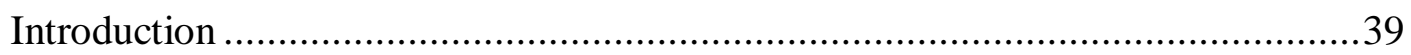

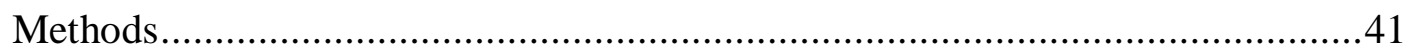

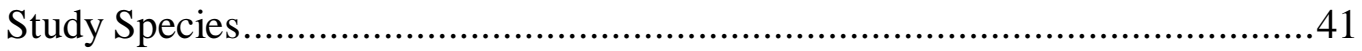

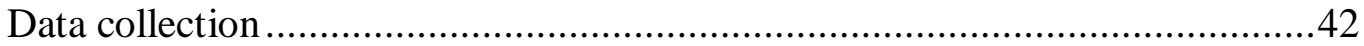

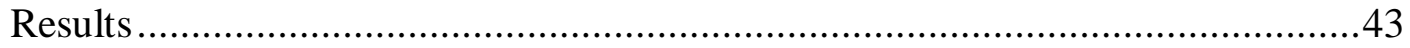

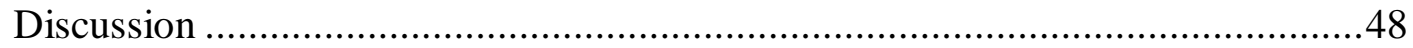

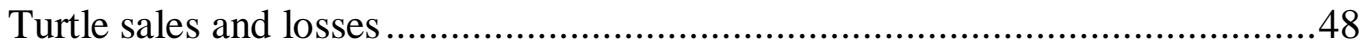

Usefulness of online trading tools ...............................................................50

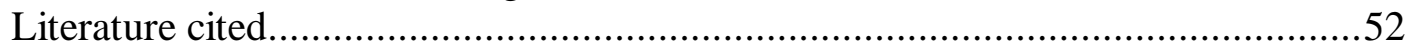

Chapter 3: Minimising false-negatives when predicting the potential .....................54 distribution of an invasive species: a bioclimatic envelope for the red-eared slider at

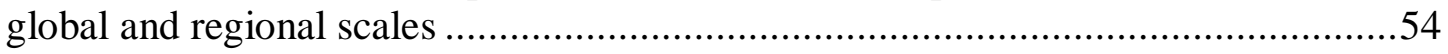

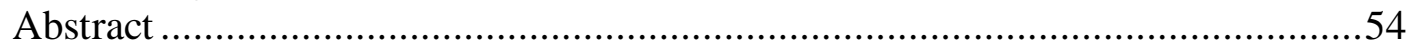

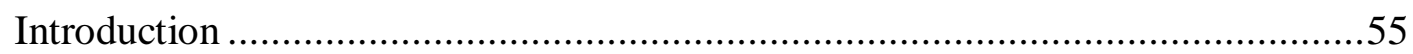

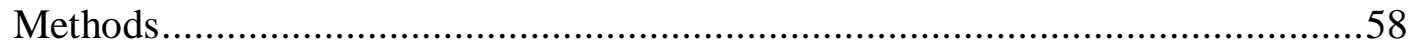

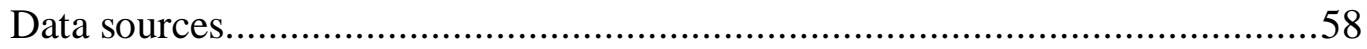

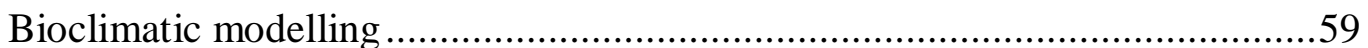

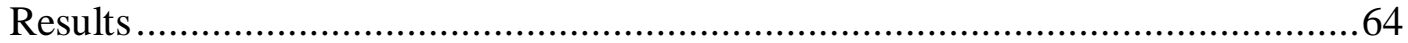

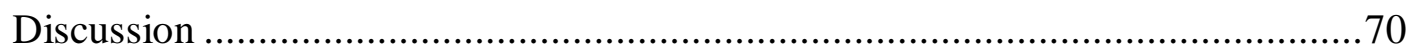

Global predictions and the climate envelope for RES ..................................70

Assessing potential for establishment at a regional level (New Zealand) ..........71

Climate Envelope Approach....................................................................73

Choice of model metrics ......................................................................... 73

Conservation and Management Implications ................................................ 75

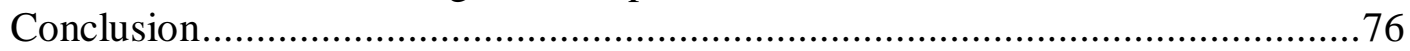

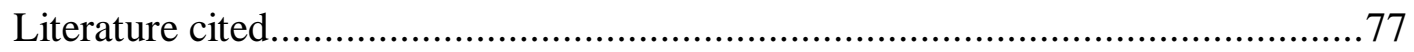

Chapter 4: Predicting the potential for exotic reptile establishment in New Zealand

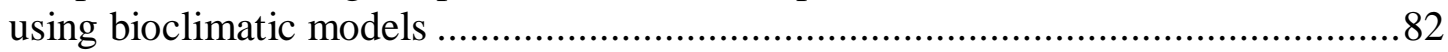

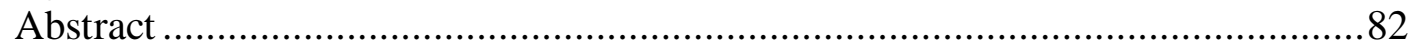

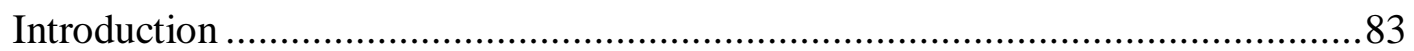

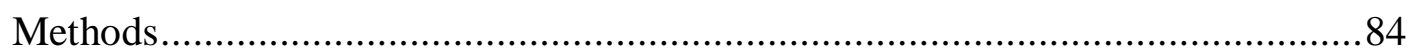




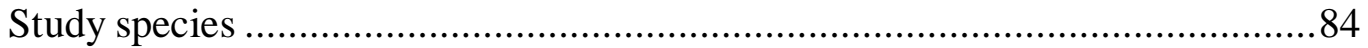

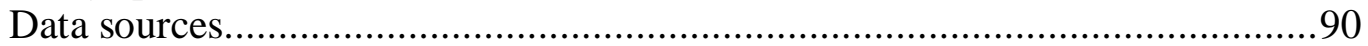

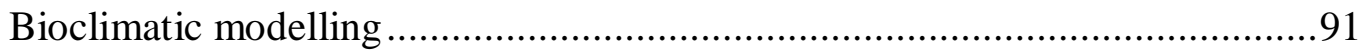

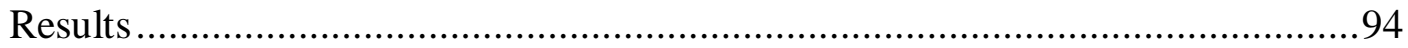

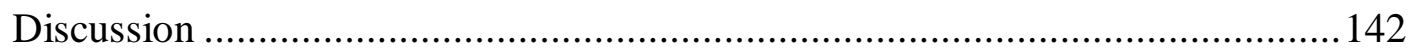

Climatic factors important in predicting distribution range ......................... 142

Other factors to consider when predicting establishment risk........................146

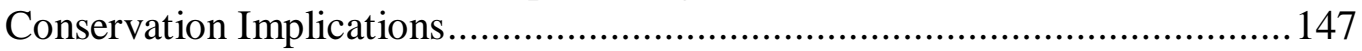

Chapter 5: Developmental degree-day models to assess the establishment potential of red-eared slider turtles and other exotic reptiles in New Zealand ...........................151

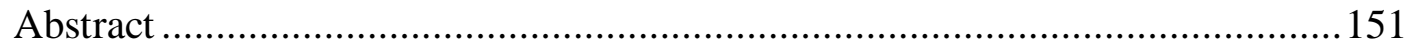

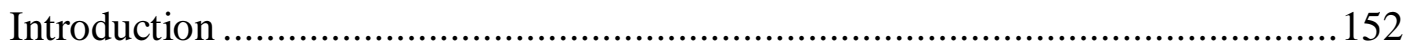

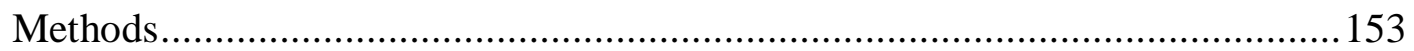

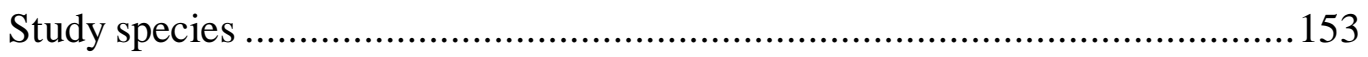

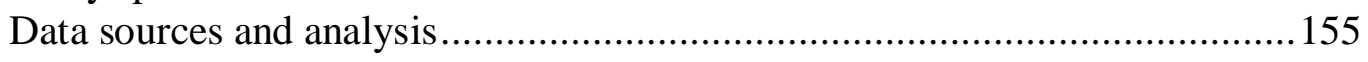

Degree-day measurements from the environment .................................... 156

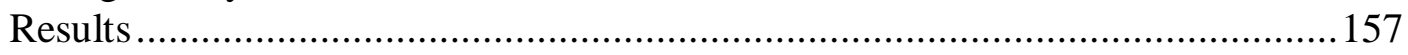

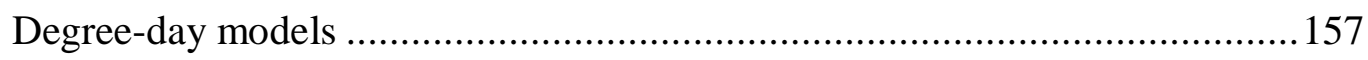

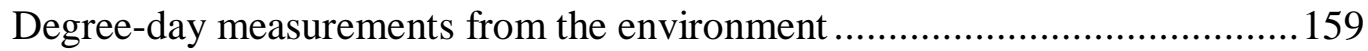

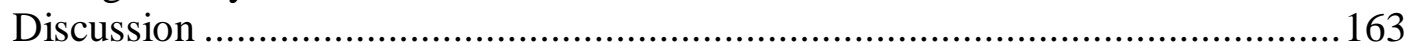

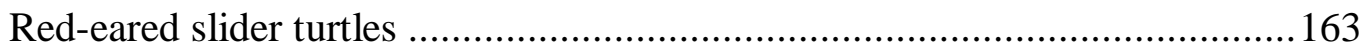

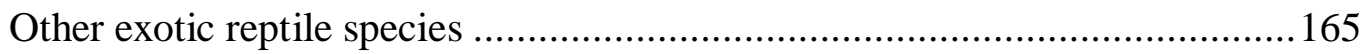

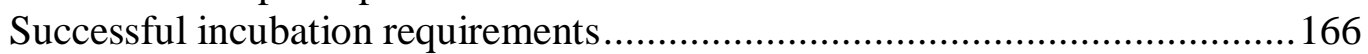

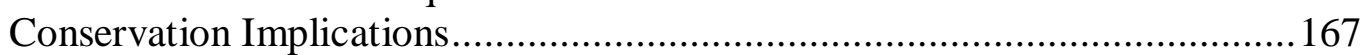

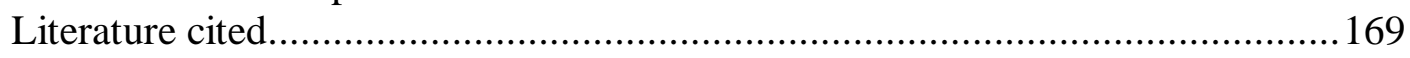

Chapter 6: Salmonella prevalence and detected serovars associated with captive

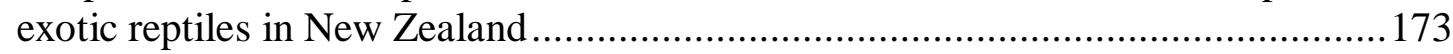

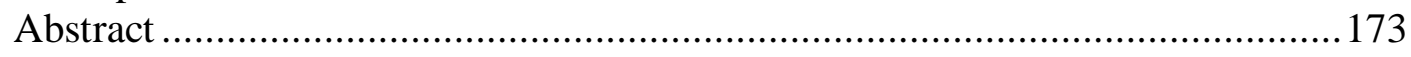

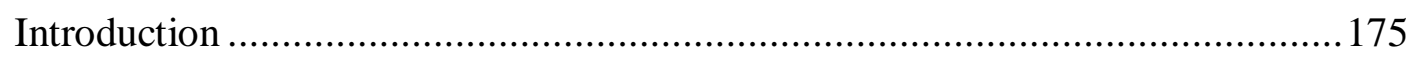

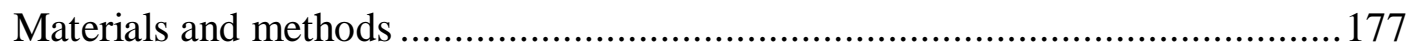

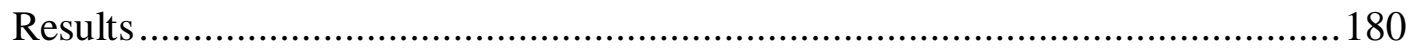

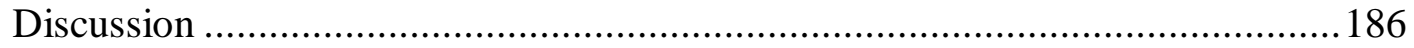

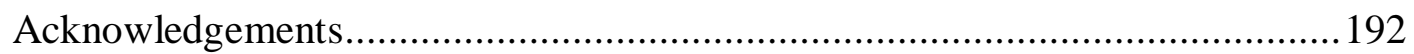

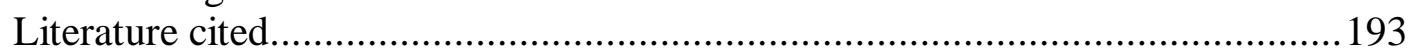

Chapter 7: Overall establishment risk assessment of exotic reptiles in New Zealand

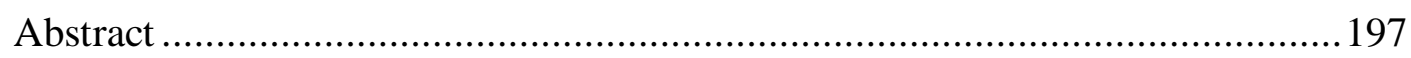

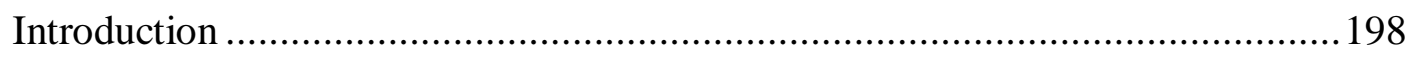

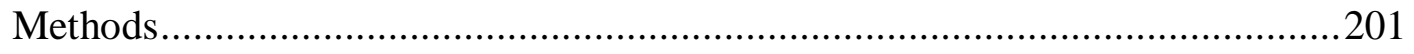

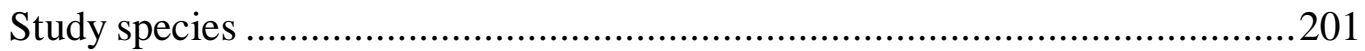

Selection of criteria and methods for risk assessment ................................202

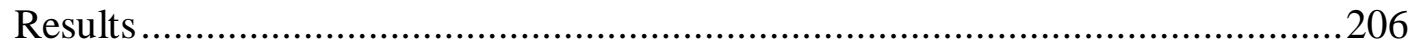

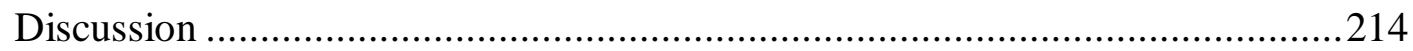

Establishment risk of exotic reptiles in New Zealand ................................2215

Other factors to consider in risk analyses...............................................217

Future research directions ....................................................................219

Recommendations to prevent the establishment of exotic reptiles in New Zealand

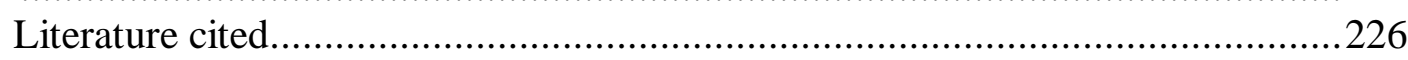

Appendix 1: Red-eared slider turtle (Trachemys scripta elegans) ........................230 
Appendix 2: Snake-neck turtle (Chelodina longicollis) .......................................2239

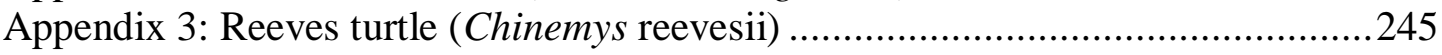

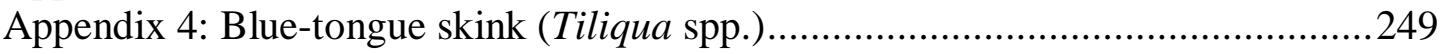

Appendix 5: Bearded dragon (Pogona spp.)...................................................25

Appendix 6: Australian waterdragon (Physignathus lesueurii) ..............................261

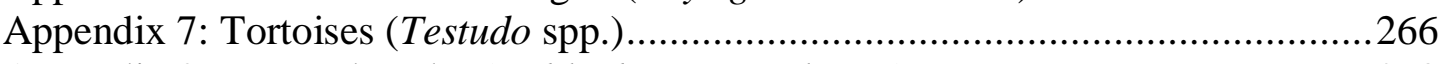

Appendix 8: Leopard gecko (Eublepharis macularius) ......................................2270

Appendix 9: Supplementary Information for Chapter 3 ....................................2273

Appendix 10: Supplementary Information for Chapter 4 ....................................282

Appendix 11: Supplementary Information for Chapter 5 ...................................301 


\section{Chapter 1: Exotic reptiles in New Zealand: Introduction and Overview}

\section{Invasive species}

In addition to habitat loss and climate change, invasive pest species are a significant threat to biodiversity loss worldwide (Wittenberg and Cock 2001; Campbell and Donlan 2005; Nogales et al. 2006). Although not all introductions are successful (Williamson and Fitter 1996), species that are able to persist and establish populations outside of their natural range often affect native organisms in a negative manner (Kolar and Lodge 2001). Negative effects of invasive species occur via predation, competition for resources, habitat alteration, hybridization, and/or by the introduction of novel diseases and pathogens (Manchester and Bullock 2000; Duffey 2001; Cole et al. 2005). In addition, invasive pests are often associated with severe economic impacts. For example, in New Zealand, the estimated annual costs associated with invasive species, encompassing economic losses and control measures, amount to over 840 Million NZD (Pimentel 2002), while in larger countries, such as the USA, these costs reach figures of 137 Billion USD (Pimentel et al. 2000).

Predation of native species by invasive pests is an immense problem worldwide. For example, introduced cats (Felis cattus), foxes (Vulpes vulpes), and mongoose (Herpestes javanicus) have caused declines of many native species, and in some cases extinctions, in areas where they have established (Invasive Species Specialist Group (ISSG) 2004). The vast majority of New Zealand's mammals are 


\section{Chapter 1: Introduction and overview}

introduced (King 2005), and through direct predation and habitat modification have caused many native species to become extinct or relegated to predator-free offshore islands. For example, stoats (Mustela erminea), ferrets (M. furo), and rats (Rattus norvegicus, $R$. rattus, and $R$. exulans) have reduced populations of iconic New Zealand species, such as kiwi (Apteryx spp.) and tuatara (Sphenodon punctatus) (Hutching 2004).

Many invasive species become successful by outcompeting, and thus replacing, native species. For example, $\sim 60 \%$ of the native vegetation in the South African fynbos has been replaced by stronger-growing Australian and Mediterranean vegetation (Heywood 1989). Invasive species are also capable of habitat alteration in their introduced ranges; for example removal of vegetation via grazing and trampling by invasive mammals has resulted in major soil erosion in some parts of the world (Macdonald et al. 1989). Additionally, hybridisation between native species and invasive species can occur. In New Zealand, the introduced mallard (Anas platyrhychos) has successfully bred with the native grey duck (A. superciliosa), resulting in a decline in 'pure' grey ducks (Macdonald et al. 1989).

Another major concern associated with non-native species is the introduction of novel pathogens and diseases into a new environment (Mack et al. 2000). These pathogens and diseases have the ability to negatively affect native species, agricultural products, and humans (Mack et al. 2000). In North America, for example, the invasive insect Cryptococcus fagisuga is responsible for spreading beech bark disease, causing mortality of American beech trees (Fagus grandifolia) (Gwiazdowski et al. 2006). Similarly, introduced mosquitoes and birds are linked with the spread of fatal avian pox and malaria among native birds in Hawaii (Simberloff 1996). In Europe, plant pathogens introduced with seed crops are 


\section{Chapter 1: Introduction and overview}

responsible for the loss of $8.3 \%$ of potential agricultural production, amounting to an annual economic loss of billions of dollars (Pimentel 2002).

Non-native species can also act as disease vectors. In New Zealand, introduced Australian brushtail possums (Trichosurus vulpecula) act as a vector for Bovine Tuberculosis, which has the potential to threaten New Zealand's agricultural exports of beef, venison, and dairy products, as well as human health (Clout 2002). Additionally, exotic diseases, such as Cholera, HIV/AIDS, and Influenza, have been transported all around the world and have been responsible for millions of human deaths (Kim 2002). On the other hand, it is hypothesized that some invasive species are successful in their new surroundings because they may have escaped their natural parasites (Torchin et al. 2003). In some cases, invasive species are derived from small founder populations, which may increase the chances of the colonists leaving behind pathogens and parasites in the native habitat (Torchin et al. 2003). It is possible, however, that an introduced invader may be a competent host for a native parasite, thus increasing disease risk for native species via "parasite spillback" (Kelly et al. 2009).

\section{Stages of Invasion}

In order for a species to become invasive, it must first be transported to a new geographic location (Williamson 1996). Natural colonisation by species can occur (White et al. 2008), however humans are responsible for the majority of recent introductions, both accidental and intentional (Heywood 1989). Many species have deliberately been transported to new locales across the globe for food, companionship, biological control, sport, or aesthetic purposes. For example, cane toads (Bufo marinus) as a biocontrol agent in Australia (Invasive Species Specialist Group (ISSG) 


\section{Chapter 1: Introduction and overview}

2004) and red deer (Cervus elaphus) for hunting in New Zealand (Brown 1989).

After arrival, a species must be introduced (either deliberately or accidentally) into the new environment and those individuals that survive and colonise may go on to establish self-sustaining populations. Those that successfully establish may go on to spread from their point of introduction and become classified as pests (Catford et al. 2009). At each "stage" of the invasion process, many species are "filtered out", with fewer and fewer species going on to complete the entire process (Lodge et al. 2009). In an effort to quantify the rate of invasions, Williamson introduced the "tens rule" in 1986. It states that approximately $10 \%$ of species introduced into an area may become established, and of those, approximately $10 \%$ become pests (Williamson and Brown 1986). It is not a rigid rule (Williamson 1993), but gives us a better understanding of the proportion of non-native species that become a problem in new surroundings.

\section{Predicting invasions}

In an effort to predict future invasions, many attempts have been made to identify general characteristics of successful invaders (Holdgate 1986; Rejmanek and Richardson 1996; Kolar and Lodge 2001). While certain factors, such as high fecundity, generalist diets, and high rates of dispersal seem to apply to a large proportion of successful invaders, no set "rules" apply evenly across all taxa. Bomford (2003) also warns that some species may develop "new unpredictable behaviour patterns" when introduced to a new environment, and Phillips and Shine (2005) also note that invasive species are often able to adapt to their new surroundings, making predictions regarding a species' potential pest status difficult. Additionally, if there are more than two invasive species involved, their combined 


\section{Chapter 1: Introduction and overview}

effects "may result in synergistic effects that exceed the sum of the individual species effects" (Pitt et al. 2005)

One theory behind the success or failure of species introductions is the availability of a vacant functional niche (or 'place in the biotic environment') for that species (Williamson 1996). Some species may fail to establish in new areas when they find their niche is already occupied, however, others may evolve upon introduction to a new area, allowing them to expand into new niches (Simberloff 1989; Broennimann et al. 2007). Often areas with lower species diversity tend to have a higher proportion of vacant niches, or 'broader' niches due to reduced competition, and are thus believed to have a higher susceptibility to invasion (Loope and Mueller-Dombois 1989; Stachowicz and Tilman 2005). New Zealand was considered an 'easy' target for the establishment of exotic, predatory mammals, as no ecological equivalents existed before their arrival (Ehrlich 1989). Additionally, smaller, isolated environments, such as islands, seem to be more susceptible to invaders than larger mainland areas (Brown 1989).

Identifying a species' 'bioclimatic envelope', which constitutes the climatic component of a species' fundamental ecological niche, is an important tool to consider in predicting the potential distribution of invasive species (Pearson and Dawson 2003). This correlative approach compares the climate parameters from a species' native range to an area of interest in order to identify overlaps, and thus areas that may be suitable for establishment (Thuiller et al. 2005). Model predictions, however, must be interpreted with caution, as perceived limits in a species' climate space observed in one region do not necessarily limit their potential invasion elsewhere (Broennimann et al. 2007). In other words, a species may be capable of surviving in a climate different to that of its native range (Williamson 1996). 


\section{Chapter 1: Introduction and overview}

Examples include tropical deer (Cervus timorensis and Axis porcinus) that have established in temperate areas, and temperate species, such as Mus musculus, Rattus norvegicus, and Equus asinus, that have invaded tropical areas (Brown 1989). Reasons for an apparent expansion of the realised niche in introduced areas may include release from biotic constraints such as natural enemies (Wolfe 2002).

Bioclimatic predictive modelling also does not account for the evolutionary potential of invasive species (Pearson and Dawson 2003). These models assume that a species' ecological niche remains constant as they establish in a new environment (Holt et al. 2005). Despite these limitations, climate-matching is a good 'first step' in assessing the establishment potential of a species of interest (Ficetola et al. 2007). If a species is found to have a similar climate-match to the area investigated, further research into factors such as biotic interactions and habitat availability should be conducted (Pearson et al. 2004).

A complement to the correlative bioclimatic model approach is the use of mechanistic models. Rather than incorporate species distribution data, they focus upon environmental influences on physiological processes of a species, such as development and growth (Hartley et al. 2010) and can assist in identifying areas where a species' survival is physiologically impossible (Kearney et al. 2008). Degree-day models are a type of physiological model often used for species whose development is temperature-dependent in order to help predict timing of pest outbreaks or geographic limits of distribution (Broufas and Koveos 2000; Hartley and Lester 2003; Baek et al. 2008). They require the determination of a threshold temperature above which development can occur (Blank et al. 2000), which is then compared to the environment to see where those requirements can be met. In comparison, the correlative model approach examines realised distributions and is 


\section{Chapter 1: Introduction and overview}

often better at predicting species' distributions, while mechanistic models aim to define the fundamental niche and are stronger at explaining the distributions (Kearney and Porter 2004). Used in conjunction, they can help elucidate a species' potential distribution in a new environment based on both on its current distribution and its physiological requirements (Kearney et al. 2008; Phillips et al. 2008; Elith et al. 2010).

Although associated with a level of uncertainty (Sikder et al. 2006), predictive models allow us to investigate the establishment potential of species of interest. It is much more efficient and cost-effective to prevent a species from establishing than attempting to control it once it has become established (Mack et al. 2000; Manchester and Bullock 2000). Eradication can be a costly endeavour, and is often impossible (Usher 1989; Keller and Drake 2009), making the prevention of alien species introductions a logical priority in order to avoid the economic and ecological effects often associated with invaders.

\section{Invasive reptiles}

As a group, reptiles are very successful invaders (e.g., Buden et al. 2001). The main pathways for exotic reptile introductions include accidental introductions via cargo and the horticultural nursery trade, and deliberate introductions for the pet trade, biocontrol, aesthetic purposes, and for use as food (Kraus 2007; Kraus 2009). Globally, some species of exotic reptile are implicated in serious ecological and economic disruption. The most famous invasive reptile is the brown tree snake, Boiga irregularis, which has flourished in Guam since its accidental introduction after the Second World War (Savidge 1987). It is responsible for the extinction of the majority of Guam's native bird species (Wiles et al. 2003) and the decimation of 


\section{Chapter 1: Introduction and overview}

many species of native lizard (Rodda et al. 1997). Attacks on humans have also been reported, with the mildly-venomous snakes biting dozens of sleeping adults and children annually, causing a reaction similar to a bee sting (Lever 2003). Numerous power outages on the island are also attributed to the brown tree snake, as the snakes have a tendency to climb along electrical transmission lines and subsequently become electrocuted, causing power outages. In recent years, over 200 outages annually have been recorded, with a single major outage in 1987 estimated to have cost 3.5 million USD in lost productivity (Fritts 2002). Annual costs associated with this pest, including control measures and loss of productivity, amount to over 5.5 million USD (Pimentel et al. 2000).

All of Hawaii's terrestrial reptiles, over a dozen species, are introduced (McKeown 1978; Lever 2003). Many exotic reptile populations, such as those of veiled and Jackson's chameleons (Chamaeleo calyptratus and C. jacksonii) are likely the result of deliberate releases or escapes of pets (Hawaiian Ecosystems at Risk (HEAR) 2007), however some species are thought to have arrived with Polynesian settlers or, more recently, as stowaways in cargo shipments (McKeown 1978). Another U.S. state which has a plethora of introduced reptile species is Florida (Townsend et al. 2002). Many of these established populations are directly attributed to escapes and deliberate releases associated with the exotic pet trade (Lever 2003; Enge et al. 2004; Krysko et al. 2004; Krysko 2005; Krysko and Enge 2005). Several of the introduced species in the United States are relatively small lizards (100-200 mm Snout-to-Vent-Length (SVL)) which may compete with native species, (e.g., bloodsucker lizard (Calotes versicolor) (Enge and Krysko 2004), knight anole (Anolis equestris) (Krysko 2000), brown basilisk (Basiliscus vittatus) (Krysko et al. 2006), butterfly lizard (Leiolepis belliana) (Krysko and Enge 2005), veiled chameleon 


\section{Chapter 1: Introduction and overview}

(Chamaeleo calyptratus) (Krysko et al. 2004), Madagascar giant day gecko (Phelsuma madagascariensis grandis) (Krysko et al. 2003), and African rainbow lizard (Agama agama africana) (Enge et al. 2004). Some larger lizards (>200 mm SVL), such as the green iguana (Iguana iguana) have also established populations and have been reported to prey upon native invertebrates (Townsend et al. 2005), and at least one species of large, carnivorous lizard, the Nile monitor (Varanus niloticus) has also become established and been reported to consume native wildlife (Enge et al. 2004; Campbell 2005). Several species of large constrictor snake have also become established in southern Florida (Snow et al. 2007; Reed et al. 2010).

\section{Invasive reptiles in New Zealand}

New Zealand currently holds the dubious honour of having the highest number of introduced mammals in the world and the second highest number of introduced birds (New Zealand Biodiversity 2000). Several species of exotic reptile have also been found living in the wild in New Zealand. In 1886, numerous specimens of the English scaly lizard (Lacerta vivipara) were found on Tinakori Hill in Wellington, however it is believed that they were accidentally introduced with plants headed for the Botanic Gardens, and are not thought to have established sustainable populations (Robb 1980). Geckos are also often intercepted in cargo shipments (Gill et al. 2001). Specimens of Gehyra oceanica and Lepidodactylus lugubris have been recorded on several islands off the coast of northern New Zealand (Robb 1980) and there have also been reports of the deliberate introduction of Cunningham's skinks (Egernia cunninghami) onto Rangitoto Island (near Auckland); at least one specimen has previously been captured from the island (DR Towns, pers. comm. 2007, New Zealand Department of Conservation). Accidental imports of 


\section{Chapter 1: Introduction and overview}

other species continue to occur, most recently a live Australian agamid lizard (Lophognathus spp.) which was found in a traveller's luggage in Blenheim (Wong 2010).

To date, only one reptile (the Australian skink, Lampropholis delicata) is known to have successfully established and is currently spreading within New Zealand (Gill et al. 2001; Peace 2004). Lampropholis delicata is thought to have arrived accidentally in New Zealand in the 1960's in cargo shipments (Henle 1981; Gill et al. 2001; Peace 2004). It is also invasive on Lord Howe Island and the Hawaiian Islands (Lever 2003). In the last century, over fifty species of exotic reptile have been intercepted at New Zealand's borders (Gill et al. 2001), including over 700 individual specimens within the last six years (Ministry of Agriculture and Forestry (MAF), unpubl. data). As international trade intensifies, the number of reptiles accidentally imported to New Zealand is expected to increase (Gill et al. 2001).

In addition to further accidental introductions of exotic reptiles, the deliberate release of unwanted pets is another pathway in which non-native reptiles may gain a foothold. Reptiles are popular pets in New Zealand and at least ten exotic species are legally kept in captivity (Table 1). These range from Asian and Australian lizards to aquatic and terrestrial chelonians native to North America, Australia, Europe, and Asia (Thornton 1999; Burne 2000; The Turtle and Reptile Farm 2006). Terrestrial snakes are not present in New Zealand and are illegal in this country (Environmental Risk Management Authority 2008). 
Table 1: The ten most common exotic reptile species found in the New Zealand pet trade. Please see Appendices 1-8 for detailed descriptions of each species. Average prices were obtained from personal observations in New Zealand pet stores and online auction websites (www.trademe.co.nz).

\begin{tabular}{|c|c|c|c|c|}
\hline Order & Scientific Name & Common Name & Native Range & $\begin{array}{c}\text { Average Price } \\
\text { (NZD) }\end{array}$ \\
\hline \multirow[t]{5}{*}{ Testudines } & Chelodina longicollis & snake-neck turtle & Australia & 120 \\
\hline & Chinemys reevesii & Reeves turtle & Asia & 300 \\
\hline & $\begin{array}{l}\text { Trachemys scripta } \\
\text { elegans }\end{array}$ & $\begin{array}{l}\text { red-eared slider } \\
\text { turtle }\end{array}$ & USA & 75 \\
\hline & Testudo graeca & Greek tortoise & Europe/ Asia & 3,500 \\
\hline & Testudo hermanni & Hermanns tortoise & Europe/ Asia & 6,000 \\
\hline \multirow[t]{5}{*}{ Squamata } & Pogona vitticeps & $\begin{array}{l}\text { inland bearded } \\
\text { dragon }\end{array}$ & Australia & 400 \\
\hline & Pogona barbata & $\begin{array}{l}\text { coastal bearded } \\
\text { dragon }\end{array}$ & Australia & 600 \\
\hline & Physignathus lesueurii & waterdragon & Australia & 700 \\
\hline & Tiliqua scincoides & blue-tongue skink & Australia & 300 \\
\hline & Eublepharis macularius & leopard gecko & Asia & 1,000 \\
\hline
\end{tabular}

Red-eared slider turtles (Trachemys scripta elegans; RES), are by far the most abundant and affordable exotic reptile pet in New Zealand. From October 2007 to October 2009, over 1500 RES were sold on the online auction site, TradeMe (www.trademe.co.nz). It is unknown how many more RES were sold privately or through pet stores during that time. On the contrary, some species in Table 1 are rarely seen offered for sale (Figure 1). For example, only one Hermanns tortoise was sold on TradeMe within the same two year period, commanding a price of $\sim 6,000$ NZD. In late 2009, leopard geckos (Eublepharis macularius) also began appearing for sale on TradeMe (KH Kikillus, pers. obs.), commanding no less than 1,000 NZD per specimen. In May 2010, leopard geckos began being advertised in Auckland-area pet stores for 890 NZD (Hollywood Fish Farm 2010). 
Figure 1: Exotic reptiles sold on the online auction site, TradeMe (www.trademe.co.nz) between October 2007 and October 2009. Excluded from this graph are red-eared slider turtles (RES), which had over 1,500 sales (See Chapter 2). It does, however, include the sale of a single RES x Florida cooter turtle hybrid, which was sold online in September 2008 for 900 NZD. Scientific names of species are outlined in Tables 1 and 2. $\mathrm{N}=550$.

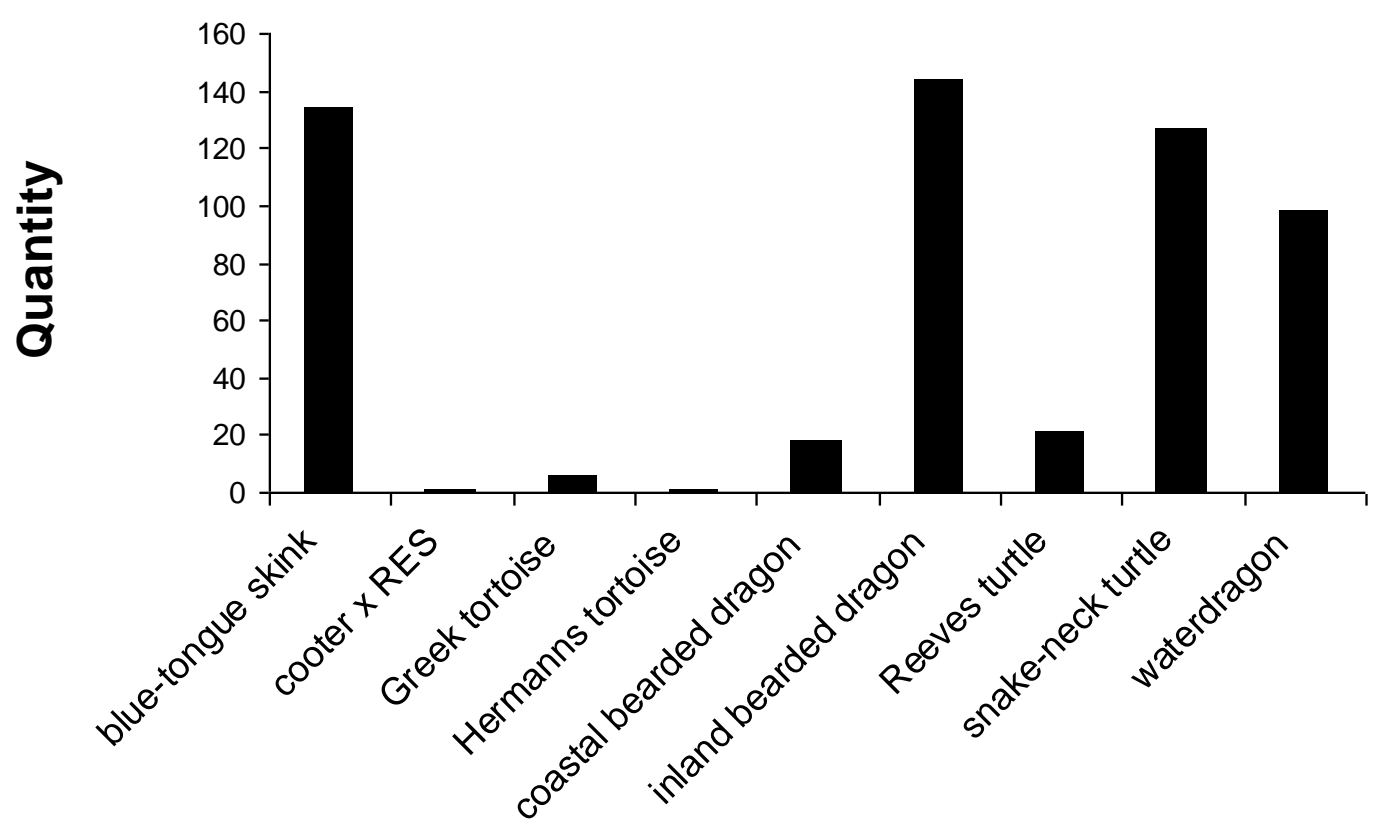

Species

While the reptiles listed in Table 1 are the most common species encountered within the New Zealand pet trade, there are additional species present in the country (Table 2). Many are represented by single individuals, or small, same-sex groups. The majority of these species are believed to be confined to authorised containment facilities (e.g. zoos). 
Table 2: Exotic reptiles housed in zoological parks, aquariums, and private collections in New Zealand. Species commonly found in the pet trade in New Zealand are listed in Table 1.

\begin{tabular}{|c|c|c|c|}
\hline Order & Scientific Name & Common Name & Native Range \\
\hline \multirow[t]{16}{*}{ Testudines } & Cuora amboinensis & Malayan box turtle & Asia \\
\hline & C. flavomarginata & yellow-margined box turtle & Asia \\
\hline & Cyclemys atripons & black-bridged leaf turtle & Asia \\
\hline & Emydura macquarii & Murray River turtle & Australia \\
\hline & Geochelone carbonaria & red-footed tortoise & South America \\
\hline & G. chilensis & Chaco tortoise & South America \\
\hline & G. denticulata & yellow-footed tortoise & South America \\
\hline & G. elegans & star tortoise & India, Pakistan, Sri Lanka \\
\hline & G. pardalis & leopard tortoise & Africa \\
\hline & G. sulcata & spur-thigh tortoise & Africa \\
\hline & Gopherus agassizii & desert tortoise & USA, Mexico \\
\hline & G. berlandieri & Texas tortoise & USA \\
\hline & Malaclemys terrapin & diamond-backed terrapin & USA \\
\hline & Pseudemys concinna & Florida cooter turtle & USA \\
\hline & Terrapene carolina & box turtle & USA, Mexico \\
\hline & Trionyx ferox & Florida soft-shell turtle & USA \\
\hline \multirow[t]{11}{*}{ Squamata } & Calotes versicolor & bloodsucker lizard & Asia \\
\hline & Chamaeleo jacksoni & Jackson's chameleon & East Africa \\
\hline & Chlamydosaurus kingii & frilled lizard & Australia \\
\hline & Egernia cunninghami & Cunningham's skink & Australia \\
\hline & Gecko monarchus & spotted house gecko & Asia \\
\hline & Gehyra australis & house gecko & Northern Australia \\
\hline & Iguana iguana & green iguana & $\begin{array}{l}\text { South and Central } \\
\text { America }\end{array}$ \\
\hline & $\begin{array}{l}\text { Phelsuma } \\
\text { madagascariensis }\end{array}$ & day gecko & Madagascar \\
\hline & Tiliqua nigrolutea & blotched blue-tongue skink & Australia \\
\hline & Tiliqua rugosa & shingleback skink & Australia \\
\hline & Varanus gouldii & sand monitor & Australia \\
\hline
\end{tabular}




\begin{tabular}{llll} 
Crocodilia & $\begin{array}{l}\text { Alligator } \\
\text { mississippiensis } \\
\text { Crocodylus porosus }\end{array}$ & $\begin{array}{l}\text { American alligator } \\
\text { Australian saltwater } \\
\text { crocodile }\end{array}$ & USA \\
\hline
\end{tabular}

It is extremely difficult to legally import an exotic reptile into New Zealand, however exotic reptiles that were legally present in the country before the Hazardous Substances and New Organisms Act 1996 (HSNO) can be bred and traded without regulation. The green iguana (Iguana iguana) has recently been classified as a "New Organism" in New Zealand. The Ministry of Agriculture and Forestry (MAF) had records of two permits to import a total of four green iguanas to Hawkes Bay Marineland and Aquarium in the mid-1980s and early 1990s (MAF import permits 84/z/5 and 91/z/01) (Environmental Risk Management Authority 2006). According to MAF, these are the only import permits ever issued for the importation of green iguanas into New Zealand. In July 2005, however, an online auction website advertised "New Zealand bred baby green iguanas" (See http://www.trademe.co.nz/ Home-living/Pets-animals/Other/auction-31657809.htm) (TradeMe 2005). Although the advertisement insisted that the iguanas "were brought into New Zealand in the late 80 's under a permit", no records for permits to import green iguanas for the pet trade could be located. MAF concluded that these animals were in the country illegally, according to the Hazardous Substances and New Organisms Act 1996 (HSNO). The animals in question and their offspring (some of which had already been sold to new owners for 5,000 NZD each) (Anonymous 2007) were seized and destroyed after they were found to carry Salmonella Mountpleasant, a type of Salmonella previously unreported in New Zealand and the green iguana became classified as "New Organisms" in New Zealand (see Environmental Risk Management Authority Determination S2606001, 31 May 2006: 


\section{Chapter 1: Introduction and overview}

http://www.ermanz.govt.nz/search/registers.html?id=15622). Despite the fact that green iguanas are illegal to keep in New Zealand outside of a "recognised safekeeping facility" (e.g., zoo), in 2006, New Zealand reptile breeders were still advertising that "iguanas are still being bred, in large numbers, here in New Zealand" (See http://www.reptiles-nz.net/Price\%20List.htm) (The Turtle and Reptile Farm 2006).

\section{Some potential threats posed by invasive reptiles to New Zealand}

With the exception of high-profile cases, such as the brown tree snake and Nile monitor, many non-native reptiles are not considered to be a problem because (a) the species may be cryptic and difficult to notice or study and/or (b) the effects of non-native reptiles on humans may appear to be little or nonexistent (Kraus 2007; Kraus 2009). In addition to possible predation by, and competition with, invasive reptiles, native organisms may be susceptible to pathogens and/or parasites introduced by exotic species. The justification for banning the import of RES into New Zealand in the 1960s was that they were found to be carriers of several strains of Salmonella previously unreported in the country (Robb 1980; Feldman 2005). Nonetheless, red-eared sliders were subsequently allowed to remain in the New Zealand pet trade. Many reptiles are asymptomatic carriers of Salmonella, which can infect other species, including humans (Center for Disease Control 2005). Although human cases of salmonellosis are generally not severe, reports of septicemia and meningitis, sometimes fatal, have been associated with infections acquired from reptiles (Nagano et al. 2006).

With the massive global pet trade in exotic reptiles (Bomford 2003), combined with the current trade in New Zealand of numerous species of exotic 


\section{Chapter 1: Introduction and overview}

reptiles (Hot House Turtles 2006; The Turtle and Reptile Farm 2006), and the known release of unwanted pets (See Chapter 2), intentional and accidental releases of exotic reptiles is likely. In order to determine the risk of establishment of exotic reptiles within New Zealand, a risk assessment is necessary. Control measures for invasive species are costly (Pimentel et al. 2000; Bomford 2003), and with few methods for successful eradication of invasive reptiles, their cost could be even higher. If the exotic reptiles currently within New Zealand are found to have the ability to establish wild populations, appropriate and cost-effective management actions can be taken to avoid negative consequences to the New Zealand environment and economy. On the other hand, if exotic reptiles are found to pose no threat to New Zealand, commercial breeders will be able to safely supply reptiles to the lucrative local pet trade without scrutiny.

\section{Thesis structure}

The aim of this thesis is to investigate the scope of the exotic reptile trade in New Zealand and determine if any of the species legally traded in this country pose an establishment risk and, therefore, a potential risk to native flora and fauna. The terms "alien", "non-native", and "exotic" are used interchangeably to describe the species investigated. From preliminary observations, it was clear that the RES is the most popular and numerous species of exotic pet reptile available in New Zealand. Because of their high trade volume, and the fact that RES have established alien populations in countries all over the world, some chapters deal primarily with this species (see below).

In Chapter 2, I use a novel data collection method to investigate the "population structure" of a potentially invasive species. By monitoring online sales 


\section{Chapter 1: Introduction and overview}

of RES on the popular New Zealand online auction site TradeMe

(www.trademe.co.nz), I was able to gather a significant amount of information about animals that are being traded throughout the country (e.g., age, sex, and location of animals for sale, as well as identify sales patterns). In this chapter I also investigate whether online trading is a useful method of predicting establishment of exotic species based on different levels of propagule pressure.

An increasingly popular method to predict areas where exotic species may establish is bioclimatic modelling. In Chapter 3 I use bioclimatic models to identify areas within New Zealand and worldwide that may be climatically suitable for RES to establish. This chapter develops methods for calculating suitability scores for a country or region and has been published as part of an invited symposium presentation at the $6^{\text {th }}$ World Congress of Herpetology, Manaus, Brazil as:

Kikillus KH, KM Hare, and S Hartley (2010) Minimizing falsenegatives when predicting the potential distribution of an invasive species: a bioclimatic envelope for the red-eared slider at global and regional scales. Animal Conservation. 13 (Suppl. 1): 5-15. DOI: 10.1111/j.1469-1795.2008.00299.x.

In Chapter 4 I continue with the theme of bioclimatic modelling, applying similar methods developed in Chapter 3 to the other species of exotic reptile commonly encountered in the New Zealand pet trade (Table 1). As the methods for partitioning the test data and training data and for defining the model weightings differed slightly from the methods used in Chapter 3, the RES was rerun with the updated methods and results can be found in Appendix 10. Although it is not known if they are present within the New Zealand pet trade, blotched blue-tongue skinks (Tiliqua nigrolutea) and shingleback skinks (T. rugosa) were included in this analysis as they have recently been classified as a Surveillance Pest (meaning prohibition of 


\section{Chapter 1: Introduction and overview}

the sale, breeding, and exhibition) and as a pest when not held in secure confinement, respectively, by the Auckland Regional Council (Auckland Regional Council 2007).

An excellent complement to bioclimatic modelling is the utilisation of physiological models. In Chapter 5 I use degree-day models to investigate the potential for successful egg incubation and establishment of populations of oviparous exotic reptiles in New Zealand. All of the species investigated via bioclimatic modelling (Chapters 3 and 4) were included, with the exception of the three species of blue-tongue lizard (T. scincoides, T. nigrolutea, and T. rugosa), as they are viviparous. Additionally, as the land tortoise incubation information was similar for Greek and Hermanns tortoises, only Greek tortoises (Testudo graeca) were selected and analysed as a representative of this group. More Greek tortoises were sold online in New Zealand over a two year period (Figure 1), and may therefore be more common than Hermanns tortoises.

One of the negative impacts associated with invasive species is the ability to transfer pathogens to native fauna. In Chapter 6 I provide the results of a baseline survey in which 24 species of captive exotic reptile were screened for Salmonella. This chapter is currently in review as:

Kikillus, KH and BD Gartrell (in review) Salmonella prevalence and detected serovars associated with captive exotic reptiles in New Zealand. New Zealand Veterinary Journal.

Finally, in Chapter 7, I perform an establishment risk assessment of all of the species investigated. A risk assessment protocol used for alien reptiles and amphibians in Australia was modified for New Zealand and used for this purpose (Bomford et al. 2005) and allows species to be ranked based on their establishment risk scores. 


\section{Statement of Authorship}

My supervisors, Stephen Hartley and Kelly Hare were both very supportive in helping to formulate research questions in regards to this thesis. Likewise, Brett Gartrell provided advice on the disease screening portion of the project (appropriate sample sizes, suggested methods, etc.). They also provided constructive comments on the drafts I wrote.

I collected all of the data in relation to this thesis, which included monitoring the exotic reptile trade daily via online sources (Chapter 2), collection of exotic reptile distribution records (Chapters 3 and 4), gathering incubation data for species of interest and deploying and retrieving dataloggers (Chapter 5), and swabbing several hundred reptile cloacas throughout New Zealand (Chapter 6).

The R computer code used in the bioclimatic modelling chapters was based on a previous project of Stephen Hartley's in which he sought to predict the potential range of invasive ants in New Zealand. This code was modified by both myself and Stephen Hartley to apply it to exotic reptiles, and was published as Supplementary Information in Kikillus, Hare, and Hartley, 2010. Although I ran the final analyses, Stephen was always willing to assist with programming difficulties and interpretation of results. Similarly, the regression model used in the degree-day predictions (Chapter 5) was also based on a previous project of Stephen Hartley's involving invasive ants, which we applied to oviparous exotic reptiles.

I gathered all of the swabs to be tested for Salmonella (Chapter 6), however, the actual diagnostic tests were performed by New Zealand Veterinary Pathology. Brett Gartrell provided advice and assistance regarding statistical tests for this portion of the project. Kelly Hare also provided comments on all drafts, assistance with tables/figures, and helpful advice for the formatting of documents. 


\section{Literature cited}

Anonymous (2007). "Reptile Sting." Retrieved February 6, 2007, from http://www.stuff.co.nz/print/3901023a6004.html.

Auckland Regional Council (2007). Regional Pest Management Strategy 2007-2012 Auckland, New Zealand, Auckland Regional Council: Pages 119-120.

Baek, S., K. Cho, Y. H. Song and J.-L. Lee (2008). "Degree-day based models for forecasting the flight activity of adult Helicoverpa assulta (Lepidoptera: Noctuidae) in hot pepper fields." International Journal of Pest Management 54(4): 295-300.

Blank, R., G. Gill and J. Kelly (2000). "Development and mortality of greedy scale (Homoptera: Diaspidae) at constant temperatures." Environmental Entomology 29(5): 934-942.

Bomford, M. (2003). Risk Assessment for the import and keeping of exotic vertebrates in Australia. Bureau of Rural Sciences. Canberra, Australia.

Bomford, M., F. Kraus, M. Braysher, L. Walter and L. Brown (2005). Risk assessment model for the import and keeping of exotic reptiles and amphibians. Department of Environment and Heritage, Bureau of Rural Sciences, Canberra, Australia.

Broennimann, O., U. Treier, H. Müller-Schärer, W. Thuiller, A. Peterson and A. Guisan (2007). "Evidence of climate niche shift during biological invasion." Ecology Letters 10(8): 701-709.

Broufas, G. D. and D. S. Koveos (2000). "Threshold temperature for post-diapause development and degree-days to hatching of winter eggs of the European red mite (Acari: Tetranychidae) in northern Greece." Environmental Entomology 29(4): 710713.

Brown, J. (1989). Patterns, modes and extents of invasions by vertebrates. Biological Invasions: A Global Perspective. J. Drake, H. Mooney, F. di Castriet al. Chichester, UK, John Wiley and Sons.

Buden, D., D. Lynch and G. Zug (2001). "Recent records of exotic reptiles on Pohnpei, Eastern Caroline Islands, Micronesia." Pacific Science 55: 165-170.

Burne, C. (2000). The ultimate guide to keeping freshwater turtles successfully in New Zealand. Napier, New Zealand, Brebner Print.

Campbell, K. and J. Donlan (2005). "Feral goat eradication on islands." Conservation Biology 19(5): 1362-1374.

Campbell, T. (2005). Eradication of introduced carnivorous lizards from the Cape Coral area. Final report to the Charlotte Harbor National Estuary Program. 1926 Victoria Avenue, Fort Myers, Florida 33901 USA: 30 pages. 
Catford, J., R. Jansson and C. Nilsson (2009). "Reducing redundancy in invasion ecology by integrating hypotheses into a single theoretical framework." Diversity and Distributions 15(1): 22-40.

Center for Disease Control (2005). "Salmonellosis associated with pet turtlesWisconsin and Wyoming 2004." Morbidity and Mortality Weekly Report 54(9): 223226.

Clout, M. (2002). Ecological and economic costs of alien vertebrates in New Zealand. Biological Invasions: Economic and environmental costs of alien plant, animal, and microbe species. D. Pimentel. Boca Raton, Florida, USA, CRC Press LLC.

Cole, N., C. Jones and S. Harris (2005). "The need for enemy-free space: The impact of an invasive gecko on island endemics." Biological Conservation 125: 467-474.

Duffey, E. (2001). "Introduced pest species and biodiversity conservation in New Zealand." Biological Conservation 99: 1.

Ehrlich, P. (1989). Attributes of invaders and the invading processes: Vertebrates. Biological Invasions: A Global Perspective. J. Drake, H. Mooney, F. di Castriet al. Chichester, UK, John Wiley and Sons.

Elith, J., M. Kearney and S. Phillips (2010). "The art of modelling range-shifting species." Methods in Ecology and Evolution doi: 10.1111/j.2041-210X.2010.00036.x.

Enge, K. and K. Krysko (2004). "A new exotic species in Florida, the bloodsucker lizard, Calotes versicolor (Daudin 1802) (Sauria: Agamidae)." Florida Scientist 67(3): 226-230.

Enge, K., K. Krysko, K. Hankins, T. Campbell and W. King (2004). "Status of the Nile monitor (Varanus niloticus) in southwestern Florida." Southeastern Naturalist 3(4): 571-582.

Enge, K., K. Krysko and B. Talley (2004). "Distribution and ecology of the introduced African rainbow lizard, Agama agama africana (Sauria: Agamidae) in Florida." Florida Scientist 67(4): 303-310.

Environmental Risk Management Authority (2006). "Application for New Organism Determination under Section 26 of the HSNO Act: Application \# S2606001." from http://www.ermanz.govt.nz/appfiles/execsumm/pdf/S2606001-003.pdf.

Environmental Risk Management Authority (2008). "List of banned animals and plants." Retrieved January 6, 2007, from http://www.ermanz.govt.nz/no/aboutno/banned.html.

Feldman, M. (2005). The red-eared slider turtle (Trachemys scripta elegans) in New Zealand. 13th Australasian Vertebrate Pest Conference Wellington, New Zealand, Landcare Research, New Zealand. 
Ficetola, G., W. Thuiller and C. Miaud (2007). "Prediction and validation of the potential global distribution of a problematic alien invasive species - the American bullfrog." Diversity and Distributions 13: 476-485.

Fritts, T. (2002). "Economic costs of electrical system instability and power outages caused by snakes on the Island of Guam." International Biodeterioration \& Biodegradation 49: 93-100.

Gill, B., D. Bejakovich and A. Whitaker (2001). "Records of foreign reptiles and amphibians accidentally imported to New Zealand." New Zealand Journal of Zoology 28: 351-359.

Gwiazdowski, R., R. Van Driesche, A. Desnoyers, S. Lyon, S. Wu, N. Kamata and B. Normark (2006). "Possible geographic origin of beech scale, Cryptococcus fagisuga (Hemiptera: Eriococcidae), an invasive pest in North America." Biological Control 39: 9-18.

Hartley, S., P. Krushelnycky and P. Lester (2010). "Integrating physiology, population dynamics and climate to make multi-scale predictions for the spread of an invasive insect: the Argentine ant at Haleakala National Park, Hawaii." Ecography 33: 83-94.

Hartley, S. and P. Lester (2003). "Temperature-dependent development of the Argentine ant, Linepithema humile (Mayr) (Hymenoptera: Formicidae): a degree-day model with implications for range limits in New Zealand." New Zealand Entomologist 26: 91-100.

Hawaiian Ecosystems at Risk (HEAR) (2007). "Vertebrates: HEAR Species Information." Retrieved September 13, 2007, from http://www.hear.org/vertebrates/.

Henle, K. (1981). "Die Herpetofauna Neuseelands Teil 2: Eingeschleppte Arten und Irrgäste." Herpetofauna 13: 25-29.

Heywood, V. (1989). Patterns, extents, and modes of invasions by terrestrial plants. Biological Invasions: A Global Perspective. J. Drake, H. Mooney, F. di Castriet al. Chichester, UK, John Wiley and Sons.

Holdgate, M. (1986). "Summary and conclusions: Characteristics and consequences of biological invasions." Philosophical Transactions of the Royal Society of London: Series B, Biological Sciences 314(1167): 733-742.

Hollywood Fish Farm (2010). Retrieved May 31, 2010, from http://www.hollywoodfishfarm.co.nz/index.php.

Holt, R., M. Barfield and R. Gomulkiewicz (2005). Theories of niche conservatism and evolution. Species invasions: Insights into ecology, evolution, and biogeography. D. Sax, J. Stachowicz and S. Gaines. Sunderland, Massachusetts, USA, Sinauer Associates Inc. 
Hot House Turtles (2006). Retrieved July 10, 2006, from http://www.hothouseturtles.co.nz.

Hutching, G. (2004). The Penguin Natural World of New Zealand. Auckland, New Zealand, Penguin group.

Invasive Species Specialist Group (ISSG) (2004). 100 of the World's Worst Invasive Alien Species.

Kearney, M., B. Phillips, C. Tracy, K. Christian, G. Betts and W. Porter (2008). "Modelling species distributions without using species distributions: the cane toad in Australia under current and future climates." Ecography 31: 423-434.

Kearney, M. and W. Porter (2004). "Mapping the fundamental niche: Physiology, climate, and the distribution of a nocturnal lizard." Ecology 85(11): 3119-3131.

Keller, R. and J. Drake (2009). Trait-based risk assessments for invasive species. Bioeconomics of invasive species: Integrating ecology, economics, policy, and management. R. Keller, D. Lodge, M. Lewis and J. Shogren. New York, New York, USA, Oxford University Press: 44-62.

Kelly, D., R. Paterson, C. Townsend, R. Poulin and D. Tompkins (2009). "Parasite spillback: a neglected concept in invasion ecology?" Ecology 90(8): 2047-2056.

Kim, Y. (2002). World Exotic Diseases. Biological Invasions: Economic and environmental costs of alien plant, animal, and microbe species. D. Pimentel. Boca Raton, Florida, USA, CRC Press LLC.

King, C., Ed. (2005). The handbook of New Zealand mammals: Second edition. Melbourne, Australia, Oxford University Press.

Kolar, C. and D. Lodge (2001). "Progress in invasion biology: predicting invaders." Trends in Ecology and Evolution 16(4): 199-204.

Kraus, F. (2007). Using pathway analysis to inform prevention strategies for alien reptiles and amphibians. Managing Vertebrate Invasive Species Symposium, National Wildlife Research Center, Fort Collins, Colorado, USA, USDA/ APHIS/ WS.

Kraus, F. (2009). Alien reptiles and amphibians: a scientific compendium and analysis, Springer Netherlands.

Krysko, K. (2000). "A fishing technique for collecting the introduced knight anole (Anolis equestris) in southern Florida." Caribbean Journal of Science 36(1-2): 162.

Krysko, K. (2005). "Ecological status of the introduced yellow-headed gecko, Gonatodes albogularis (Sauria: Gekkonidae), in Florida." Florida Scientist 68(4): 272-280.

Krysko, K. and K. Enge (2005). "A new non-native lizard in Florida, the butterfly lizard, Leiolepis belliana (Sauria: Agamidae)." Florida Scientist 68(4): 247-249. 
Krysko, K., K. Enge and W. King (2004). "The veiled chameleon, Chamaeleo calyptratus: A new exotic lizard species in Florida." Florida Scientist 67(4): 249-253.

Krysko, K., N. Hooper and C. Sheehy III (2003). "The Madagascar giant day gecko, Phelsuma madagascariensis grandis Gray 1870 (Sauria: Gekkonidae): A new established species in Florida." Florida Scientist 66(3): 222-225.

Krysko, K., J. Seitz, J. Townsend and K. Enge (2006). "The introduced brown basilisk (Basiliscus vittatus) in Florida." Iguana 13(1): 25-30.

Lever, C. (2003). Naturalized reptiles and amphibians of the world. New York, USA, Oxford University Press.

Lodge, D., M. Lewis, J. Shogren and R. Keller (2009). Introduction to biological invasions: Biological, economic, and social perspectives. Bioeconomics of invasive species: Integrating ecology, economics, policy, and management. R. Keller, D. Lodge, M. Lewis and J. Shogren. New York, New York, USA, Oxford University Press: $1-24$.

Loope, L. and D. Mueller-Dombois (1989). Characteristics of invaded islands, with special reference to Hawaii. Biological Invasions: A Global Perspective. J. Drake, H. Mooney, F. di Castriet al. Chichester, UK, John Wiley and Sons.

Macdonald, I., L. Loope, M. Usher and O. Hamann (1989). Wildlife conservation and the invasion of nature reserves by introduced species: a global perspective. Biological Invasions: A Global Perspective. J. Drake, H. Mooney, F. di Castriet al. Chichester, UK, John Wiley and Sons.

Mack, R., D. Simberloff, W. Lonsdale, H. Evans, M. Clout and F. Bazzaz (2000). "Biotic invasions: Causes, epidemiology, global consequences, and control." Ecological Applications 10(3): 689-710.

Manchester, S. and J. Bullock (2000). "The impacts of non-native species on UK biodiversity and the effectiveness of control." Journal of Applied Ecology 37: 845864.

McKeown, S. (1978). Hawaiian reptiles and amphibians. Honolulu, Hawaii, USA, The Oriental Publishing Company.

Nagano, N., S. Oana, Y. Nagano and Y. Arakawa (2006). "A severe Salmonella enterica Serotype Paratyphi B infection in a child related to a pet turtle, Trachemys scripta elegans." Japanese Journal of Infectious Diseases 59: 132-134.

New Zealand Biodiversity (2000). "New Zealand Biodiversity Strategy." Retrieved October 6, 2007, from http://www.biodiversity.govt.nz.

Nogales, M., J. Rodriguez-Luengo and P. Marrero (2006). "Ecological effects and distribution of invasive non-native mammals on the Canary Islands." Mammal Review 36(1): 49-65. 
Peace, J. (2004). Distribution, habitat use, breeding, and behavioural ecology of rainbow skinks (Lampropholis delicata) in New Zealand. Auckland, New Zealand, University of Auckland. Master of Science Thesis.

Pearson, R. and T. Dawson (2003). "Predicting the impacts of climate change on the distribution of species: are bioclimate envelopes useful?" Global Ecology and Biogeography 12: 361-371.

Pearson, R., T. Dawson and C. Liu (2004). "Modelling species distributions in Britain: a hierarchical integration of climate and land-cover data." Ecography 27: 285-298.

Phillips, B., J. Chipperfield and M. Kearney (2008). "The toad ahead: challenges of modelling the range and spread of an invasive species." Wildlife Research 35: 222234.

Phillips, B. and R. Shine (2005). "The morphology, and hence impact, of an invasive species (the cane toad, Bufo marinus): changes with time since colonisation." Animal Conservation 8(407-413).

Pimentel, D., Ed. (2002). Biological Invasions: Economic and environmental costs of alien plant, animal, and microbe species. Boca Raton, Florida, USA, CRC Press LLC.

Pimentel, D., L. Lach, R. Zuniga and D. Morrison (2000). "Environmental and economic costs of nonindigenous species in the United States." Bioscience 50(1): 5365.

Pitt, W., D. Vice and M. Pitzler (2005). Challenges of invasive reptiles and amphibians. 11th Wildlife Damage Management Conference, Traverse City, Michigan, USA.

Rejmanek, M. and D. Richardson (1996). "What attributes make some plant species more invasive? ." Ecology 77(6): 1655-1661.

Robb, J. (1980). New Zealand Amphibians and Reptiles. Auckland, New Zealand, William Collins Publishers Ltd.

Reed, R., K. Krysko, R. Snow and G. Rodda (2010). "Is the Northern African Python (Python sebae) established in southern Florida?" IRCF Reptiles and Amphibians 17: 52-54.

Rodda, G., T. Fritts and D. Chiszar (1997). "The disappearance of Guam's wildlife." Bioscience 47(9): 565-574.

Savidge, J. (1987). "Extinction of an island forest avifauna by an introduced snake." Ecology 68(3): 660-668.

Sikder, I., S. Mal-Sarkar and T. Mal (2006). "Knowledge-based risk assessment under uncertainty for species invasion." Risk Analysis 26(1): 239-252. 
Simberloff, D. (1989). Which insect introductions succeed and which fail? Biological Invasions: A Global Perspective. J. Drake, H. Mooney, F. di Castriet al. Chichester, UK, John Wiley and Sons.

Simberloff, D. (1996). "Impacts of introduced species in the United States." Consequences 2(2).

Snow, R., K. Krysko, K. Enge, L. Oberhofer, A. Warren-Bradley and L. Wilkins (2007). Introduced populations of Boa constrictor (Boidae) and Python molurus bivittatus (Pythonidae) in southern Florida. Biology of the boas and pythons. R. Henderson and R. Powell. Eagle Mountain, Utah, USA, Eagle Mountain Publishing.

Stachowicz, J. and D. Tilman (2005). Species invasions and the relationships between species diversity, community saturation, and ecosystem functioning. Species invasions: Insights into ecology, evolution, and biogeography. D. Sax, J. Stachowicz and S. Gaines. Sunderland, Massachusetts, USA, Sinauer Associates Inc.

The Turtle and Reptile Farm (2006). Retrieved July 22, 2006, from http://www.reptiles-nz.net/.

Thornton, T. (1999). Keeping red-eared turtles in New Zealand. Warkworth, New Zealand, TJ's Books.

Thuiller, W., D. Richardson, P. Pyšek§, G. Midgley, G. Hughes and M. Rouget (2005). "Niche-based modelling as a tool for predicting the risk of alien plant invasions at a global scale." Global Change Biology 11: 2234-2250.

Torchin, M., K. Lafferty, A. Dobson, V. McKenzie and A. Kuris (2003). "Introduced species and their missing parasites." Nature 421: 628-630.

Townsend, J., K. Krysko and A. Reppas (2002). "Noteworthy records for introduced reptiles and amphibians from Florida, USA." Herpetological Review 33(1): 75.

Townsend, J., J. Slapcinsky, K. Krysko, E. Donlan and E. Golden (2005). "Predation of a tree snail Drymaeus multilineatus (Gastropoda: Bulimulidae) by Iguana iguana (Reptilia: Iguanidae) on Key Biscayne, Florida." Southeastern Naturalist 4(2): 361364.

TradeMe (2005). Retrieved January 8, 2008, from http://www.trademe.co.nz/Homeliving/Pets-animals/Other/auction-31657809.htm.

Usher, M. (1989). Ecological effects of controlling invasive terrestrial vertebrates. Biological Invasions: A Global Perspective. J. Drake, H. Mooney, F. di Castriet al. Chichester, UK, John Wiley and Sons.

White, P., A. Ford, M. Clout, R. Engeman, S. Roy and G. Saunders (2008). "Alien invasive vertebrates in ecosystems: pattern, process and the social dimension." Wildlife Research 35: 171-179. 
Wiles, G., J. Bart, R. Beck Jr. and C. Augon (2003). "Impacts of the brown tree snake: Patterns of decline and species persistence in Guam's avifauna." Conservation Biology 17(5): 1350-1360.

Williamson, M. (1993). "Invaders, weeds and the risk from genetically manipulated organisms." Experientia 49: 219-224.

Williamson, M. (1996). Biological Invasions. London, UK, Chapman and Hall.

Williamson, M. and K. Brown (1986). "The analysis and modelling of British invasions." Philosophical Transactions of the Royal Society of London B 314: 505522.

Williamson, M. and A. Fitter (1996). "The varying success of invaders." Ecology 77(6): 1666-1670.

Wittenberg, R. and M. Cock (2001). Invasive alien species. How to address one of the greatest threats to biodiversity: A toolkit of best prevention and management practices. CAB International. Wallingford, Oxon, UK: 215 pages.

Wolfe, L. (2002). "Why alien invaders succeed: Support for the escape-from-enemy hypothesis." The American Naturalist 160(6): 705-711.

Wong, S. (2010). "'Ta-ta' lizard says hello, New Zealand." The Marlborough Express. Retrieved April 30, 2010, from http://www.stuff.co.nz/marlboroughexpress/news/3643091/Ta-ta-lizard-says-hello-New-Zealand. 


\title{
Chapter 2: \\ Using online trading tools as a method of estimating propagule pressure of an invasive species: A case study using red-eared slider turtles in New Zealand
}

\begin{abstract}
In the past, the internet has been used to track the sale of endangered wildlife. I investigated if it was a useful method to estimate propagule pressure of potentially invasive species present within the pet trade by tracking animal sales and demographics. The online trade in red-eared slider turtles (Trachemys scripta elegans; RES) was tracked daily from October 2007 to October 2009 in New Zealand and information such as age, sex, season, and location was recorded from online advertisements. I found over 1500 RES sales and over 80 reports of lost or missing RES throughout New Zealand. Logically, the region with the highest human population in New Zealand (Auckland) also had the largest amount of sold and lost RES. Other than this, no clear pattern between RES sales and losses could be found. While this method was not consistently helpful in predicting areas where RES were living in the wild, it was helpful in providing much information regarding sex, age, and location of sold and lost turtles. This information could be useful if planning a management or eradication plan for feral RES in New Zealand. Education campaigns should be aimed at pet owners throughout the country to dissuade them from releasing their pets into the wild. In conclusion, the monitoring of online sales of potentially-invasive species can provide ample demographic information regarding
\end{abstract}




\section{Chapter 2: Tracking turtles via online trading}

the animals being traded, as well as give an indication of propagule pressure and areas into which they are being released. This technique is applicable to other species and may be a useful tool to help prevent the establishment of additional exotic species outside of their native ranges.

\section{Introduction}

The internet has become an invaluable tool for facilitating commerce and communication worldwide. With its increased popularity, and ability to bring people from around the world into instant contact with one other, the opportunities to trade in live animals have increased. Monitoring of online auctions has helped determine the extent of trade in endangered wildlife around the world and within country borders (International Fund for Animal Welfare (IFAW) 2008) as well as identify websites advertising prohibited species (Suiter and Sferrazza 2007). Another useful, but to our knowledge unused, context in which information from online auctions could be used is to monitor the sale and movement of particular species to areas to which they are not native and may potentially establish invasive populations (Derraik and Phillips 2010). Much useful data are available in online advertisements, including the species, sex, and age of a particular animal for sale or lost. These data can provide details of the "population structure" of a potentially invasive species. Whether this publicly available information can be used as a useful prediction and monitoring tool for escapees/releases of a species of interest into the wild is unknown.

Invasive species are often implicated in severe economic and ecological impacts. To date, methods for predicting establishment potential of pest species mainly include climate-matching models, which identify climatically-suitable areas for a particular species based on the amount of overlap in the climate parameters from 


\section{Chapter 2: Tracking turtles via online trading}

their native range (Hartley and Lester 2003; Kikillus et al. 2010). While suitable climate is one important factor in the establishment of a non-native species, the dispersal ability, reproductive potential and output, and propagule pressure are also significant factors (Williamson and Fitter 1996; Duncan et al. 2001; White et al. 2008). Online trading may provide the means to determine the degree of propagule pressure within a system, taken from the number of animals sold/lost and the areas from which they are being traded or lost into the local environment.

I chose to investigate if online trading could be used to predict the establishment potential of a species of interest by looking at the trade of red-eared slider turtles (Trachemys scripta elegans; RES) using online trading sites. The RES is a popular pet around the world, and through the "pet-release pathway" (Kraus 2009) has established invasive populations on every continent, save Antarctica (Ernst and Lovich 2009). It is also classified as one of the world's worst invasive species (Invasive Species Specialist Group (ISSG) 2004). In areas where RES have established, they have been reported to compete with native turtles and have a negative impact on native wildlife (Cadi and Joly 2004).

New Zealand is one of the few countries in which RES have not yet established, although climate-matching models show that northernmost New Zealand is climatically suitable for successful reproduction and population persistence (Kikillus et al. 2010) (also see Chapter 5). New Zealand is also a closed system, meaning that the only method by which RES can get into the wild in this country is via accidental or deliberate release. While RES are no longer permitted to be imported into New Zealand, the domestic trade in these animals is unregulated (i.e. there are currently no permits required in order to own, breed, or sell RES). However, the Auckland Regional Council (ARC) has classified the red-eared slider as a 


\section{Chapter 2: Tracking turtles via online trading}

"Research Organism", a category in which an animal's potential impact on the environment requires further research, and also as a pest "only where they are not held in secure containment" (Auckland Regional Council 2007).

The aim of this paper is to determine whether online trading resources are useful tools for determining the degree of propagule pressure on a system. Specifically, I use one of the "World's Worst Invaders" (the RES) and one of the few areas where RES are not known to have yet established (New Zealand) as our representative systems. I aim to: (1) determine how many RES are currently being traded in New Zealand and where and at what rate these animals are being released into the wild; (2) determine the potential population structure of both traded and released animals; (3) determine whether online sales data accurately predicts records of wild RES; and (4) provide details of the usefulness of online auction sites as a predictor of propagule pressure in the local environment.

\section{Methods}

\section{Study Species}

Red-eared sliders are native to the Mississippi Valley area of the United States of America, but due to the pet trade, they have become the most widespread freshwater turtle in the world (Ernst and Lovich 2009). Sexual maturity in RES appears to be size-related rather than age related, with males reaching maturity when their shell is approximately $10 \mathrm{~cm}$ in length, and females at about $17 \mathrm{~cm}(\mathrm{Newbery}$ 1984). Adult RES exhibit sexual dimorphism, with males being smaller than females, and possessing longer foreclaws, thicker tails, and a more concave plastron (Gibbons 1990; Gibbons and Lovich 1990; Thornton 1999). However, sexual dimorphism is often not apparent before $\sim$ two years of age (Gibbons and Lovich 1990; Thornton 
1999). Females are capable of storing sperm and laying up to three clutches of eggs per year, and can have between 5 - 24 eggs per clutch (Thornton 1999; Tucker 2001; Bringsøe 2006).

\section{Data collection}

Data on RES sales were collected over two years (October 2007- October 2009) using the New Zealand online auction site, TradeMe (www.trademe.co.nz). TradeMe is the most popular online auction site in New Zealand, with over 2.5 million registered members (TradeMe 2010). The TradeMe site was checked daily and RES sales, and classified advertisements for lost or missing pet RES were recorded. Sales were only included if a purchase price was able to be confirmed (i.e., a winning bid was made or a fixed-price offer was available). Factors recorded included: date, age (if specified), sex (if specified), and location. Age designations were split into 4 categories: 1) "Juvenile" = $<1$ year of age, "Subadult" = between 1 and 2 years of age, "Adult" = $>2$ years of age, and "Unspecified".

Data on RES losses were obtained using a wider time-frame (1999-2010) and multiple sources in order to obtain a large dataset. These included TradeMe $(n=51)$, "Pets on the Net" (www.petsonthenet.co.nz) (a website where lost and found pets are listed) $(\mathrm{n}=14)$, newspaper reports/journal articles $(\mathrm{n}=4)$, regional council records $(n=11)$, and personal reports from members of the public $(n=3)$. Information regarding human population within geographic localities in New Zealand was obtained from the 2006 Census results via Statistics New Zealand (http://www.stats.govt.nz). Regional areas were divided into: "Northland", “Auckland”, "Waikato”, "Bay of Plenty”, “Gisborne”, “Taranaki”, "Manawatu- 
Chapter 2: Tracking turtles via online trading

Wanganui”, "Hawkes Bay”, "Wellington”, “Tasman/Marlborough/Nelson”, “Canterbury", "West Coast", "Otago", and "Southland".

\section{Results}

From October 2007 to October 2009, 1588 RES were sold on TradeMe with a total value of 170,956 NZD. May had the most RES sales in both years, although sales have increased in 2009 c.f. 2008 . Hatchling turtles accounted for the majority of sales in May (65\%). Overall, however, adult RES comprised the largest portion of the sales, with $50 \%$ of turtles sold being over 2 years of age (Figure 1). Many turtles sold were of unspecified sex (58\%). For advertisements which did specify the sex of the turtle, $55 \%$ were listed as males and $45 \%$ were listed as females (Table 1).

Areas of higher human population generally had a higher proportion of RES

sales (Figure 2). The regions of Auckland, Manawatu-Wanganui, and Canterbury had the largest number of RES sales, with 321, 284, and 255 turtles, respectively, sold within the 2 year period (Table 2). 
Figure 1: Numbers and age brackets of red-eared slider turtle (Trachemys scripta elegans) sales by season (October 2007- October 2009) from www.trademe.co.nz. Spring = September - November, summer $=$ December - February, autumn $=$ March - May, and winter $=$ June - August. Juvenile $=<1$ year, Subadult $=1-2$ years, Adult $=>2$ years. $\mathrm{N}=1588$.

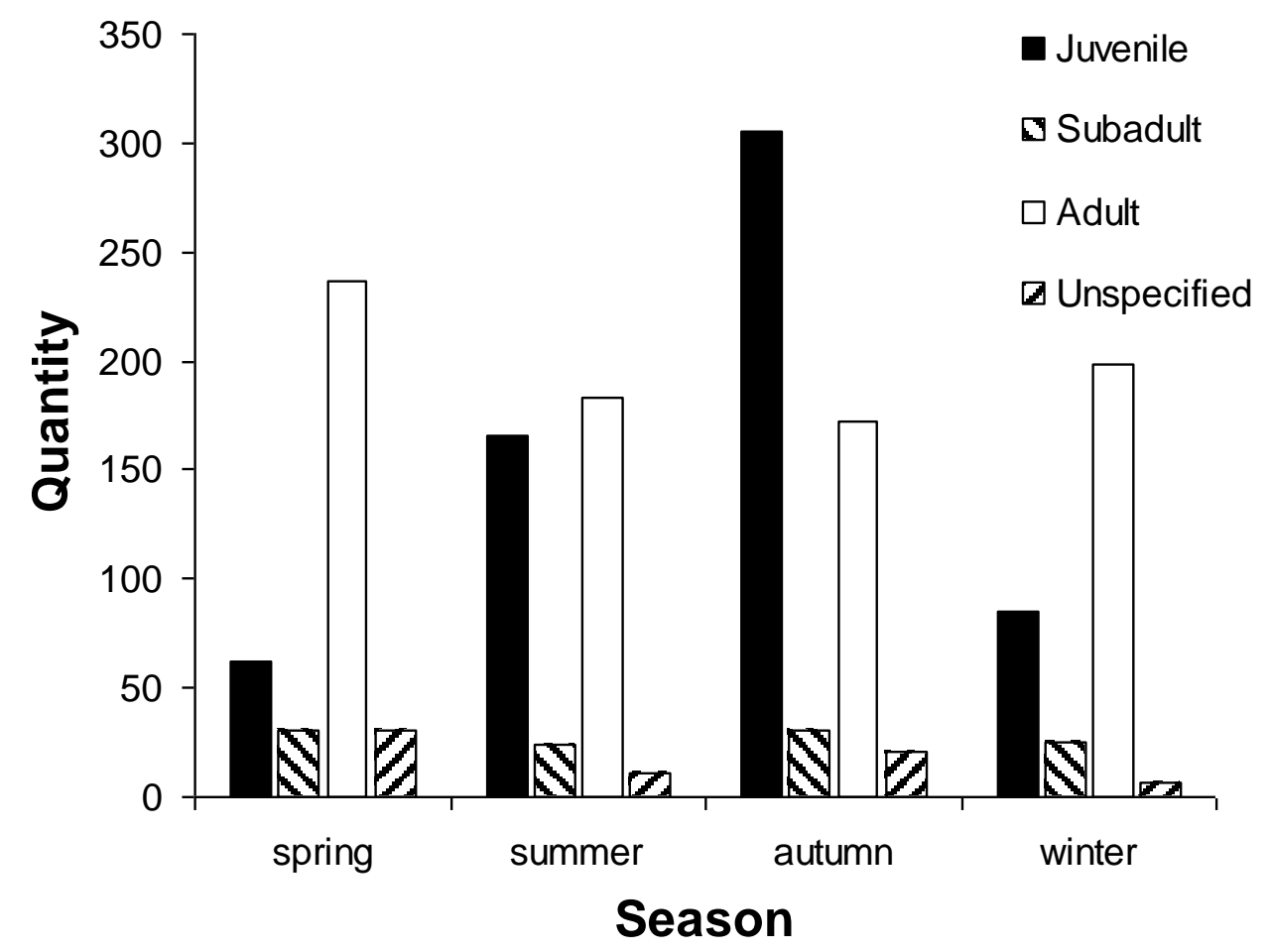

Table 1: Sex and age bracket of red-eared sliders (Trachemys scripta elegans) sold on TradeMe (October 2007-October 2009). (Juvenile $=<1$ year, Subadult $=1-2$ years, Adult $=>2$ years).

\begin{tabular}{lccccc}
\hline Sex & \multicolumn{2}{c}{ Age bracket } & \multicolumn{2}{c}{ Total } \\
& \multicolumn{1}{c}{ Adult } & Juvenile & Subadult & Unspecified & \\
\hline Female & 273 & 3 & 28 & 1 & 305 \\
Male & 334 & 9 & 22 & 1 & 366 \\
Unspecified & 183 & 606 & 60 & 68 & 917 \\
Total & 790 & 618 & 110 & 70 & $\mathbf{1 5 8 8}$
\end{tabular}


Figure 2: Number of red-eared sliders (Trachemys scripta elegans; RES) sales on www.trademe.co.nz during October 2007 - October 2009 in relation to region and human population density. $(\mathrm{R}=0.72)$.

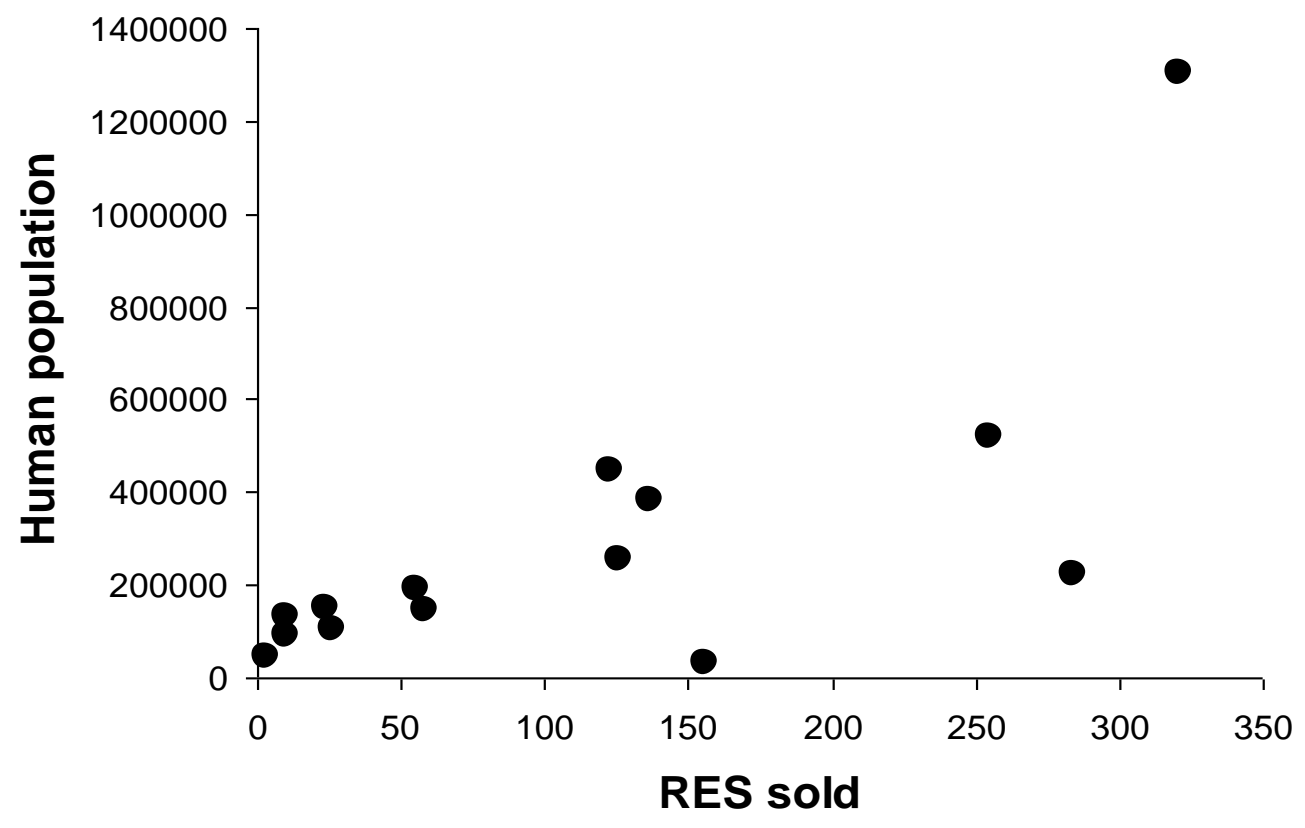

Table 2: Numbers of red-eared slider turtles (Trachemys scripta elegans; RES) sold on TradeMe (October 2007- October 2009) and reported lost (1999-2010) in New Zealand in relation to region.

$\begin{array}{lll}\text { Region Human Population } & \text { RES sold }\end{array}$

\begin{tabular}{|c|c|c|c|}
\hline Northland & 148470 & 24 & 2 \\
\hline Auckland & 1303068 & 321 & 38 \\
\hline Waikato & 382713 & 137 & 5 \\
\hline Bay of Plenty & 257379 & 126 & 5 \\
\hline Gisborne & 44499 & 3 & 0 \\
\hline Taranaki & 104124 & 26 & 1 \\
\hline Manawatu-Wanganui & 222423 & 284 & 4 \\
\hline Hawkes Bay & 147783 & 58 & 5 \\
\hline Wellington & 448956 & 123 & 13 \\
\hline Tasman/Marlborough/Nelson & 130071 & 10 & 1 \\
\hline Canterbury & 521832 & 255 & 7 \\
\hline West Coast & 31329 & 156 & 0 \\
\hline Otago & 193800 & 55 & 2 \\
\hline Southland & 90873 & 10 & 0 \\
\hline
\end{tabular}


I located 83 reports of lost or missing RES in locations throughout New Zealand between the years of 1999 and 2010 (Figure 3). Across all years, most turtles were reported missing in summer (December - February) (45\%), followed by spring (September - November) (31\%), autumn (March - May) (20\%), and winter (June - August) (4\%). Adult RES comprised the majority of lost/missing turtle reports (72\%) (Figure 4) and of these $39 \%$ were females and $28 \%$ were males (Table 3). Very few juveniles (1\%) were reported as lost or missing.

Figure 3: Map of lost RES in NZ (1999-2010) denoted by black dots. $N=83$.

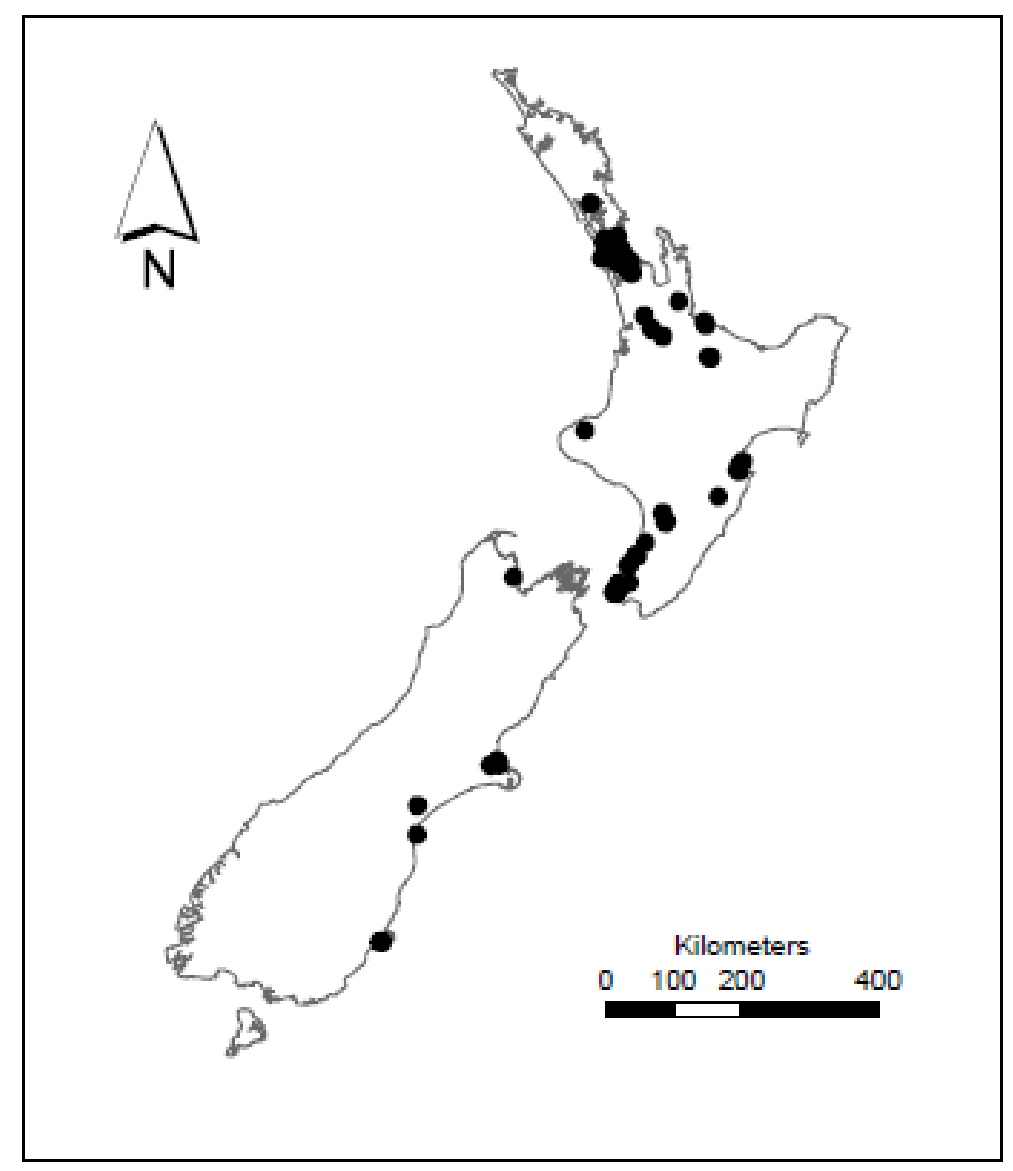


Figure 4: Numbers and age brackets of lost red-eared slider turtles (Trachemys scripta elegans) by season in New Zealand (1999-2010). Spring = September - November, summer $=$ December February, autumn $=$ March - May, and winter $=$ June - August. Juvenile $=<1$ year, Subadult $=1-2$ years, Adult $=>2$ years). $\mathrm{N}=83$.

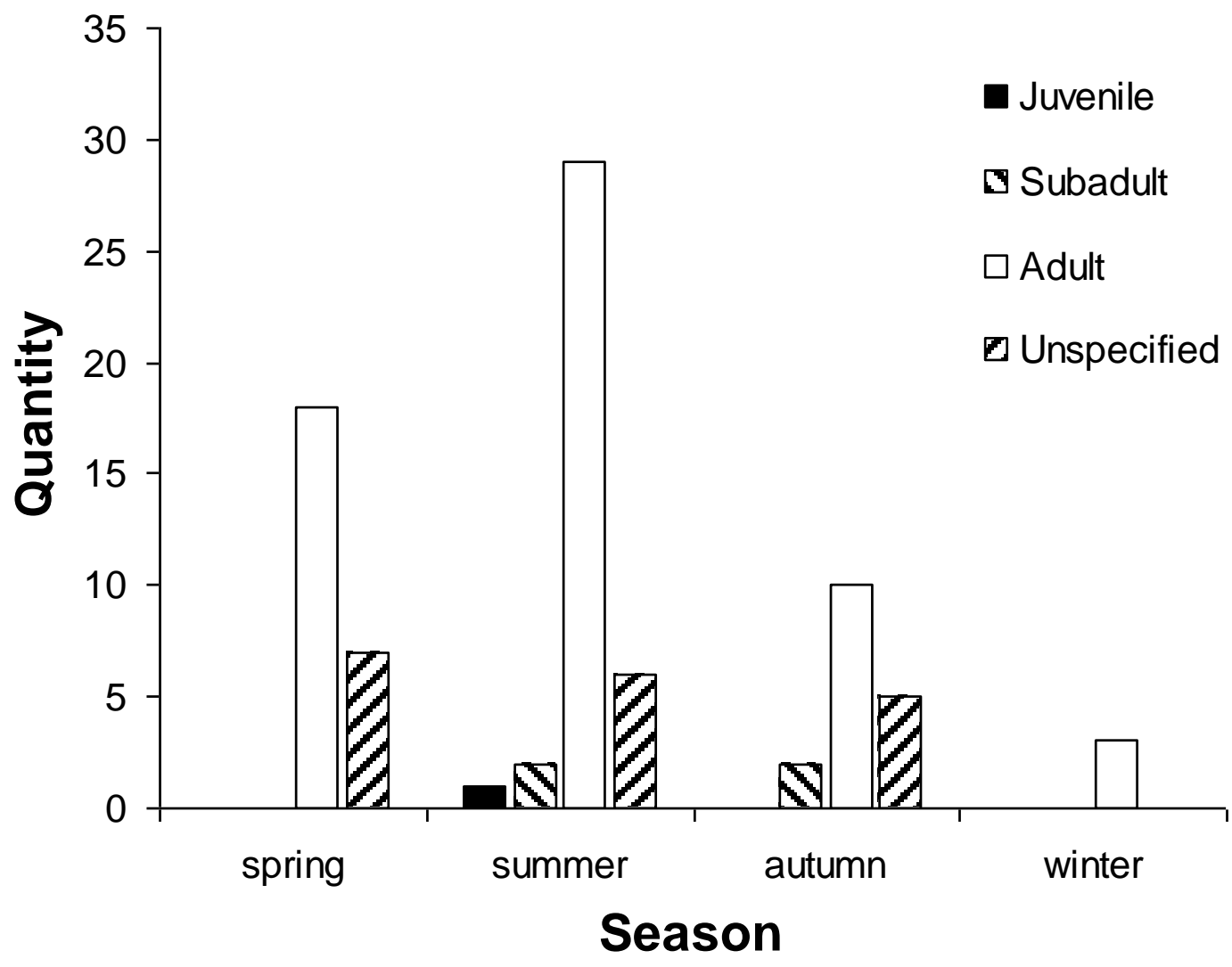

Table 3: Sex and age bracket of lost red-eared sliders (Trachemys scripta elegans) in New Zealand (1999-2010). (Juvenile $=<1$ year, Subadult $=1-2$ years, Adult $=>2$ years).

\begin{tabular}{lccccc}
\hline Sex & \multicolumn{5}{c}{ Age bracket } \\
& Adult & Juvenile & Subadult & Unspecified & Total \\
\hline Female & 31 & 0 & 1 & 0 & 32 \\
Male & 20 & 0 & 3 & 0 & 23 \\
Unspecified & 9 & 1 & 0 & 18 & 28 \\
Total & 60 & 1 & 4 & 18 & $\mathbf{8 3}$ \\
\hline
\end{tabular}


Similar to RES sales, the majority of reported lost RES in New Zealand were from the Auckland region (46\%) (Table 2). Other areas of high RES sales (e.g. Manawatu-Wanganui and Canterbury) had relatively low numbers of lost RES reported, whereas the Wellington and Hawkes Bay regions had a large proportion of RES lost (Figure 5).

Figure 5: Numbers of lost red-eared slider (Trachemys scripta elegans; RES) reports (1999-2010) $(\mathrm{n}=$ $83)$ in relation to region and human population density $(\mathrm{R}=0.97)$.

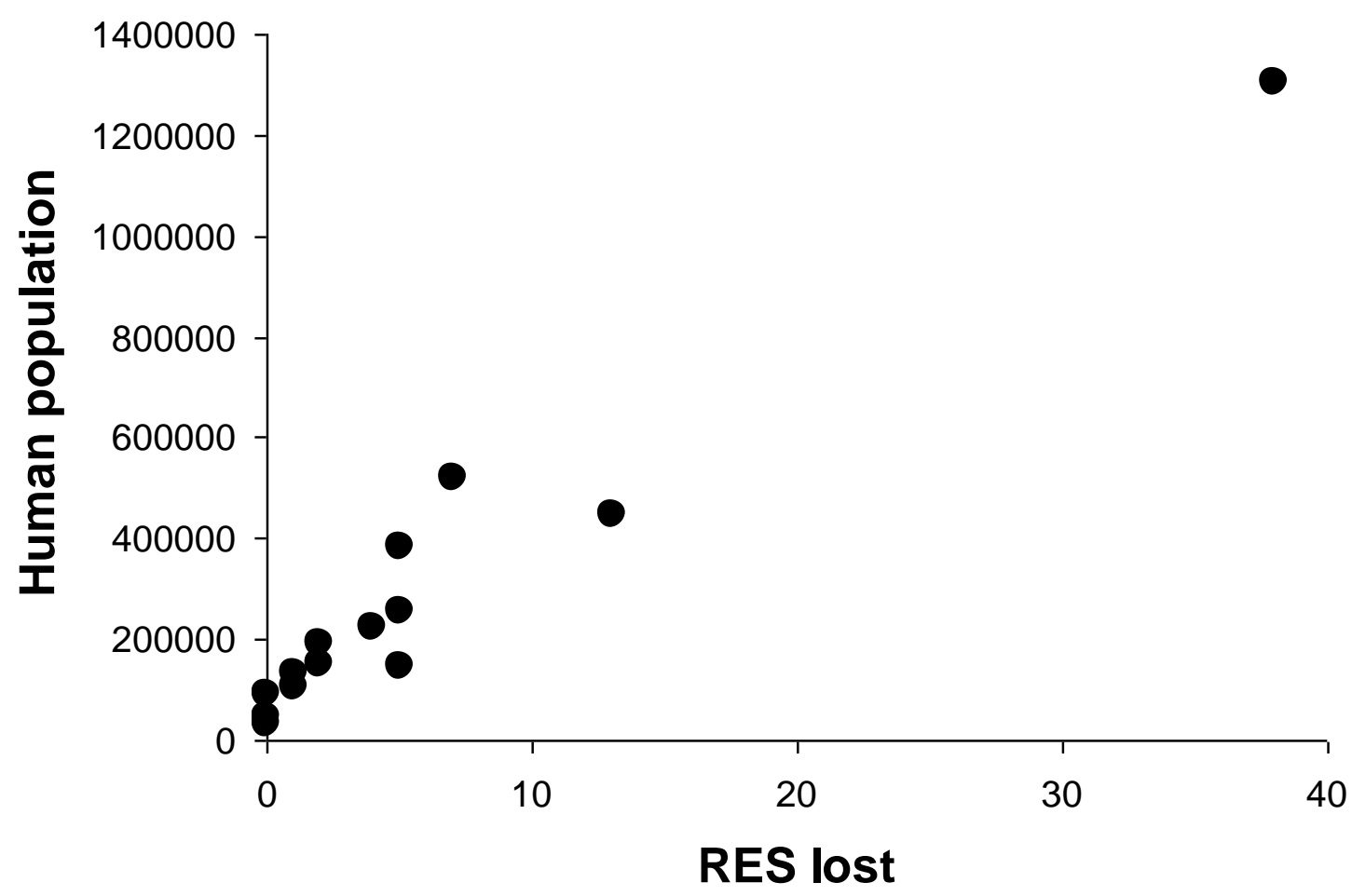

\section{Discussion}

\section{Turtle sales and losses}

Over the course of two years, I recorded the sale of over 1500 RES within the online pet trade in New Zealand. I also found more than 80 reports for lost or missing RES from 1999-2010. The information available online was helpful in creating a "population profile" for RES in the New Zealand pet trade. For example, half of all RES sold on TradeMe were adults, followed closely by juveniles. Red- 


\section{Chapter 2: Tracking turtles via online trading}

eared sliders tended to be reported lost in summer and were most likely to be adult turtles. Of these lost turtles, $39 \%$ were females and $28 \%$ were males. This confirms that both sexes are being released into the New Zealand environment, as opposed to a single sex, which may find it challenging to establish a self-sustaining population in new surroundings. This information could also be useful if one were planning an eradication or management plan for feral RES in New Zealand, as the sexes exhibit different behaviours. For example, male RES are more motile than sperm-storing females, being much more likely to move between aquatic habitats in search of mating opportunities (Morreale and Gibbons 1986; Tuberville et al. 1996; Thomas and Parker 2000).

The majority of both sales and lost pets were from the Auckland region. It is not surprising that the area with both the highest number of turtle sales and the highest number of lost turtles reported came from Auckland, the area with the highest human population in New Zealand. This is likely because a higher number of humans can be associated with a higher number of pet owners, and hence a higher potential number of pet trades and escapes. Previous predictive models for RES have included a "human footprint" component, a measure of human influence on the global surface, and found it to be a useful variable in the prediction of RES establishment (Ficetola et al. 2008). Recent studies show that areas in the northern North Island of New Zealand are the most climatically suitable for this species (Kikillus et al. 2010) and areas in the Auckland region may provide suitable incubation temperatures for RES (See Chapter 5). Red-eared sliders released in this area will likely have a better chance at survival, and possibly establishment, than RES released in other parts of the country. 
Chapter 2: Tracking turtles via online trading

\section{Usefulness of online trading tools}

Aside from the data obtained for the Auckland region, online sales data did not accurately predict records of wild RES throughout the rest of New Zealand. For example, New Zealand's West Coast region had the highest number of RES sales per number of human inhabitants, but had no RES reported lost or missing. Similarly, Hawkes Bay and Wellington had the largest number of RES losses per number of human inhabitants, but this did not match with the rate of sold RES in these regions. This may be attributed to scenarios such as pet owners in Hawkes Bay and Wellington being more likely to lose their turtle than pet owners in other regions, or perhaps being more likely to report their turtle missing than pet owners from other areas. Additionally, just because an animal is sold in a particular area, does not mean it remains in the area after the sale. Many sellers of RES offer shipping options to potential buyers, and turtles are regularly couriered throughout the country (Kikillus, personal observation).

While taking note of the RES sales on TradeMe may give us a better idea of the number of turtles being successfully sold online, it is an underestimate of the actual number of turtles being sold within New Zealand. Turtles that are sold privately or in pet shops are not included in this analysis. Additionally, the map depicting the possible whereabouts of RES within the New Zealand environment is also likely underestimated, as not every turtle owner will post an online classified ad if their pet goes missing. Similarly, ads will not be posted by owners illegally dumping their pets; therefore it is highly likely that there are many unaccounted RES living in the wild throughout New Zealand. As RES have become invasive in many areas outside of their native range, the number of individuals existing in the wild in New Zealand is concerning. 
Education campaigns should be targeted at prospective turtle owners (as well as current owners who may be unaware) to inform them that turtles are a long-lived commitment. This may prevent impulse buys of turtles, as well as help RES to shed the reputation of being a "disposable pet" and reduce the potential to establish in New Zealand.

In this case, online trading allowed us to better understand the RES pet trade in New Zealand and the areas into which these animals are being released. It may be more difficult, however, to use this method in a situation where the species of interest is being imported into a country, as numbers of the animals will be constantly supplemented. Nonetheless, the monitoring of online sales of potentially-invasive species can provide ample demographic information regarding the animals being traded, as well as give an indication of propagule pressure and areas into which they are being released. This technique is applicable to other species and may be a useful tool to help prevent the establishment of additional exotic species outside of their native ranges. 


\section{Literature cited}

Auckland Regional Council (2007). Regional Pest Management Strategy 2007-2012 Auckland, New Zealand, Auckland Regional Council: Pages 119-120.

Bringsøe, H. (2006). NOBANIS- Invasive alien species fact sheet- Trachemys scripta, North European and Baltic Network on Invasive Alien Species- NOBANIS.

Cadi, A. and P. Joly (2004). "Impact of the introduction of the red-eared slider (Trachemys scripta elegans) on survival rates of the European pond turtle (Emys orbicularis)." Biodiversity and Conservation 13: 2511-2518.

Derraik, J. and S. Phillips (2010). "Online trade poses a threat to biosecurity in New Zealand." Biological Invasions 12: 1477-1480.

Duncan, R., M. Bomford, D. Forsyth and L. Conibear (2001). "High predictability in introduction outcomes and the geographical range size of introduced Australian birds: A role for climate." The Journal of Animal Ecology 70(4): 621-632.

Ernst, C. and J. Lovich (2009). Turtles of the United States and Canada. Baltimore, Maryland, USA, The Johns Hopkins University Press.

Ficetola, G., W. Thuiller and E. Padoa-Schioppa (2008). "From introduction to establishment of alien species: bioclimatic differences between presence and reproduction localities in the slider turtle." Diversity and Distributions 2009(15): 108116.

Gibbons, J., Ed. (1990). The slider turtle. Life history and ecology of the slider turtle. Washington DC, USA, Smithsonian Institution Press.

Gibbons, J. and J. Lovich (1990). "Sexual dimorphism in turtles with emphasis on the slider turtle (Trachemys scripta)." Herpetological Monographs 4: 1-29.

Hartley, S. and P. Lester (2003). "Temperature-dependent development of the Argentine ant, Linepithema humile (Mayr) (Hymenoptera: Formicidae): a degree-day model with implications for range limits in New Zealand." New Zealand Entomologist 26: 91-100.

International Fund for Animal Welfare (IFAW) (2008). "Killing with Keystrokes." Retrieved March 5, 2010, from http://www.ifaw.org/Publications/Program_Publications/Wildlife_Trade/Campaign_S cientific Publications/asset upload file848 49629.pdf.

Invasive Species Specialist Group (ISSG) (2004). 100 of the World's Worst Invasive Alien Species.

Kikillus, K. H., K. M. Hare and S. Hartley (2010). "Minimizing false-negatives when predicting the potential distribution of an invasive species: a bioclimatic envelope for the red-eared slider at global and regional scales." Animal Conservation 13(Suppl. 1): 1-11 (doi:10.1111/j.1469-1795.2008.00299.x). 
Kraus, F. (2009). Alien reptiles and amphibians: a scientific compendium and analysis, Springer Netherlands.

Morreale, S. J. and J. W. Gibbons (1986). Habitat suitability index models: Slider turtle. U.S. Fish Wildl. Serv. Biol. Rep. 82: 14.

Newbery, R. (1984). "The American red-eared terrapin in South Africa." African Wildlife 38(5): 186-189.

Suiter, K. and S. Sferrazza (2007). Monitoring the sale and trafficking of invasive vertebrate species using automated internet search and surveillance tools. Managing Vertebrate Invasive Species: Proceedings of an International Symposium, Fort Collins, Colorado, USA, USDA/ APHIS/ Wildlife Research Center.

Thomas, R. and W. Parker (2000). "Intrasexual variations in overland movements of slider turtles (Trachemys scripta)." Journal of Herpetology 34(3): 469-472.

Thornton, T. (1999). Keeping red-eared turtles in New Zealand. Warkworth, New Zealand, TJ's Books.

TradeMe (2010). Retrieved March 5, 2010, from http://www.trademe.co.nz/Abouttrade-me/Site-stats.

Tuberville, T., J. Gibbons and J. Greene (1996). "Invasion of new aquatic habitats by male freshwater turtles." Copeia 1996(3): 713-715.

Tucker, J. (2001). "Clutch frequency in the red-eared slider (Trachemys scripta elegans)." Journal of Herpetology 35(4): 664-668.

White, P., A. Ford, M. Clout, R. Engeman, S. Roy and G. Saunders (2008). "Alien invasive vertebrates in ecosystems: pattern, process and the social dimension." Wildlife Research 35: 171-179.

Williamson, M. and A. Fitter (1996). "The varying success of invaders." Ecology 77(6): 1666-1670. 


\title{
Chapter 3:
}

\section{Minimising false-negatives when predicting the potential distribution of an invasive species: a bioclimatic envelope for the red-eared slider at global and regional scales ${ }^{1}$}

\begin{abstract}
Invasive species threaten biodiversity, hence predicting where they may establish is vital for conservation. My aim is to provide a robust predictive model for an invasive species suitable for managers acting at both global and regional scales. Specifically, I investigate one of the world's worst invasive species (the red-eared slider turtle; RES; Trachemys scripta elegans) and one of the world's biodiversity hotspots (New Zealand) as our representative systems. I used bioclimatic data and location records to define a bioclimatic envelope for the species. Multi-model inference was used to predict areas suitable for RES establishment, weighting in favour of models with low false-negative and high true-positive rates in predictive cross-validation tests. My performance criterion was the partial area-under-the-curve (pAUC) of a ROC plot where sensitivity exceeded 0.95. I generated both conservative (best-case scenario) and liberal (worst-case scenario) predictions, based on different levels of information about breeding potential. All predictions were expressed on a standard scale of suitability relative to existing known distribution. Globally, the best climate matches for RES outside of their native range in North

\footnotetext{
${ }^{1}$ Based on Kikillus KH, KM Hare, and S Hartley (2010) Minimizing false-negatives when predicting the potential distribution of an invasive species: a bioclimatic envelope for the red-eared slider at global and regional scales. Animal Conservation. 13 (Suppl. 1): 5-15. DOI: 10.1111/j.14691795.2008.00299.x
} 


\section{Chapter 3: Predicting global and local invasions}

America include southeast Asia, and parts of Europe; areas where RES have already established. The best available site in New Zealand is considered climatically more suitable than $16 \%$ of global sites where RES have bred successfully. While RES can survive in several areas throughout New Zealand, the potential to establish a selfsustaining (i.e. breeding) population appears restricted to the upper areas of the North Island where mean daily temperatures in the hottest month exceed $24^{\circ} \mathrm{C}$. The methods developed here were designed to reduce false-negative predictions as that represents a precautionary approach for species that pose biosecurity risk. They could readily be adapted, however, to reduce false positives when predicting areas suitable for translocation of rare and endangered species.

\section{Introduction}

In addition to habitat loss and climate change, invasive pest species are a significant threat to biodiversity worldwide (Wittenberg \& Cock, 2001; Campbell \& Donlan, 2005; Nogales, Rodriguez-Luendo, \& Marrero, 2006), as well as affecting agriculture productivity and human health (Fritts, McCoid, \& Haddock, 1990; Pimentel et al., 2000). Consequently, much time, money, and effort is spent each year in eradication, control and mitigation. It is estimated that over 480,000 species worldwide have been introduced outside of their native range (Pimentel et al., 2002), yet not all of these are capable of surviving, reproducing and establishing viable populations (Mack et al., 2000).

Climate-matching is a useful tool which is often used to elucidate areas that may be susceptible to the potential establishment and invasion by a species of interest (e.g., Forsyth et al., 2004; Rodda, Jarnevich, \& Reed 2009). Although climate-based predictions of potential invasions are associated with a level of uncertainty (Sikder, 
Mal-Sarkar, \& Mal, 2006), it is generally more cost-effective to attempt to identify potential invaders and to keep them out of the environment than to control a species once it has become established (Mack et al., 2000; Manchester \& Bullock, 2000). Bioclimatic niche models identify areas suitable for a species' survival and potential establishment. They are based on statistical associations between climate variables and the presence or absence of a species, both within and outside of its native range, and provide valuable assessments of the likelihood of establishment before a species is introduced into an area (Thuiller et al., 2005).

The red-eared slider (RES; Trachemys scripta elegans) is classified by the World Conservation Union's (IUCN) Invasive Species Specialist Group as one of the “World's Worst Invasive Alien Species” (Invasive Species Specialist Group (ISSG), 2004). This turtle is also one of the most popular reptilian pets world-wide (Connor, 1992; Burne, 2000). Upon reaching adulthood, RES are much larger and more aggressive than when purchased as hatchlings, and subsequently, adults are often discarded into local waterways (Cadi \& Joly, 2004). In their exotic range, RES outcompete native turtles (e.g., European pond turtles, Emys orbicularis; (Lever, 2003), disrupt food-webs by consuming aquatic vegetation, invertebrates and vertebrates (Ernst, Lovich, \& Barbour, 1994; Ligon, 2007; Prevot-Julliard et al., 2007), and negatively affect birdlife, e.g., by drowning eggs while basking in waterbird nests (ISSG, 2006). The RES is native to the Mississippi Valley area, USA, and has established wild populations in several countries, including Australia, Spain, France, Italy, Taiwan, Japan, Guam, as well as outside of its native range in North America, among others (Ng, Chou, \& Lam, 1993; Chen \& Lue, 1998; Bomford, 2003; Lever 2003; Cadi et al., 2004; ISSG 2004; Ficetola, Thuiller, \& Padoa-Schioppa, 2009). 


\section{Chapter 3: Predicting global and local invasions}

Invasive species often have the greatest detrimental effects in regions where there are no ecological equivalents in the naïve environments. An excellent example is New Zealand, where for 80 million years evolution proceeded without the influence of terrestrial mammals (except bats) (King 2005). Since the introduction of terrestrial mammals, the native fauna has undergone dramatic declines. Resident reptiles in New Zealand consist of the endemic tuatara (Order: Rhyncocephalia) and lizards (Order: Squamata). No crocodilians or freshwater turtles are naturally present. The RES is one of the most affordable (from 50 NZD) and easily obtained exotic reptiles in the New Zealand pet trade (KHK, pers. obs.). Although the importation of RES has been banned since 1965, local reptile breeders legally contribute approximately 2,000 turtles annually to the New Zealand market (Feldman, 2005), and RES have been found living in the wild throughout New Zealand (Thomas \& Hartnell, 2000, Hoskins, 2006; Dykes, 2007). Some Regional Councils now classify RES as pests in the wild and advocate further research to determine if this species poses a threat to New Zealand's environment (Auckland Regional Council, 2007; Greater Wellington Regional Council, 2007).

The aim of this paper is to provide a predictive model for an invasive species worldwide, and to use this data to estimate probabilities of establishment of that invasive species across a case-study region. Specifically, I use one of the worst invasive species world-wide (the RES) and one of the most highly vulnerable habitats (New Zealand) as our representative systems. I aim to: 1) predict areas of suitable RES habitat globally with a model chosen for its low false-negative and high truepositive prediction rate; 2) use the global data to predict areas in New Zealand that are susceptible to RES establishment; 3) provide both conservative (best-case scenario) and liberal (worst-case scenario) predictions to be made based on a 
knowledge of breeding status; and 4) express all predictions on an intuitive scale that is independent of the sample size and relative to the suitability across the full range of known occurrences.

\section{Methods}

\section{Data sources}

Current distribution records of RES presence were collected from scientific publications, online databases, and wildlife field guides (Appendix 9: Supplementary Tables 1 and 2). If latitude-longitude coordinates were given, these were recorded. If coordinates were not supplied, locations were obtained using Google Earth (http://earth.google.com) and latitude-longitude coordinates (WGS84) were acquired. Location records were assigned to two possible categories: 1) conservative dataset (records where RES have bred successfully in native and introduced ranges), and 2) liberal dataset: (records from the conservative dataset plus RES sightings, but where breeding was not confirmed). If a location record did not list breeding status, even if successful breeding was highly likely (e.g., juveniles found in the wild), they were placed in the liberal dataset.

Global climate data for temperature and precipitation were obtained from the Intergovernmental Panel on Climate Change (IPCC) as an array of half-degree latitude x longitude grid cells (New, Hulme, \& Jones, 1999). Monthly averages for the period 1961-1990 were used to calculate mean annual temperature (MAT), mean temperature in the hottest month (MAXAVG), mean temperature in the coldest month (MINAVG), mean daily maximum temperature in the hottest month (MAXMAX), mean daily minimum temperature in the coldest month (MINMIN), and total annual precipitation (PPT). 


\section{Bioclimatic modelling}

The presence or absence of RES was modelled using binary logistic regression performed with R v.2.8.1 (R Development Core Team, 2007). All halfdegree gridcells with no record of RES were treated as absences. Twelve alternative models, incorporating different combinations of temperature and precipitation variables, were constructed (Table 1). The multi-model approach allowed us to estimate the consistency of predictions on a site-by-site basis in the face of uncertainty about which is the "correct" model (Hartley, Harris, \& Lester, 2006). It also enabled us to identify which climatic variables were most effective in defining a climatic envelope for the species that could be transferred across space. Furthermore, when there is some uncertainty regarding the correct model, predictions based on multi-model inference are generally regarded as more robust than those derived from a single model defined a priori. (Roura-Pascual et al., 2009). 
Table 1: Twelve different specifications representing the set of plausible candidate models. MINMIN: lowest average daily minimum in coldest month, MINAVG: lowest average daily mean in coldest month, MAT: mean annual temperature, MAXAVG: highest average daily mean in hottest month, MAXMAX: highest average daily maximum in hottest month, PPT: total annual precipitation.

\begin{tabular}{|c|c|c|c|c|c|c|c|}
\hline Model & Description & & Cli & nate & aria & & \\
\hline & & 忘 & 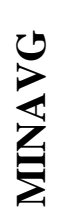 & $\sum^{E}$ & $\sum_{\substack{x \\
\sum}}^{b}$ & $\sum_{i}^{\infty}$ & ڤ̆ \\
\hline $\mathrm{a}$ & $\begin{array}{l}\text { winter daily mean, summer daily mean, } \\
\text { and total annual precipitation }\end{array}$ & & $\checkmark$ & & $\checkmark$ & & $\checkmark$ \\
\hline $\mathrm{b}$ & (a) + all 2-way interactions & & $\checkmark$ & & $\checkmark$ & & $\checkmark$ \\
\hline $\mathrm{c}$ & $\begin{array}{l}\text { winter minimum, summer maximum, and } \\
\text { total annual precipitation }\end{array}$ & $\checkmark$ & & & & $\checkmark$ & $\checkmark$ \\
\hline $\mathrm{d}$ & (c) + all 2-way interactions & $\checkmark$ & & & & $\checkmark$ & $\checkmark$ \\
\hline $\mathrm{e}$ & $\begin{array}{l}\text { summer daily mean, total annual } \\
\text { precipitation, }+2 \text {-way interaction }\end{array}$ & & & & $\checkmark$ & & $\checkmark$ \\
\hline $\mathrm{f}$ & $\begin{array}{l}\text { winter daily mean, total annual } \\
\text { precipitation, }+2 \text {-way interaction }\end{array}$ & & $\checkmark$ & & & & $\checkmark$ \\
\hline $\mathrm{g}$ & $\begin{array}{l}\text { summer maximum, total annual } \\
\text { precipitation, }+2 \text {-way interaction }\end{array}$ & & & & & $\checkmark$ & $\checkmark$ \\
\hline $\mathrm{h}$ & $\begin{array}{l}\text { winter minimum, total annual } \\
\text { precipitation, }+2 \text {-way interaction }\end{array}$ & $\checkmark$ & & & & & $\checkmark$ \\
\hline $\mathrm{i}$ & $\begin{array}{l}\text { mean annual temperature and total annual } \\
\text { precipitation }\end{array}$ & & & $\checkmark$ & & & $\checkmark$ \\
\hline $\mathrm{j}$ & (i) + 2-way interaction & & & $\checkmark$ & & & $\checkmark$ \\
\hline $\mathrm{k}$ & $\begin{array}{l}\text { winter minimum, summer maximum, } \\
\text { winter daily mean, summer daily mean, } \\
\text { and total annual precipitation }\end{array}$ & $\checkmark$ & $\checkmark$ & & $\checkmark$ & $\checkmark$ & $\checkmark$ \\
\hline 1 & $(\mathrm{k})+$ all 2-way interactions & $\checkmark$ & $\checkmark$ & & $\checkmark$ & $\checkmark$ & $\checkmark$ \\
\hline
\end{tabular}




\section{Chapter 3: Predicting global and local invasions}

The predictive ability of each of the 12 models was evaluated using crossvalidation. For cross-validation purposes the global dataset was partitioned into five geographic areas with a minimum of ten positive occurrences in each: (1) Western North America: comprised of both introduced and native range records, (2) Central North America: comprised of native range records only, (3) Central-eastern North America comprised of both introduced and native range records, (4) Eastern North America comprised of both introduced and native range records, and (5) Rest of World comprised of introduced range records only. (Figure 1). Each model was run using three of these geographic areas as "Training data" (calibration) and the remaining two areas as "Test data" (evaluation). The coarse-scale geographic separation of the test and training data minimises the chances of identifying spurious relationships due to cross-correlations between spatially autocorrelated predictor variables (Hartley et al. 2006; Lennon 2000). Every possible combination of three training data groups and two test data groups was fitted and evaluated. Our specific metric for quantifying predictive ability of the models was based on Receiver Operating Characteristic (ROC) plots of the test data calculated using the ROCR package (Sing et al., 2004). 
Figure 1: Global distribution of records for red-eared sliders (RES; Trachemys scripta elegans) displayed against a backdrop of Mean Annual Temperature (MAT). The geographic zones (labelled 15) were used to create different combinations of training data (any three zones) and test data (the remaining two zones) (refer to text for details). Zones 2 and 3 include the native range.

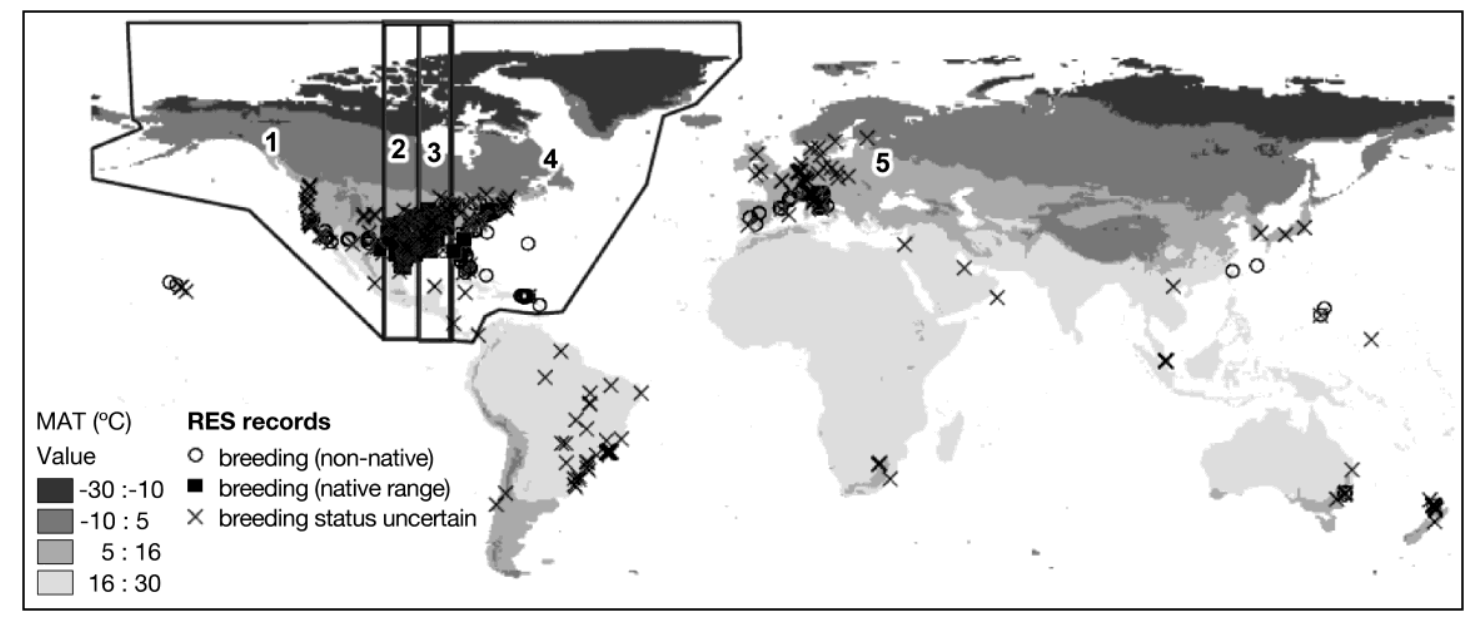

To produce a ROC plot, the predicted probability of occurrence (a continuous value between 0 and 1 ) is converted into a binary prediction of presence or absence, using a threshold value. The binary predictions are then cross-classified with the observed data and the proportion of true positives (also referred to as "Sensitivity") is plotted against the proportion of false positives (" 1 - Specificity"). A curve is generated by repeating this process for all possible thresholds between 0 and 1 (Fielding and Bell 1997; Peterson, Papeş, \& Soberón, 2008). The region in the upper-left $(0,1)$ corner of the ROC plot represents a model and threshold that maximises true positives while minimising false positives (Fielding and Bell 1997).

Often the area under the curve (AUC) is used as a performance measure for ROC plots, as it integrates performance across all possible thresholds (Fielding and Bell 1997). In a biosecurity context, however, a precautionary approach would suggest that it is important to achieve a high rate of true-positives and few falsenegatives, even though this may come at the expense of a high number of falsepositives. We are not interested, therefore, in how models perform with low thresholds which minimise false positives at the expense of true positives (the left- 
hand side of a traditional ROC plot). Instead, I set a lower limit on our required true positive rate (Specificity) of 0.95 , and measured the area under the curve to the right of this specificity limit (Figure 2). This performance measure is called the partial area under the curve (pAUC) (see also Peterson et al. 2008). Each bioclimatic model was scored based on the number of times it was selected as the best predictive model (i.e. the one with the highest pAUC of the test data) out of the ten possible combinations of the data partitions (Table 2). The scores were divided by ten to convert them into model weights, which represent our relative belief in the predictive ability of each model (Burnham \& Anderson, 2002).

Figure 2: Example of a Receiver Operating Characteristic (ROC) plot plotting true positive rate (Sensitivity) against false positive rate $(1-$ Specificity) with a threshold of 0.95 . When a high level of true positives is required (e.g. Sensitivity $>0.95$ ), a useful measure of model performance is the partial area under the curve (pAUC), shaded grey, to the right of the threshold intersection.

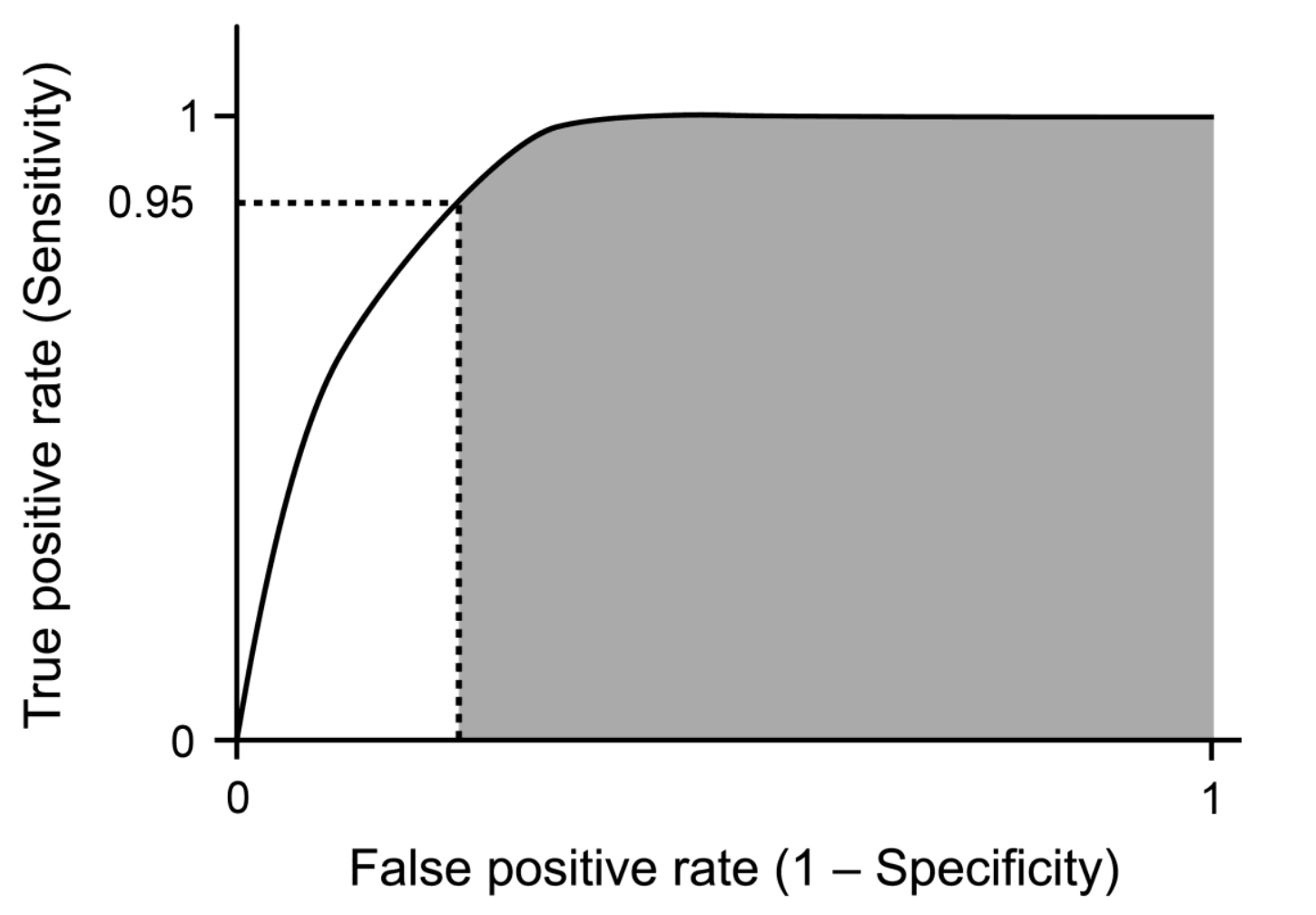

Final predictions were made from a multimodel weighted average fitted to the complete dataset of all known records and presumed absences. (Table 2 and 


\section{Chapter 3: Predicting global and local invasions}

Appendix 9: Supplementary Table 3). The predictions of the weighted model average from both the conservative and the liberal datasets were visualised as (i) climate envelopes in climate space, (ii) as maps of predicated suitability and (iii) as box plots of suitability for specified geographic regions of management interest. In each of the above visualisations, the predicted probability of occurrence from the logistic regression (a value from 0 to 1 that is sensitive to prevalence in the fitting data set) was rescaled into a score of relative suitability that has a more intuitive interpretation. For example, a suitability score of 0.2 indicates that the location in question has been modelled to have a predicted probability of occurrence equal to or greater than $20 \%$ of the sites from which the species has been recorded. A consistent colour-scheme was adopted for visualising "suitability" with break points at the $0^{\text {th }}, 1^{\text {st }}, 5^{\text {th }}, 10^{\text {th }}, 50^{\text {th }}$, and $90^{\text {th }}$ percentiles of the predicted probability of occurrence of the positive sites. The values of the $1^{\text {st }}$ and $5^{\text {th }}$ percentiles were reflected back across the $0^{\text {th }}$ percentile, on the logit scale, to create a value for a " -1 st" and " $-5^{\text {th" }}$ percentile; these latter two representing values below the suitability of even the least suitable occupied site. Maps were redrawn at a finer resolution (5 minute resolution) for New Zealand using data from WorldClim (Hijmans et al., 2005) in order to determine more precisely which areas of New Zealand may be climatically suitable for RES.

\section{Results}

The conservative dataset had 191 locations of confirmed breeding sites of RES (Appendix 9: Supplementary Table 1). Some sites were in the same terrestrial grid cell and were not counted twice, meaning that 163 location records were used in analyses. The liberal dataset contained 459 location records (including the records 
from the conservative dataset) (Appendix 9: Supplementary Table 2). Again, only one record per terrestrial grid cell was used, resulting in 352 location records.

Based on the pAUC values of the test data partition, "Model l", had the best predictive ability for the confirmed breeding dataset, with a relative weighting of 0.4 (Table 2). For the liberal dataset, "Model $\mathrm{j}$ " was the best performing model with a relative weighting of 0.3 (Appendix 9: Supplementary Table 3). For consistency, model "l" was used to generate a description of the RES climate envelope for both datasets (Figure 3a and Appendix 9: Supplementary Figure 1a). 
Table 2: Comparison of models from Table 1 using the conservative dataset (confirmed breeding redeared slider (Trachemys scripta elegans) records, (a) Cross-validation indicates performance in predicting withheld, geographically separated, test data (mean of ten partitions), pAUC = partial area under the curve measured where specificity $\geq 0.95$. (b) Performance under self-validation, where all available data was used to make final predictions of suitability. (c) Model weights determined from the number of times models were selected as the best predictive model (i.e., the one with the highest pAUC of the test data). Models in bold account for greater than $50 \%$ of the total weight. (d) Suitability score $=$ rank of New Zealand's most suitable site relative to all the positive location records, based on the modelled probability of occurrence. A score of 0.2 indicates that New Zealand's most suitable site is modelled as being at least as favourable as $20 \%$ of the locations from which RES have been recorded to breed successfully.

\begin{tabular}{|c|c|c|c|c|c|c|}
\hline \multirow[b]{2}{*}{ Model } & \multicolumn{3}{|c|}{ Cross-validation $^{\mathrm{a}}$} & \multicolumn{3}{|c|}{ Final fit $^{b}$} \\
\hline & $\mathbf{A U C}$ & pAUC & $\begin{array}{l}\text { Model } \\
\text { weight }^{\mathrm{c}}\end{array}$ & $\mathbf{A U C}$ & pAUC & $\begin{array}{c}\text { NZ } \\
\text { suitability }^{\text {score }} \\
\text { scor }^{\text {d }}\end{array}$ \\
\hline $\mathrm{a}$ & 0.876 & 0.667 & 0 & 0.933 & 0.743 & 0.101 \\
\hline b & 0.867 & 0.641 & 0.1 & 0.942 & 0.789 & 0.080 \\
\hline $\mathrm{c}$ & 0.857 & 0.637 & 0.1 & 0.916 & 0.597 & 0.117 \\
\hline d & 0.867 & 0.662 & 0 & 0.932 & 0.734 & 0.193 \\
\hline $\mathrm{e}$ & 0.797 & 0.613 & 0 & 0.871 & 0.652 & 0.058 \\
\hline $\mathrm{f}$ & 0.873 & 0.639 & 0 & 0.907 & 0.724 & 0.997 \\
\hline g & 0.803 & 0.630 & 0.1 & 0.873 & 0.651 & 0.338 \\
\hline $\mathrm{h}$ & 0.862 & 0.606 & 0 & 0.891 & 0.637 & 0.986 \\
\hline $\mathrm{i}$ & 0.870 & 0.688 & 0.1 & 0.902 & 0.727 & 0.997 \\
\hline $\mathrm{j}$ & 0.869 & 0.656 & 0.2 & 0.903 & 0.708 & 1.000 \\
\hline $\mathrm{k}$ & 0.870 & 0.673 & 0 & 0.941 & 0.819 & 0.156 \\
\hline 1 & 0.883 & 0.642 & 0.4 & 0.960 & 0.836 & 0.144 \\
\hline $\begin{array}{l}\text { Weighted } \\
\text { multi- } \\
\text { model } \\
\text { average }\end{array}$ & NA & NA & NA & 0.958 & 0.840 & 0.160 \\
\hline
\end{tabular}

Global predictions of areas with suitable climate for RES derived from the multimodel average are shown in Figure 3b and Appendix 9: Supplementary Figure 1b. As expected, the global predictions for each dataset highlighted the species' 


\section{Chapter 3: Predicting global and local invasions}

native range in the south-eastern United States of America as an area highly suitable for RES. When utilising the conservative dataset (confirmed breeding records), areas identified as the best climatic match (suitability of 0.5 or greater) occurred in southeastern China, northern India, southern Turkey, central Europe (especially along the eastern Adriatic coast), and South America (Uruguay and Argentina, near Buenos Aires). Other suitable areas (suitability $\geq 0.1$ ) included parts of eastern and western Australia, northern Africa, southern Africa, Madagascar, Europe, Asia, South America, and areas surrounding the RES native range in North America (Figure 3b). Results obtained with the liberal dataset expanded on areas highlighted by the conservative dataset, with the most suitable sites identified for the presence of RES in North America (native range), South America, Europe, Asia, and eastern Australia (Appendix 9: Supplementary Figure 1b).

The "overlap" in suitability between the worldwide set of grid cells occupied by RES, and grid cells available in New Zealand is evident in Figure 3c and Appendix 9: Supplementary Figure 1c. The suitability of the "best" available site in New Zealand was 0.16 based on the conservative dataset and the final fit using the multimodel average. In other words, the best site available in New Zealand is believed to be climatically better than $16 \%$ of sites incorporated into the model where RES have already been recorded to breed successfully. With regard to the liberal dataset, the relative New Zealand suitability score was 0.822 , meaning that in terms of adult survival, the New Zealand environment is as suitable as at least $82 \%$ of the other locations from which free-living RES have been recorded from across the world. 
Higher resolution, regional-scale predictions, predicted that areas in the northern portion of New Zealand's North Island would be more suitable as RES establishment sites than areas further south (Figure 3d). When RES location records where breeding status was unknown were incorporated (liberal dataset), the model predicted a larger area of suitable habitat where RES could survive in New Zealand (Appendix 9: Supplementary Figure 1d). These results are consistent with reports of RES living in the wild in New Zealand (Hoskins, 2006). Currently, there are no records of RES breeding in New Zealand outside of captivity. 
Figure 3: (a) Red-eared slider (RES; Trachemys scripta elegans) climate envelope of the best model, "model 1" (Table 1), fitted to the conservative dataset at three different levels of precipitation: (i) $<300$ $\mathrm{mm} /$ year, (ii) 300-1200 mm/year, and (iii) >1200 mm/year. Black squares indicate sites with a recorded presence. White dots are sites where RES is presumed absent, but for clarity only a $20 \%$ random sample of all presumed absences have been drawn. Purple diamonds show New Zealand's top ten most suitable RES sites. To calculate predicted probabilities MINMIN (not shown) was set equal to MINAVG minus $5^{\circ} \mathrm{C}$, MAXMAX (not shown) was set equal to MAXAVG plus $5^{\circ} \mathrm{C}$, and MAT (not shown) was set to the average of MINAVG and MAXAVG. (b) Global bioclimatic predictions derived from the weighted multimodel for areas of suitable RES habitat derived from the conservative dataset (native or established RES range). The red areas denote a more suitable climate for RES than blue areas. (c) Vertical lines and summary box plots illustrate the distribution of predicted probability of occurrence for all RES occupied sites (top) with the central line equal to the median, boxes extend from the $10^{\text {th }}$ to $90^{\text {th }}$ percentile and whiskers across the full range. These percentiles are used to define a relative suitability score. Below is the distribution of suitability for all sites available in New Zealand. (d) Bioclimatic predictions for areas of suitable RES habitat, derived from weighted multimodel applied to higher resolution climate data of New Zealand and utilising the conservative dataset (confirmed breeding records). The red areas denote a more suitable climate than blue areas for RES. (e) Colour-coding for the suitability scale (refer to part (b) and text for details).

(a)

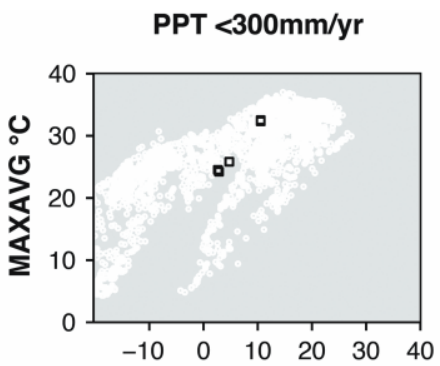

PPT 300-1200mm/yr

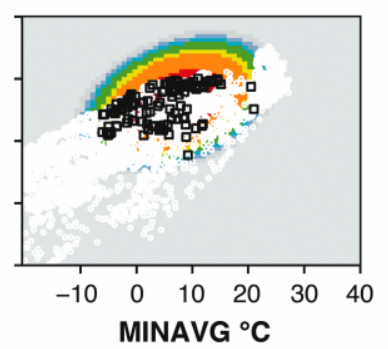

PPT $>1200 \mathrm{~mm} / \mathrm{yr}$

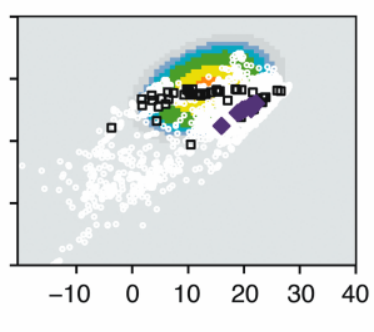

(b)

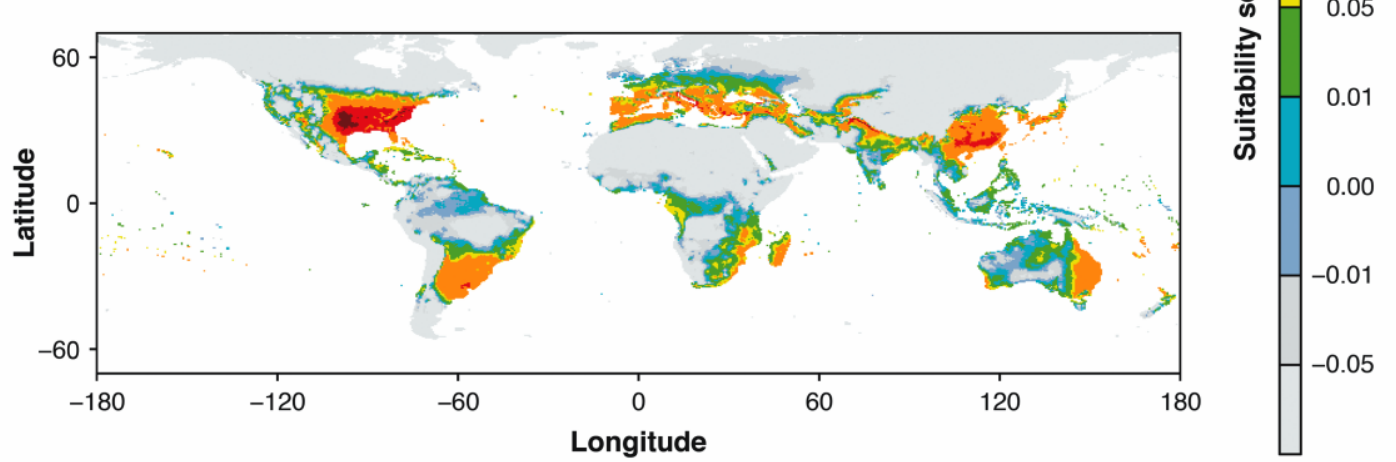

(c)

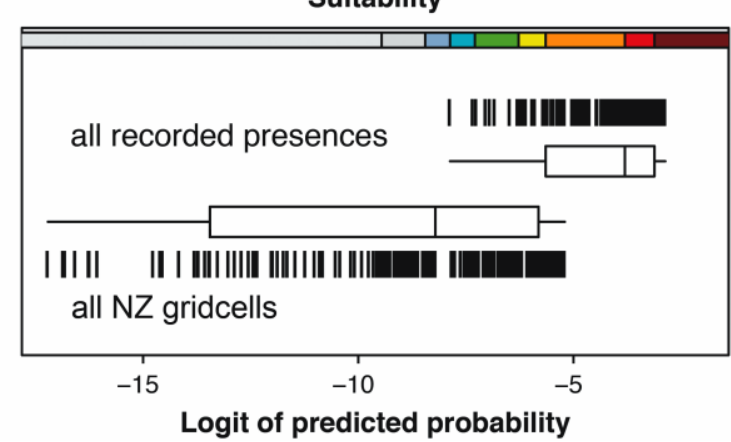

(d)

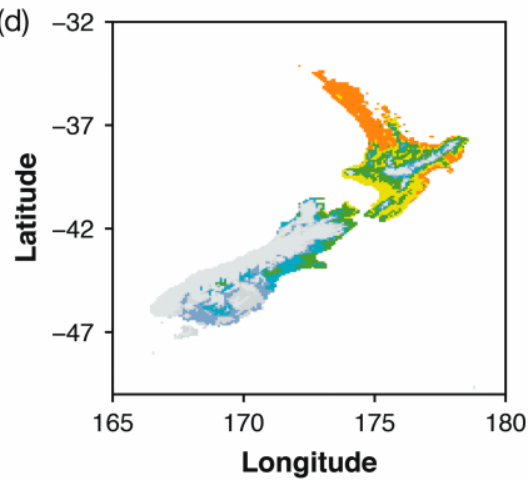

(e)

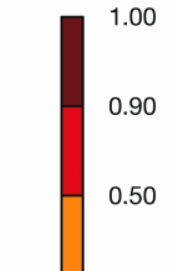

¿ั. 0.10

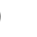




\section{Discussion}

\section{Global predictions and the climate envelope for RES}

Our results indicate that a number of areas not currently known to be occupied by RES possess climates that are highly suitable for their breeding and establishment. Most notably, large areas of south-east Asia are predicted to be just as suitable as the majority of the native range. This is a concern as RES are farmed in China and can be found for sale in Chinese markets (Shi, 2008). Turtles, including RES, are often liberated into the wild in Asia as part of religious ceremonies, and work is currently being conducted in and around Singapore to determine if the vast numbers of released sliders are successfully reproducing in the wild (Ramsay, Ng, O'Riordan, \& Chou, 2007). Feral RES are also found in Thailand, Hong Kong, Malaysia, Vietnam, Korea, Japan, Indonesia, and Taiwan (Ramsay et al. 2007).

Among the models that received some support (weights $\geq 0.1$ ) for predicting the breeding range all the different environmental variables are represented. This indicates that there is not one single climatic factor that dominates the definition of this species' fundamental niche. With the liberal dataset (including potential nonbreeding records) mean annual temperature and climate variables relating to winter minima (MINAVG and MINMIN) were most highly represented.

In their native range, RES occupy a variety of habitats, suggesting they possess a broad tolerance of environmental conditions (Newbery, 1984). The adult RES is able to tolerate cold temperatures and can survive winter conditions where temperatures drop below $-10^{\circ} \mathrm{C}$ for extended periods (Cadi \& Joly, 2004). Juvenile RES, however, are not as cold tolerant as the adults and hatchlings may die at temperatures of $-0.6^{\circ} \mathrm{C}$. In their native range, juvenile RES are known to overwinter in their nests in attempts to avoid or limit their exposure to freezing temperatures, and 
emerge the following spring (Tucker \& Packard, 1998). The limited cold tolerance of hatchling RES may restrict their potential invasive range. At the other extreme, RES within their native range may survive body temperatures of over $40^{\circ} \mathrm{C}$, although their preferred body temperature is $28^{\circ} \mathrm{C}$ (Crawford, Spotila, \& Standora, 1893).

\section{Assessing potential for establishment at a regional level (New Zealand)}

New Zealand's most suitable site received a suitability of score of 0.16 based on the multi-model average. This was similar to the prediction of the single best model, model "l”. However, models which included only mean annual temperature or winter minima (models “f”, “h”, “i”, and “j”) among their predictors generated much higher suitability scores than those that included a measure of summer maxima. This suggests that summer temperatures are the pivotal factor in determining whether or not the New Zealand climate is considered suitable for the establishment of RES. While adult RES are able to successfully overwinter in the warmer parts of New Zealand (Hoskins, 2006), it is unknown if they are able to successfully reproduce in the wild and, thus, establish self-sustaining populations.

Adult females are able to store sperm for years and are capable of producing up to three clutches of between 3-24 eggs per year (Thornton, 1999; ISSG, 2006; O'Keeffe, 2006). Successful incubation of RES eggs requires temperatures between $22^{\circ} \mathrm{C}$ and $33^{\circ} \mathrm{C}$ for 55-80 days (Congdon \& Gibbons, 1990; ISSG, 2006). The only reported record of successful RES breeding outdoors in New Zealand was in an outdoor exhibit at a zoo (Feldman 1992). Feldman (1992) constructed an artificial turtle nest during a cooler than normal year in Northland, New Zealand. The temperature of the constructed nest hovered in the low $20^{\circ} \mathrm{C}$ range, but reached $27^{\circ} \mathrm{C}$ on occasion. Based on the results of this single nest, Feldman (1992) concluded that 


\section{Chapter 3: Predicting global and local invasions}

RES were unable to reproduce in New Zealand. Red eared sliders exhibit temperature-dependent sex determination, where males are produced at cooler incubation temperatures (below c. $28^{\circ} \mathrm{C}$ ) and females produced at higher temperatures (above c. $30^{\circ} \mathrm{C}$ ), with a pivotal temperature (where both males and females are produced) at around $29^{\circ} \mathrm{C}$, (Congdon and Gibbons 1990; Etchberger et al., 1991; Dodd, Murdock, \& Wibbels, 2006). In New Zealand, RES would likely experience cool incubation temperatures, which may produce only male hatchlings from successful nests. As it can be difficult to infer soil temperatures from air temperature data (Hartley and Lester 2003), and given that the metabolic activity of developing eggs may raise the surrounding soil temperature (Burger, 1976), further research on potential nest temperatures in New Zealand is required.

Previous attempts to model areas of climatic suitability for RES at a regional scale have included additional variables such as amount of solar radiation and "human footprint", a measure of human influence on the global surface (Ficetola $e t$ al., 2009). These factors are relevant, as RES are dependent on environmental warmth to regulate body temperature and for egg incubation, and released pets are often concentrated in areas of high human density. Such predictions developed on a fine-scale regional area are not always transferable to a global scale (Randin et al., 2006). However, our global-scale results are broadly consistent with the predictions for northern Italy made by Ficetola et al. (2009). Furthermore, both studies confirm that reproductive populations are associated with a warmer bioclimatic envelope than populations where breeding status in not certain. 


\section{Climate Envelope Approach}

Climate matching between a species' native and non-native ranges is considered only a "first step" in predicting establishment risk (Ficetola, Thuiller, \& Miaud, 2007). Climate suitability can be thought of as a coarse-scale filter of whether a species can establish in a country or region, then, given that the climate is suitable, a more detailed analysis should examine the role of biotic interactions and the fine-scale distribution of suitable habitat (Pearson, Dawson, \& Liu, 2004). Further factors to consider include propagule pressure and the history of invasions elsewhere, although this information is not always available (Kolar and Lodge 2001; Bomford et al., 2009). Nonetheless climate matching provides an opportunity to assess a species' establishment potential (Thuiller et al. 2005).

The use of the two datasets ("Conservative" (confirmed RES breeding) and "Liberal" (unconfirmed RES breeding)) in this study allowed us to better visualise the potential range of RES. The conservative dataset may lead to predictions of potential range that are too conservative, and although the liberal dataset may overestimate the potential breeding range, the two datasets help to define the two extremes of what might be possible.

\section{Choice of model metrics}

From a management perspective, the suitability of the most vulnerable site within a region is a meaningful summary of a region's vulnerability to invasion, particularly against non-native species which are regularly released throughout the region. In other instances, the specific suitability at points of entry (e.g. airports and seaports) may provide the best estimate of risk. The development of a suitability score that is independent of the number of positive records in the dataset will also 


\section{Chapter 3: Predicting global and local invasions}

allow biosecurity managers to more easily compare the invasion threat of multiple species, making it possible to rank species in order of threat level and, therefore, guide management decisions and allocation of resources.

There are many measures of classification performance available (Fielding \& Bell, 1997), and different rationales for selecting specific classification thresholds (Liu et al., 2005). In a biosecurity context, false negative predictions are more costly than false positives, as it is more costly to eradicate a pest than to identify a species that may become a problem (Mack et al. 2000). If one knew the relative cost of false negatives versus false positives, a cost minimisation approach could be used to select the most efficient threshold (Hartley et al. 2006), however this is rarely the case. Thus, in this paper I adopted a precautionary threshold by only comparing models across the range of thresholds with high sensitivity $(\geq 0.95)$ and low rates of false negatives, using the partial-AUC as our integrated performance criterion. If we were producing a bioclimatic niche model for a rare species of conservation concern (e.g. to identify sites most suitable for reintroduction), then we might define the pAUC differently, by setting a lower limit on the false negative rate (e.g. 1 -Sensitivity $=0.05)$ and measuring the area under the curve that lies above this horizontal line in order to minimize the risk of including unsuitable sites in the selected set, even at the cost of excluding some good ones.

I did not use AIC (Akaike Information Criteria), (which is based on maximum likelihood methods and a correct estimation of the degrees of freedom in the model) as a measure of model performance since the spatial autocorrelation of predictors and response variable invalidates the supposed degrees of freedom. Hartley et al. (2006) considered a quasi-AIC, but concluded that predictive performance in independent test data was the more reliable criterion for model weighting. Multimodel inferences 
are more robust to errors in model specification (Chatfield 1995; Marmion et al., 2009), and also allow a more meaningful assessment of uncertainty - which is crucial in risk assessment.

Finally, global scale data were used to parameterise the models, but if finer scale climate data are available for particular areas (e.g. a country) then fine-scale predictions for a selected species can be made. Here I made those predictions for New Zealand, however the method could equally be applied to other regional or national study areas and to species of high conservation importance.

\section{Conservation and Management Implications}

At a global scale, the RES has already demonstrated itself to be a threat to local biodiversity (e.g., Cadi \& Joly, 2004; ISSG, 2006) and the potential for it to continue to expand its range into south-east Asia suggests that tighter regulation of the pet trade in these areas is warranted. In bioclimatically-suitable areas such as Florida, owners require permits to keep RES (FWC, 2008).

Our regional-scale predictions indicate that, while RES are able to survive in several areas throughout New Zealand, the potential to establish self-sustaining (i.e. breeding) populations appears restricted to the upper areas of the North Island where mean daily temperatures in the hottest month exceed $24^{\circ} \mathrm{C}$, such as Northland, Coromandel, and parts of the Bay of Plenty. Due to the temperature-dependent sex determination of RES, it is possible that conditions in these areas may produce primarily male hatchlings, however, with the constant supplementation of individuals (including adult females with the ability to store sperm) to the population via deliberate releases and escapes from captivity, combined with their longevity, the potential for negative impacts on the New Zealand environment exists. Further 


\section{Chapter 3: Predicting global and local invasions}

research, including the incorporation of predicted climate change, research into nest temperatures that could be achieved in New Zealand, biotic interactions, diet, and disease transmission is needed to complete a more holistic risk assessment of whether RES pose a credible risk to New Zealand's environment and economy. In the meantime, precautionary measures should be taken to ensure that more RES are not released into the wild and that existing feral individuals are removed from the New Zealand environment.

\section{Conclusion}

With increasing global travel and the sustained demand for unusual pets there is a continuing need to develop methods for quantifying the risk of establishment for a range of invasive species. The methods developed in this paper are particularly suited for modelling the potential distribution of both invasive and "at risk" species where false negatives and false positives do not have equal costs or consequences. Multi-model inference was used to increase robustness of our predictions, and for communicating the range of plausible predictions. Finally, the development of a suitability score was used as an aid to intuitive interpretation of the relative risk of establishment, irrespective of the prevalence of the species records or whether or not the species has reached an equilibrium. This suite of methods should prove useful in increasing the accuracy of the climate-envelope approach, and more importantly in communicating these results to those charged with prioritising biosecurity and conservation resources. 


\section{Literature cited}

Auckland Regional Council (ARC) (2007). Auckland Regional Pest Strategy 20072012.). Auckland Regional Council, New Zealand.

Bomford, M. (2003). Risk assessment for the import and keeping of exotic vertebrates in Australia. Bureau of Rural Sciences: Canberra Australia (Ed.).

Bomford, M., Kraus, F., Berry, S., \& Lawrence, E. (2009). Predicting establishment success for alien reptiles and amphibians: A role for climate matching. Biol.

Invasions, 11: 713-724.

Burger, J. (1976). Temperature relationships in nests of the northern diamondback terrapin, Malaclemys terrapin terrapin. Herpetologica. 32: 412-418.

Burne, C. (2000). The ultimate guide to keeping freshwater turtles successfully in New Zealand. Napier, New Zealand: Brebner Print.

Burnham, K. P. \& Anderson, D. R. (2002). Model selection and multimodel inference: A practical information-theoretic approach. New York, NY, USA: Springer-Verlag.

Cadi, A., Delmas, V., Prevot-Julliard, A., Joly, P., Pieau, C., \& Girondot, M. (2004). Successful reproduction of the introduced slider turtle (Trachemys scripta elegans) in the south of France. Aquatic Conservation: Marine and Freshwater Ecosystems, 14: 1362-1374.

Cadi, A., Joly, P. (2004). Impact of the introduction of the red-eared slider (Trachemys scripta elegans) on survival rates of the European pond turtle (Emys orbicularis). Biodiversity Conservation, 13: 2511-2518.

Campbell, K. \& Donlan, J. (2005). Feral goat eradication on islands. Conservation Biology, 19: 1362-1374.

Chatfield, C. (1995). Model uncertainty, data mining and statistical interference. Journal of the Royal Statistical Society, Series A, 158: 419-466.

Chen, T.-H. , Lue, K.-Y. (1998). Ecological notes on feral populations of Trachemys scripta elegans in northern Taiwan. Chelonian Conservation and Biology, 3: 87-90.

Congdon, J. \& Gibbons, J. (1990). Turtle eggs: Their ecology and evolution. In: Life history and ecology of the slider turtle. Gibbons, J. (Ed.). Washington, DC, USA: Smithsonian Institution Press.

Connor, M. (1992). The red-eared slider, Trachemys scripta elegans. Tortuga Gazette, 28: $1-3$.

Crawford, K., Spotila, J., \& Standora, E. (1983). Operative environmental temperatures and basking behavior of the turtle Pseudemys scripta. Ecology 64: 989999. 
Dodd, K., Murdock, C., \& Wibbels, T. (2006). Interclutch variation in sex ratios produced at pivotal temperature in the red-eared slider, a turtle with temperaturedependent sex determination. Journal of Herpetology, 40: 544-549.

Dykes, M. (2007). Red-eared slider turtle a potential hazard. In: Manawatu Standard. Palmerston North, New Zealand.

Ernst, C., Lovich, J., \& Barbour, R. (1994). Turtles of the United States and Canada. Washington, D.C., USA: Smithsonian Institution Press.

Etchberger, C., Phillips, J., Ewert, M., Nelson, C., \& Prange, H. (1991). Effects of oxygen concentration and clutch on sex determination and physiology in red-eared slider turtles (Trachemys scripta). Journal of Experimental Zoology, 258: 394-403.

Feldman, M. (1992). Can turtles reproduce in New Zealand? Moko, 1992: 14-16.

Feldman, M. (2005). The red-eared slider turtle (Trachemys scripta elegans) in New Zealand. In: 13th Australasian Vertebrate Pest Conference. Wellington, New Zealand.

Ficetola, G., Thuiller, W., \& Miaud, C. (2007). Prediction and validation of the potential global distribution of a problematic alien invasive species - the American bullfrog. Diversity and Distributions, 13: 476-485.

Ficetola, G., Thuiller, W., \& Padoa-Schioppa, E. (2009). From introduction to establishment of alien species: Bioclimatic differences between presence and reproduction localities in the slider turtle. Diversity and Distributions, 15: 108-116.

Fielding, A. \& Bell, J. (1997). A review of methods for the assessment of prediction errors in conservation presence/ absence models. Environmental Conservation, 24: $38-49$.

Florida Fish and Wildlife Conservation Commission (FWC) 2008. http://www.floridaconservation.org/newsroom/08/statewide/News_08_X_NewCaptiv e.htm (accessed January 12, 2008).

Forsyth, D., Duncan, R., Bomford, M., \& Moore, G. (2004). Climatic suitability, lifehistory traits, introduction effort, and the establishment and spread of introduced mammals in Australia. Conservation Biology, 18: 557-569.

Fritts, T., McCoid, M., \& Haddock, R. (1990). Risks to infants on Guam from bites of the brown tree snake (Boiga irregularis). American Journal of Tropical Medicine and Hygiene, 42: 607-611.

Greater Wellington Regional Council (2007). Review of the Greater Wellington Regional Pest Management Strategy 2002- 2022.). Greater Wellington Regional Council, New Zealand.

Hartley, S., Harris, R., \& Lester, P. (2006). Quantifying uncertainty in the potential distribution of an invasive species: Climate and the Argentine ant. Ecology Letters, 9: 1068-1079. 
Hartley, S. \& Lester, P. (2003). Temperature-dependent development of the Argentine ant, Linepithema humile (Mayr) (Hymenoptera: Formicidae): A degree-day model with implications for range limits in New Zealand. New Zealand Entomologist, 26: $91-100$.

Hijmans, R., Cameron, S., Parra, J., Jones, P. \& Jarvis, A. (2005). Very high resolution interpolated climate surfaces for global land areas. International Journal of Climatology, 25: 1965-1978.

Hoskins, G. (2006). Personal Communication: November 14, 2006. Auckland, New Zealand: Auckland Regional Council.

Invasive Species Specialist Group (ISSG), (2006).

www.issg.org/database/species/ecology.asp?si=71\&ver=print (accessed July 12, 2006).

Invasive Species Specialist Group (ISSG) (2004). 100 of the world's worst invasive alien species. Online document: http://issg.org/booklet.pdf (accessed July 12, 2006).

King, C. M. (Ed.) (2005) The handbook of New Zealand mammals, 2nd edition, Oxford, Oxford University Press.

Kolar, C. \& Lodge, D. (2001). Progress in invasion biology: Predicting invaders. Trends in Ecology and Evolution, 16: 199-204.

Lennon, J. (2000) Red-shifts and red herrings in geographical ecology. Ecography, 23: 101-113.

Lever, C. (2003). Naturalized reptiles and amphibians of the world. New York, USA: Oxford University Press.

Ligon, D. (2007). Trachemys scripta elegans (red-eared slider). Predation. Herpetological Review, 38: 201-202.

Liu, C., Berry, P., Dawson, T., \& Pearson, R. (2005). Selecting thresholds of occurrence in the prediction of species distributions. Ecography, 28: 385-393.

Mack, R., Simberloff, D., Lonsdale, W., Evans, H., Clout, M., \& Bazzaz, F. (2000). Biotic invasions: Causes, epidemiology, global consequences, and control. Ecological Applications, 10: 689-710.

Manchester, S. \& Bullock, J. (2000). The impacts of non-native species on UK biodiversity and the effectiveness of control. Journal of Applied Ecology, 37: 845864.

Marmion, M., Parviainen, M., Luoto, M., Heikkinen, R., \& Thuiller, W. (2009) Evaluation of consensus methods in predictive species distribution modelling. Diversity and Distributions, 15: 59-69. 
New, M., Hulme, M., \& Jones, P. D. (1999). Representing twentieth century spacetime climate variability. Part I: Development of a 1961-90 mean monthly terrestrial climatology. Journal of Climate, 12: 829-856.

Newbery, R. (1984). The American red-eared terrapin in South Africa. African Wildlife, 38: 186-189.

$\mathrm{Ng}, \mathrm{P}$., Chou, L., \& Lam, T. (1993). The status and impact of introduced freshwater animals in Singapore. Biological Conservation, 64: 19-24.

Nogales, M., Rodriguez-Luengo, J., \& Marrero, P. (2006). Ecological effects and distribution of invasive non-native mammals on the Canary Islands. Mammal Review, 36: 49-65.

O'Keeffe, S. (2006). Red-eared slider turtle. Queensland Government, Australia. http://www.nrw.qld.gov.au/pests/pest animals/declared/red eared slider.html (accessed May 3, 2007).

Pearson, R., Dawson, T., \& Liu, C. (2004). Modelling species distributions in Britain: a hierarchical integration of climate and land-cover data. Ecography, 27: 285-298.

Peterson, A. T., Papeş, M., \& Soberón, J. (2008). Rethinking receiver operating characteristic analysis applications in ecological niche modelling. Ecological Modelling, 213: 63-72.

Pimentel, D., et al. (2000). Environmental and economic costs of nonindigenous species in the United States. BioScience, 50: 53-65.

Pimentel, D., McNair, S., Janecka, J., Wightman, J., Simmonds, C., O’Connel, C., Wong, E., Russel, L., Zean, J., Aquino, T., \& Tsomondo, T. (2002). Economic and environmental threats of alien plant, animal, and microbe invasions. In: Biological Invasions: 307-329. Pimentel, D. (Ed.). Boca Raton, Florida, USA: CRC Press.

Prevot-Julliard, A., Gousset, E., Archinard, C., Cadi, A., \& Girondot, M. (2007). Pets and invasion risks: Is the slider turtle strictly carnivorous? Amphibia-reptilia, 28: $139-143$.

R Development Core Team (2007). R: A language and environment for statistical computing. R Foundation for Statistical Computing (Ed.). Vienna, Austria.

Ramsay, N., Ng, P., O’Riordan, R., \& Chou, L. (2007). The red-eared slider (Trachemys scripta elegans) in Asia: A review. In: Biological invaders in inland waters: Profiles, distribution, and threats. Gherardi, F. (Ed.). Springer Netherlands.

Randin, C., Dirnböck, T., Dullinger, S., Zimmermann, N., Zappa, M., \& Guisan, A. (2006). Are niche-based species distributions transferable in space? Journal of Biogeography, 33: 1689-1703. 
Rodda, G., Jarnevich, C. , Reed, R. (2009). What parts of the US mainland are climatically suitable for invasive alien pythons spreading from Everglades National Park? Biological Invasions, 11: 241-252.

Roura-Pascual, N., Brotons, L., Peterson, A., \& Thuiller, W. (2009). Consensual predictions of potential distribution areas for invasive species: A case study of Argentine ants in the Iberian peninsula. Biological Invasions, 11: 1017-1031.

Shi, H. (2008). Personal Communication. Hainan Normal University.

Sikder, I., Mal-Sarkar, S., \& Mal, T. (2006). Knowledge-based risk assessment under uncertainty for species invasion. Risk Analysis, 26: 239-252.

Sing, T., Sander, O., Beerenwinkel, N., \& Lengauer, T. (2004). ROCR: An R package for visualizing the performance of scoring classifiers.

Thomas, M. \& Hartnell, P. (2000). An occurrence of a red-eared turtle (Trachemys scripta elegans) in the Waikato river at Hamilton, New Zealand. Herpetofauna, 30: 15-17.

Thornton, T. (1999). Keeping red-eared turtles in New Zealand. Warkworth, New Zealand: TJ's Books.

Thuiller, W., Richardson, D., Pyšek§, P., Midgley, G., Hughes, G., \& Rouget, M. (2005). Niche-based modelling as a tool for predicting the risk of alien plant invasions at a global scale. Global Change Biology, 11: 2234-2250.

Wittenberg, R. \& Cock, M. (2001). Invasive alien species. How to address one of the greatest threats to biodiversity: A toolkit of best prevention and management practices. Cab International (Ed.). Wallingford, Oxon, UK. 


\title{
Chapter 4: \\ Predicting the potential for exotic reptile establishment in New Zealand using bioclimatic models
}

\begin{abstract}
The establishment of alien species in areas outside of their native range is an increasing problem, ecologically and economically. Climate-matching is an important tool used to help predict areas that may be susceptible to invasion by a particular species based on the degree of climate similarity between the species range (native and/or introduced) and a geographic region of interest. This study investigates the degree of climate match between New Zealand and eleven species of exotic reptile known to exist in captivity in this country in order to better evaluate their establishment risk. A relative suitability score (ranging from 0 to 1 ) was generated by a multimodel average, allowing the species to be compared to one another. The species with the lowest New Zealand suitability score (0.03), and hence the lowest degree of climatic suitability, was the inland bearded dragon (Pogona vitticeps). Blotched blue-tongue skinks (Tiliqua nigrolutea) had the highest degree of climatic suitability, with a New Zealand suitability score of 0.99 . Of all of the species investigated, the common blue-tongue skink ( $T$. scincoides) had the largest proportion of New Zealand predicted to be climatically suitable. Areas of New Zealand that were consistently predicted to be most susceptible to invasion were the upper portion of the North Island and the eastern portion of the South Island. In general, winter temperatures in New Zealand were predicted to be suitable for most
\end{abstract}


species, whereas relatively low summer temperatures were more often the factor likely to limit species from establishing in New Zealand. A high climate suitability score does not guarantee that a species will establish, as many other biotic and abiotic factors must be considered. It does, however, substantiate the need for further research into establishment potential.

\section{Introduction}

The establishment of alien species in areas outside of their native range is an increasing problem, ecologically and economically (Pimentel 2002). The prediction of species' distribution ranges has gained in popularity in an effort to identify areas that may be susceptible to invasion (Kolar and Lodge 2001; Forsyth et al. 2004; Rodda et al. 2009). Climate-matching has been identified as a useful tool in this regard, and, although it is associated with a level of uncertainty (Sikder et al. 2006), it has been found to be an important factor in predicting the potential distribution ranges of exotic reptiles (Bomford et al. 2009; Kikillus et al. 2010).

An important pathway in which non-native reptiles are often introduced into new environments is via the release of unwanted pets (Kraus 2009) (also see Chapter 2). New Zealand has a lucrative, although relatively limited (in comparison to the USA and Europe) exotic reptile pet trade (KH Kikillus, unpublished data). This study investigates the degree of climate match between New Zealand and several species of exotic reptile present in captivity in New Zealand in order to better evaluate their establishment potential in the event they were to be released or escape into the wild. The aim of this study is to identify species that may pose a high establishment risk based on their degree of climatic suitability to New Zealand and to elucidate which areas of New Zealand are most susceptible to invasion. 


\section{Methods}

\section{Study species}

Eleven species of exotic reptile present in captivity in New Zealand were investigated. These included all of the most common species available in the New Zealand pet trade (see Chapter 1) except for the most popular exotic reptile pet in New Zealand, the red-eared slider turtle (Trachemys scripta elegans), for which information on the degree of climate match is presented in Chapter 3 and Appendix 10. A brief description of each species is given below and more detailed information is available in Appendices 2-8.

\section{Snake-neck turtle (Chelodina longicollis)}

Snake-neck turtles are a popular freshwater turtle pet often found for sale in New Zealand (Chapter 1; Appendix 2). They are native to the eastern portion of Australia (Figure 1) (Cogger 1975).

Figure 1: Distribution records (denoted by red circles) of snake-neck turtles (Chelodina longicollis) used in the bioclimatic model.

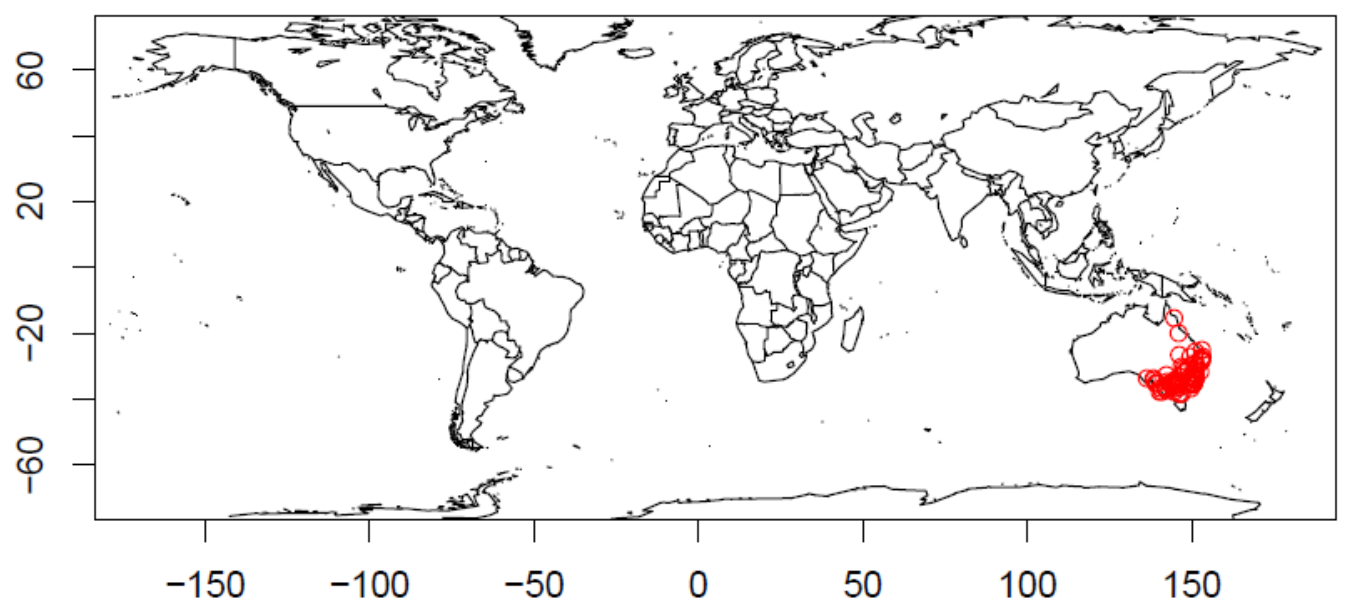




\section{Reeves turtle (Chinemys reevesii)}

Reeves turtles are a small freshwater turtle native to Asia (Figure 2). Their numbers have declined dramatically in their native range due to poaching for the pet trade and food industry (Orenstein 2001). They are occasionally found for sale online and in New Zealand pet stores (Chapter 1; Appendix 3).

Figure 2: Distribution records (denoted by red circles) of Reeves turtles (Chinemys reevesii) used in the bioclimatic model.

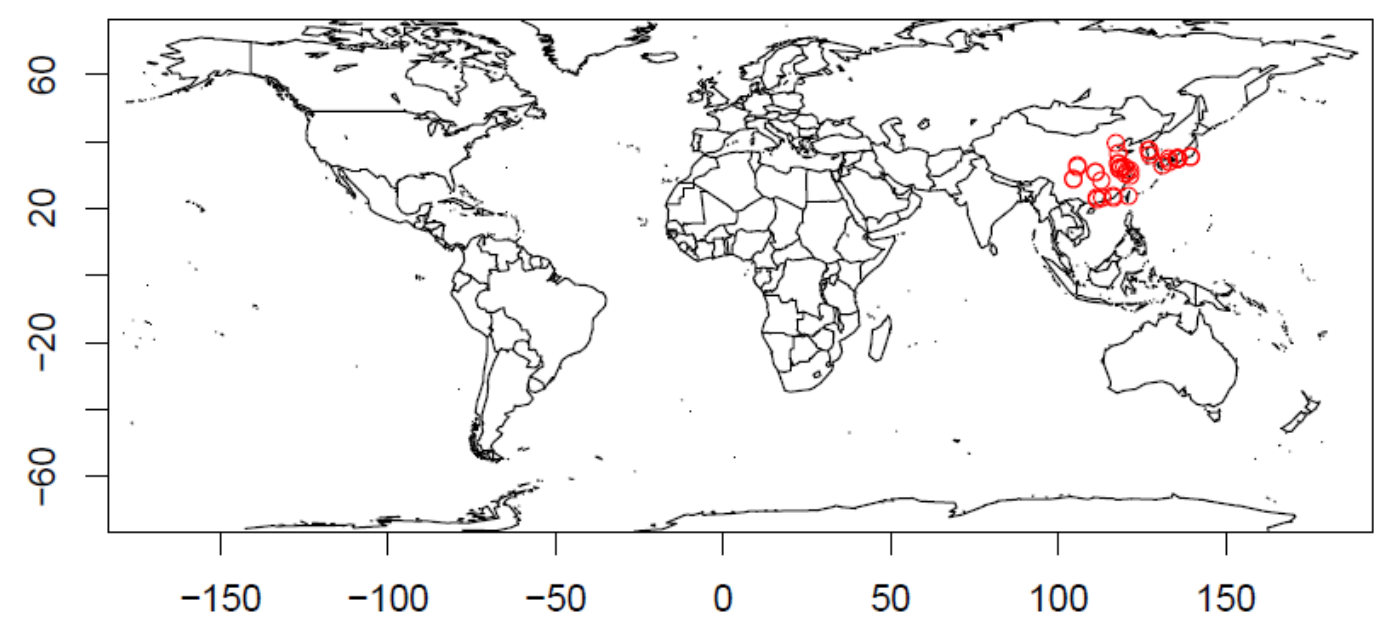

Tortoises (Testudo spp.)

At least two species of tortoise are traded within New Zealand; the Greek tortoise (Testudo graeca) and the Hermanns tortoise (T. hermanni) (Chapter 1; Appendix 7). Both species are native to Europe and Asia (Figures 3 and 4, respectively) (Wiltshier 2000; Bertolero et al. 2007). Both species are believed to have been transported by humans to other areas of Europe (e.g., Corsica, Sardinia, northern France) where they have become established (Lever 2003). Due to the uncertainty of their natural distribution, for the purposes of this analysis no difference was noted between native and introduced records. Tortoises are rarely seen offered 
for sale in New Zealand, and, when available, can command a price of over 6,000 NZD (Appendix 7).

Figure 3: Distribution records (denoted by red circles) of Greek tortoises (Testudo graeca) used in the bioclimatic model.

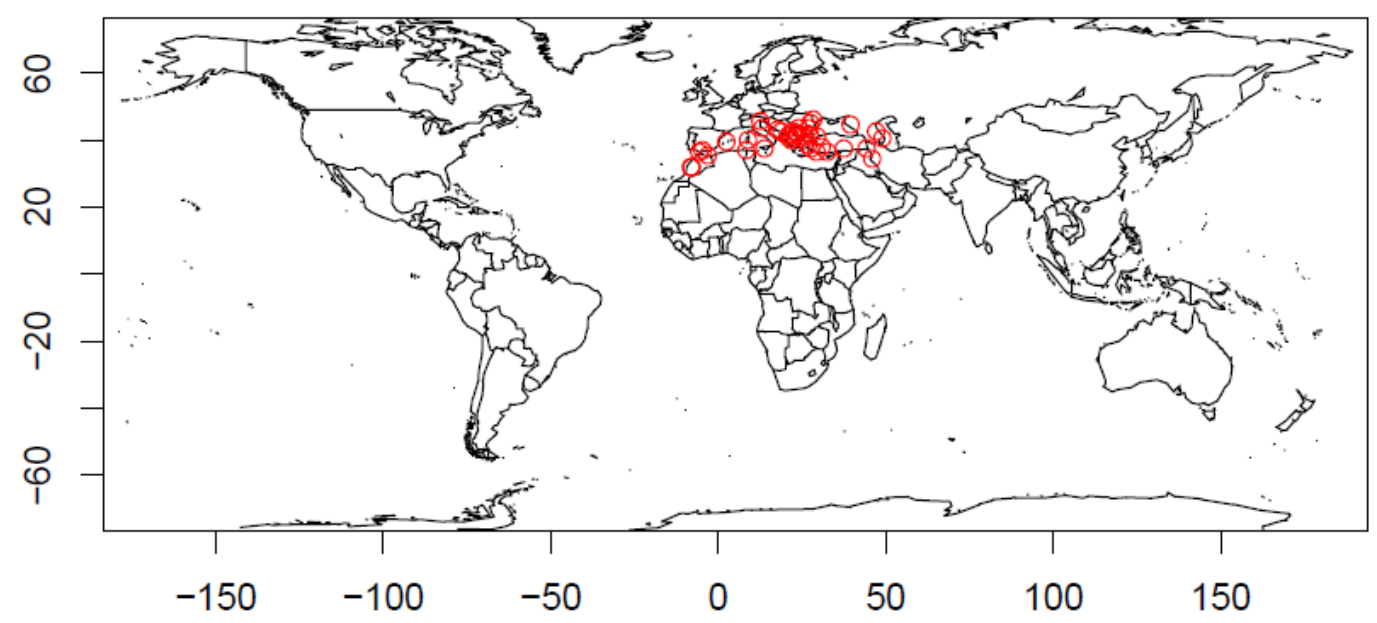

Figure 4: Distribution records (denoted by red circles) of Hermanns tortoises (Testudo hermanni) used in the bioclimatic model.

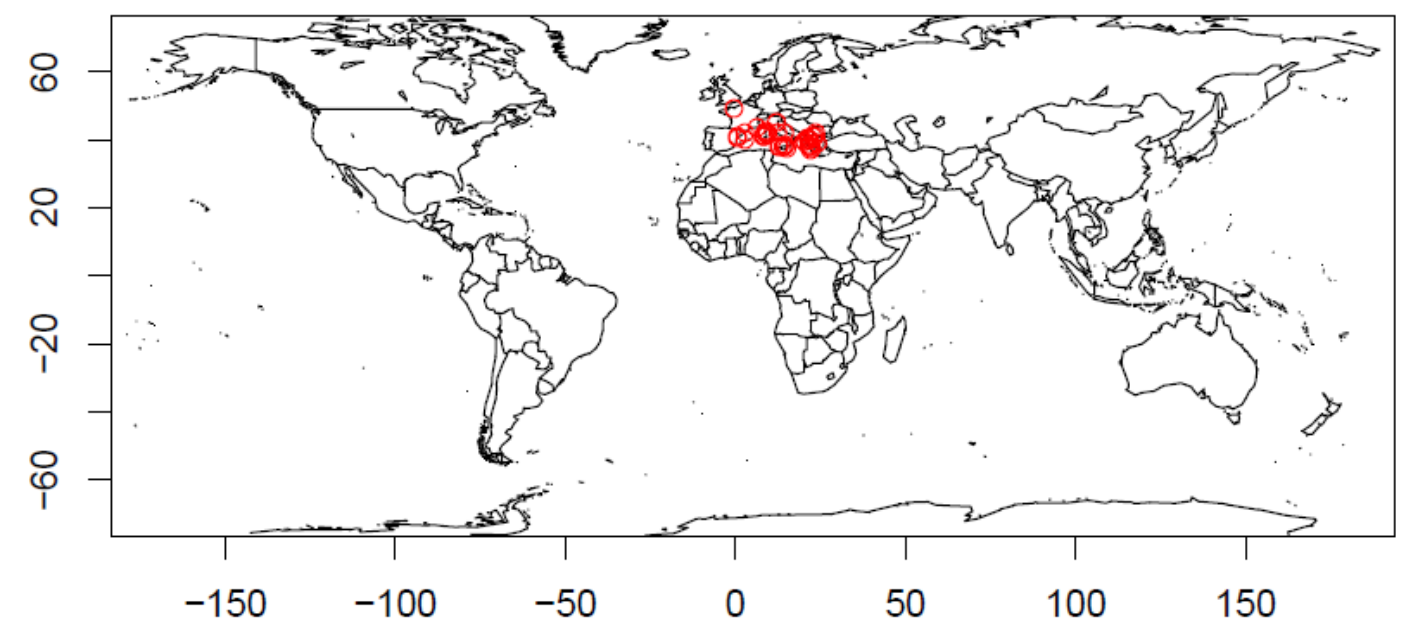

Bearded dragons (Pogona spp.)

Bearded dragons are a popular lizard pet in New Zealand. Two species of bearded dragon are available in the New Zealand pet trade; the inland bearded dragon (Pogona vitticeps) and the coastal bearded dragon (P. barbata) (Chapter 1; Appendix 5). Both species are native to Australia; as their name implies, inland bearded 
dragons (P. vitticeps) are found in the dry, inland areas of Australia (Figure 5), while the coastal bearded dragon ( $P$. barbata) is native to the eastern coastal areas (Figure 6) (Cogger 1975).

Figure 5: Distribution records (denoted by red circles) of inland bearded dragons (Pogona vitticeps) used in the bioclimatic model.

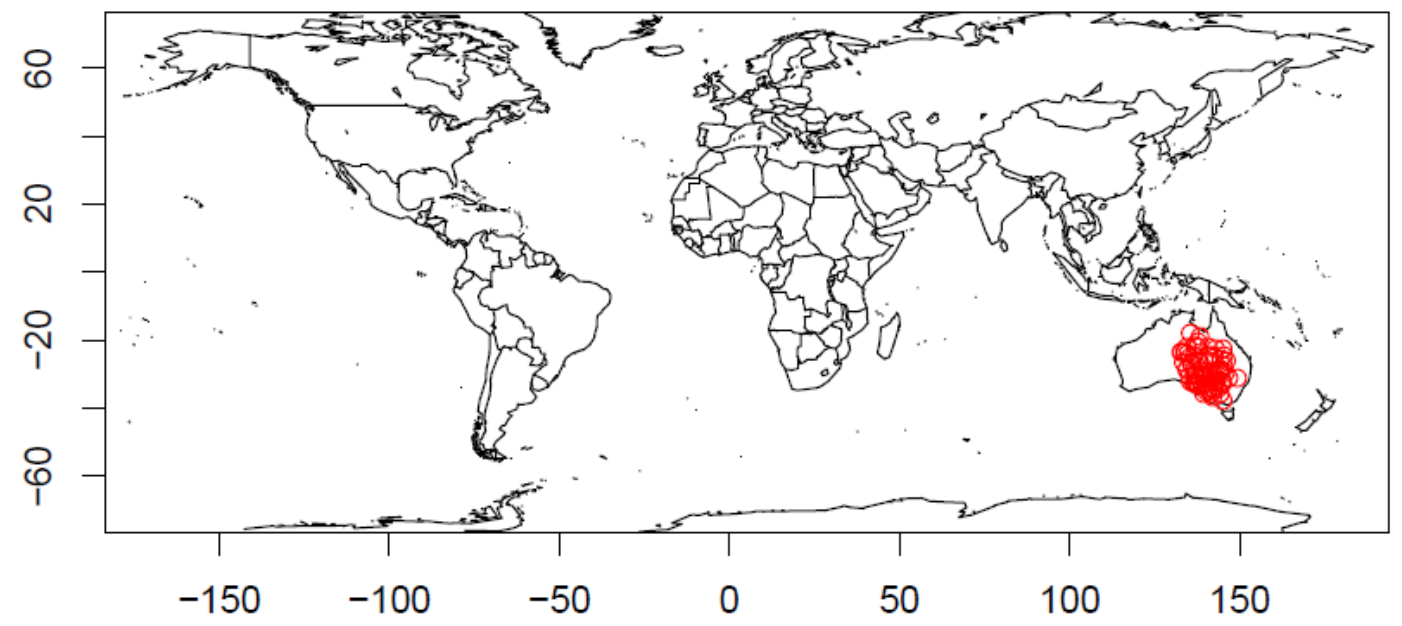

Figure 6: Distribution records (denoted by red circles) of coastal bearded dragons (Pogona barbata) used in the bioclimatic model.

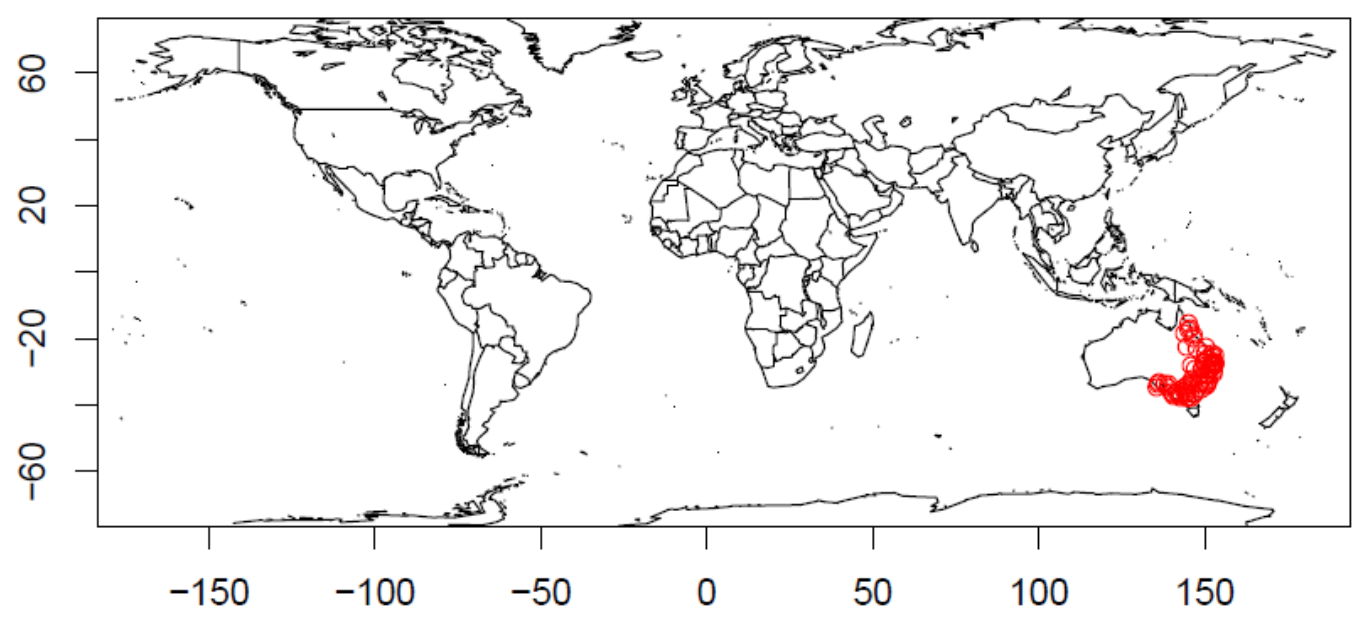

Leopard gecko (Eublepharis macularius)

Although present in New Zealand for decades, leopard geckos (Eublepharis macularius) only began appearing in the New Zealand pet trade in 2009 (Chapter 1; 
Appendix 8). Native to desert areas in Afghanistan, Pakistan, and India (Figure 7), they are a popular reptile pet worldwide (De Vosjoli et al. 2004).

Figure 7: Distribution records (denoted by red circles) of leopard geckos (Eublepharis macularius) used in the bioclimatic model.

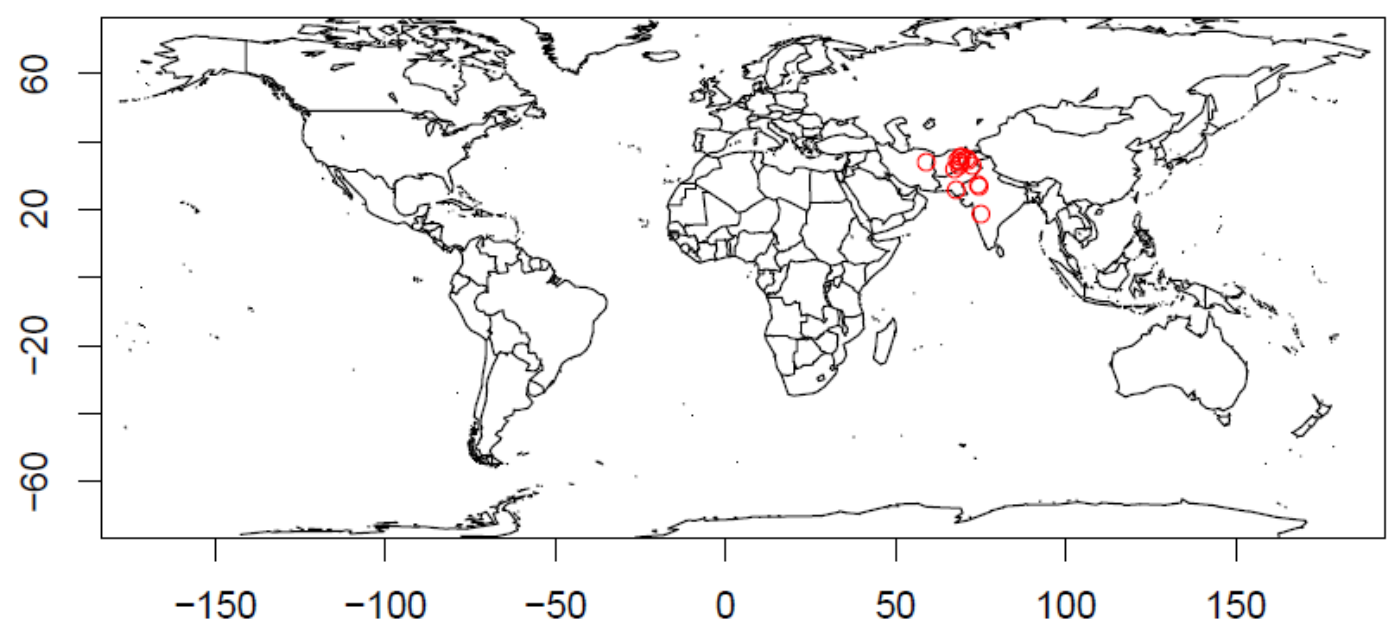

Waterdragon (Physignathus lesueurii)

Waterdragons are the largest lizard available in the New Zealand pet trade, capable of reaching a total length of $1 \mathrm{~m}$ (Burne 2009). They are native to the eastern coast of Australia (Figure 8) (Appendix 6) (Cogger 1975).

Figure 8: Distribution records (denoted by red circles) of waterdragons (Physignathus lesueurii) used in the bioclimatic model.

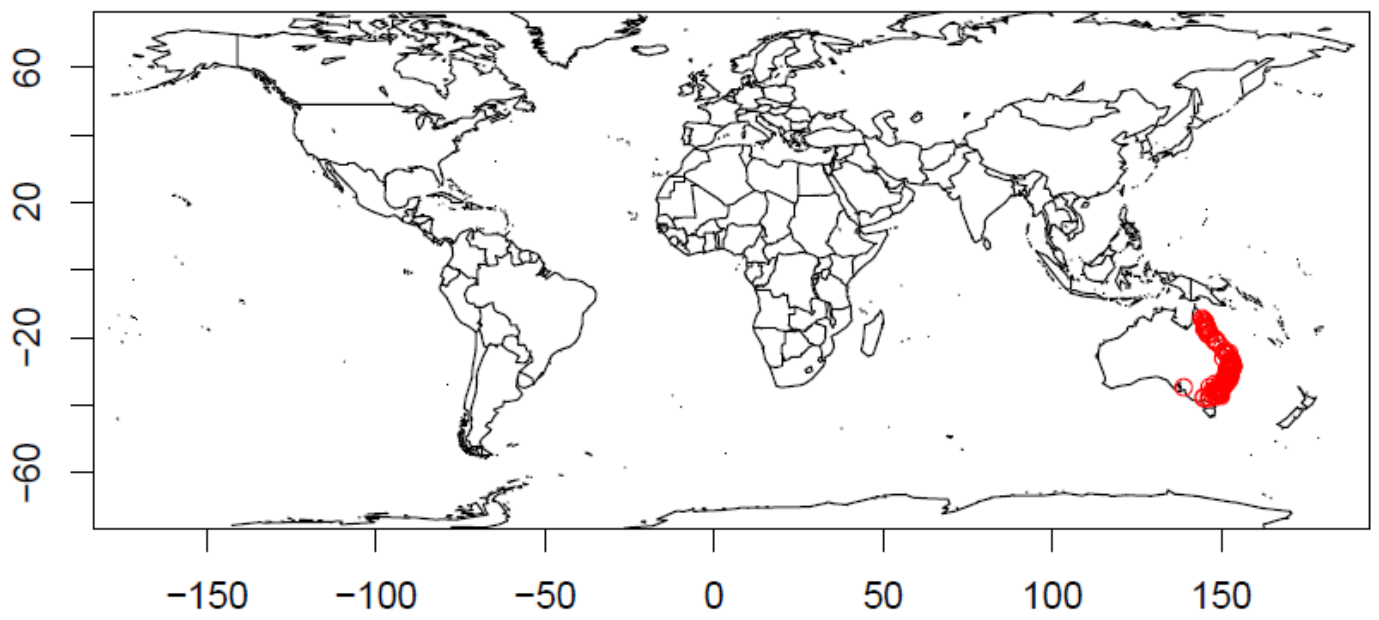


Blue-tongue lizards (Tiliqua spp.)

Also native to Australia are several species of blue-tongue lizard, the common blue-tongue skink (Tiliqua scincoides), the blotched blue-tongue skink (T. nigrolutea), and the shingleback skink (T. rugosa) (Figures 9, 10, and 11, respectively) (Cogger 1975). The species present in the New Zealand pet trade is the common blue-tongue skink (Chapter 1; Appendix 4). While blotched blue-tongue skinks and shingleback skinks are known to exist in New Zealand zoos (KH Kikillus, unpublished data), it is unclear if they are found in the pet trade. They were included in this analysis as in the Auckland region they have recently been classified as a Surveillance pest (meaning prohibition of the sale, breeding, and exhibition) and as a pest when not held in secure confinement, respectively (Auckland Regional Council 2007).

Figure 9: Distribution records (denoted by red circles) of common blue-tongue skinks (Tiliqua scincoides) used in the bioclimatic model.

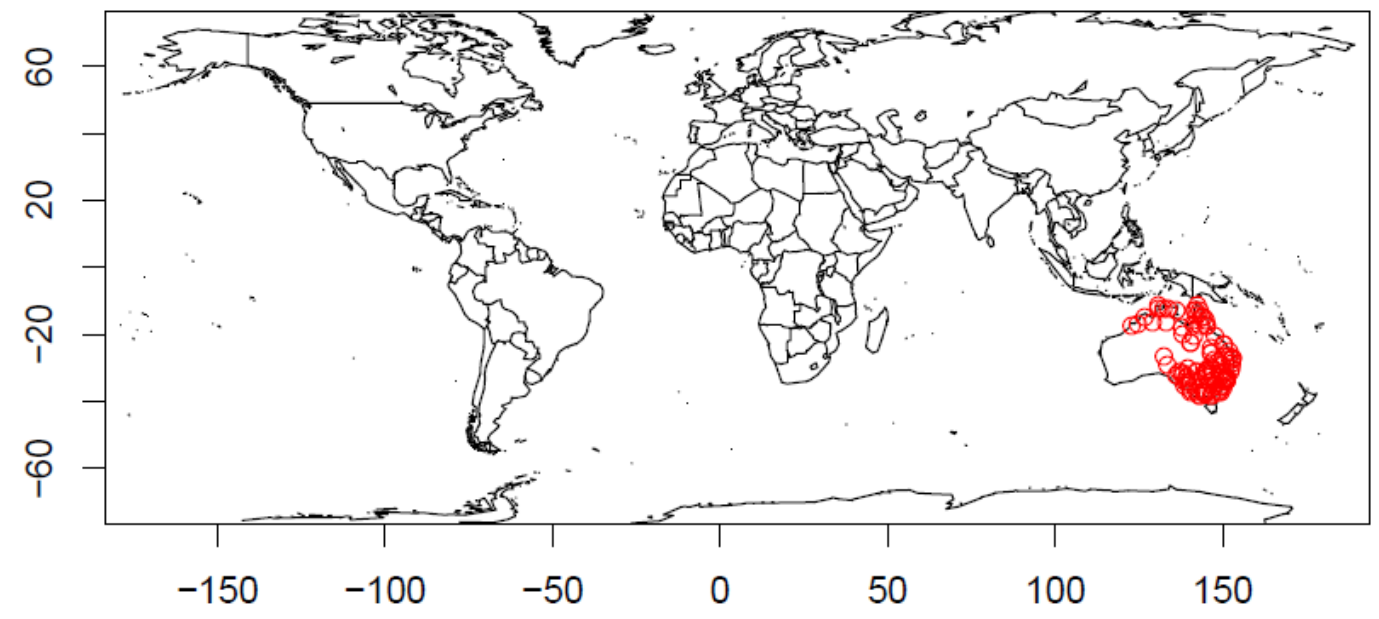


Figure 10: Distribution records (denoted by red circles) of blotched blue-tongue skinks (Tiliqua nigrolutea) used in the bioclimatic model.

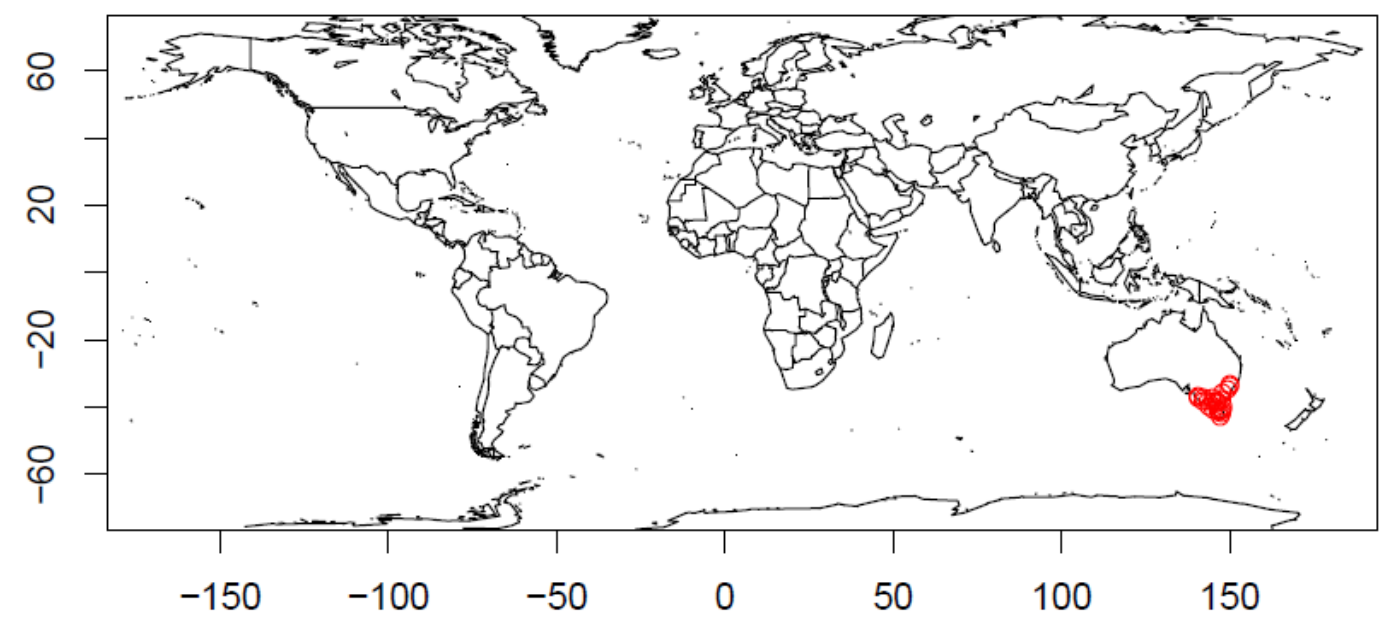

Figure 11: Distribution records (denoted by red circles) of shingleback skinks (Tiliqua rugosa) used in the bioclimatic model.

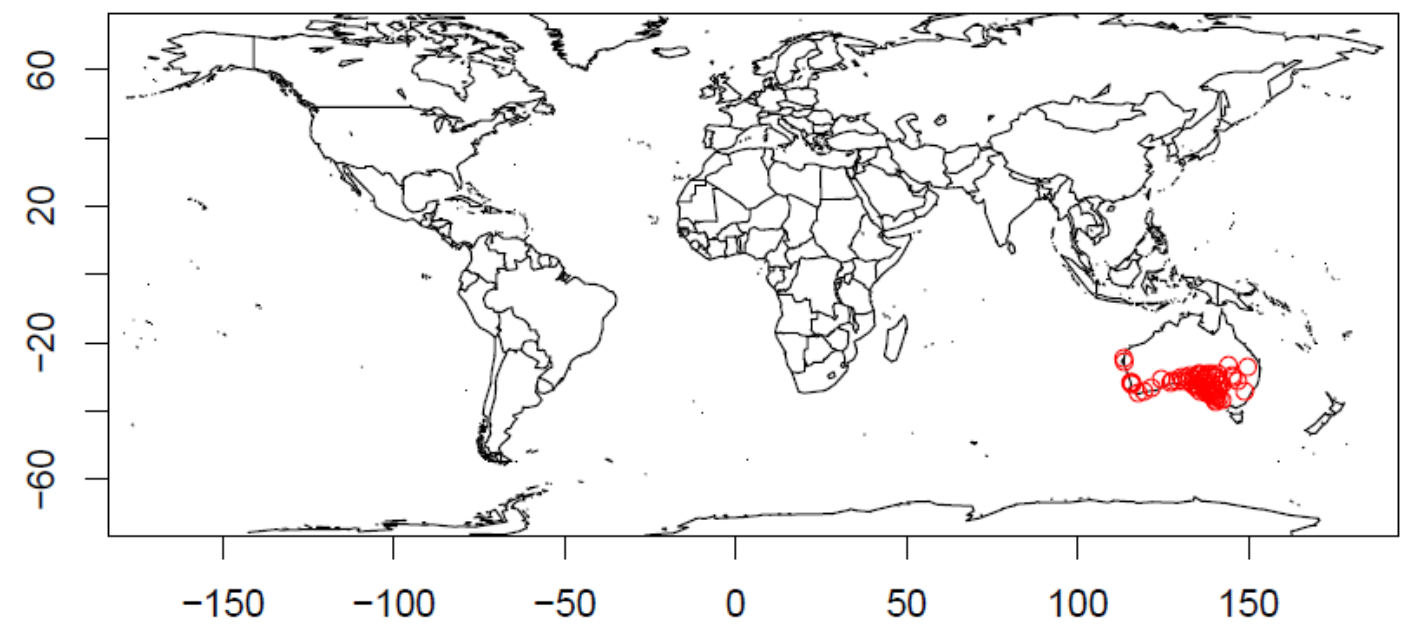

\section{Data sources}

Location records for the exotic reptile species listed above were obtained from scientific literature, field guides, and online databases (References are listed in Appendix 10). Latitude-longitude coordinates (WGS84) were obtained via Google Earth (http://earth.google.com).

Global climate data for temperature and precipitation were obtained from the Intergovernmental Panel on Climate Change (IPCC) as an array of half-degree latitude x longitude grid cells (New et al. 1999). Monthly averages for the period 
1961-1990 were used to calculate mean annual temperature (MAT), highest average daily mean in hottest month (MAXAVG), lowest average daily mean in coldest month (MINAVG), highest average daily maximum in hottest month (MAXMAX), lowest average daily minimum in coldest month (MINMIN), and total annual precipitation (PPT).

\section{Bioclimatic modelling}

The presence or absence of each of the eleven species of interest was modelled using binary logistic regression performed with R v.2.9.0 (R Development Core Team, 2009). Twelve alternative models, incorporating different combinations of temperature and precipitation variables were constructed (Table 1). See Chapter 3 for details regarding the multimodel approach. The "global view" for Australian species was restricted to -70 to -10 latitudes and 110 to 180 longitudes while European/Asian species were restricted to -70 to 70 latitudes and -20 to 180 longitudes in order to minimise absences that may be due to lack of dispersal opportunities rather than lack of climatic suitability. 
Table 1: Twelve different specifications representing the set of plausible candidate models. MINMIN: lowest average daily minimum in coldest month, MINAVG: lowest average daily mean in coldest month, MAT: mean annual temperature, MAXAVG: highest average daily mean in hottest month, MAXMAX: highest average daily maximum in hottest month, PPT: total annual precipitation.

\begin{tabular}{|c|c|c|c|c|c|c|c|}
\hline Model & Description & & Cli & late & aria & & \\
\hline & & 忘 & 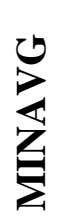 & 莡 & 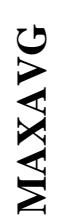 & $\sum_{i}^{\infty}$ & 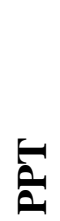 \\
\hline $\mathrm{a}$ & $\begin{array}{l}\text { winter daily mean, summer daily mean, } \\
\text { and total annual precipitation }\end{array}$ & & $\checkmark$ & & $\checkmark$ & & $\checkmark$ \\
\hline $\mathrm{b}$ & (a) + all 2-way interactions & & $\checkmark$ & & $\checkmark$ & & $\checkmark$ \\
\hline $\mathrm{c}$ & $\begin{array}{l}\text { winter minimum, summer maximum, and } \\
\text { total annual precipitation }\end{array}$ & $\checkmark$ & & & & $\checkmark$ & $\checkmark$ \\
\hline $\mathrm{d}$ & (c) + all 2-way interactions & $\checkmark$ & & & & $\checkmark$ & $\checkmark$ \\
\hline $\mathrm{e}$ & $\begin{array}{l}\text { summer daily mean, total annual } \\
\text { precipitation, }+2 \text {-way interaction }\end{array}$ & & & & $\checkmark$ & & $\checkmark$ \\
\hline $\mathrm{f}$ & $\begin{array}{l}\text { winter daily mean, total annual } \\
\text { precipitation, }+2 \text {-way interaction }\end{array}$ & & $\checkmark$ & & & & $\checkmark$ \\
\hline g & $\begin{array}{l}\text { summer maximum, total annual } \\
\text { precipitation, }+2 \text {-way interaction }\end{array}$ & & & & & $\checkmark$ & $\checkmark$ \\
\hline $\mathrm{h}$ & $\begin{array}{l}\text { winter minimum, total annual } \\
\text { precipitation, }+2 \text {-way interaction }\end{array}$ & $\checkmark$ & & & & & $\checkmark$ \\
\hline $\mathrm{i}$ & $\begin{array}{l}\text { mean annual temperature and total annual } \\
\text { precipitation }\end{array}$ & & & $\checkmark$ & & & $\checkmark$ \\
\hline $\mathrm{j}$ & (i) + 2-way interaction & & & $\checkmark$ & & & $\checkmark$ \\
\hline $\mathrm{k}$ & $\begin{array}{l}\text { winter minimum, summer maximum, } \\
\text { winter daily mean, summer daily mean, } \\
\text { and total annual precipitation }\end{array}$ & $\checkmark$ & $\checkmark$ & & $\checkmark$ & $\checkmark$ & $\checkmark$ \\
\hline 1 & $(\mathrm{k})+$ all 2-way interactions & $\checkmark$ & $\checkmark$ & & $\checkmark$ & $\checkmark$ & $\checkmark$ \\
\hline
\end{tabular}




\section{Chapter 4: Predicting exotic reptile distributions via bioclimatic models}

The predictive ability of each model was evaluated via cross-validation. For this, training (calibration) and test (evaluation) data were randomly sampled from a coarse-scale grid of sample units, each sample unit being $5 \times 5$ degrees. Seventy percent of the $5 \times 5$ degree grid cells were used for the training set and the remaining proportion of data for the test set. If either the training or test dataset contained fewer than four presences, a new random sample was generated. One-hundred jackknife partitions were performed. In order to minimise false-negative predictions, the sensitivity threshold was set at 0.95 . Model performances were evaluated by the mean partial area under the curve (pAUC) values of the resulting receiver operating characteristic (ROC) plot achieved via the jackknife cross-validation trials (see Chapter 3 for details regarding choice of model metrics). The models were ranked according to their mean pAUC in cross-validation, and the mean pAUC of the eleventh ranked model was set as the zero weight baseline, from which weightings for the best ten models were calculated. This method of weighting models differs from Chapter 3 as it was considered more appropriate when there are a large number (100) of cross-validation partitions between test and training data. The weightings were used to create a composite or multimodel average prediction of suitability. The "relative importance" of each climate variable contributing to the multimodel was calculated as the total weight afforded to the models containing that variable, relative to the expectation if model weightings were determined at random. Because the climate variable of annual precipitation (PPT) occurred equally in all 12 candidate models, its relative importance to the multimodel was always 1. Boxplots showing the relative pAUC values for each species were generated.

Final predictions from the multimodel weighted average were projected back onto the section of the world used for the species' training and test data and, 
ultimately, finer resolution climate data (Hijmans et al. 2005) was used to project the results onto a map of New Zealand. The colour bar used to visualise suitability scores (with breakpoints at the $0^{\text {th }}, 1^{\text {st }}, 5^{\text {th }}, 10^{\text {th }}, 50^{\text {th }}$, and $90^{\text {th }}$ percentiles of the predicted probability of occurrence of the positive sites) was the same as used in Chapter 3. Horizontal boxplots were generated to visualise the degree of overlap in predicted suitability between occupied gridcells and available sites in New Zealand. The New Zealand pixel with the highest suitability score in the multimodel weighted average was recorded as the "New Zealand suitability score" for the species. An empirical density function of the top New Zealand suitability scores was also generated by sampling the "New Zealand suitability score" of each model in proportion to its weighting, and from this, a 90\% confidence interval for the multimodel "New Zealand suitability score" was generated. For consistency, the relatively simple model, model "b", was chosen to visualise the climate envelope for each species, although the modelled climate envelope is a weighted composite of the ten best models.

\section{Results}

The dataset for Chelodina longicollis consisted of 87 records; 39 records were used for Chinemys reevesii, 39 records for Testudo graeca, 36 records for $T$. hermanni, 74 records for Pogona vitticeps, 79 records for P. barbata, 15 records for Eublepharis macularius, 110 records for Physignathus lesueurii, 101 records for Tiliqua scincoides, 23 records for T. nigrolutea, and 67 records for T. rugosa (References are listed in Appendix 10). 


\section{Snake-neck turtle (Chelodina longicollis)}

The best performing model for Chelodina longicollis was model “j” with a pAUC value of 0.68 and a model weighting of 0.14 . Model "e" was second-best performing model with a pAUC value of 0.67 and a weighting of 0.12 (Table 2). A boxplot visualisation of relative pAUC values for all models for snake-neck turtles can be found in Figure 12. Mean annual temperature was the climatic variable with the highest "relative importance" for snake-neck turtles (Figure 13). "Relative importance" represents the total weight afforded to each variable in the multimodel, relative to the expected weight if the model weightings were determined at random. 
Table 2: Comparison of models from Table 1 for snake-neck turtles (Chelodina longicollis), (a) Crossvalidation indicates mean performance in predicting withheld test data, AUC $=$ area under the curve, pAUC $=$ partial area under the curve measured where specificity $\geq 0.95$. (b) Performance under selfvalidation, where all available data was used to make final predictions of suitability. (c) Model weights determined from the mean pAUCs of the ten best models relative to the eleventh best, which was set as the zero-weight baseline value (d) Suitability score = rank of New Zealand's most suitable site relative to all the positive location records, based on the modelled probability of occurrence. A score of 0.40 indicates that New Zealand's most suitable site is modelled as being at least as favourable as $40 \%$ of the locations from which snake-neck turtles have been recorded to exist naturally. Numbers in parentheses represent the $90 \%$ confidence interval.

\begin{tabular}{|c|c|c|c|c|c|c|}
\hline \multirow[b]{2}{*}{ Model } & \multicolumn{3}{|c|}{ Cross-validation $^{\text {a }}$} & \multicolumn{3}{|c|}{ Final fit $^{\mathrm{b}}$} \\
\hline & $\mathbf{A U C}$ & pAUC & $\begin{array}{c}\text { Model } \\
\text { weight }^{\mathrm{c}}\end{array}$ & $\mathbf{A U C}$ & pAUC & $\begin{array}{c}\text { NZ } \\
\text { suitability } \\
\text { score }^{\mathrm{d}}\end{array}$ \\
\hline $\mathrm{a}$ & 0.882 & 0.656 & 0.104 & 0.915 & 0.715 & 0.437 \\
\hline b & 0.880 & 0.651 & 0.096 & 0.920 & 0.723 & 0.219 \\
\hline $\mathrm{c}$ & 0.876 & 0.645 & 0.089 & 0.908 & 0.712 & 0.377 \\
\hline d & 0.877 & 0.658 & 0.107 & 0.914 & 0.733 & 0.303 \\
\hline $\mathrm{e}$ & 0.875 & 0.670 & 0.124 & 0.905 & 0.697 & 0.738 \\
\hline $\mathrm{f}$ & 0.859 & 0.625 & 0.060 & 0.897 & 0.774 & 0.897 \\
\hline $\mathrm{g}$ & 0.870 & 0.654 & 0.101 & 0.900 & 0.704 & 0.328 \\
\hline h & 0.835 & 0.567 & 0 & 0.875 & 0.657 & 0.933 \\
\hline $\mathrm{i}$ & 0.868 & 0.651 & 0.096 & 0.898 & 0.757 & 0.936 \\
\hline $\mathrm{j}$ & 0.877 & 0.684 & 0.144 & 0.907 & 0.722 & 0.853 \\
\hline $\mathrm{k}$ & 0.876 & 0.638 & 0.078 & 0.919 & 0.753 & 0.256 \\
\hline 1 & 0.857 & 0.583 & 0 & 0.929 & 0.756 & 0.340 \\
\hline $\begin{array}{l}\text { Weighted } \\
\text { multi- } \\
\text { model } \\
\text { average }\end{array}$ & NA & NA & NA & 0.916 & 0.725 & $\begin{array}{c}0.402 \\
(0.218-0.936)\end{array}$ \\
\hline
\end{tabular}


Figure 12: Relative pAUC values based on cross-validation results for each of the 12 models (see Table 2) applied to snake-neck turtles (Chelodina longicollis). Mean pAUC values for each model are represented by an open circle and median pAUC values are represented by a horizontal line. The model ranked eleventh (i.e., the second-worst, model "l" in this case) was set as the zero weight baseline, from which weightings of the ten best models were calculated (Table 2).

\section{pAUC}

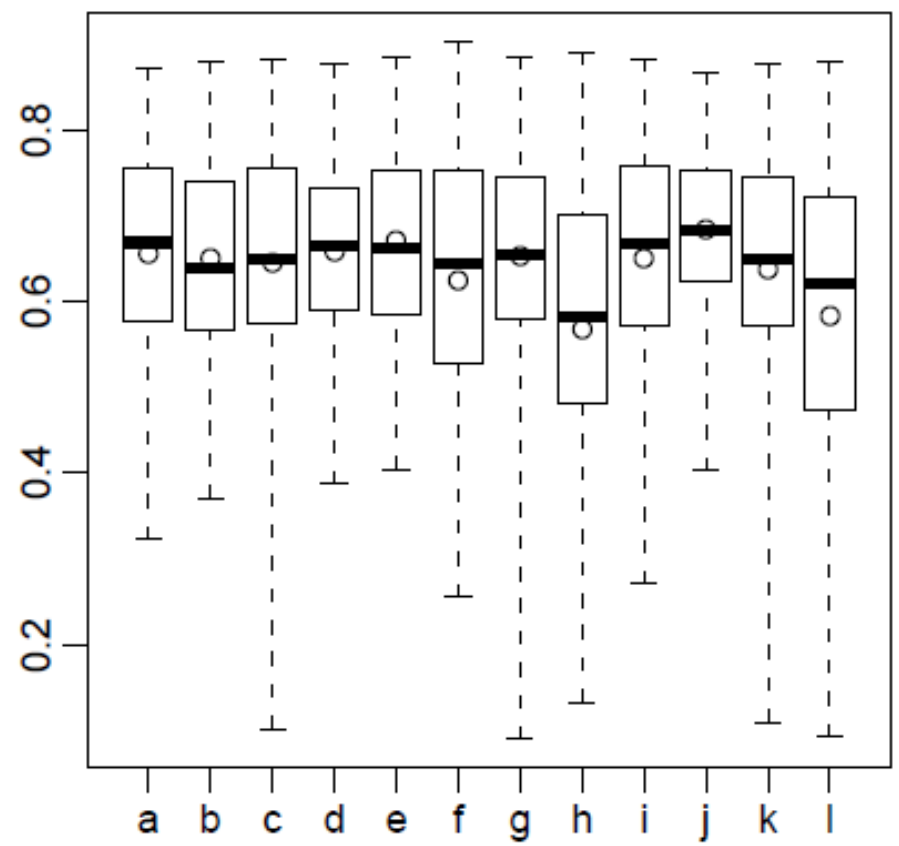

Figure 13: "Relative importance" of each of the climatic variables incorporated into the weighted multimodel (please see Table 1 and text for details) with regards to Chelodina longicollis.

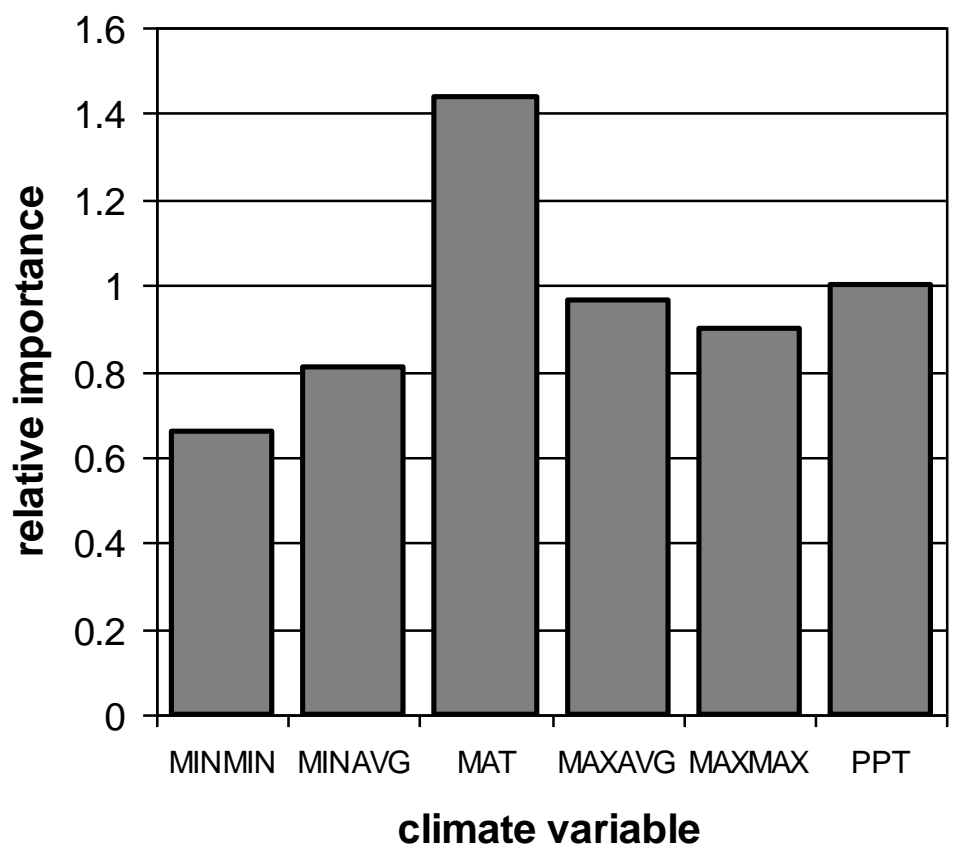


When using the multimodel average to identify areas between -10 to -70

latitude and 110 to 180 longitude possessing a suitable climate for Chelodina

longicollis, the south-western coast of Australia had a similar climate match to the species native range (suitability $\geq 0.5$ ) (Figure 14b). The degree of overlap between the investigated occupied gridcells and the available sites in New Zealand can be seen in Figure 14c. Based on the multimodel average, snake-neck turtles received a New Zealand suitability score of 0.40 (Table 2), meaning that the most suitable site in New Zealand is believed to be climatically better than $40 \%$ of sites incorporated into the model representing the native range of this species. Within New Zealand, the best climatic matches (suitability $\geq 0.1$ ) were found in the northern portion of the North Island, and the coastal areas of the Bay of Plenty, Gisborne, Hawkes Bay, and Wanganui-Manawatu (Figure 14d).

Figure 14: (a) Snake-neck turtle (Chelodina longicollis) climate envelope of model "b" (Table 1), fitted to the dataset at three different levels of precipitation: (i) $<300 \mathrm{~mm} /$ year, (ii) $300-1200 \mathrm{~mm} /$ year, and (iii) $>1200 \mathrm{~mm} /$ year. Black squares indicate sites with a recorded presence. White dots are sites where snake-neck turtles are presumed absent, but for clarity only a $20 \%$ random sample of all presumed absences have been drawn. Purple diamonds, if visible, show New Zealand's top ten most suitable snake-neck turtle sites. To calculate predicted probabilities MINMIN (not shown) was set equal to MINAVG minus $5^{\circ} \mathrm{C}$, MAXMAX (not shown) was set equal to MAXAVG plus $5^{\circ} \mathrm{C}$, and MAT (not shown) was set to the average of MINAVG and MAXAVG. (b) Global bioclimatic predictions derived from the weighted multimodel for areas of suitable snake-neck turtle habitat derived from the location record dataset. The red areas denote a more suitable climate for snake-neck turtles than blue areas. (c) Vertical lines and summary box plots illustrate the distribution of predicted probability of occurrence for all snake-neck turtle occupied sites (top) with the central line equal to the median, boxes extend from the $10^{\text {th }}$ to $90^{\text {th }}$ percentile and whiskers across the full range. These percentiles are used to define a relative suitability score. Below is the distribution of suitability for all sites available in New Zealand. (d) Bioclimatic predictions for areas of suitable snake-neck turtle habitat, derived from weighted multimodel applied to higher resolution climate data of New Zealand. The red areas denote a more suitable climate than blue areas for snake-neck turtles. (e) Colour-coding for the suitability scale (refer to part (b) and text for details). 
(a) PPT $<300 \mathrm{~mm} / \mathrm{yr}$

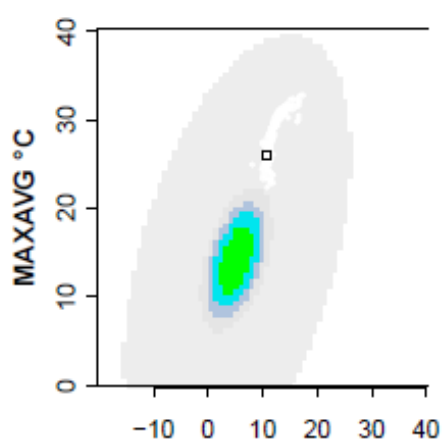

(b)

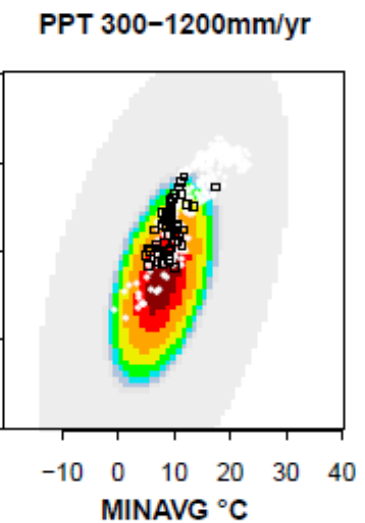

PPT $>1200 \mathrm{~mm} / \mathrm{yr}$

(e)
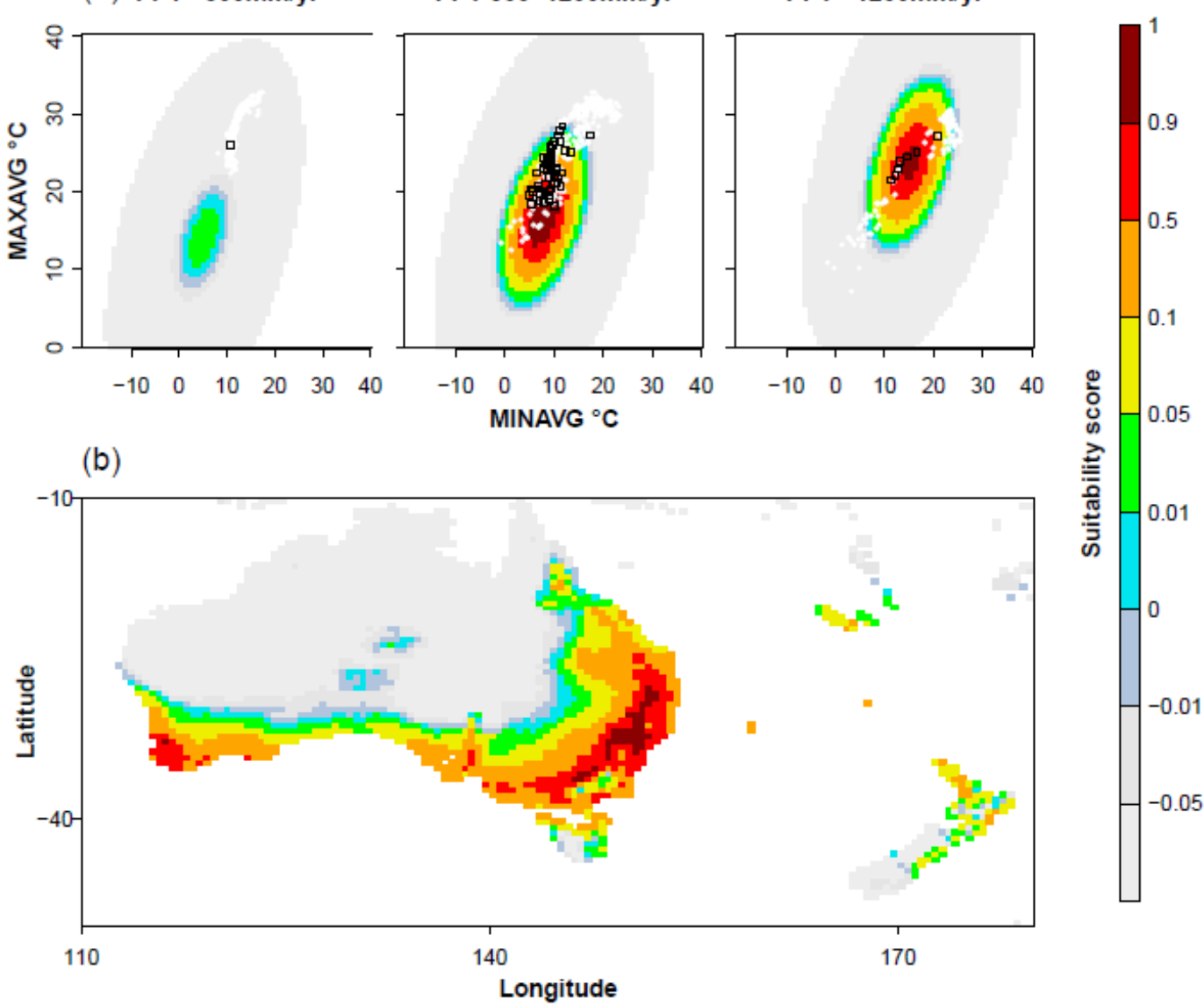

(d)

(c)

Suitability
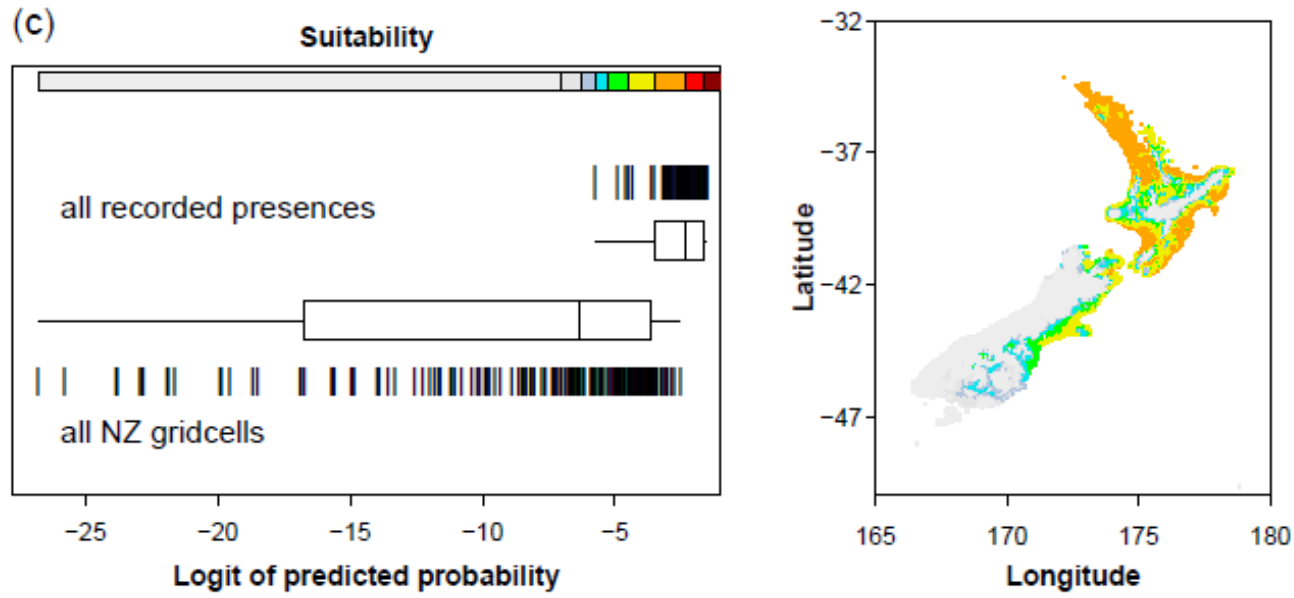


\section{Reeves turtle (Chinemys reevesii)}

For Chinemys reevesii, the best performing model, based on pAUC values of the test data jackknife partitions was model "k", with a pAUC value of 0.93 and a model weighting of 0.18 (Table 3). A boxplot visualisation of relative pAUC values for all models used for Reeves turtles can be found in Figure 15. Mean annual temperature and winter daily mean temperatures had the highest "relative importance" for Reeves turtles (Figure 16).

Table 3: Comparison of models from Table 1 for Reeves turtles (Chinemys reevesii). Please see Table 2 for further details.

\begin{tabular}{|c|c|c|c|c|c|c|}
\hline \multirow[b]{2}{*}{ Model } & \multicolumn{3}{|c|}{ Cross-validation $^{\mathrm{a}}$} & \multicolumn{3}{|c|}{ Final fit $^{\mathrm{b}}$} \\
\hline & $\mathbf{A U C}$ & pAUC & $\begin{array}{c}\text { Model } \\
\text { weight }^{\mathrm{c}}\end{array}$ & $\mathbf{A U C}$ & pAUC & $\begin{array}{c}\text { NZ } \\
\text { suitability }^{\text {score }} \\
\text { scor }^{\text {d }}\end{array}$ \\
\hline $\mathrm{a}$ & 0.973 & 0.908 & 0.162 & 0.984 & 0.965 & 0 \\
\hline b & 0.959 & 0.817 & 0.074 & 0.986 & 0.962 & 1 \\
\hline $\mathrm{c}$ & 0.961 & 0.834 & 0.090 & 0.978 & 0.950 & 0.031 \\
\hline $\mathrm{d}$ & 0.941 & 0.713 & 0 & 0.982 & 0.943 & 1 \\
\hline $\mathrm{e}$ & 0.884 & 0.760 & 0.018 & 0.918 & 0.802 & 1 \\
\hline$f$ & 0.942 & 0.847 & 0.103 & 0.965 & 0.910 & 1 \\
\hline $\mathrm{g}$ & 0.909 & 0.801 & 0.058 & 0.936 & 0.852 & 1 \\
\hline h & 0.933 & 0.817 & 0.074 & 0.960 & 0.900 & 1 \\
\hline $\mathrm{i}$ & 0.952 & 0.873 & 0.128 & 0.968 & 0.899 & 0.999 \\
\hline $\mathrm{j}$ & 0.946 & 0.854 & 0.110 & 0.967 & 0.893 & 1 \\
\hline $\mathrm{k}$ & 0.976 & 0.931 & 0.184 & 0.988 & 0.972 & 0.026 \\
\hline 1 & 0.939 & 0.741 & 0 & 0.990 & 0.974 & 0.860 \\
\hline $\begin{array}{l}\text { Weighted } \\
\text { multi- } \\
\text { model } \\
\text { average }\end{array}$ & NA & NA & NA & 0.986 & 0.966 & $\begin{array}{r}0.069 \\
(0-1)\end{array}$ \\
\hline
\end{tabular}


Figure 15: Relative pAUC values based on cross-validation results for each of the 12 models (see Table 3) applied to Reeves turtles (Chinemys reevesii). Please see Figure 12 for further details.

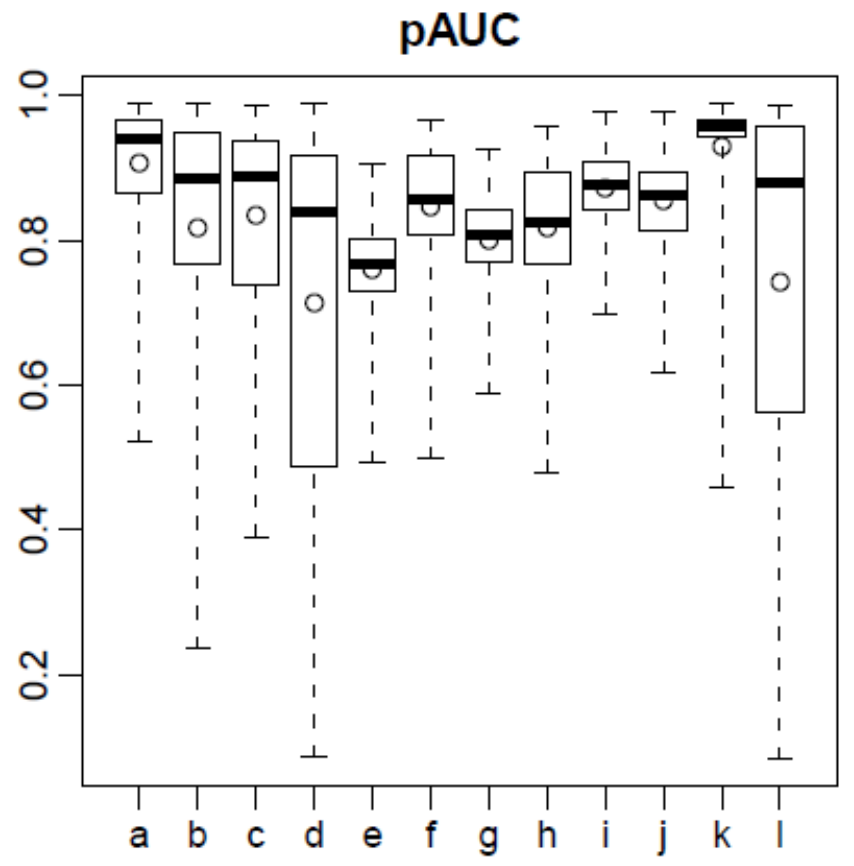

Figure 16: "Relative importance" of each of the climatic variables incorporated into the weighted multimodel (please see Table 1 and text for details) with regards to Chinemys reevesii.

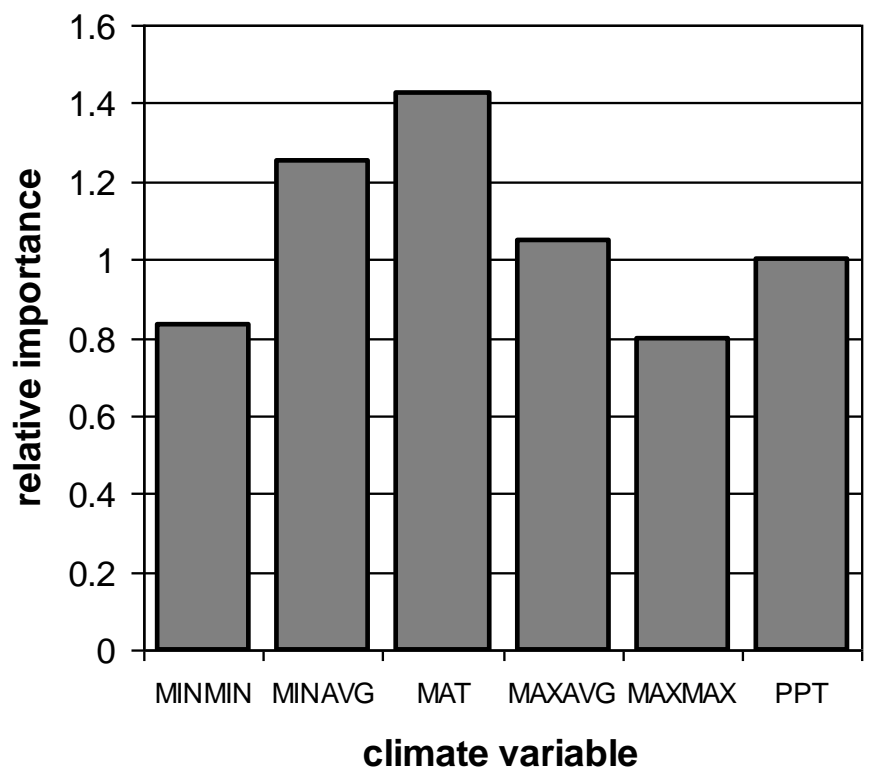

Areas outside of the native range of Chinemys reevesii, but within the range of -70 to 70 latitudes and -20 to 180 longitudes, with the best climate matches (suitability $\geq 0.1$ ) were northern India, northern Italy, the eastern coasts of the Adriatic and Black Seas, and a small pocket along the east coast of Australia (Figure 
17b). The degree of overlap between the investigated occupied gridcells and the available sites in New Zealand can be seen in Figure 17c. Reeves turtles received a New Zealand suitability score of 0.069 based on the multimodel average (Table 3). Within New Zealand, the best climate match (suitability $\geq 0.1$ ) was found in the eastern portion of the Coromandel peninsula. Other areas with a lesser degree of climate match (suitability $\geq 0.01$ ) were found in the remainder of the Coromandel peninsula, Gisborne, Northland, the west coast of the North Island (approximately Hamilton to New Plymouth), and the northwest coast of the South Island (Figure 17d). 
Figure 17: Climate envelope and predicted suitability for the Reeves turtle (Chinemys reevesii). Details as described in Figure 14.

(a) $\mathrm{PPT}<300 \mathrm{~mm} / \mathrm{yr}$

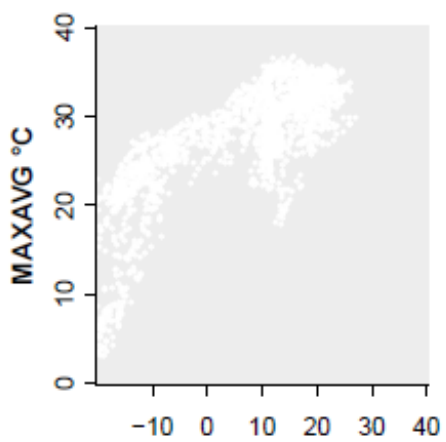

(b)

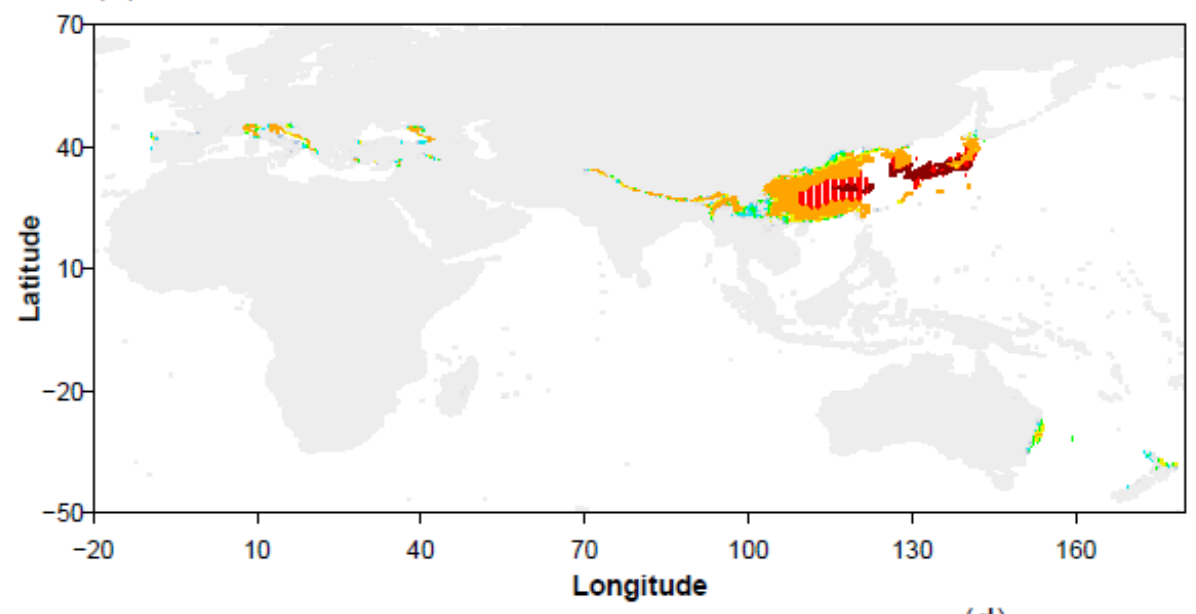

(d)

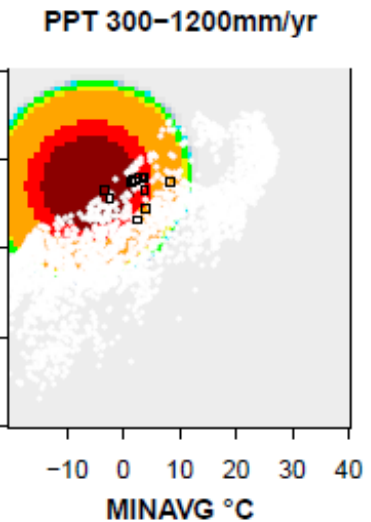

PPT $>1200 \mathrm{~mm} / \mathrm{yr}$

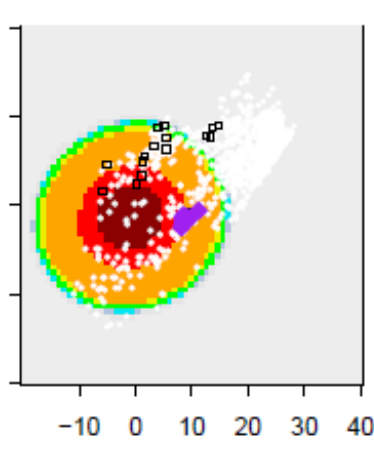

(e)

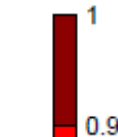

0.9
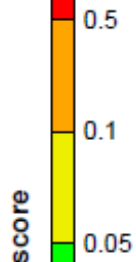

(c)

Suitability
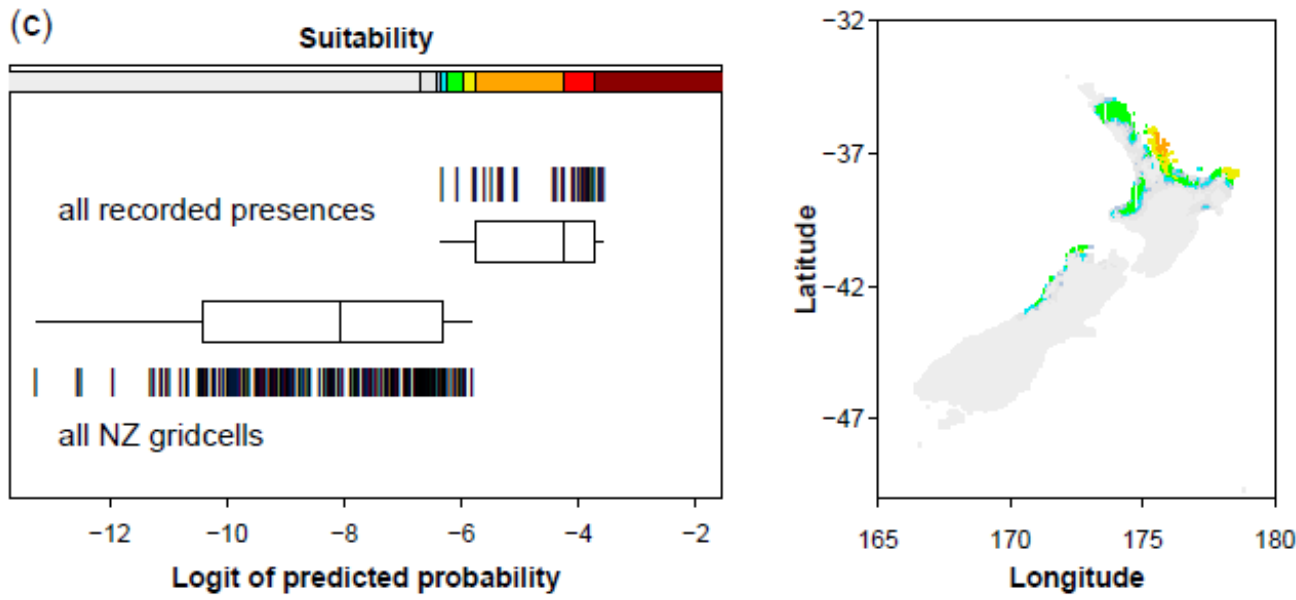

Tortoises (Testudo spp.)

Model "l" was the best performing model for Greek tortoises (Testudo graeca), with a pAUC value of 0.84 and an assigned weight of 0.14 . Models "f $\mathrm{f}$ " and 
“j” followed, both with assigned weightings of 0.12 (Table 4). For Hermanns tortoises (T. hermanni), model "k", closely followed by model "a" (both with assigned weightings of 0.14 ) were the best performing models based of pAUC values (Table 5). Boxplot visualisations of relative pAUC values for both Testudo species can be found in Figures 18 and 20. Mean annual temperature, followed by winter daily temperatures, had the highest "relative importance" for both species (Figures 19 and 21).

Table 4: Comparison of models from Table 1 for Greek tortoises (Testudo graeca). Please see Table 2 for further details.

\begin{tabular}{|c|c|c|c|c|c|c|}
\hline \multirow[b]{2}{*}{ Model } & \multicolumn{3}{|c|}{ Cross-validation $^{\mathrm{a}}$} & \multicolumn{3}{|c|}{ Final fit $^{b}$} \\
\hline & $\mathbf{A U C}$ & pAUC & $\begin{array}{c}\text { Model } \\
\text { weight }^{\mathrm{c}}\end{array}$ & $\mathbf{A U C}$ & pAUC & $\begin{array}{c}\text { NZ } \\
\text { suitability } \\
\text { score }^{\text {d }}\end{array}$ \\
\hline $\mathrm{a}$ & 0.936 & 0.804 & 0.102 & 0.950 & 0.842 & 0.204 \\
\hline $\mathrm{b}$ & 0.941 & 0.797 & 0.096 & 0.960 & 0.858 & 0 \\
\hline $\mathrm{c}$ & 0.922 & 0.746 & 0.049 & 0.940 & 0.798 & 0.303 \\
\hline d & 0.919 & 0.751 & 0.053 & 0.945 & 0.829 & 0.232 \\
\hline e & 0.902 & 0.693 & 0 & 0.919 & 0.746 & 0.527 \\
\hline $\mathrm{f}$ & 0.930 & 0.822 & 0.120 & 0.942 & 0.848 & 0.995 \\
\hline $\mathrm{g}$ & 0.899 & 0.662 & 0 & 0.917 & 0.753 & 0.587 \\
\hline $\mathrm{h}$ & 0.916 & 0.795 & 0.094 & 0.930 & 0.820 & 0.999 \\
\hline $\mathrm{i}$ & 0.935 & 0.818 & 0.116 & 0.943 & 0.843 & 0.880 \\
\hline $\mathrm{j}$ & 0.937 & 0.827 & 0.123 & 0.947 & 0.855 & 0.886 \\
\hline $\mathrm{k}$ & 0.941 & 0.812 & 0.110 & 0.960 & 0.864 & 0.093 \\
\hline 1 & 0.952 & 0.840 & 0.136 & 0.980 & 0.925 & 0.049 \\
\hline $\begin{array}{l}\text { Weighted } \\
\text { multi- } \\
\text { model } \\
\text { average }\end{array}$ & NA & NA & NA & 0.968 & 0.891165 & $\begin{array}{c}0.163 \\
(0-0.999)\end{array}$ \\
\hline
\end{tabular}


Figure 18: Relative pAUC values based on cross-validation results for each of the 12 models (see Table 4) applied to Greek tortoises (Testudo graeca). Please see Figure 12 for further details.

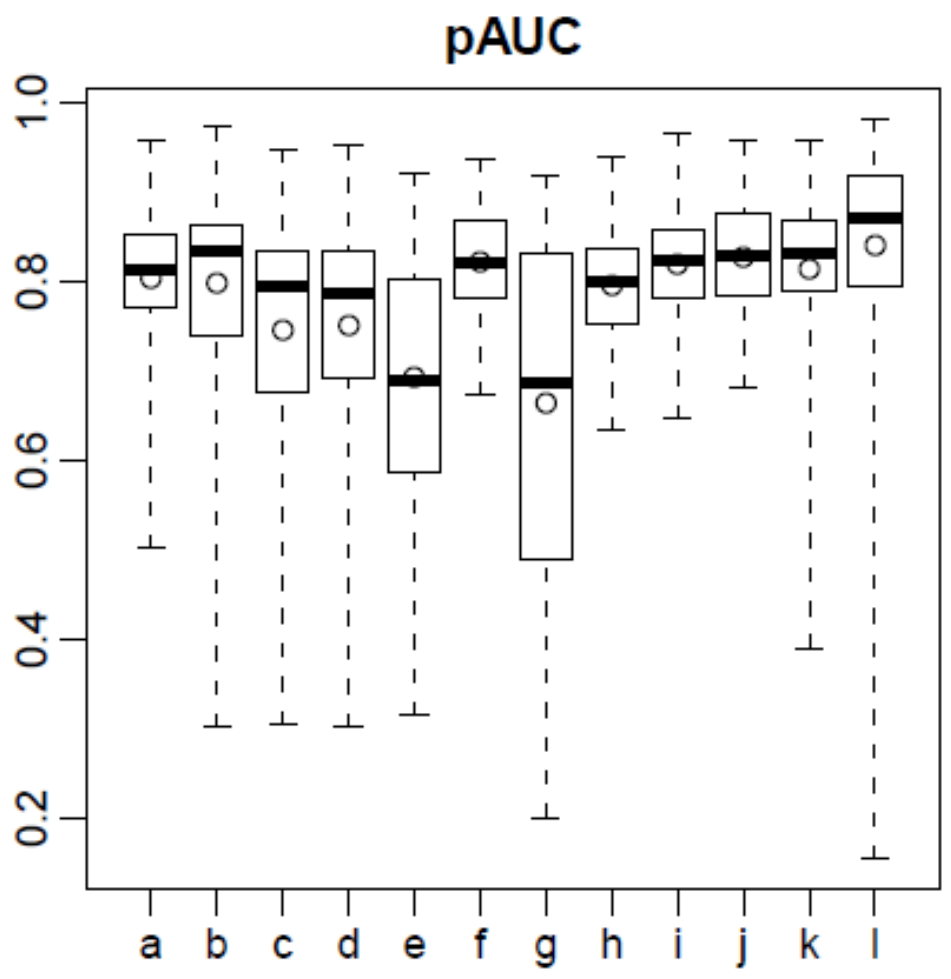

Figure 19: "Relative importance" of each of the climatic variables incorporated into the weighted multimodel (please see Table 1 and text for details) with regards to Testudo graeca.

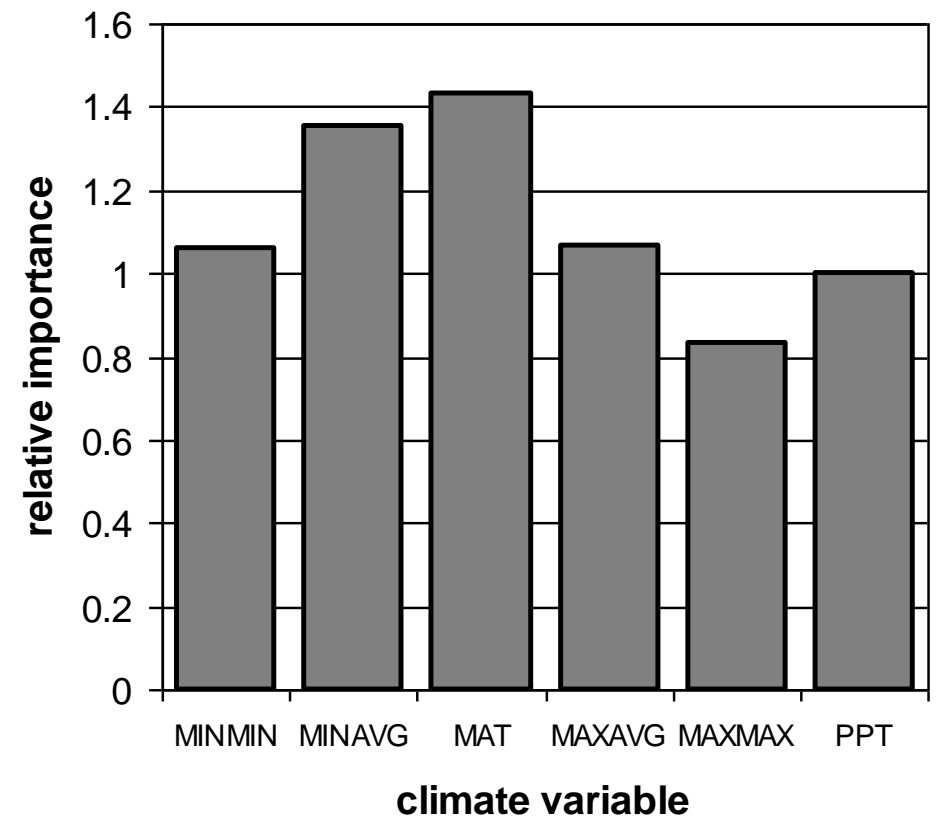


Table 5: Comparison of models from Table 1 for Hermanns tortoises (Testudo hermanni). Please see Table 2 for further details.

\begin{tabular}{|c|c|c|c|c|c|c|}
\hline \multirow[b]{2}{*}{ Model } & \multicolumn{3}{|c|}{ Cross-validation $^{\text {a }}$} & \multicolumn{3}{|c|}{ Final fit $^{\mathrm{b}}$} \\
\hline & $\mathbf{A U C}$ & pAUC & $\begin{array}{c}\text { Model } \\
\text { weight }^{\mathrm{c}}\end{array}$ & $\mathbf{A U C}$ & pAUC & $\begin{array}{c}\text { NZ } \\
\text { suitability } \\
\text { score }^{\mathrm{d}}\end{array}$ \\
\hline $\mathrm{a}$ & 0.972 & 0.890 & 0.138 & 0.984 & 0.929 & 0.110 \\
\hline $\mathrm{b}$ & 0.938 & 0.773 & 0.065 & 0.986 & 0.953 & 0 \\
\hline $\mathrm{c}$ & 0.967 & 0.873 & 0.127 & 0.982 & 0.941 & 0.274 \\
\hline $\mathrm{d}$ & 0.933 & 0.720 & 0.032 & 0.983 & 0.933 & 0.335 \\
\hline e & 0.936 & 0.722 & 0.034 & 0.965 & 0.849 & 0.114 \\
\hline$f$ & 0.959 & 0.859 & 0.118 & 0.980 & 0.917 & 0.986 \\
\hline $\mathrm{g}$ & 0.915 & 0.632 & 0 & 0.959 & 0.809 & 0.095 \\
\hline h & 0.950 & 0.834 & 0.103 & 0.972 & 0.896 & 0.853 \\
\hline $\mathrm{i}$ & 0.968 & 0.880 & 0.132 & 0.978 & 0.924 & 0.443 \\
\hline $\mathrm{j}$ & 0.960 & 0.846 & 0.111 & 0.979 & 0.920 & 0.567 \\
\hline $\mathrm{k}$ & 0.973 & 0.892 & 0.139 & 0.988 & 0.929 & 0.124 \\
\hline 1 & 0.912 & 0.668 & 0 & 0.995 & 0.979 & 0.665 \\
\hline $\begin{array}{l}\text { Weighted } \\
\text { multi- } \\
\text { model } \\
\text { average }\end{array}$ & NA & NA & NA & 0.986 & 0.933 & $\begin{array}{c}0.170 \\
(0-0.986)\end{array}$ \\
\hline
\end{tabular}


Figure 20: Relative pAUC values based on cross-validation results for each of the 12 models (see Table 5) applied to Hermanns tortoises (Testudo hermanni). Please see Figure 12 for further details.

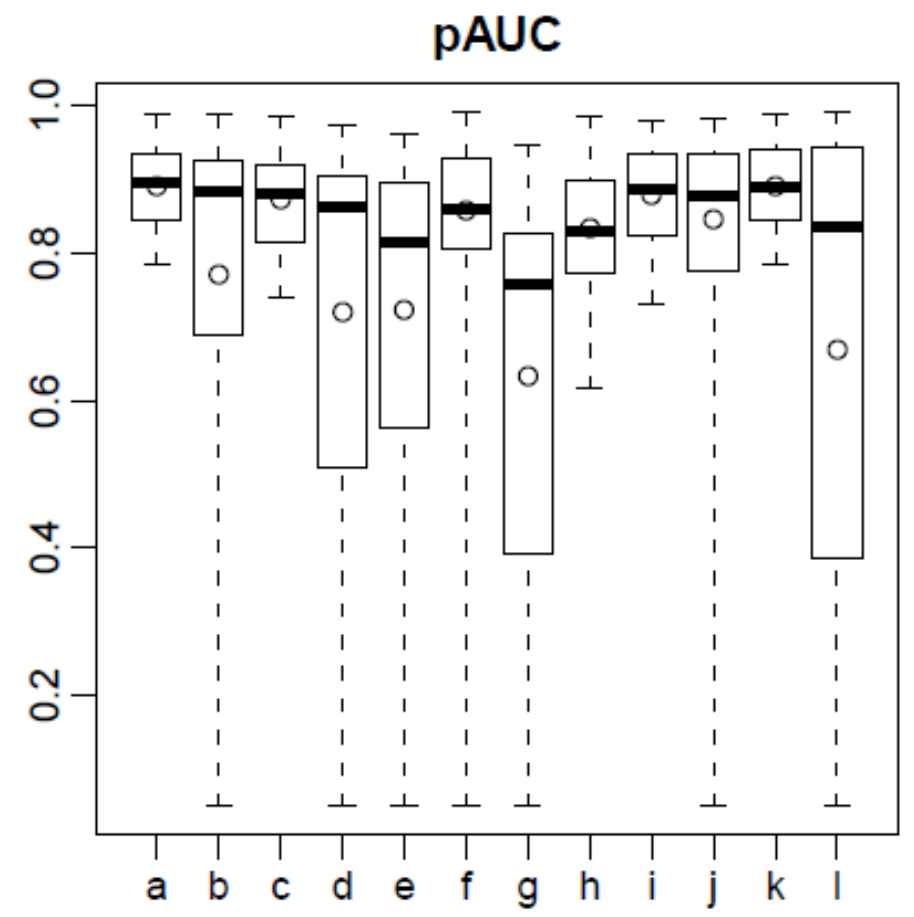

Figure 21: "Relative importance" of each of the climatic variables incorporated into the weighted multimodel (please see Table 1 and text for details) with regards to Testudo hermanni.

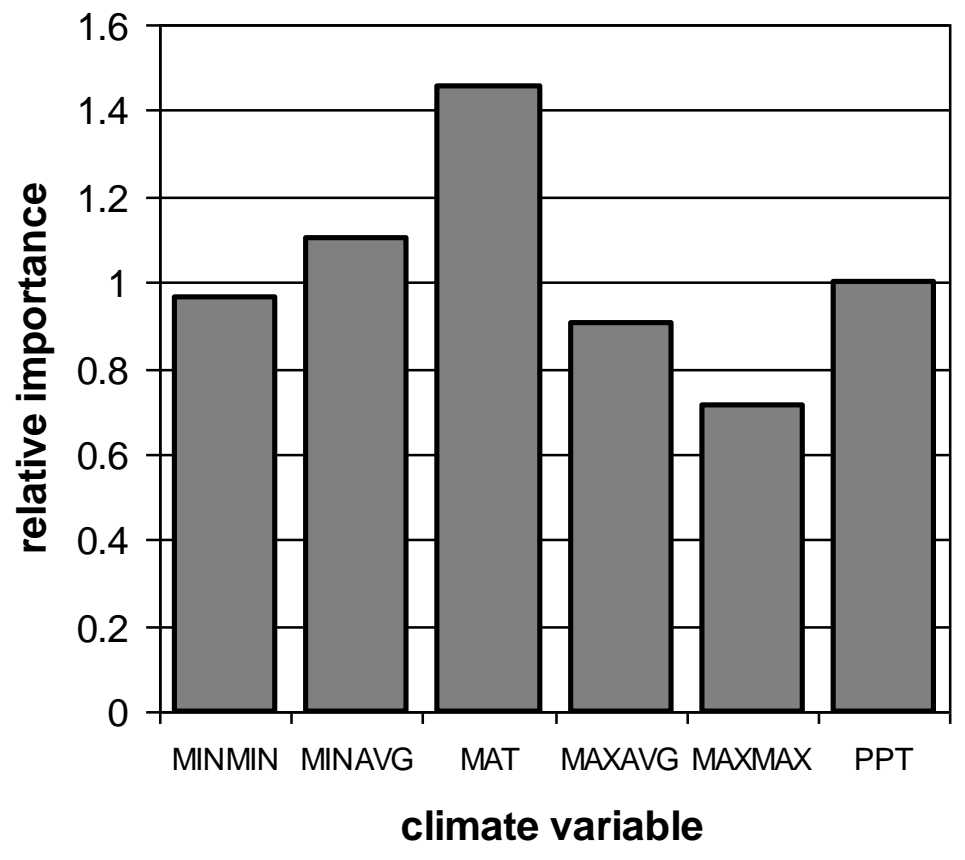


The native ranges of both Testudo graeca and T. hermanni were identified as having a high degree of climate match. Results outside the native ranges, but within the range of -70 to 70 latitudes and -20 to 180 longitudes were similar for both species, with the best climate matches (suitability $\geq 0.1$ ) predicted in the areas surrounding their native ranges, southeast Asia, southern Africa, and the southeastern and south-western coasts of Australia (Figures 22b and 23b). The degree of overlap between the suitability of the investigated occupied gridcells and the sites available in New Zealand can be seen in Figures 22c and 23c. Testudo graeca and T. hermanni both received New Zealand suitability scores of $\sim 0.16$ based on the multimodel average (Tables 4 and 5, respectively). Within New Zealand, the best climate matches for $T$. graeca (suitability $\geq 0.1$ ) were found in the eastern coast of the South Island and in Hawkes Bay (Figure 22d) with almost identical results for $T$. hermanni (Figure 23d). 
Figure 22: Climate envelope and predicted suitability for the Greek tortoise (Testudo graeca). Details as described in Figure 14.

(a)

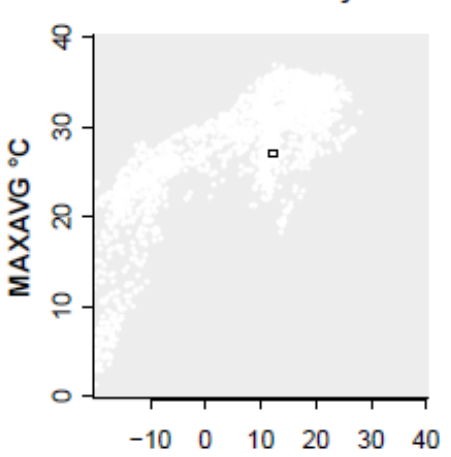

(b)

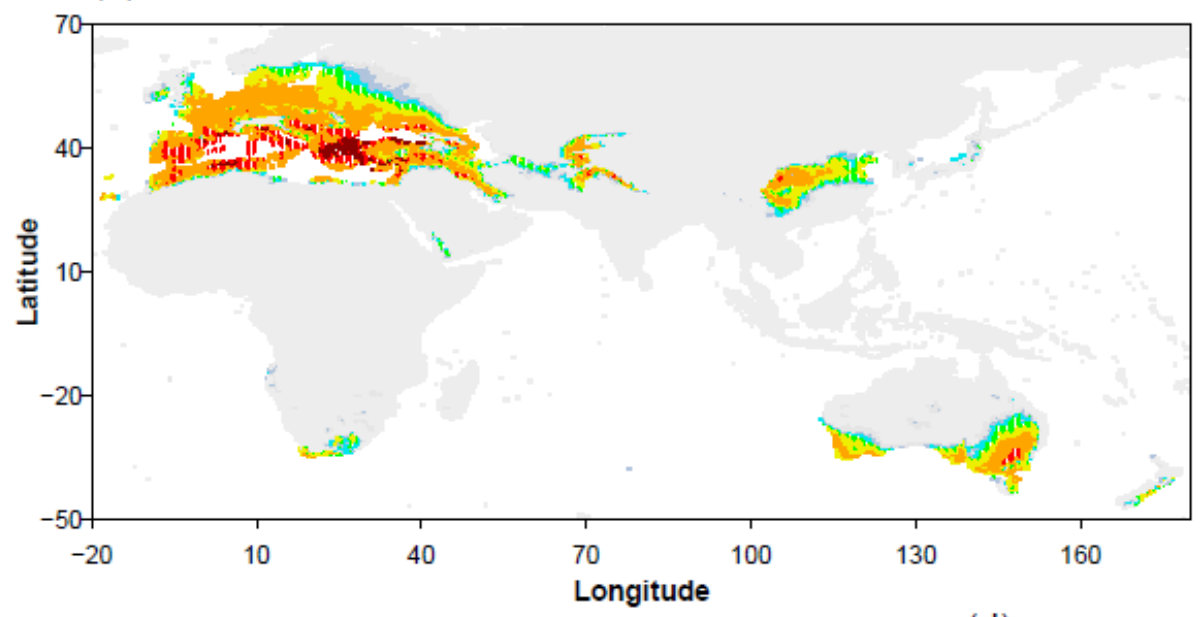

(d)

(c)

Suitability

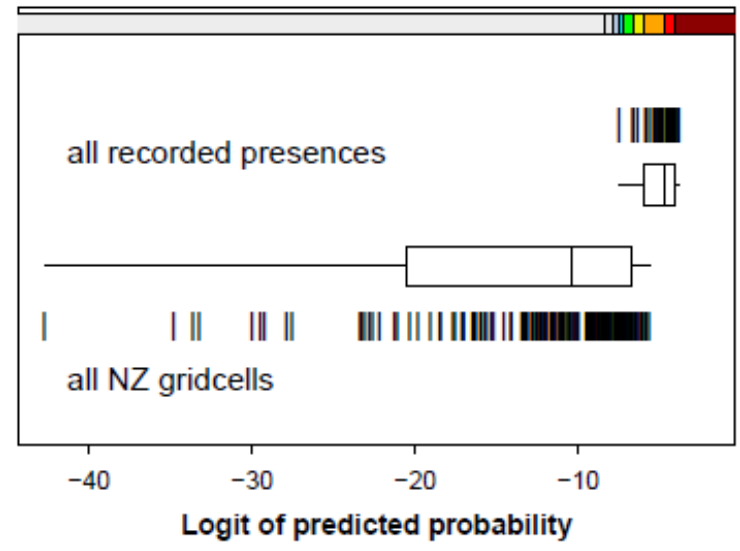

(e)
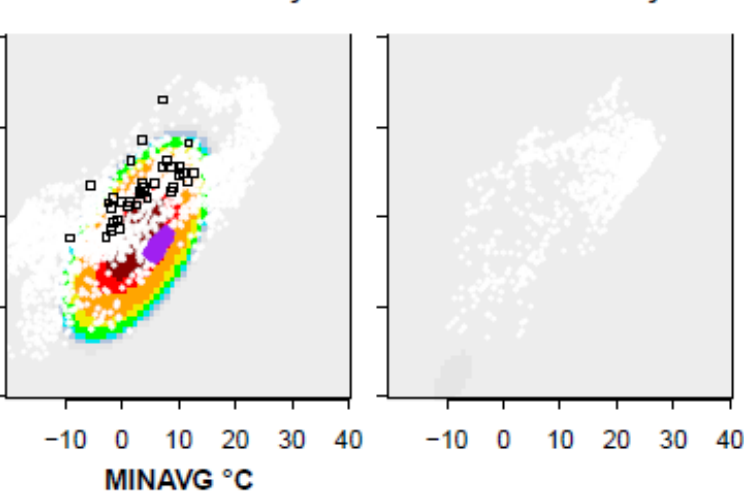

ัํำ

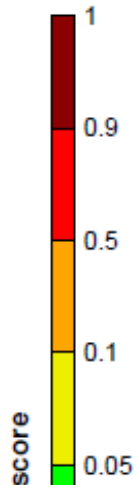

0.01

0

$-0.01$

$-0.05$

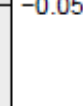


Figure 23: Climate envelope and predicted suitability for the Hermanns tortoise (Testudo hermanni). Details as described in Figure 14.

(a) PPT $<300 \mathrm{~mm} / \mathrm{yr}$

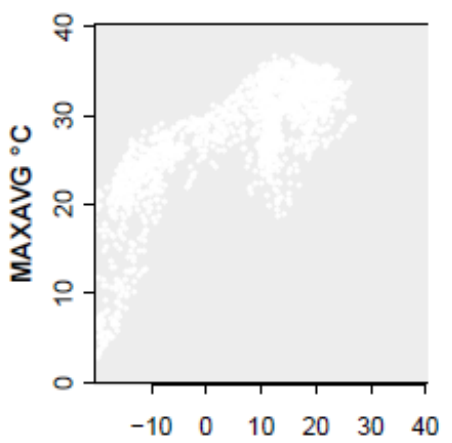

(b)

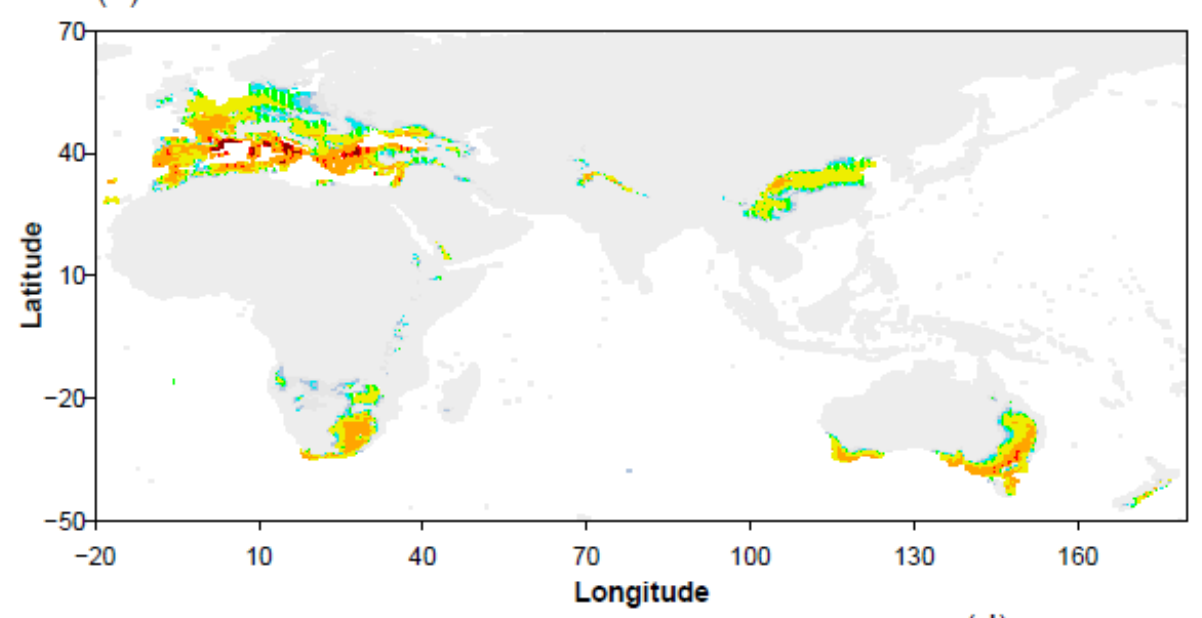

(d) (e)
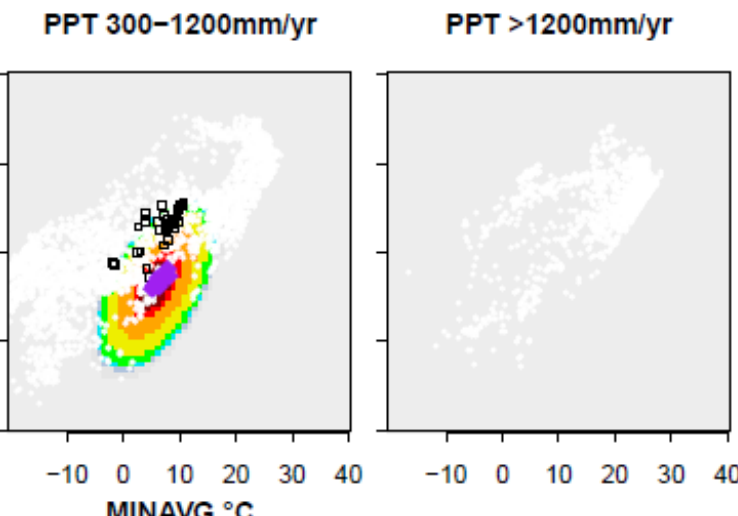

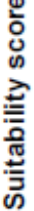

(c)

Suitability
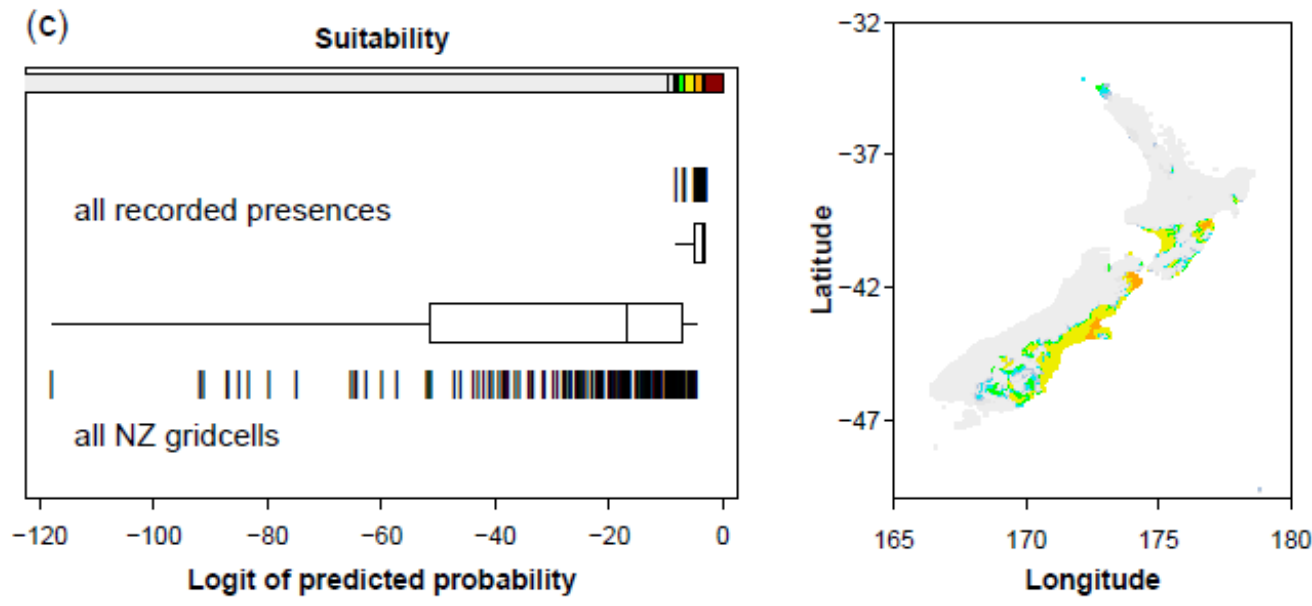


\section{Bearded dragons (Pogona spp.)}

Based on pAUC values of the test data jackknife partitions, model "c" (mean pAUC $=0.425)$, followed closely by model " $k$ ", had the best predictive ability for inland bearded dragons (Pogona vitticeps). Both models had a weight of 0.2 (Table 6). Model "f" was the best performing model for coastal bearded dragons (P. barbata) with a mean pAUC value of 0.631 and a weight of 0.16 (Table 7). Boxplot visualisations of relative pAUC values for both species can be found in Figures 24 and 26. Winter minimum and summer maximum temperatures were the climatic variables with the highest "relative importance" for inland bearded dragons (Figure 25). For coastal bearded dragons, mean annual temperature, followed by winter daily mean temperatures, were the climatic variables with the highest "relative importance" (Figure 27). 
Table 6: Comparison of models from Table 1 for inland bearded dragons (Pogona vitticeps). Please see Table 2 for further details.

\begin{tabular}{|c|c|c|c|c|c|c|}
\hline \multirow[b]{2}{*}{ Model } & \multicolumn{3}{|c|}{ Cross-validation $^{\mathrm{a}}$} & \multicolumn{3}{|c|}{ Final fit $^{\mathrm{b}}$} \\
\hline & $\mathbf{A U C}$ & pAUC & $\begin{array}{l}\text { Model } \\
\text { weight }^{\mathrm{c}}\end{array}$ & $\mathbf{A U C}$ & pAUC & $\begin{array}{c}\text { NZ } \\
\text { suitability }_{\text {score }^{d}}\end{array}$ \\
\hline $\mathrm{a}$ & 0.729 & 0.413 & 0.139 & 0.782 & 0.464 & 0.743 \\
\hline $\mathrm{b}$ & 0.733 & 0.393 & 0.012 & 0.791 & 0.385 & 0.767 \\
\hline $\mathrm{c}$ & 0.735 & 0.425 & 0.211 & 0.786 & 0.457 & 0.036 \\
\hline d & 0.726 & 0.393 & 0.015 & 0.787 & 0.406 & 0.059 \\
\hline e & 0.698 & 0.396 & 0.029 & 0.757 & 0.381 & 0.011 \\
\hline $\mathrm{f}$ & 0.733 & 0.391 & 0 & 0.776 & 0.386 & 0.502 \\
\hline $\mathrm{g}$ & 0.712 & 0.405 & 0.088 & 0.765 & 0.390 & 0 \\
\hline $\mathrm{h}$ & 0.755 & 0.413 & 0.137 & 0.784 & 0.399 & 0.195 \\
\hline $\mathrm{i}$ & 0.711 & 0.399 & 0.050 & 0.760 & 0.371 & 0.115 \\
\hline $\mathrm{j}$ & 0.700 & 0.383 & 0 & 0.760 & 0.375 & 0.121 \\
\hline $\mathrm{k}$ & 0.748 & 0.423 & 0.205 & 0.816 & 0.490 & 0.314 \\
\hline 1 & 0.765 & 0.409 & 0.115 & 0.849 & 0.520 & 0.115 \\
\hline $\begin{array}{l}\text { Weighted } \\
\text { multi- } \\
\text { model } \\
\text { average }\end{array}$ & NA & NA & NA & 0.818 & 0.476 & $\begin{array}{c}0.031 \\
(0-0.743)\end{array}$ \\
\hline
\end{tabular}


Figure 24: Relative pAUC values based on cross-validation results for each of the 12 models (see Table 6) applied to inland bearded dragons (Pogona vitticeps). Please see Figure 12 for further details.

pAUC

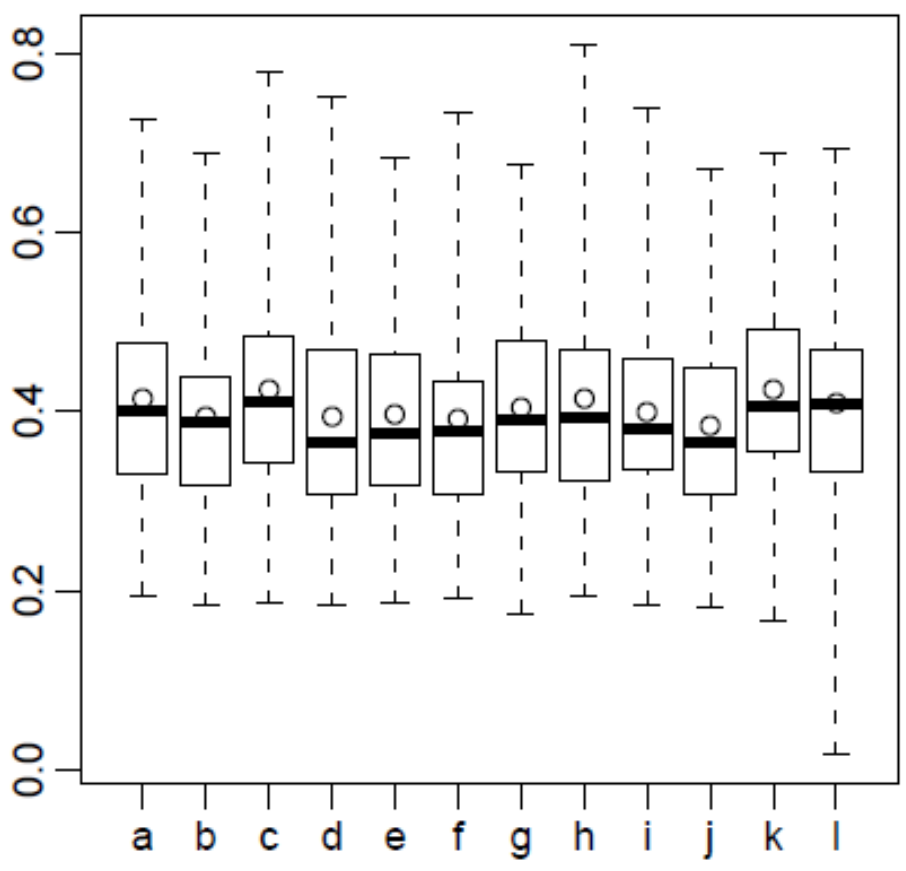

Figure 25: "Relative importance" of each of the climatic variables incorporated into the weighted multimodel (please see Table 1 and text for details) with regards to Pogona vitticeps.

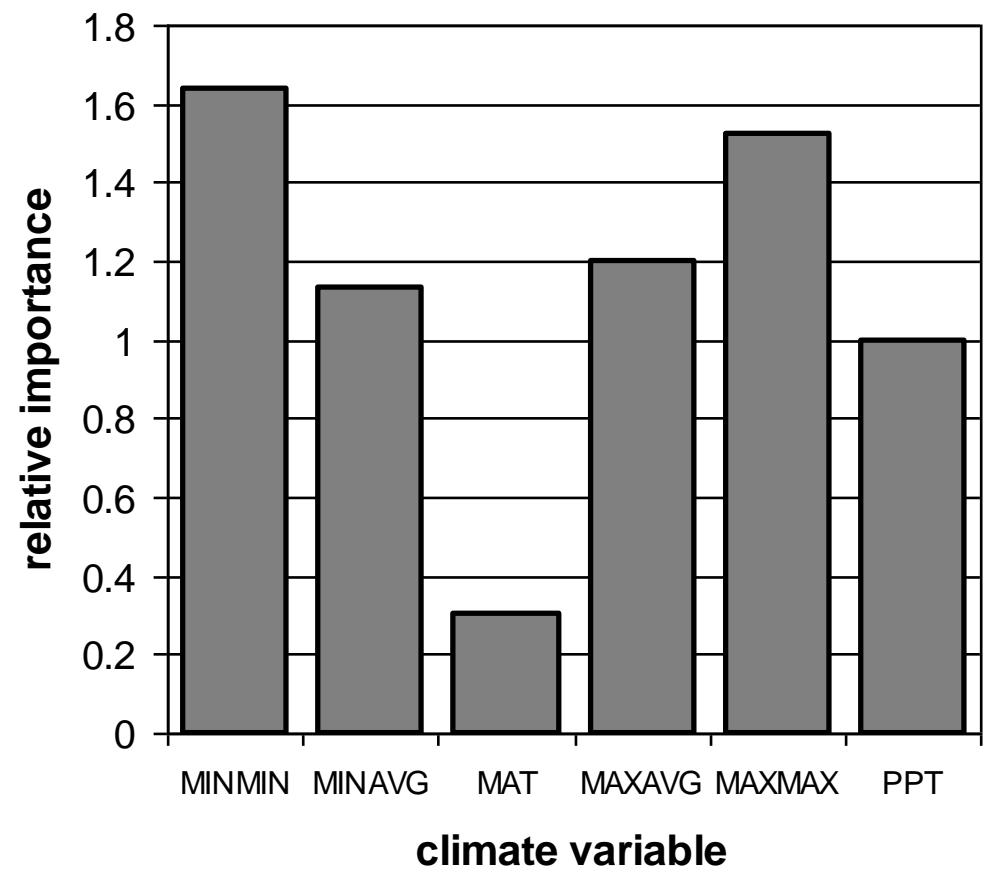


Table 7: Comparison of models from Table 1 for coastal bearded dragons (Pogona barbata). Please see Table 2 for further details.

\begin{tabular}{|c|c|c|c|c|c|c|}
\hline \multirow[b]{2}{*}{ Model } & \multicolumn{3}{|c|}{ Cross-validation $^{\mathrm{a}}$} & \multicolumn{3}{|c|}{ Final fit' } \\
\hline & $\mathbf{A U C}$ & pAUC & $\begin{array}{c}\text { Model } \\
\text { weight }^{c}\end{array}$ & $\mathbf{A U C}$ & pAUC & $\begin{array}{c}\text { NZ } \\
\begin{array}{c}\text { suitability } \\
\text { score }^{\mathrm{d}}\end{array}\end{array}$ \\
\hline $\mathrm{a}$ & 0.860 & 0.610 & 0.121 & 0.892 & 0.712 & 0.565 \\
\hline b & 0.862 & 0.607 & 0.116 & 0.900 & 0.703 & 0.234 \\
\hline $\mathrm{c}$ & 0.868 & 0.591 & 0.087 & 0.898 & 0.699 & 0.245 \\
\hline d & 0.864 & 0.613 & 0.126 & 0.899 & 0.709 & 0.136 \\
\hline e & 0.857 & 0.586 & 0.077 & 0.887 & 0.650 & 0.593 \\
\hline $\mathrm{f}$ & 0.839 & 0.631 & 0.160 & 0.874 & 0.699 & 0.870 \\
\hline $\mathrm{g}$ & 0.864 & 0.591 & 0.087 & 0.893 & 0.690 & 0.210 \\
\hline h & 0.812 & 0.544 & 0 & 0.854 & 0.641 & 0.952 \\
\hline $\mathrm{i}$ & 0.833 & 0.574 & 0.055 & 0.870 & 0.692 & 0.951 \\
\hline $\mathrm{j}$ & 0.852 & 0.619 & 0.138 & 0.884 & 0.700 & 0.798 \\
\hline $\mathrm{k}$ & 0.857 & 0.561 & 0.032 & 0.904 & 0.747 & 0.216 \\
\hline 1 & 0.792 & 0.355 & 0 & 0.908 & 0.754 & 0.099 \\
\hline $\begin{array}{l}\text { Weighted } \\
\text { multi- } \\
\text { model } \\
\text { average }\end{array}$ & NA & NA & NA & 0.898 & 0.722 & $\begin{array}{c}0.368 \\
(0.136-0.951)\end{array}$ \\
\hline
\end{tabular}


Figure 26: Relative pAUC values based on cross-validation results for each of the 12 models (see Table 7) applied to coastal bearded dragons (Pogona barbata). Please see Figure 12 for further details.

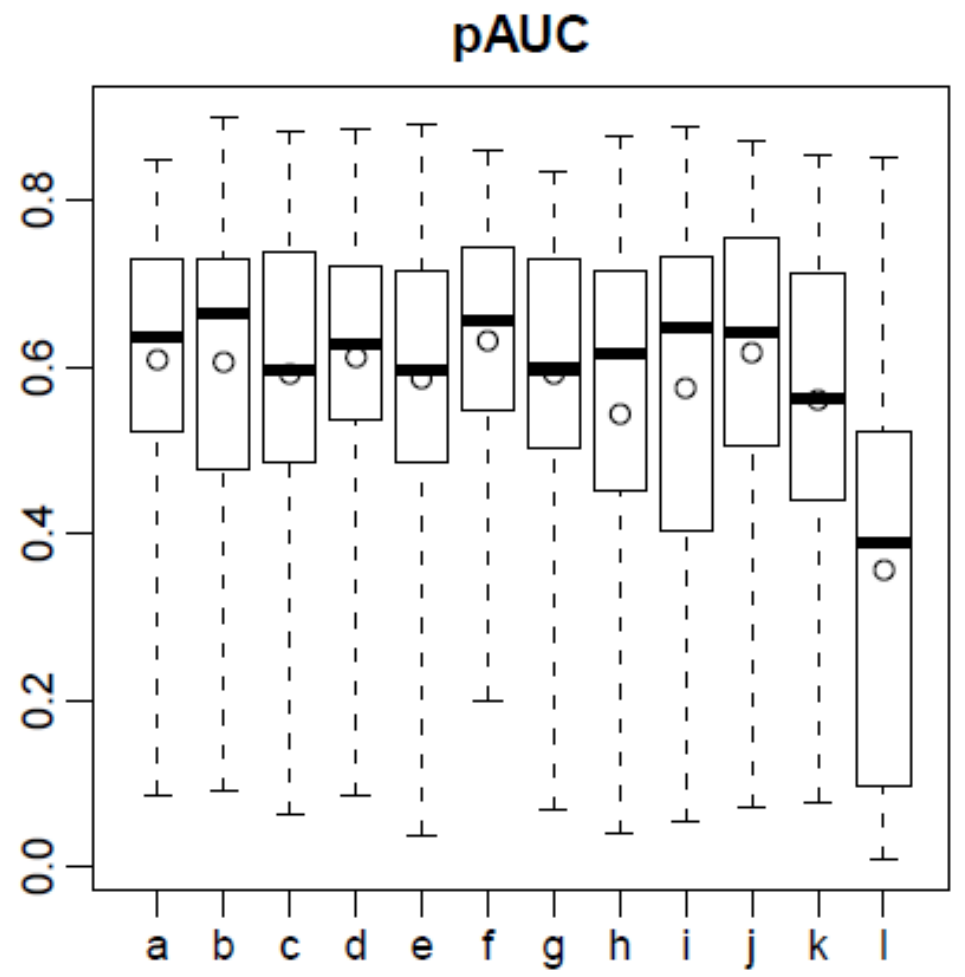

Figure 27: "Relative importance" of each of the climatic variables incorporated into the weighted multimodel (please see Table 1 and text for details) with regards to Pogona barbata.

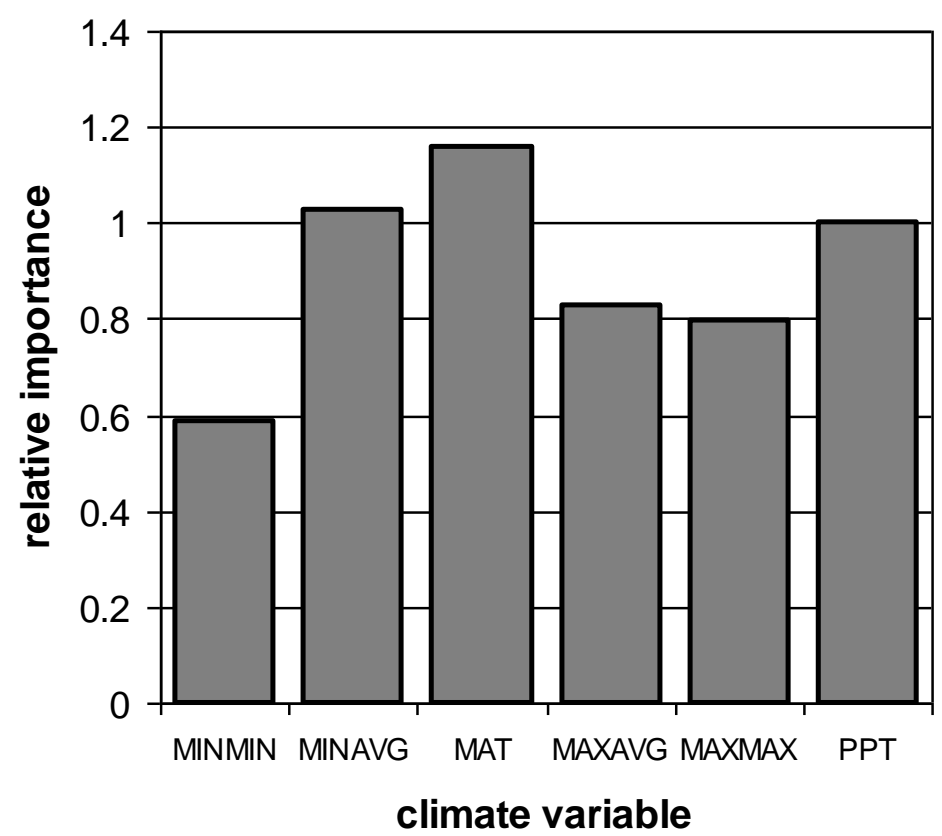


When using the multimodel weighted average to identify areas possessing a suitable climate for bearded dragons, the native range of both species of bearded dragons was considered a high climate match (Figures $28 \mathrm{~b}$ and 29b). The degree of 'overlap' between the suitability of the occupied investigated grid cells and the available sites in New Zealand can be seen in Figures 28c (P. vitticeps) and Figure 29c ( $P$. barbata). Based on the multimodel average, the 'best' available site in New Zealand for $P$. vitticeps received a score of 0.03 (Table 6). Pogona barbata received a New Zealand suitability score of 0.37 based on the multimodel weighted average (Table 7). The most suitable area in New Zealand for $P$. vitticeps (suitability $\geq 0.01$ ) was predicted to be a small area in the Canterbury Plains (Figure 28d), whereas $P$. barbata had a wider range and higher degree of climatic suitability $(\geq 0.1)$ found in the northern portion of the North Island, and along the coastal areas in the Bay of Plenty, Hawkes Bay, and the Wanganui-Manawatu areas (Figure 29d). 
Figure 28: Climate envelope and predicted suitability for the inland bearded dragons (Pogona vitticeps). Details as described in Figure 14.

(a) PPT $<300 \mathrm{~mm} / \mathrm{yr}$

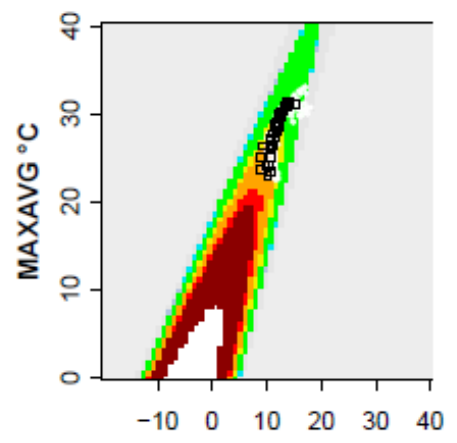

(b)
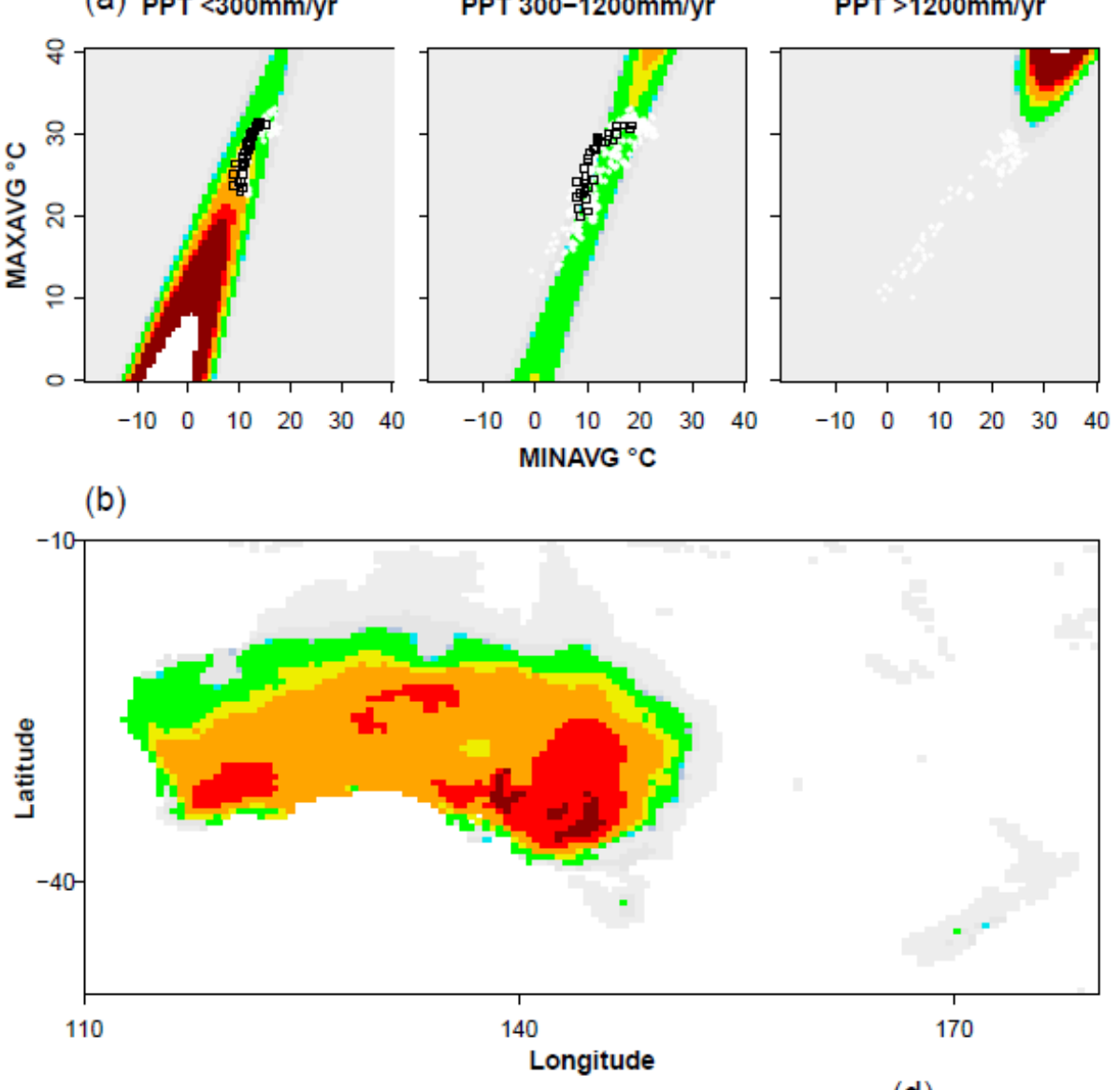

(e)

(c)

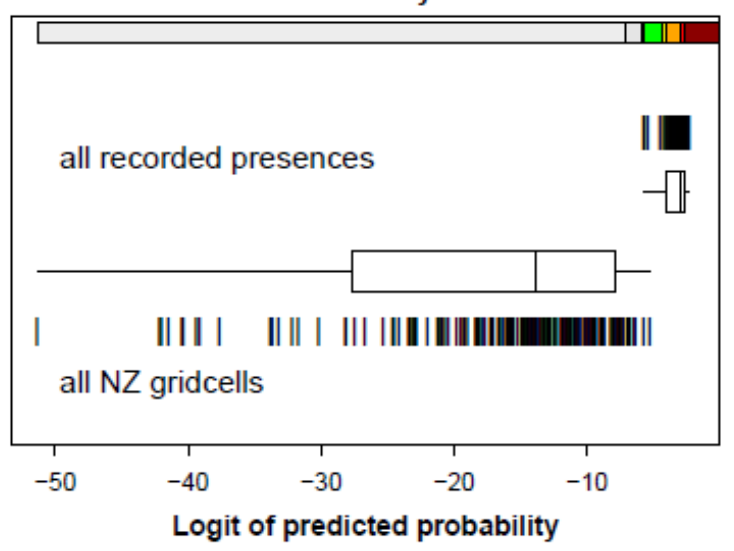

(d)

\%

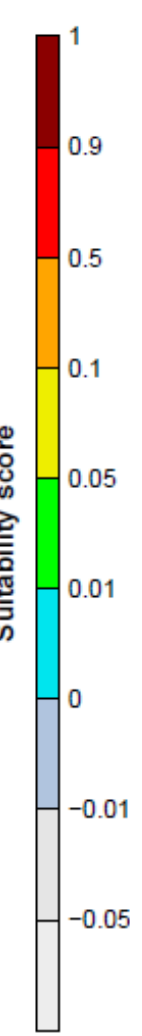

高 0.01

के $-0.01$

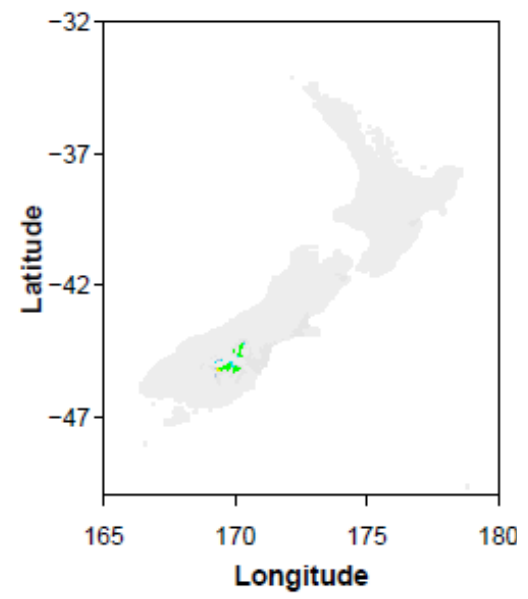


Figure 29: Climate envelope and predicted suitability for the coastal bearded dragon (Pogona barbata). Details as described in Figure 14.

(a) PPT $<300 \mathrm{~mm} / \mathrm{yr}$

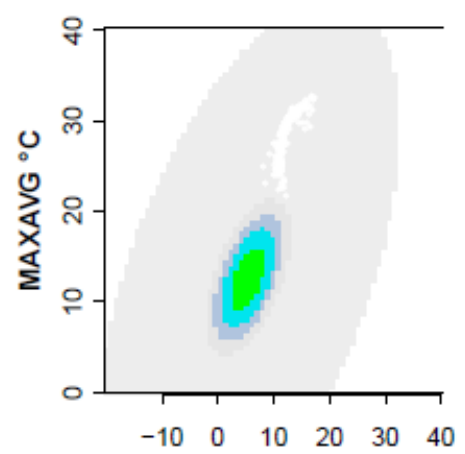

(b)

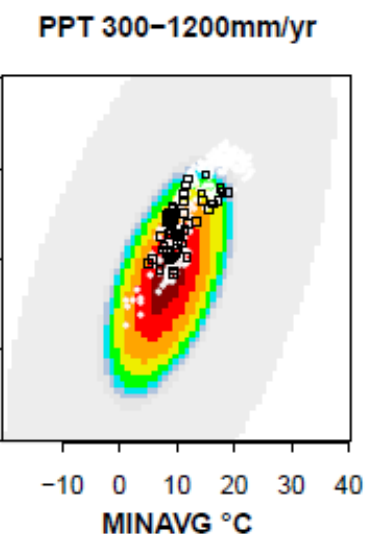

PPT $>1200 \mathrm{~mm} / \mathrm{yr}$

(e)

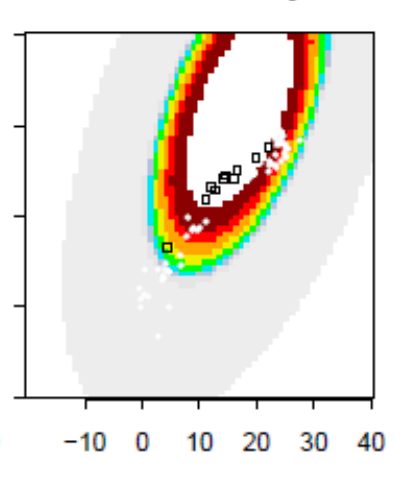

잉

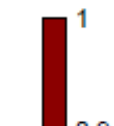

0.9

0.5

0.1

0.05

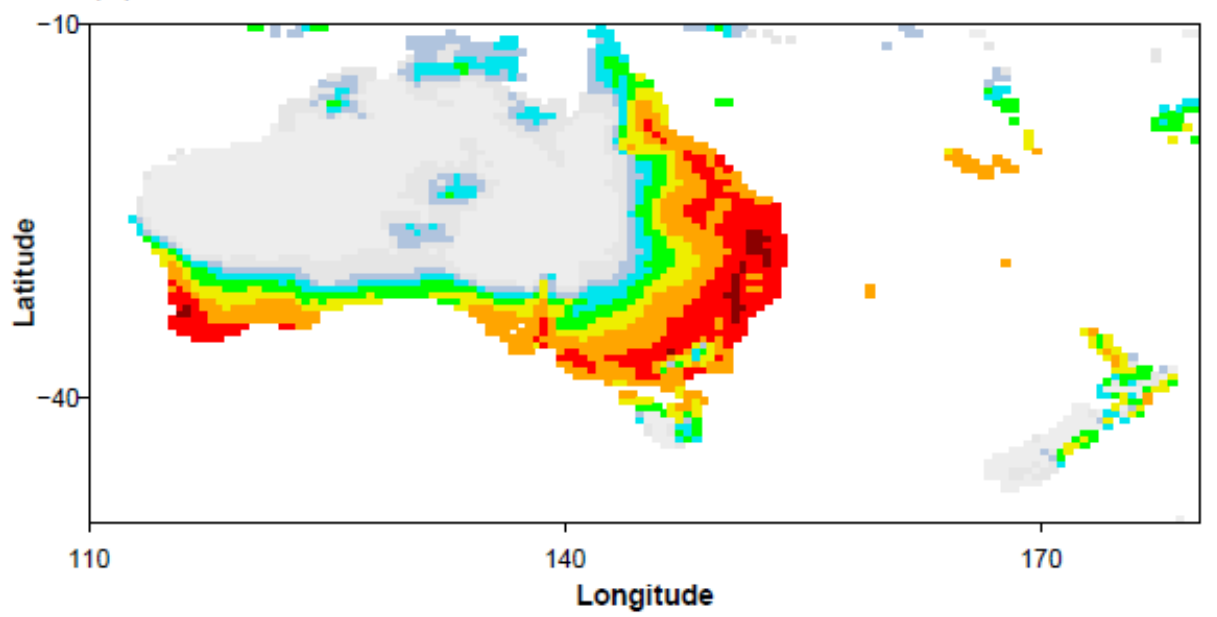

(d)

(c)

Suitability
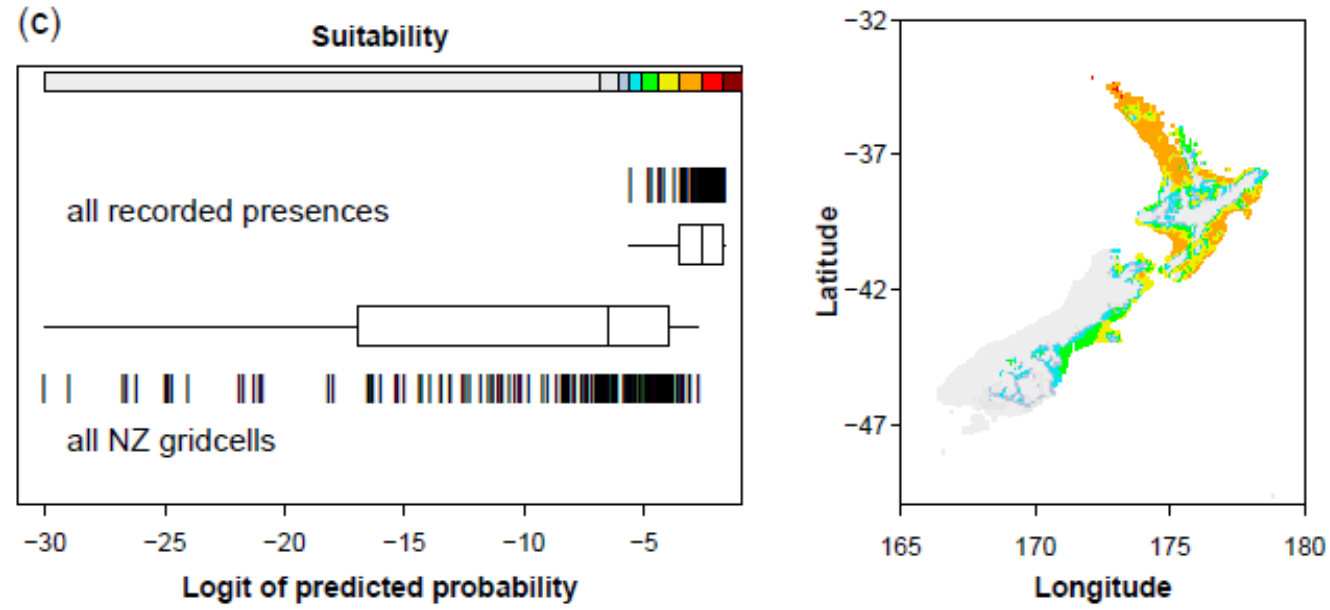
Leopard gecko (Eublepharis macularius)

The best performing model for Eublepharis macularius was model "a", with a pAUC value of 0.63 and a model weighting of 0.13 . Models "c" and " $h$ " were the next best performing models, both with weightings of 0.12 (Table 8). A boxplot visualisation of relative pAUC values for all models used for leopard geckos can be found in Figure 30. Mean annual temperature and winter temperatures all had high “relative importance" for leopard geckos (Figure 31).

Table 8: Comparison of models from Table 1 for leopard geckos (Eublepharis macularius). Please see Table 2 for further details.

\begin{tabular}{|c|c|c|c|c|c|c|}
\hline \multirow[b]{2}{*}{ Model } & \multicolumn{3}{|c|}{ Cross-validation $^{\mathrm{a}}$} & \multicolumn{3}{|c|}{ Final fit $^{\mathrm{b}}$} \\
\hline & $\mathbf{A U C}$ & pAUC & $\begin{array}{c}\text { Model } \\
\text { weight }^{\mathrm{c}}\end{array}$ & $\mathbf{A U C}$ & pAUC & $\begin{array}{c}\text { NZ } \\
\text { suitability }^{\text {score }} \\
\text { s }^{\text {s. }}\end{array}$ \\
\hline $\mathrm{a}$ & 0.813 & 0.634 & 0.134 & 0.898 & 0.686 & 0.663 \\
\hline$b$ & 0.835 & 0.594 & 0.111 & 0.937 & 0.760 & -0.05 \\
\hline $\mathrm{c}$ & 0.806 & 0.606 & 0.118 & 0.904 & 0.622 & 0.657 \\
\hline $\mathrm{d}$ & 0.815 & 0.575 & 0.101 & 0.925 & 0.706 & 0.095 \\
\hline $\mathrm{e}$ & 0.688 & 0.410 & 0.007 & 0.812 & 0.522 & 0.202 \\
\hline $\mathrm{f}$ & 0.791 & 0.599 & 0.114 & 0.877 & 0.651 & 0.994 \\
\hline $\mathrm{g}$ & 0.685 & 0.398 & 0 & 0.799 & 0.501 & 0.198 \\
\hline $\mathrm{h}$ & 0.792 & 0.604 & 0.117 & 0.877 & 0.657 & 0.958 \\
\hline $\mathrm{i}$ & 0.767 & 0.588 & 0.108 & 0.845 & 0.643 & 0.719 \\
\hline $\mathrm{j}$ & 0.745 & 0.540 & 0.080 & 0.845 & 0.638 & 0.715 \\
\hline $\mathrm{k}$ & 0.820 & 0.593 & 0.110 & 0.922 & 0.688 & 0.450 \\
\hline 1 & 0.768 & 0.340 & 0 & 0.986 & 0.871 & 0.003 \\
\hline $\begin{array}{l}\text { Weighted } \\
\text { multi- } \\
\text { model } \\
\text { average }\end{array}$ & NA & NA & NA & 0.923 & 0.709 & $\begin{array}{c}0.175 \\
(-0.05- \\
0.994)\end{array}$ \\
\hline
\end{tabular}


Figure 30: Relative pAUC values based on cross-validation results for each of the 12 models (see Table 8) applied to leopard geckos (Eublepharis macularius). Please see Figure 12 for further details.

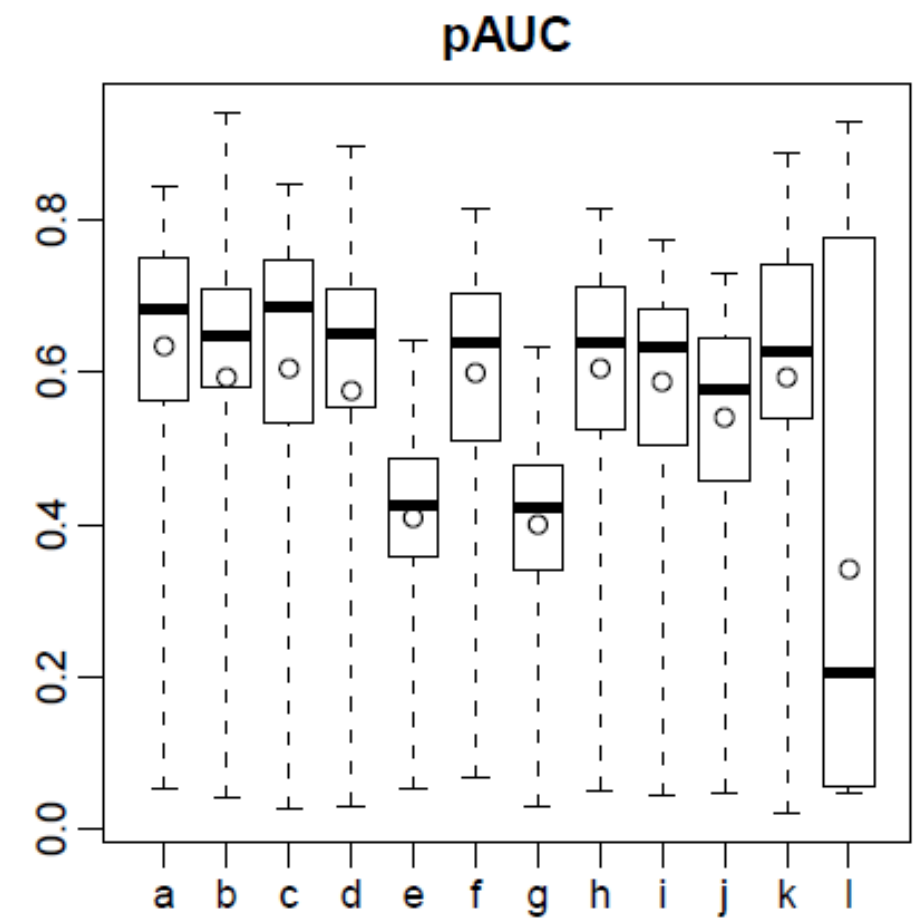

Figure 31: "Relative importance" of each of the climatic variables incorporated into the weighted multimodel (please see Table 1 and text for details) with regards to Eublepharis macularius

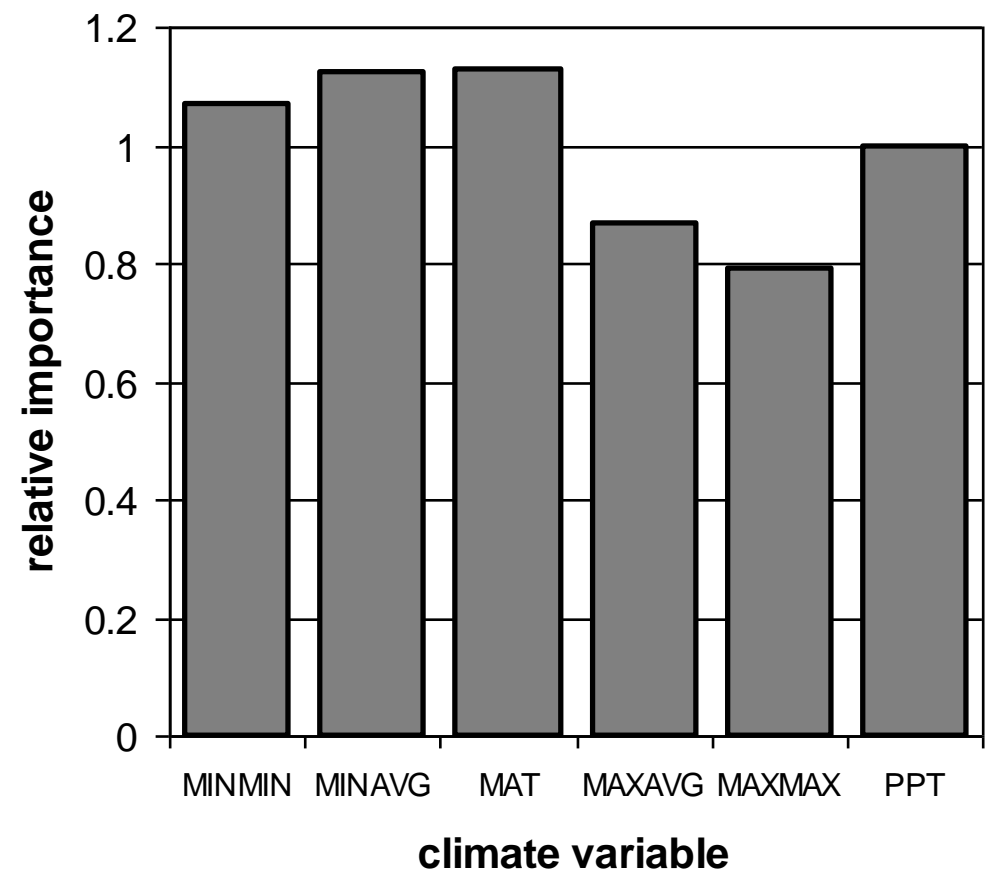


In addition to the native range of leopard geckos, areas with a high climatic suitability (0.5 or greater) included northern Africa, Spain, the Middle East (Syria, Iraq, Jordan), southern Africa, south-eastern China, and inland Australia (Figure 32b). The degree of overlap between the climatic suitability of the investigated occupied gridcells and the available sites in New Zealand can be found in Figure 32c. Based on the multimodel average, E. macularius received a New Zealand suitability score of 0.17 (Table 8). Within New Zealand, the best climate matches (suitability $\geq 0.1$ ) were found in the inland areas of Canterbury and Otago (Figure 32d). 
Figure 32: Climate envelope and predicted suitability for the leopard gecko (Eublepharis macularius). Details as described in Figure 14.

(a) PPT $<300 \mathrm{~mm} / \mathrm{yr}$

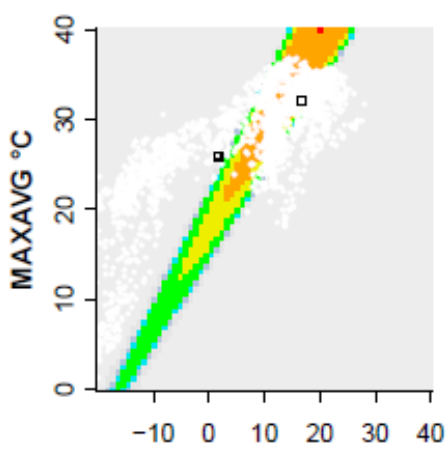

(b)

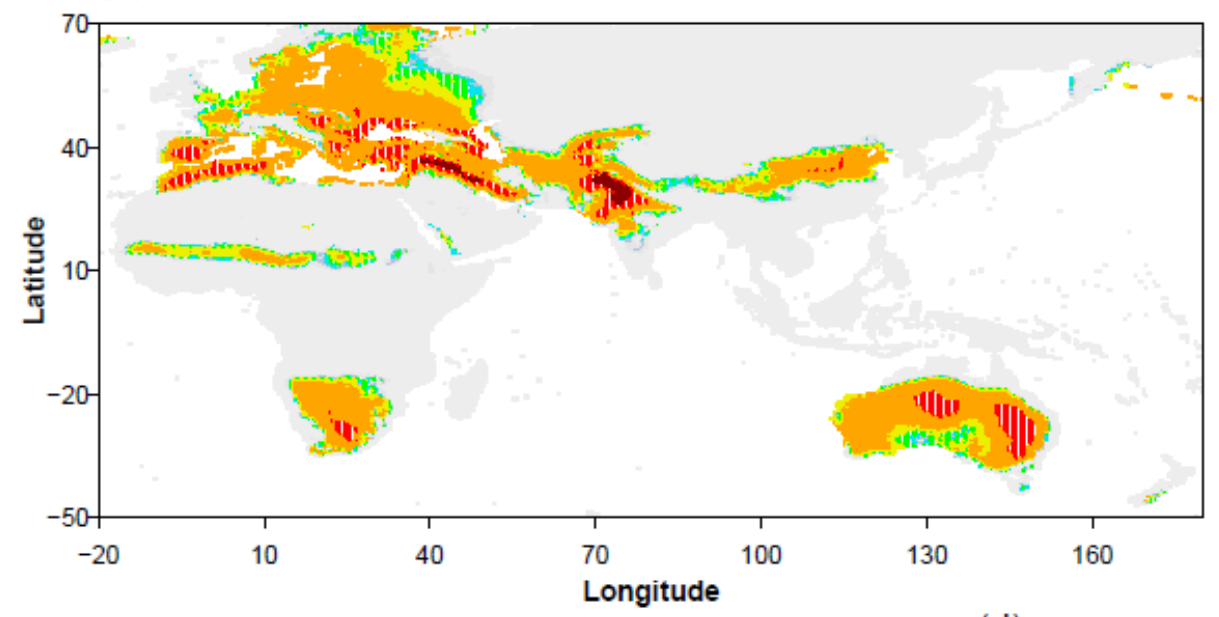

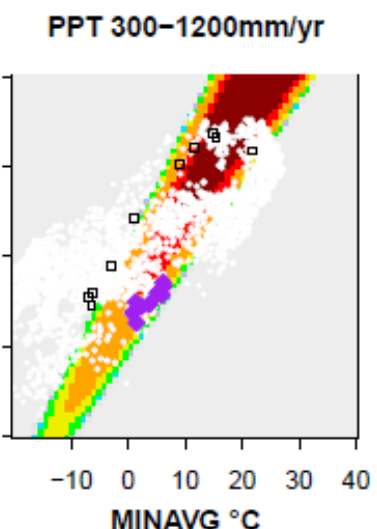

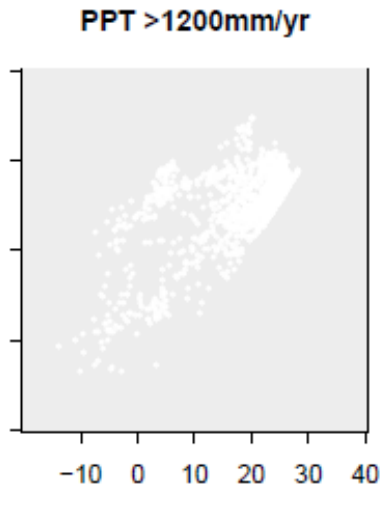

(c)

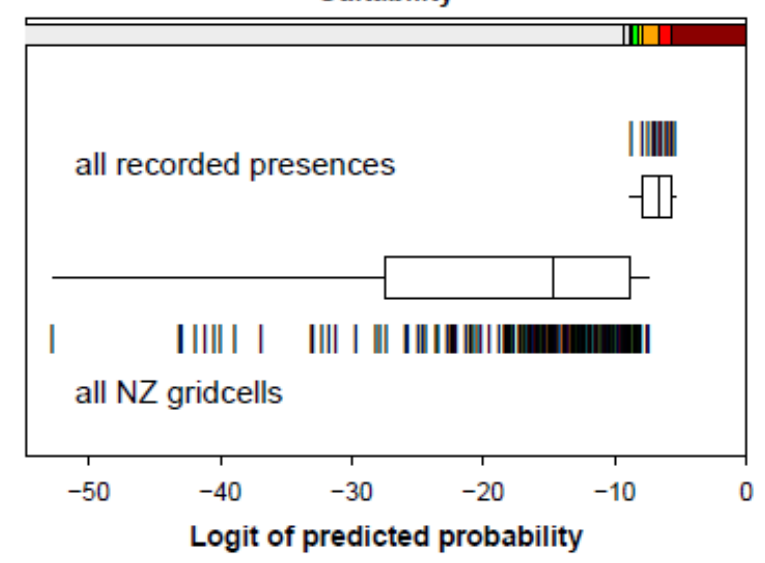

(d)

ํํำ

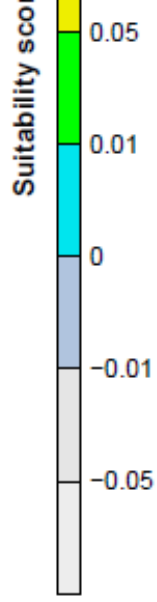

(e)
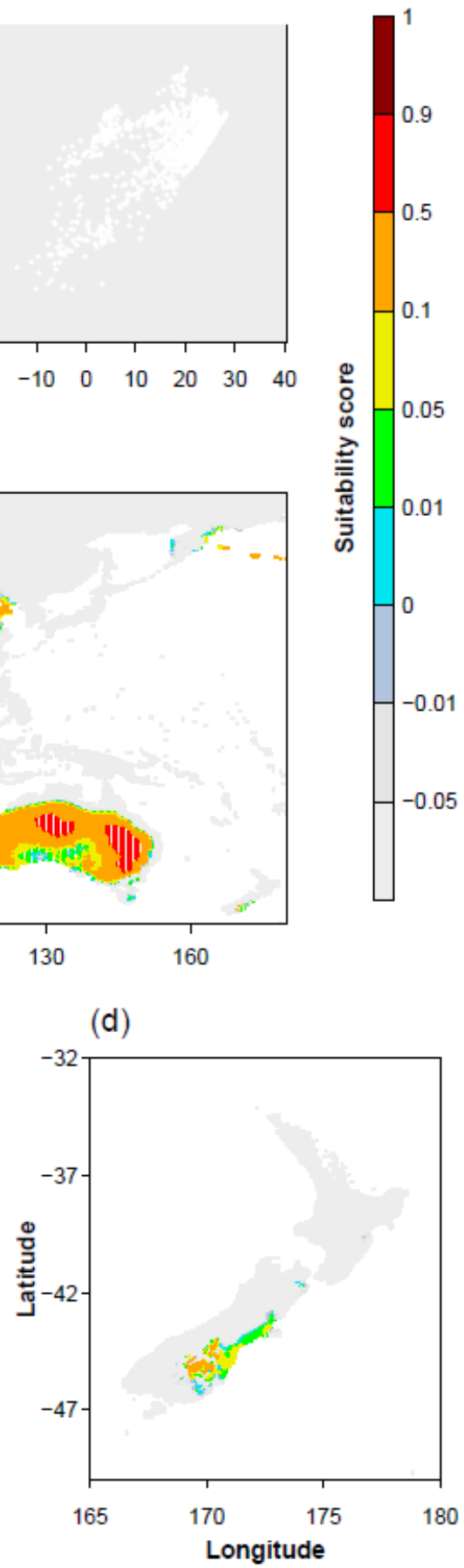


\section{Waterdragon (Physignathus lesueurii)}

Based on pAUC values of the test data jackknife partitions, model "d" (pAUC $=0.81$ and a weighting of 0.16 ) followed closely by models " $b$ " and "c", had the best predictive ability for waterdragons (Physignathus lesueurii) (Table 9). A boxplot visualisation of relative pAUC values for all models for waterdragons can be found in Figure 33. Summer maximum temperatures, followed by winter minimum temperatures, were the climatic variables with the highest "relative importance" for waterdragons (Figure 34).

Table 9: Comparison of models from Table 1 for waterdragons (Physignathus lesueurii). Please see Table 2 for further details.

\begin{tabular}{|c|c|c|c|c|c|c|}
\hline \multirow[b]{2}{*}{ Model } & \multicolumn{3}{|c|}{ Cross-validation $^{\mathrm{a}}$} & \multicolumn{3}{|c|}{ Final fit $^{\mathrm{b}}$} \\
\hline & $\mathbf{A U C}$ & pAUC & $\begin{array}{c}\text { Model } \\
\text { weight }^{\mathrm{c}}\end{array}$ & $\mathbf{A U C}$ & pAUC & $\begin{array}{c}\text { NZ } \\
\text { suitability } \\
\text { score }^{d}\end{array}$ \\
\hline $\mathrm{a}$ & 0.922 & 0.759 & 0.063 & 0.960 & 0.836 & 0.561 \\
\hline $\mathrm{b}$ & 0.949 & 0.806 & 0.148 & 0.971 & 0.904 & 0.201 \\
\hline c & 0.936 & 0.804 & 0.146 & 0.966 & 0.873 & 0.491 \\
\hline $\mathrm{d}$ & 0.951 & 0.814 & 0.162 & 0.971 & 0.868 & 0.275 \\
\hline e & 0.917 & 0.763 & 0.071 & 0.955 & 0.866 & 0.727 \\
\hline $\mathrm{f}$ & 0.911 & 0.751 & 0.048 & 0.947 & 0.845 & 0.952 \\
\hline $\mathrm{g}$ & 0.931 & 0.795 & 0.128 & 0.960 & 0.852 & 0.277 \\
\hline h & 0.906 & 0.724 & 0 & 0.942 & 0.799 & 0.984 \\
\hline $\mathrm{i}$ & 0.887 & 0.702 & 0 & 0.939 & 0.827 & 0.871 \\
\hline $\mathrm{j}$ & 0.910 & 0.754 & 0.053 & 0.951 & 0.862 & 0.887 \\
\hline $\mathrm{k}$ & 0.932 & 0.793 & 0.125 & 0.967 & 0.887 & 0.278 \\
\hline 1 & 0.932 & 0.755 & 0.056 & 0.976 & 0.907 & 0.217 \\
\hline $\begin{array}{l}\text { Weighted } \\
\text { multi- } \\
\text { model } \\
\text { average }\end{array}$ & NA & NA & NA & 0.971 & 0.895 & $\begin{array}{c}0.263 \\
(\mathbf{0 . 2 0 1}- \\
\mathbf{0 . 8 8 7})\end{array}$ \\
\hline
\end{tabular}


Figure 33 Relative pAUC values based on cross-validation results for each of the 12 models (see Table 9) applied to waterdragons (Physignathus lesueurii). Please see Figure 12 for further details.

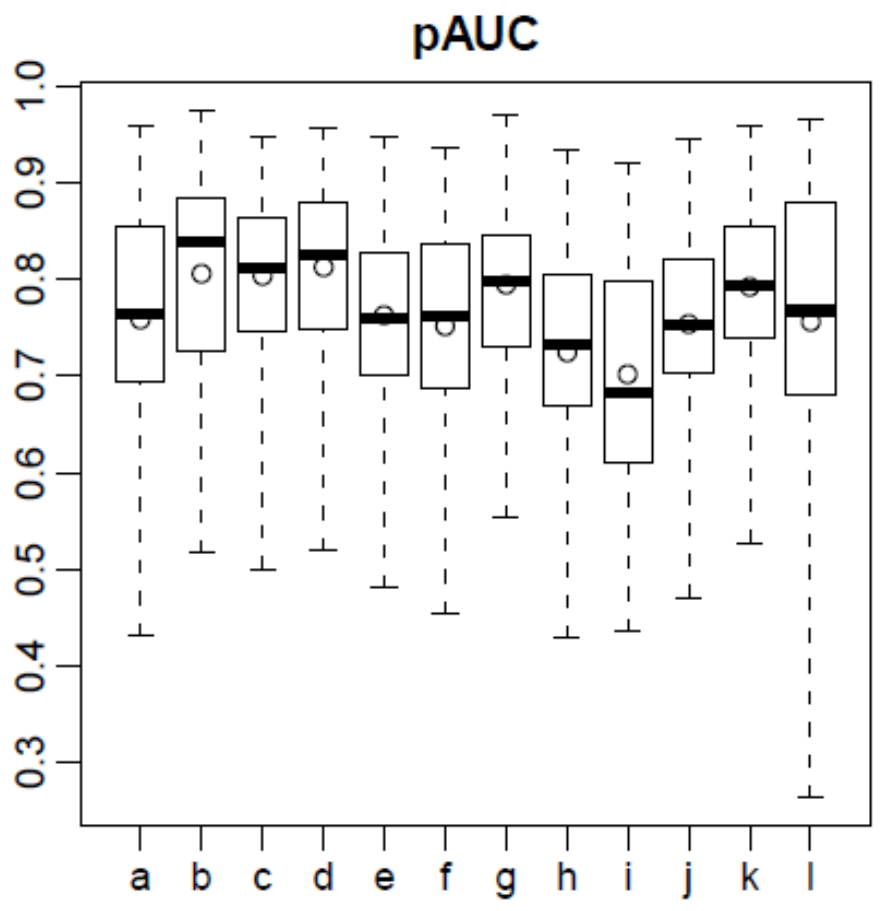

Figure 34: "Relative importance" of each of the climatic variables incorporated into the weighted multimodel (please see Table 1 and text for details) with regards to Physignathus lesueurii.

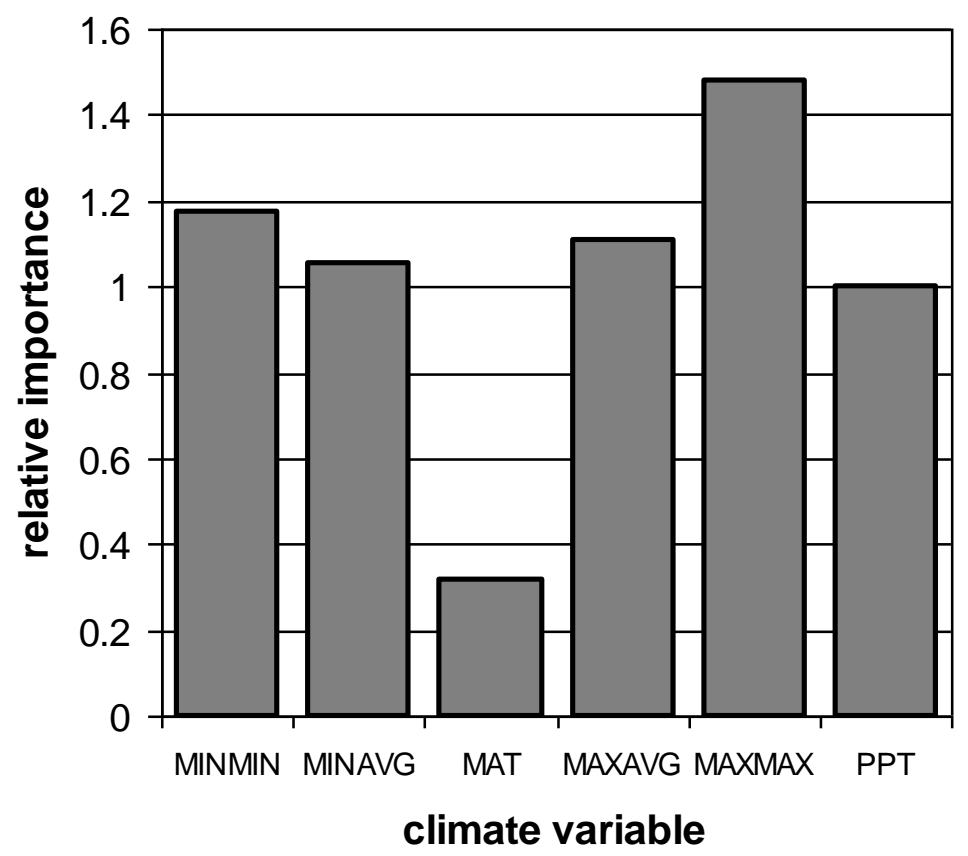


Outside of its native range, areas with the highest degree of climate match (suitability $\geq 0.1$ ) for Physignathus lesueurii included the south-western coast of Australia, along with New Caledonia and surrounding islands (Figure 35b). The degree of overlap between the occupied gridcells incorporated into the model and the available gridcells in New Zealand can be seen in Figure 35c. Waterdragons received a New Zealand suitability score of 0.26 based on the multimodel average (Table 9). The best climate matches in New Zealand (suitability $\geq 0.1$ ) were found in the northern portion of the North Island, and along the coastal areas of the Bay of Plenty, Gisborne, and Hawkes Bay (Figure 35d). 
Figure 35: Climate envelope and predicted suitability for the waterdragon (Physignathus lesueurii). Details as described in Figure 14.

(a) PPT $<300 \mathrm{~mm} / \mathrm{yr}$

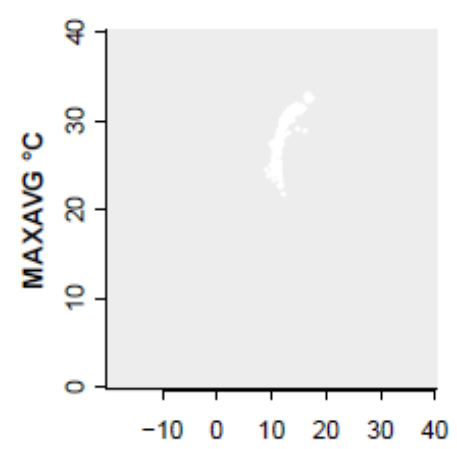

(b)
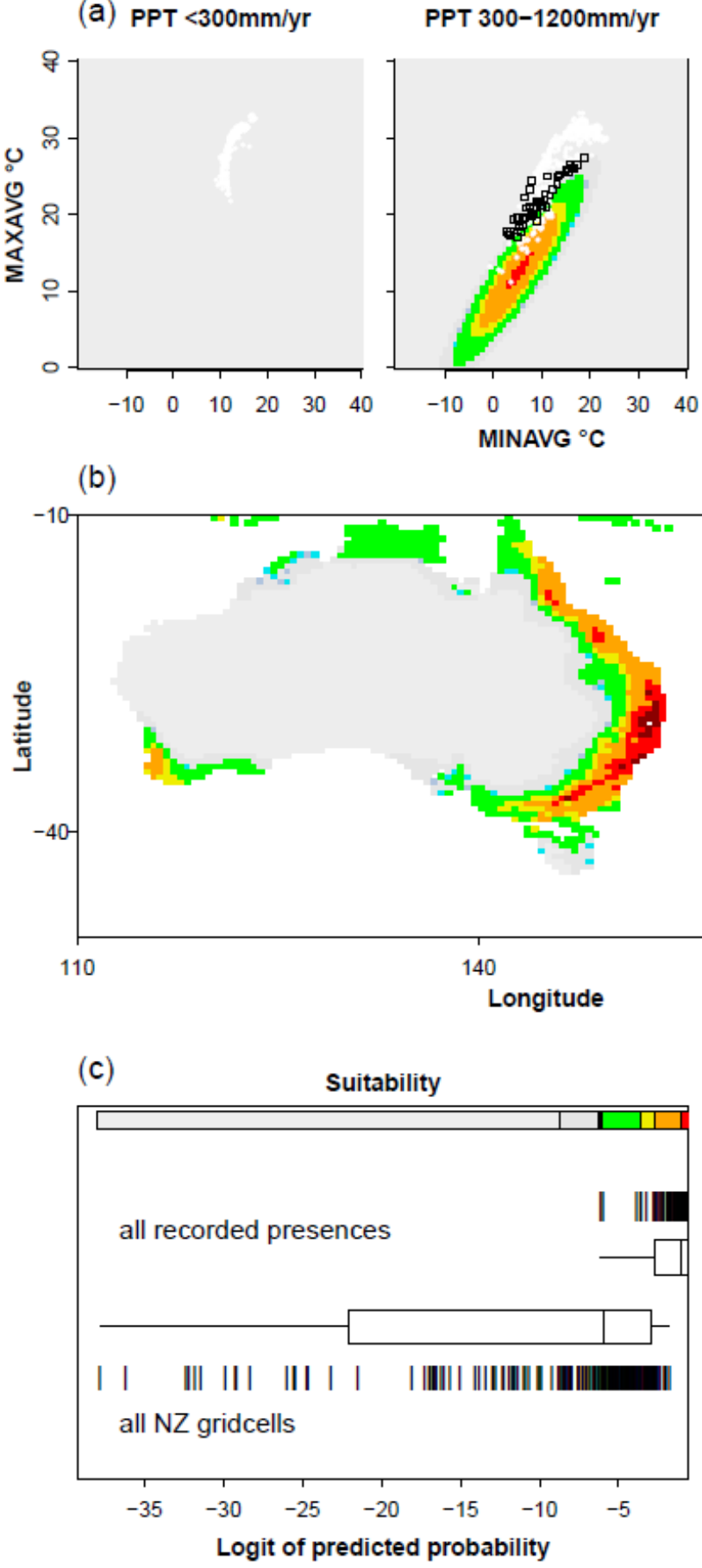

(e)

PPT $>1200 \mathrm{~mm} / \mathrm{yr}$

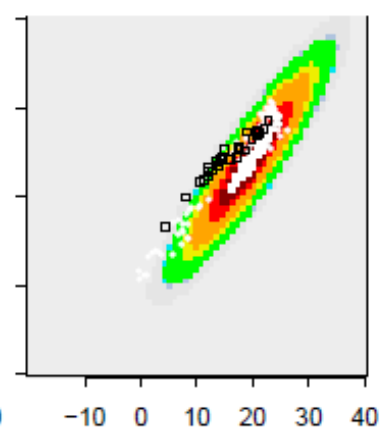

总 -0.05

क 0.01

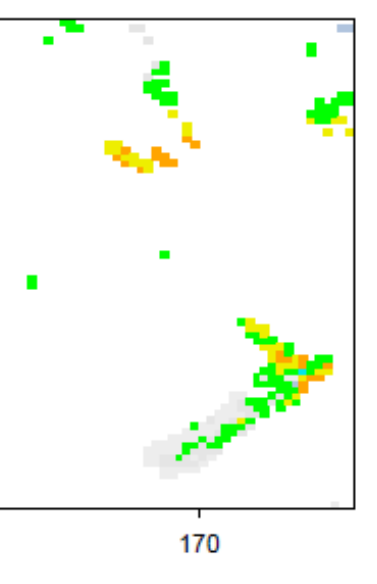

(d)

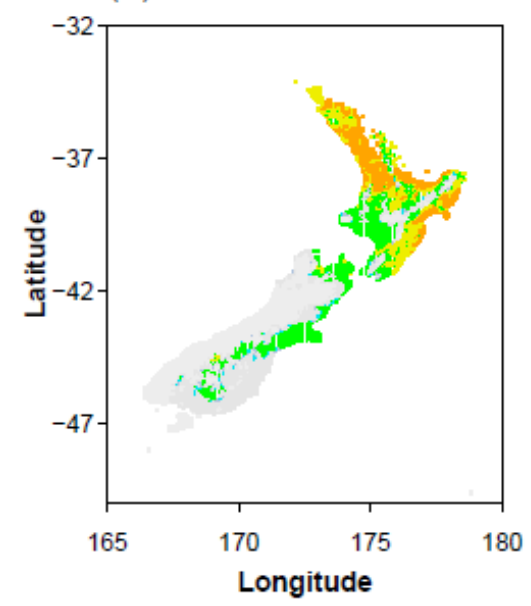




\section{Blue-tongue lizards (Tiliqua spp.)}

For the common blue-tongue skink (Tiliqua scincoides), the best performing model was model "g" (mean pAUC = 0.315), followed closely by models "a", "c", and "e", which all received similar model weightings $(\sim 0.14)$ (Table 10). Model "i" was the best performing model for blotched blue-tongue skinks (T. nigrolutea), with a mean pAUC score of 0.88 , followed closely by models "a", "g" and "j". All four models received a weighting of 0.13 (Table 11). For shingleback skinks (T. rugosa), model " $\mathrm{k}$ " was the best performing model, with a pAUC score of 0.61 and a model weighting of 0.15 , followed closely by model "g" (Table 12). Boxplot visualisations of relative pAUC values for the three Tiliqua species can be found in Figures 36, 38, and 40, respectively. For $T$. scincoides, the climatic variables with the highest "relative importance" were summer temperatures. Mean annual temperature was the climatic variable with the highest "relative importance" for $T$. nigrolutea, while mean annual temperature and summer maximum temperatures were most important for $T$. rugosa (Figures 37, 39, and 41, respectively). 
Table 10: Comparison of models from Table 1 for common blue-tongue skinks (Tiliqua scincoides). Please see Table 2 for further details.

\begin{tabular}{|c|c|c|c|c|c|c|}
\hline \multirow[b]{2}{*}{ Model } & \multicolumn{3}{|c|}{ Cross-validation $^{\text {a }}$} & \multicolumn{3}{|c|}{ Final fit $^{b}$} \\
\hline & $\mathbf{A U C}$ & pAUC & $\begin{array}{c}\text { Model } \\
\text { weight }^{\mathrm{c}}\end{array}$ & $\mathbf{A U C}$ & pAUC & $\begin{array}{c}\text { NZ } \\
\text { suitability } \\
\text { score }^{\text {d }}\end{array}$ \\
\hline $\mathrm{a}$ & 0.733 & 0.312 & 0.138 & 0.779 & 0.385 & 0.413 \\
\hline b & 0.716 & 0.298 & 0.107 & 0.780 & 0.366 & 0.464 \\
\hline $\mathrm{c}$ & 0.729 & 0.311 & 0.135 & 0.772 & 0.315 & 0.456 \\
\hline d & 0.721 & 0.308 & 0.129 & 0.777 & 0.304 & 0.583 \\
\hline $\mathrm{e}$ & 0.717 & 0.311 & 0.135 & 0.762 & 0.345 & 0.708 \\
\hline$f$ & 0.709 & 0.277 & 0.062 & 0.748 & 0.297 & 1 \\
\hline $\mathrm{g}$ & 0.728 & 0.315 & 0.143 & 0.767 & 0.289 & 0.388 \\
\hline h & 0.691 & 0.253 & 0.009 & 0.735 & 0.260 & 1 \\
\hline $\mathrm{i}$ & 0.689 & 0.249 & 0 & 0.732 & 0.273 & 0.927 \\
\hline $\mathrm{j}$ & 0.717 & 0.287 & 0.083 & 0.758 & 0.355 & 0.691 \\
\hline $\mathrm{k}$ & 0.715 & 0.276 & 0.059 & 0.785 & 0.293 & 0.650 \\
\hline 1 & 0.686 & 0.207 & 0 & 0.802 & 0.307 & 0.999 \\
\hline $\begin{array}{l}\text { Weighted } \\
\text { multi- } \\
\text { model } \\
\text { average }\end{array}$ & NA & NA & NA & 0.775 & 0.341 & $\begin{array}{c}0.392 \\
(0.388-1)\end{array}$ \\
\hline
\end{tabular}


Figure 36 Relative pAUC values based on cross-validation results for each of the 12 models (see Table 10) applied to common blue-tongue skinks (Tiliqua scincoides). Please see Figure 12 for further details.

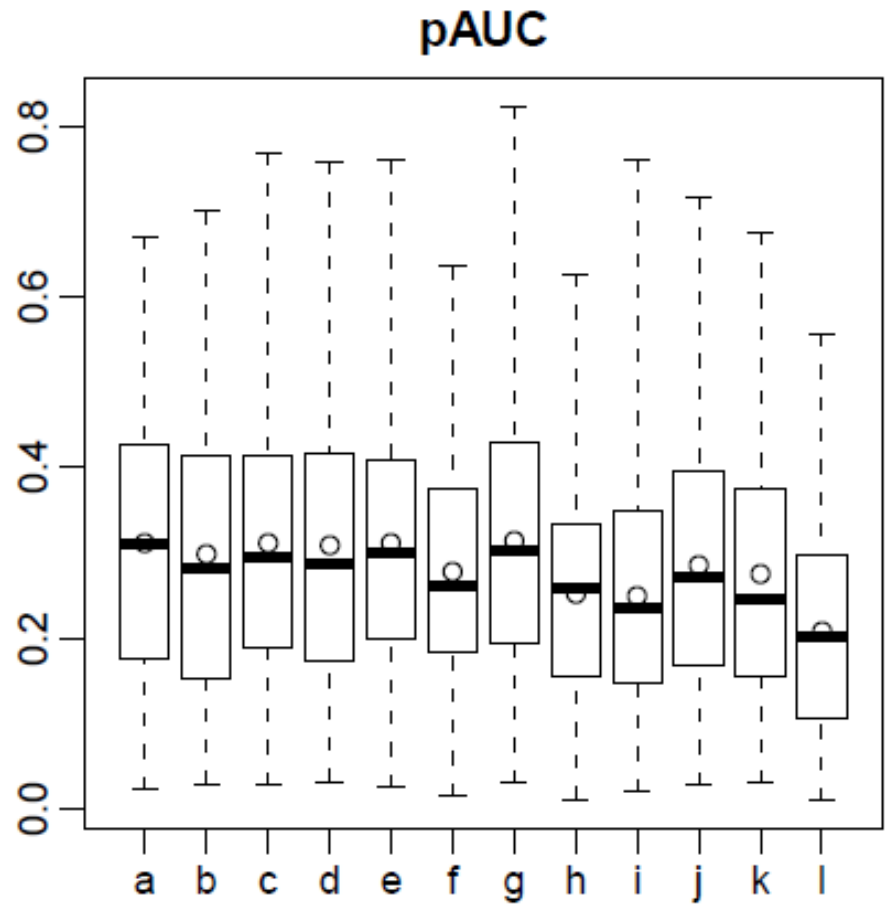

Figure 37: "Relative importance" of each of the climatic variables incorporated into the weighted multimodel (please see Table 1 and text for details) with regards to Tiliqua scincoides.

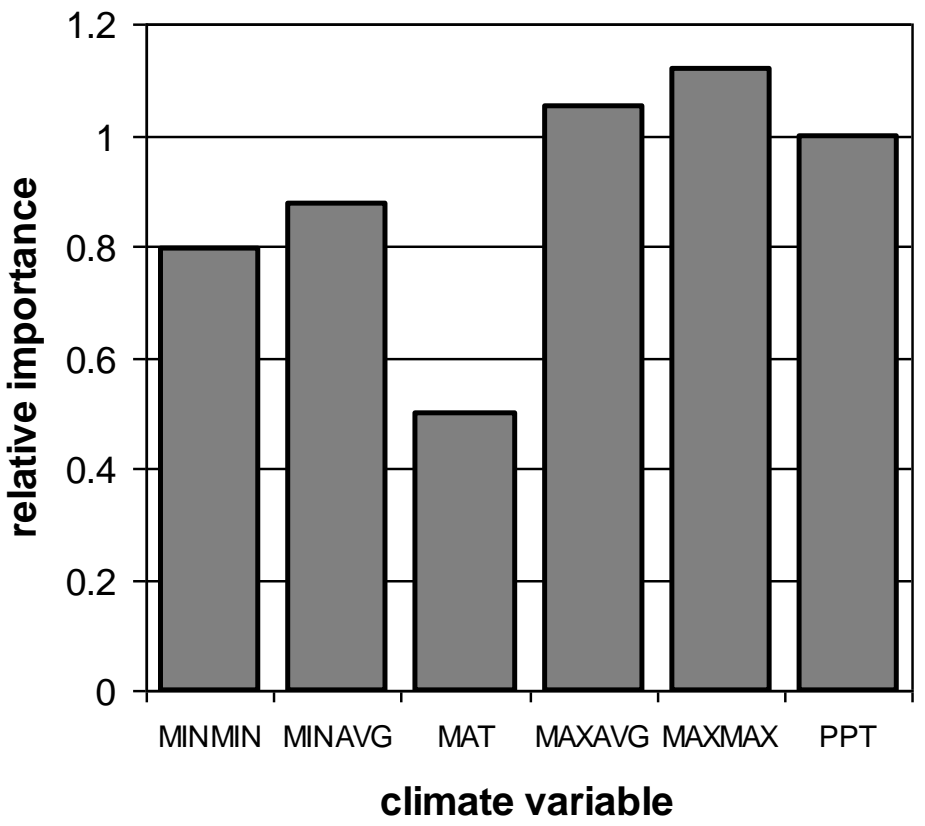


Table 11: Comparison of models from Table 1 for blotched blue-tongue skinks (Tiliqua nigrolutea). Please see Table 2 for further details.

\begin{tabular}{|c|c|c|c|c|c|c|}
\hline \multirow[b]{2}{*}{ Model } & \multicolumn{3}{|c|}{ Cross-validation $^{\mathrm{a}}$} & \multicolumn{3}{|c|}{ Final fit' } \\
\hline & $\mathbf{A U C}$ & pAUC & $\begin{array}{l}\text { Model } \\
\text { weight }^{\mathrm{c}}\end{array}$ & $\mathbf{A U C}$ & pAUC & $\begin{array}{c}\text { NZ } \\
\text { suitability } \\
\text { score }^{\text {d }} \\
\end{array}$ \\
\hline $\mathrm{a}$ & 0.942 & 0.878 & 0.133 & 0.970 & 0.938 & 1 \\
\hline b & 0.887 & 0.753 & 0.018 & 0.971 & 0.943 & 1 \\
\hline $\mathrm{c}$ & 0.938 & 0.837 & 0.096 & 0.968 & 0.919 & 0.994 \\
\hline d & 0.880 & 0.734 & 0 & 0.970 & 0.933 & 0.960 \\
\hline $\mathrm{e}$ & 0.919 & 0.841 & 0.099 & 0.968 & 0.935 & 0.982 \\
\hline $\mathrm{f}$ & 0.930 & 0.850 & 0.108 & 0.959 & 0.909 & 1 \\
\hline $\mathrm{g}$ & 0.940 & 0.876 & 0.132 & 0.966 & 0.922 & 0.977 \\
\hline h & 0.915 & 0.798 & 0.059 & 0.944 & 0.866 & 1 \\
\hline $\mathrm{i}$ & 0.943 & 0.878 & 0.134 & 0.968 & 0.937 & 1 \\
\hline $\mathrm{j}$ & 0.940 & 0.876 & 0.132 & 0.968 & 0.941 & 1 \\
\hline $\mathrm{k}$ & 0.933 & 0.831 & 0.090 & 0.977 & 0.943 & 0.483 \\
\hline 1 & 0.753 & 0.380 & 0 & 0.984 & 0.958 & 1 \\
\hline $\begin{array}{l}\text { Weighted } \\
\text { multi- } \\
\text { model } \\
\text { average }\end{array}$ & NA & NA & NA & 0.971 & 0.934 & $\begin{array}{c}0.991 \\
(0.483-1)\end{array}$ \\
\hline
\end{tabular}


Figure 38: Relative pAUC values based on cross-validation results for each of the 12 models (see Table 11) applied to blotched blue-tongue skinks (Tiliqua nigrolutea). Please see Figure 12 for further details.

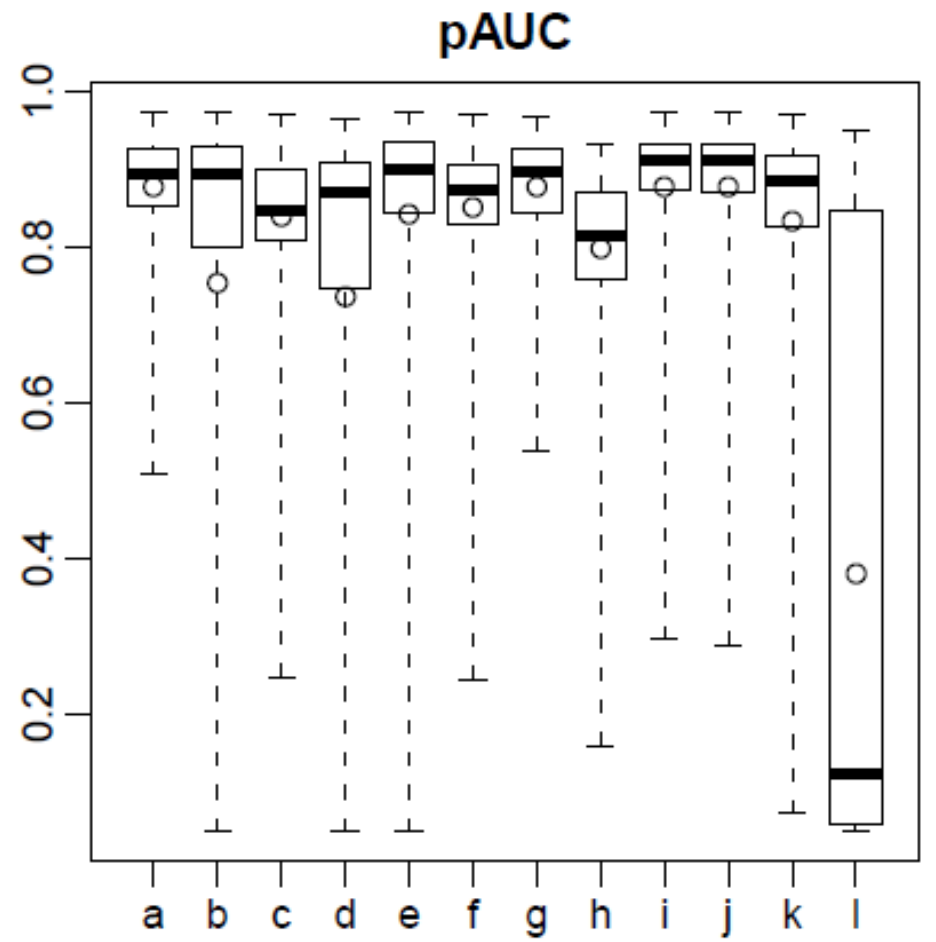

Figure 39: "Relative importance" of each of the climatic variables incorporated into the weighted multimodel (please see Table 1 and text for details) with regards to Tiliqua nigrolutea.

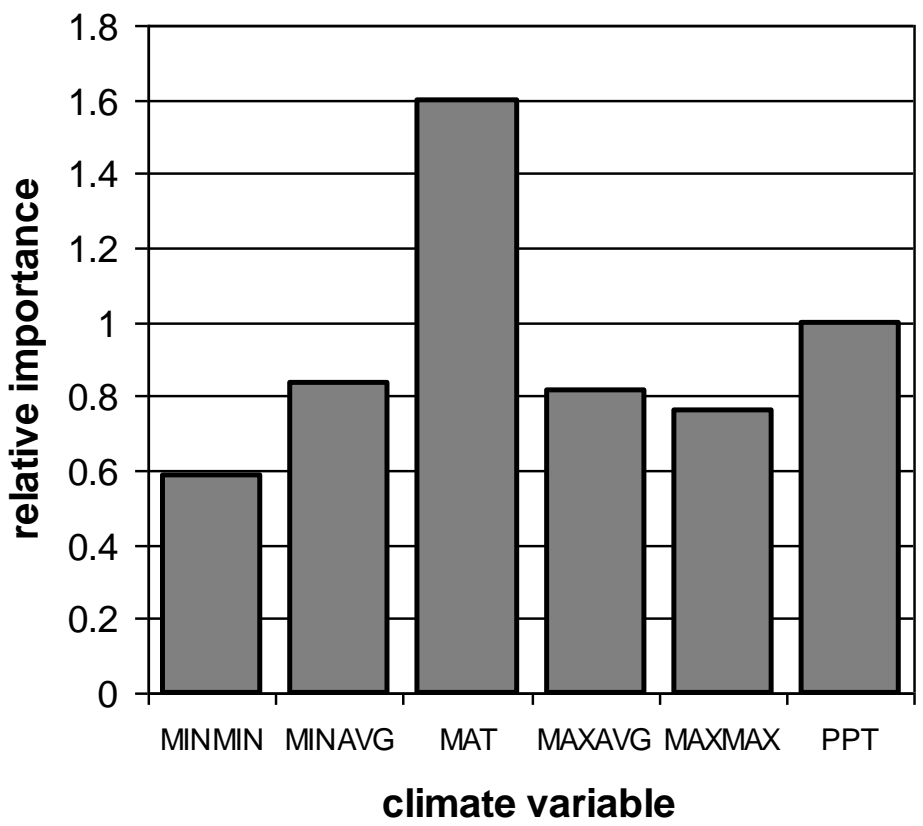


Table 12: Comparison of models from Table 1 for shingleback skinks (Tiliqua rugosa). Please see Table 2 for further details.

\begin{tabular}{|c|c|c|c|c|c|c|}
\hline \multirow[b]{2}{*}{ Model } & \multicolumn{3}{|c|}{ Cross-validation $^{\text {a }}$} & \multicolumn{3}{|c|}{ Final fit $^{\mathrm{b}}$} \\
\hline & AUC & pAUC & $\begin{array}{c}\text { Model } \\
\text { weight }^{\mathrm{c}}\end{array}$ & $\mathbf{A U C}$ & pAUC & $\begin{array}{c}\text { NZ } \\
\text { suitability }_{\text {dy }} \\
\text { score }^{\text {d }}\end{array}$ \\
\hline $\mathrm{a}$ & 0.836 & 0.538 & 0.063 & 0.874 & 0.661 & 0.272 \\
\hline b & 0.824 & 0.510 & 0.030 & 0.875 & 0.654 & 0.238 \\
\hline $\mathrm{c}$ & 0.855 & 0.557 & 0.087 & 0.889 & 0.640 & 0.057 \\
\hline d & 0.848 & 0.559 & 0.088 & 0.891 & 0.646 & 0.047 \\
\hline $\mathrm{e}$ & 0.835 & 0.581 & 0.116 & 0.869 & 0.664 & 0.402 \\
\hline $\mathrm{f}$ & 0.773 & 0.486 & 0 & 0.814 & 0.496 & 0.057 \\
\hline $\mathrm{g}$ & 0.855 & 0.602 & 0.141 & 0.884 & 0.662 & 0.306 \\
\hline $\mathrm{h}$ & 0.708 & 0.345 & 0 & 0.777 & 0.363 & 0.063 \\
\hline $\mathrm{i}$ & 0.825 & 0.584 & 0.120 & 0.859 & 0.587 & 0.297 \\
\hline $\mathrm{j}$ & 0.825 & 0.585 & 0.120 & 0.861 & 0.595 & 0.370 \\
\hline $\mathrm{k}$ & 0.868 & 0.611 & 0.153 & 0.906 & 0.699 & 0.001 \\
\hline 1 & 0.842 & 0.553 & 0.082 & 0.914 & 0.723 & 0.065 \\
\hline $\begin{array}{l}\text { Weighted } \\
\text { multi- } \\
\text { model } \\
\text { average }\end{array}$ & NA & NA & NA & 0.893 & 0.680 & $\begin{array}{c}\mathbf{0 . 0 7 6} \\
(\mathbf{0 . 0 0 1}- \\
\mathbf{0 . 4 0 2})\end{array}$ \\
\hline
\end{tabular}


Figure 40: Relative pAUC values based on cross-validation results for each of the 12 models (see Table 12) applied to shingleback skinks (Tiliqua rugosa). Please see Figure 12 for further details.

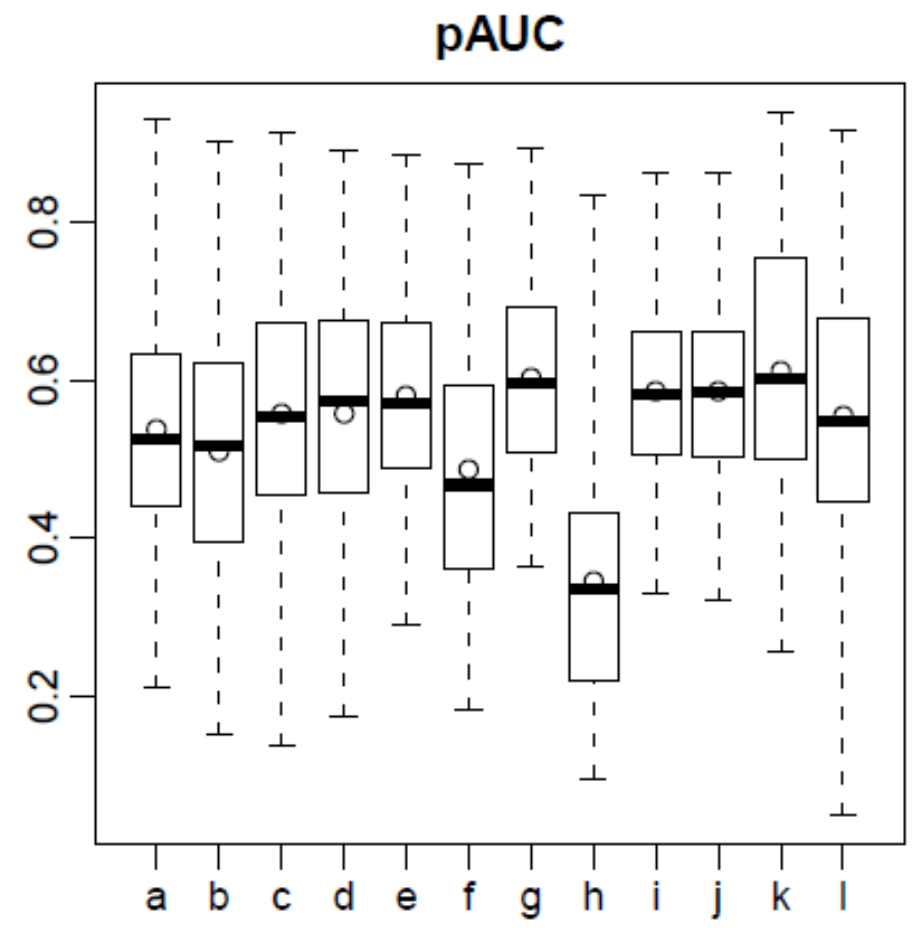

Figure 41: "Relative importance" of each of the climatic variables incorporated into the weighted multimodel (please see Table 1 and text for details) with regards to Tiliqua rugosa.

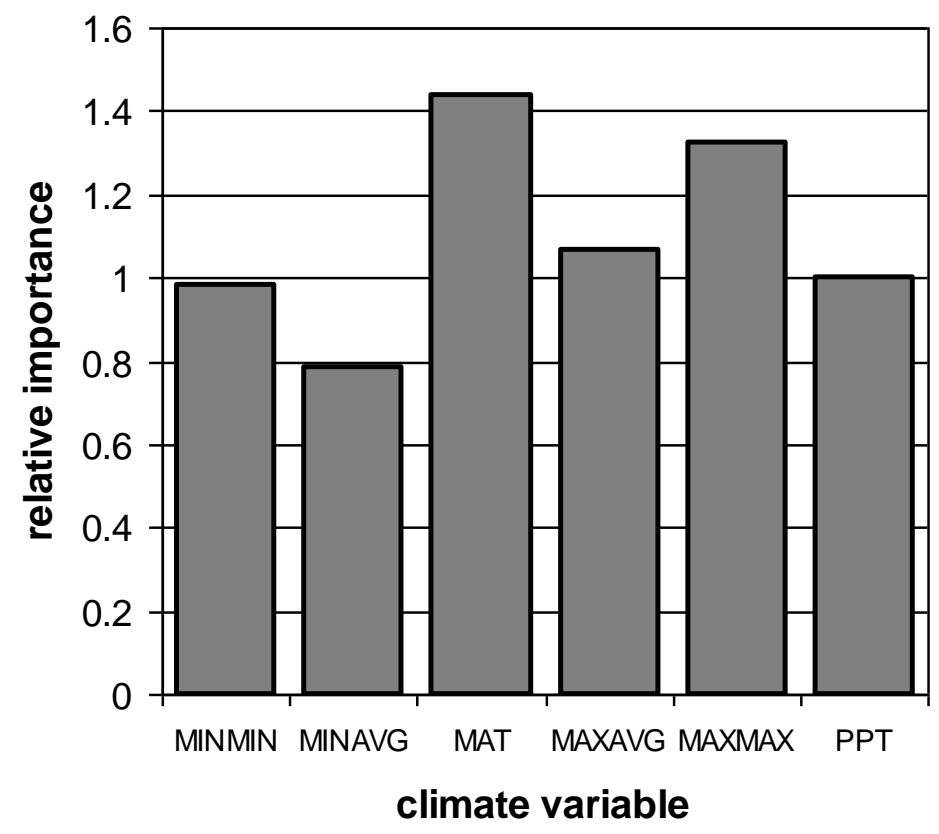


The native range of each Tiliqua species was identified as a high climate match (Figures 42b, 43b, and 44b). The degree of overlap between the occupied investigated gridcells and the available sites in New Zealand can be found in Figures 42c, 43c, and 44c. Tiliqua scincoides received a New Zealand suitability score of 0.39 based on the multimodel average, $T$. nigrolutea received a score of 0.99 , and $T$. rugosa received a score of 0.07 (Tables 10,11, and 12, respectively). When the weighted multimodel bioclimatic predictions were applied to higher resolution climate data of New Zealand, the most suitable areas for T. scincoides (suitability $\geq$ 0.1) were found throughout the country, with the exception of the central North Island, and the western and southern coasts and interior of the South Island (Figure 42d). A very high climate match for $T$. nigrolutea in New Zealand (suitability $\geq 0.9$ ) was predicted along the eastern coast of the South Island, from Blenheim to Timaru. Other areas of high climate match (suitability $\geq 0.5$ ) included sections of Otago and Southland, as well as parts of Manawatu and Hawkes Bay (Figure 43d). In comparison, few areas of suitable climate match were predicted for T. rugosa (suitability $\geq 0.01$ ). These were small pockets in coastal areas of the North Island (Northland and Hawkes Bay) and the South Island (Blenheim and Christchurch) (Figure 44d). 
Figure 42: Climate envelope and predicted suitability for the common blue-tongue skink (Tiliqua scincoides). Details as described in Figure 14.

(a) PPT $<300 \mathrm{~mm} / \mathrm{yr}$

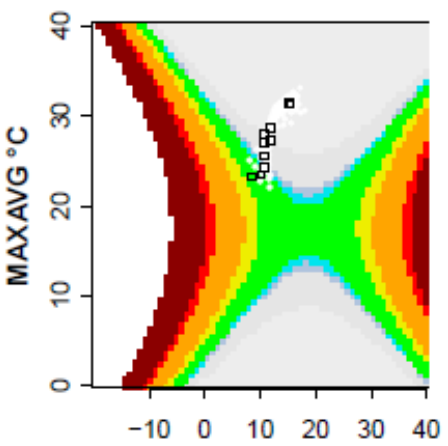

(b)

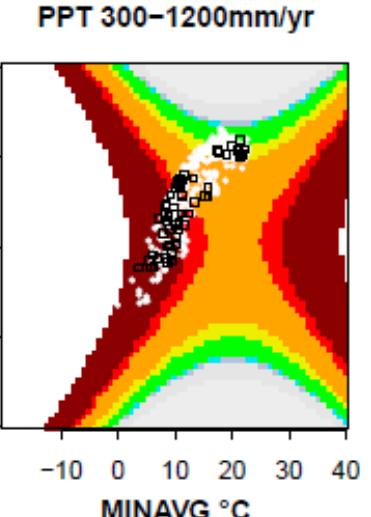

PPT $>1200 \mathrm{~mm} / \mathrm{yr}$
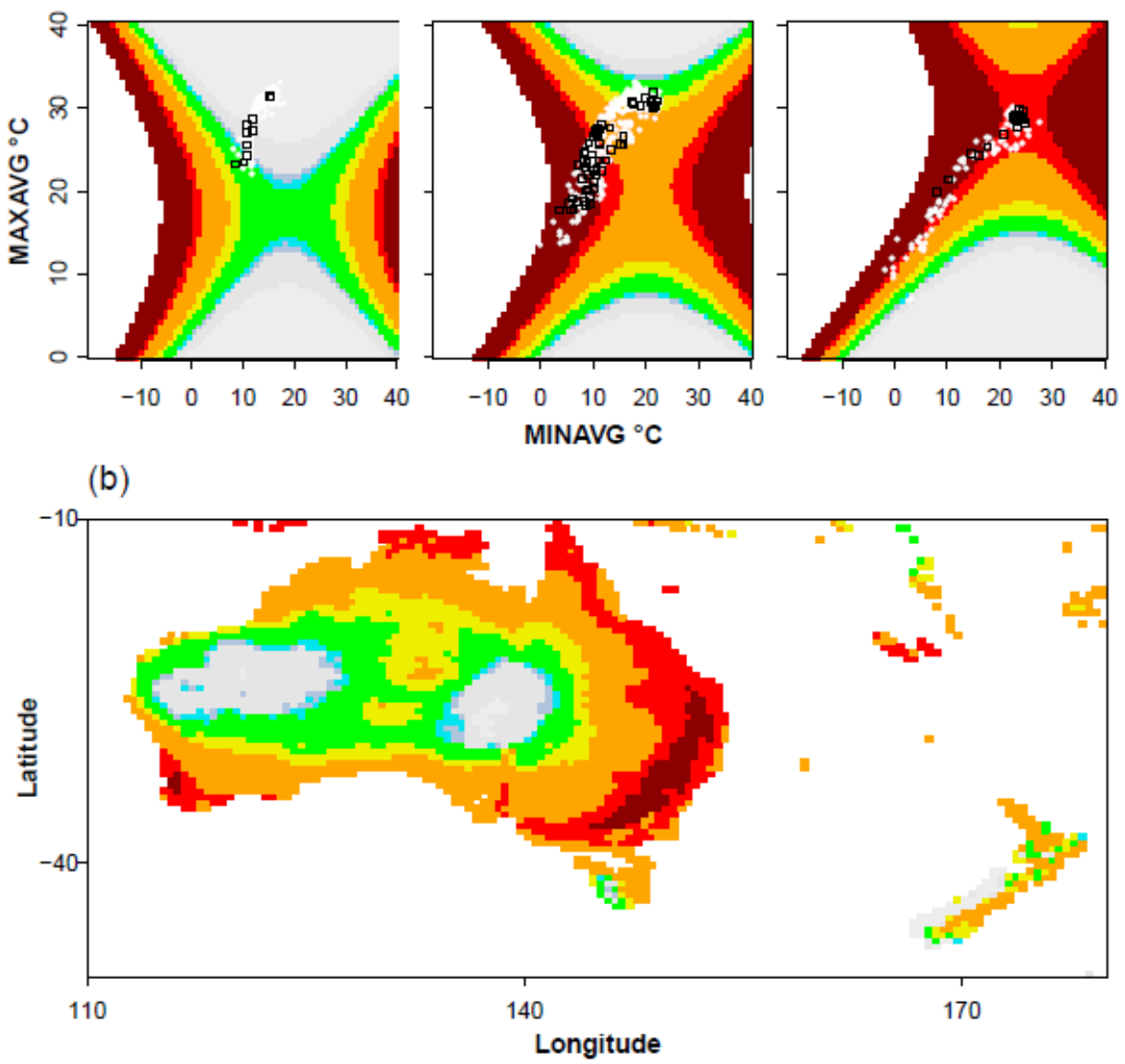

(d)
衣

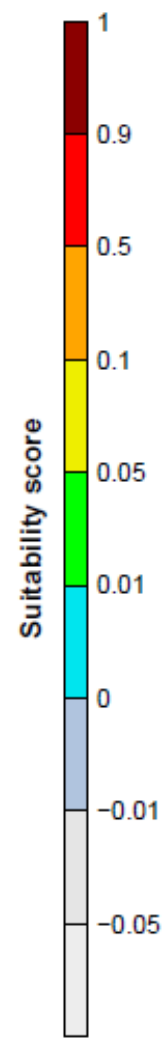

(e) (c)

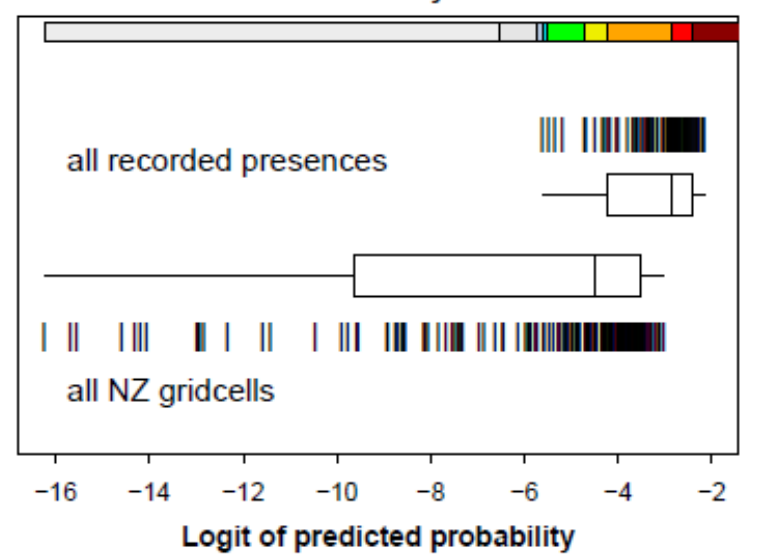

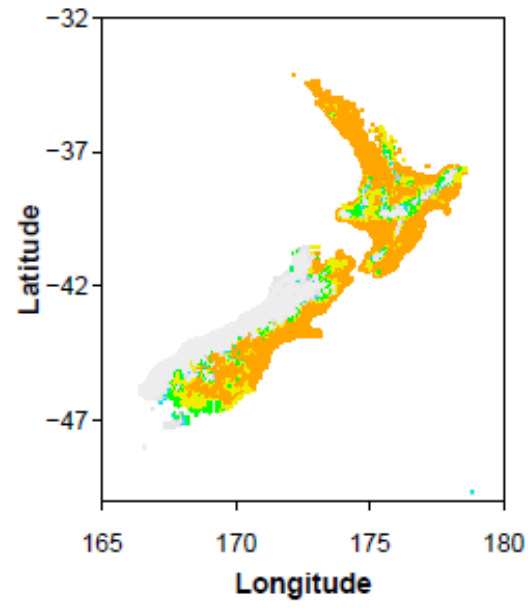


Figure 43: Climate envelope and predicted suitability for the blotched blue-tongue skink (Tiliqua nigrolutea). Details as described in Figure 14.

(a) $\mathrm{PPT}<300 \mathrm{~mm} / \mathrm{yr}$

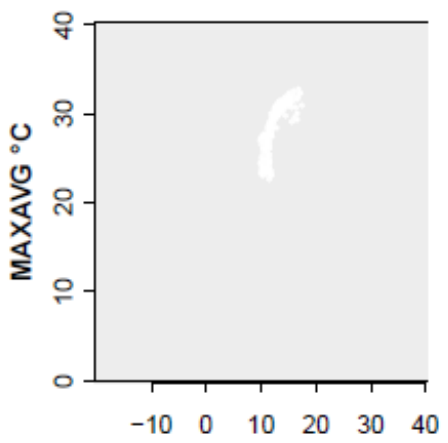

(b)

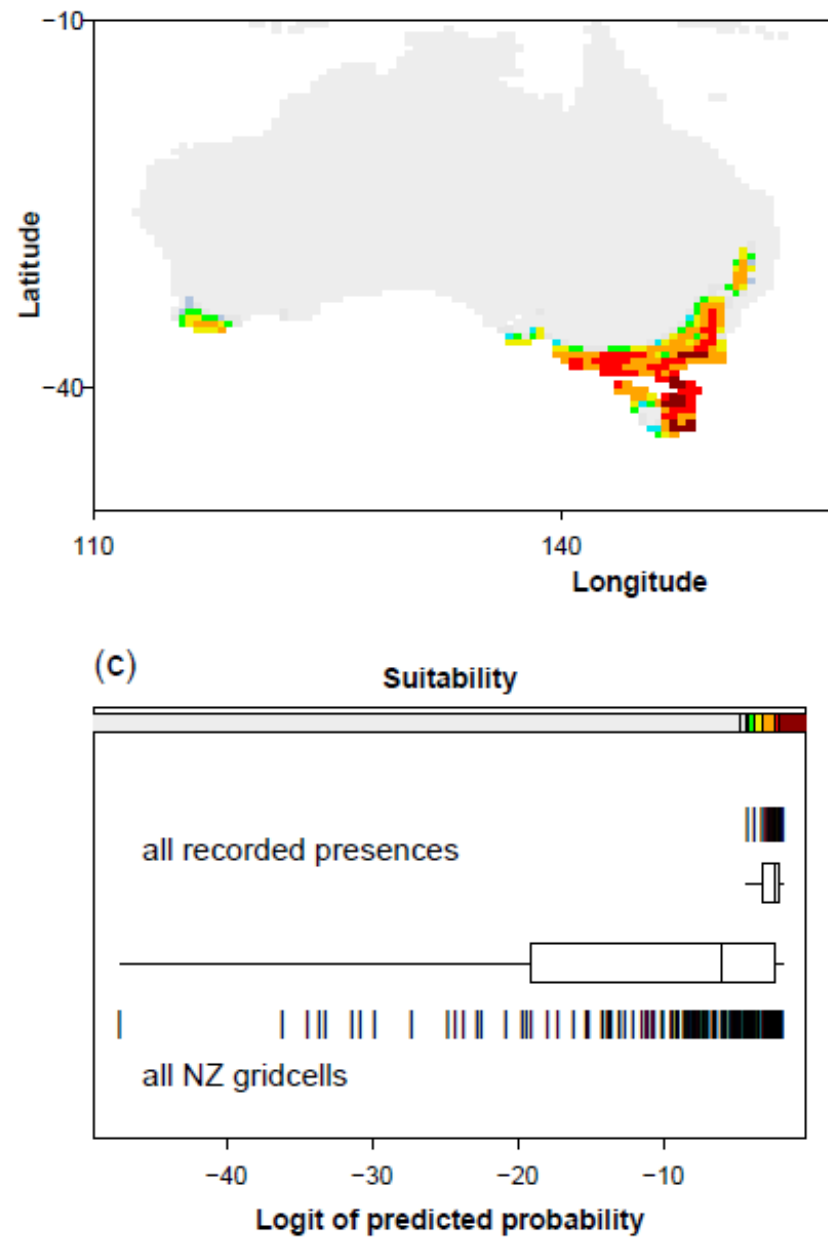

(e)

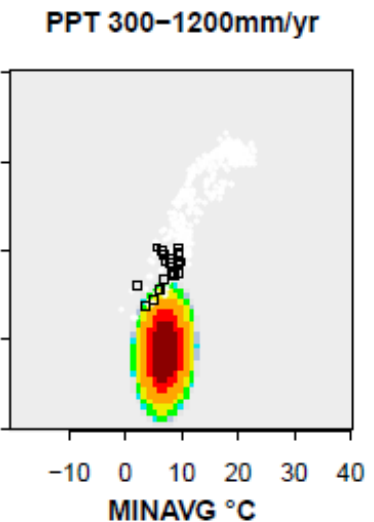

PPT $>1200 \mathrm{~mm} / \mathrm{yr}$

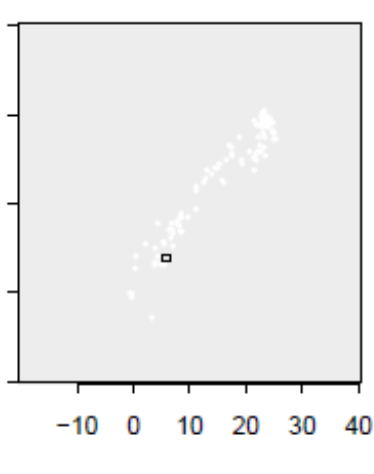

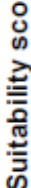

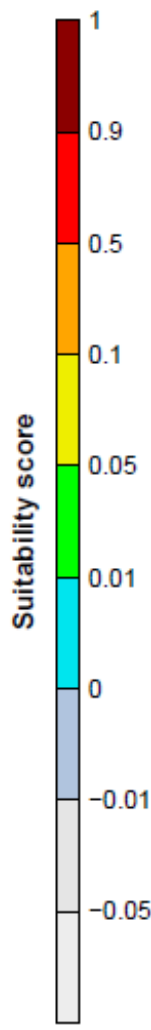

(d)

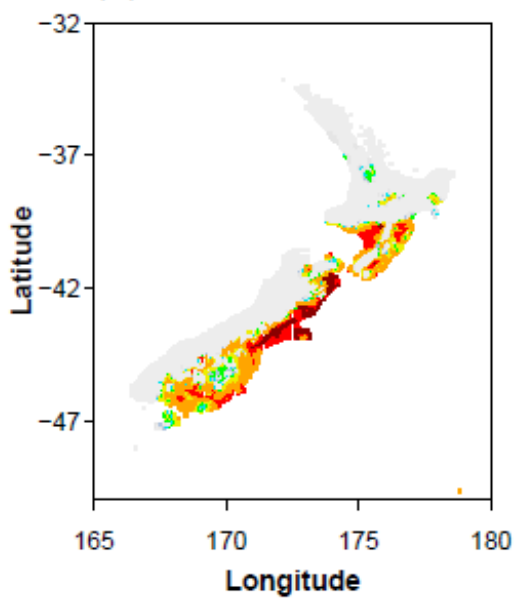


Figure 44: Climate envelope and predicted suitability for the shingleback skink (Tiliqua rugosa). Details as described in Figure 14.

(a) PPT $<300 \mathrm{~mm} / \mathrm{yr}$

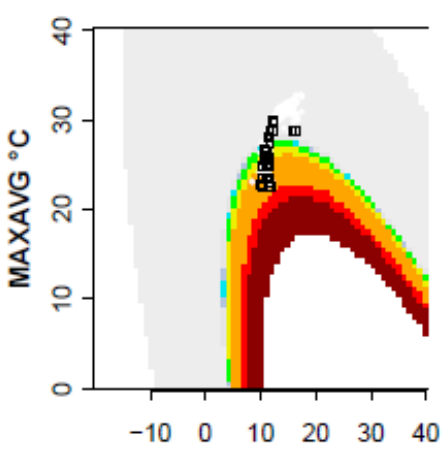

(b)

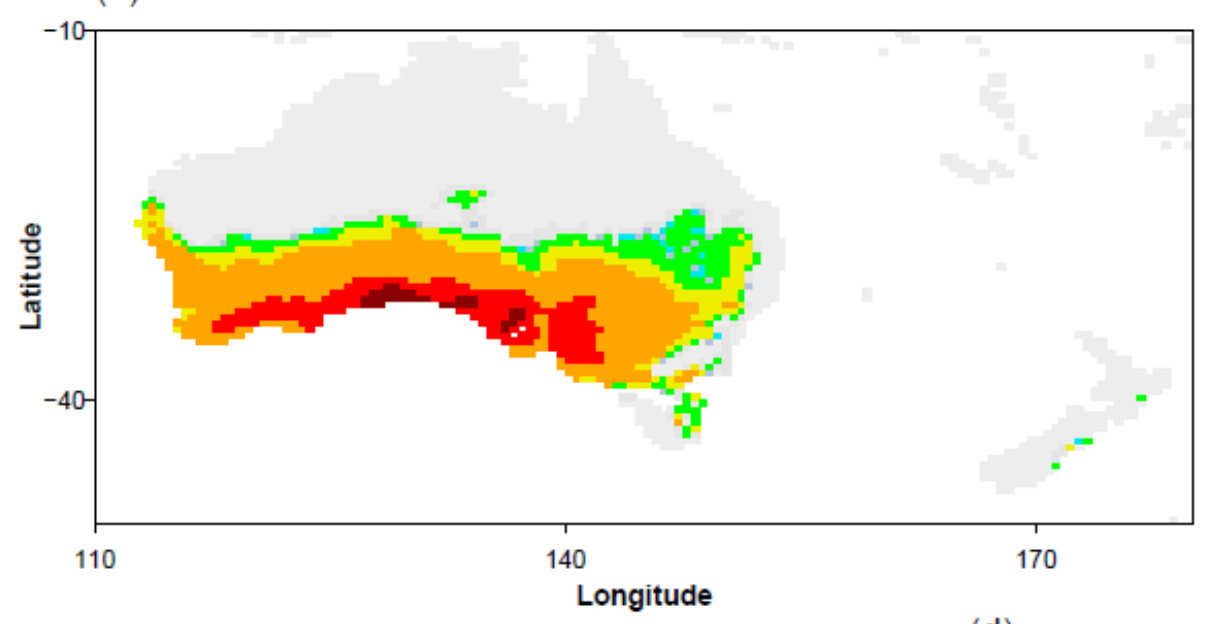

(d)
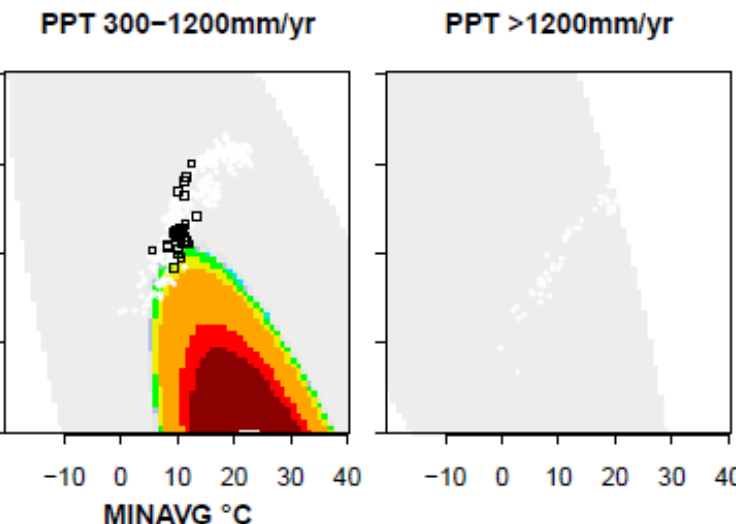

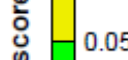

党 0.01 0 $-0.01$ $-0.05$ (c) Suitability
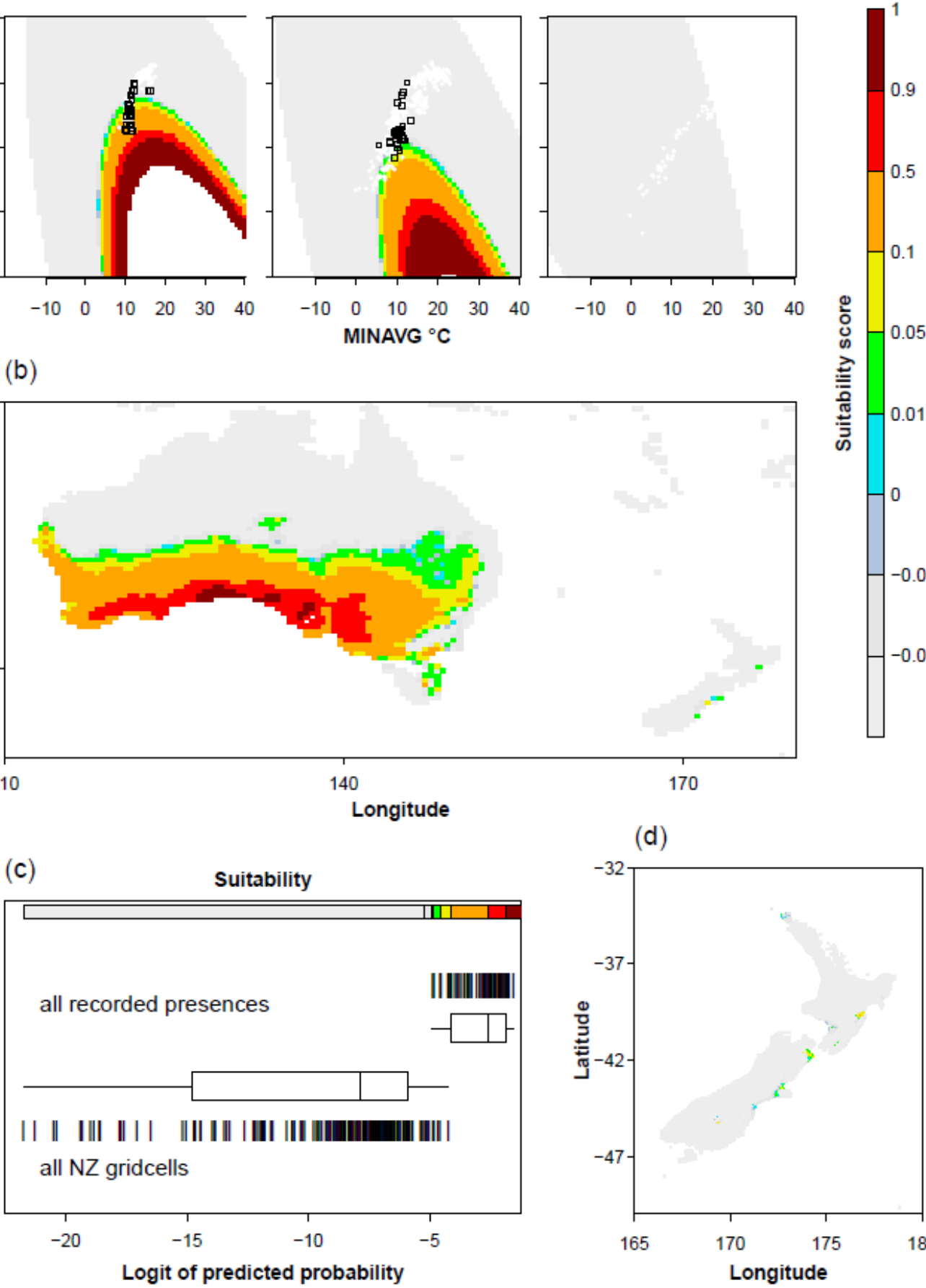

0.5

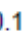

05 1

(e) 
The proportion of New Zealand with predicted suitability $>0.1$ was calculated for each species (Table 13). The New Zealand Suitability Score and the proportion of New Zealand with suitability $>0.1$ were not highly correlated (Figure 45). A summary figure allowing for the comparison of New Zealand suitability between species can be found in Figure 46.

Table 13: Summary table comparing all reptile species investigated with regards to New Zealand (NZ) suitability score based on weighted multimodel average, $90 \%$ Confidence Interval (CI), and proportion of NZ with a suitability $>0.1$. Values in bold denote highest highest scores.

\begin{tabular}{cccc}
\hline Species & $\begin{array}{c}\text { NZ Suitability } \\
\text { Score }\end{array}$ & $\mathbf{9 0 \%}$ CI range & $\begin{array}{c}\text { Proportion of NZ } \\
\text { with suitability }>\mathbf{0 . 1}\end{array}$ \\
\hline Chelodina longicollis & 0.40 & $0.22-0.94$ & 0.16 \\
Chinemys reevesii & 0.07 & $0-1$ & 0.01 \\
Testudo graeca & 0.16 & $0-1$ & 0.03 \\
Testudo hermanni & 0.17 & $0-0.99$ & 0.01 \\
Pogona vitticeps & 0.03 & $0-0.74$ & 0 \\
Pogona barbata & 0.37 & $0.14-0.95$ & 0.12 \\
Eublepharis macularius & 0.18 & $0-0.99$ & 0.02 \\
Physignathus lesueurii & 0.26 & $0.20-0.89$ & 0.11 \\
Tiliqua scincoides & 0.39 & $0.39-1$ & $\mathbf{0 . 4 5}$ \\
Tiliqua nigrolutea & $\mathbf{0 . 9 9}$ & $0.48-1$ & 0.25 \\
Tiliqua rugosa & 0.08 & $0-0.4$ & 0
\end{tabular}


Figure 45: Predicted New Zealand suitability of exotic reptiles in relation to the proportion of New Zealand with a suitability $>0.1$. $(\mathrm{R}=0.65)$.

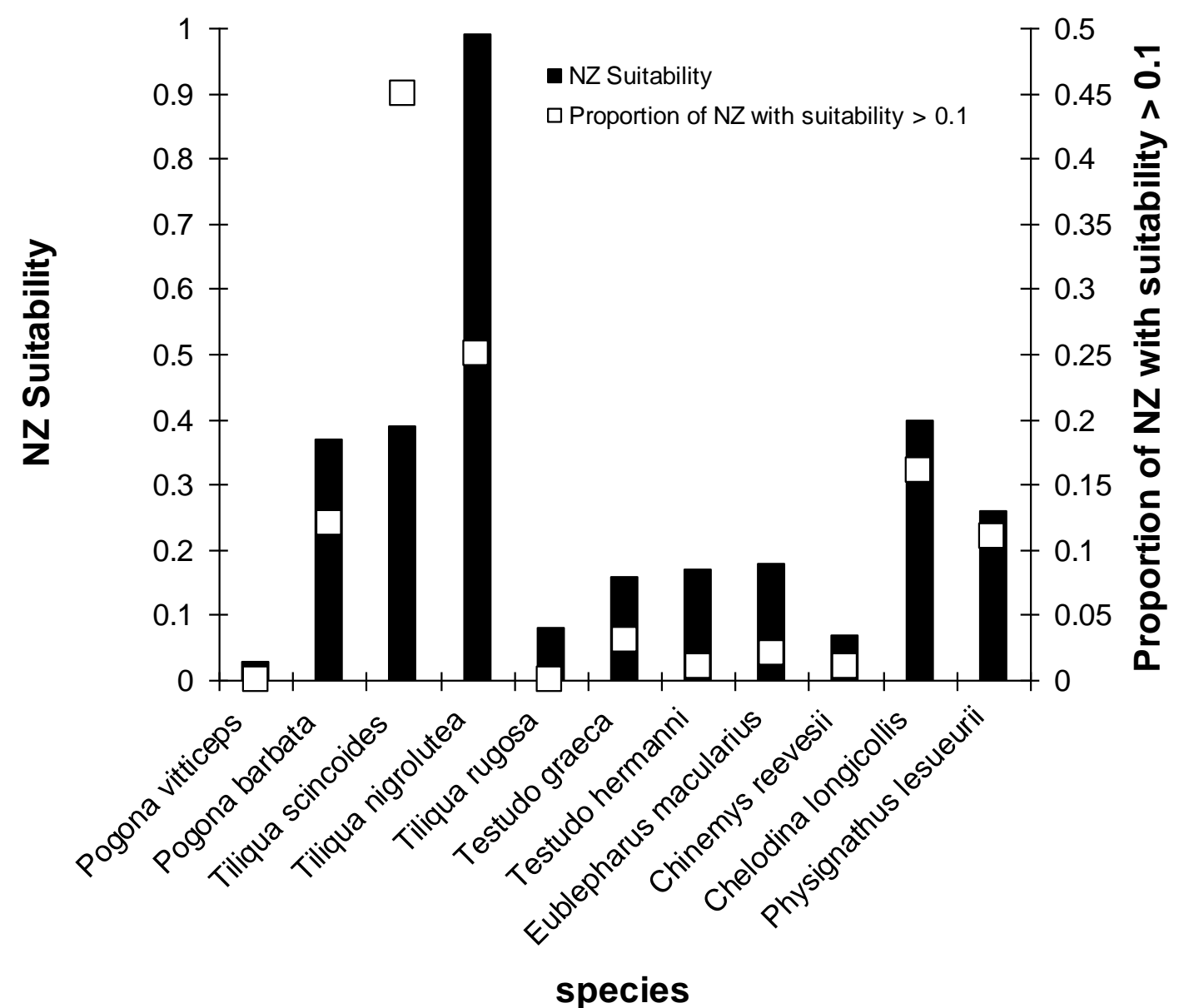


Figure 46: Summary figure allowing for the visualisation of New Zealand suitability of the eleven species of exotic reptile investigated in this study. Please see Figure 14b and text for details on colour-coded suitability scale.
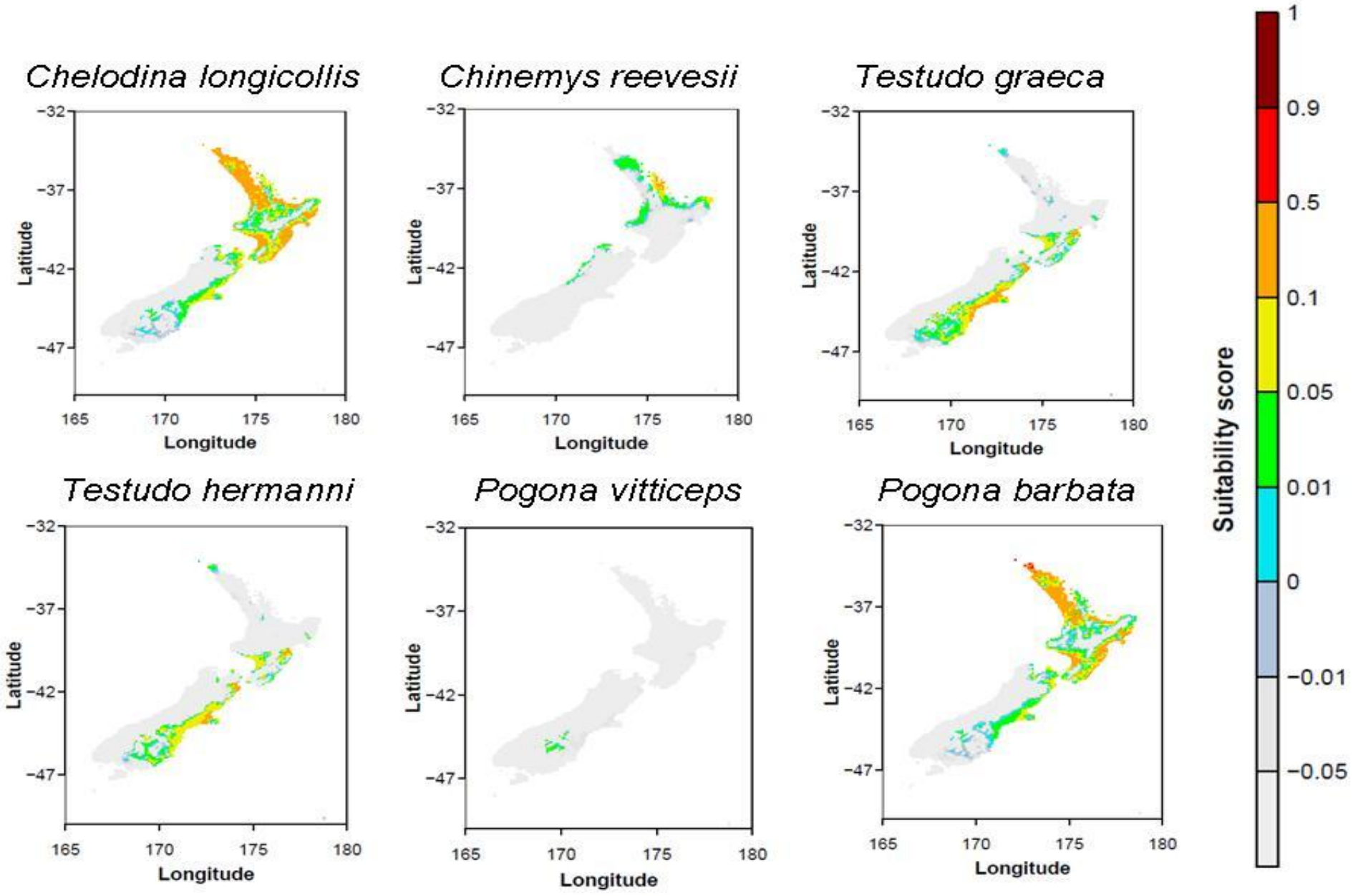


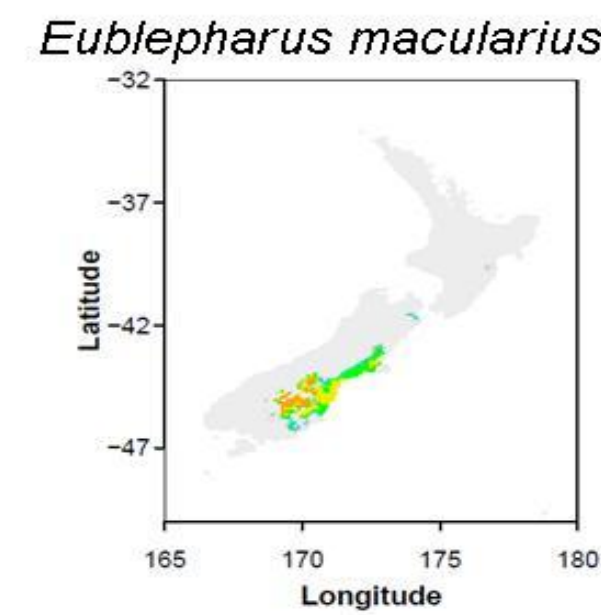

Tiliqua scincoides

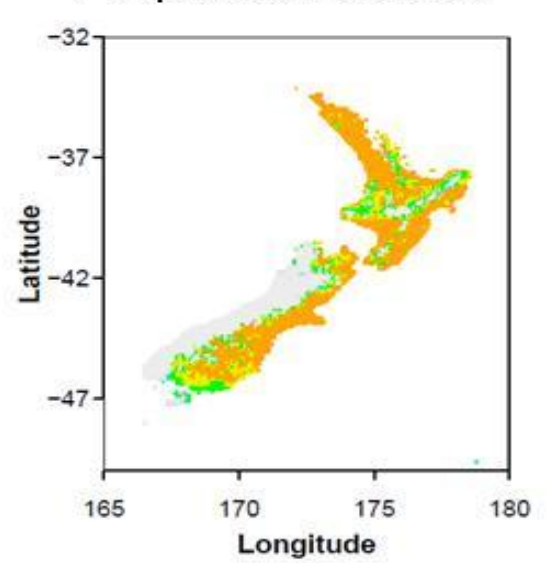

Tiliqua nigrolutea

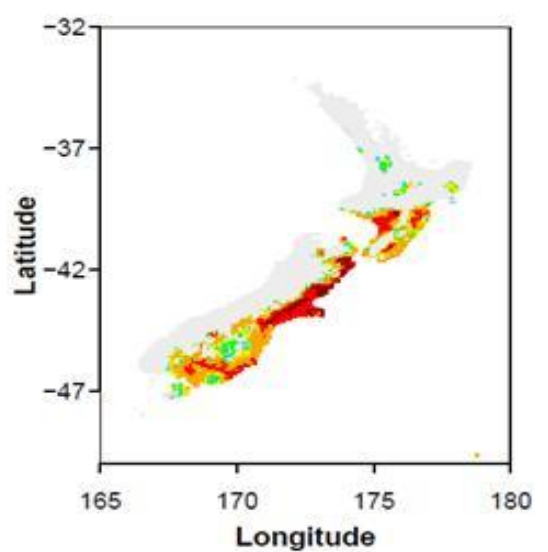

\section{Physignathus lesueurii}

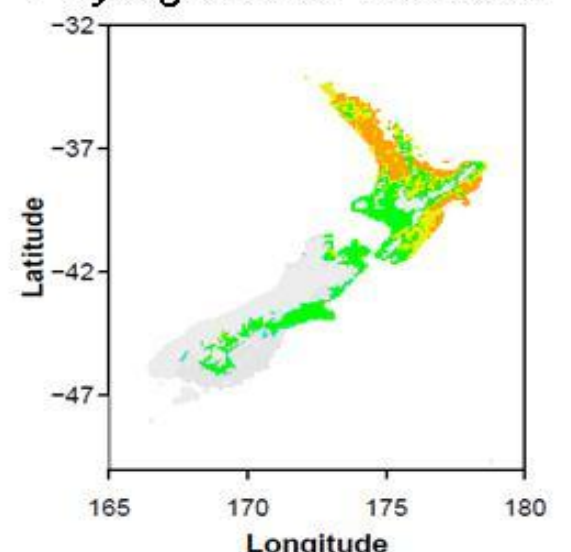

Longitude
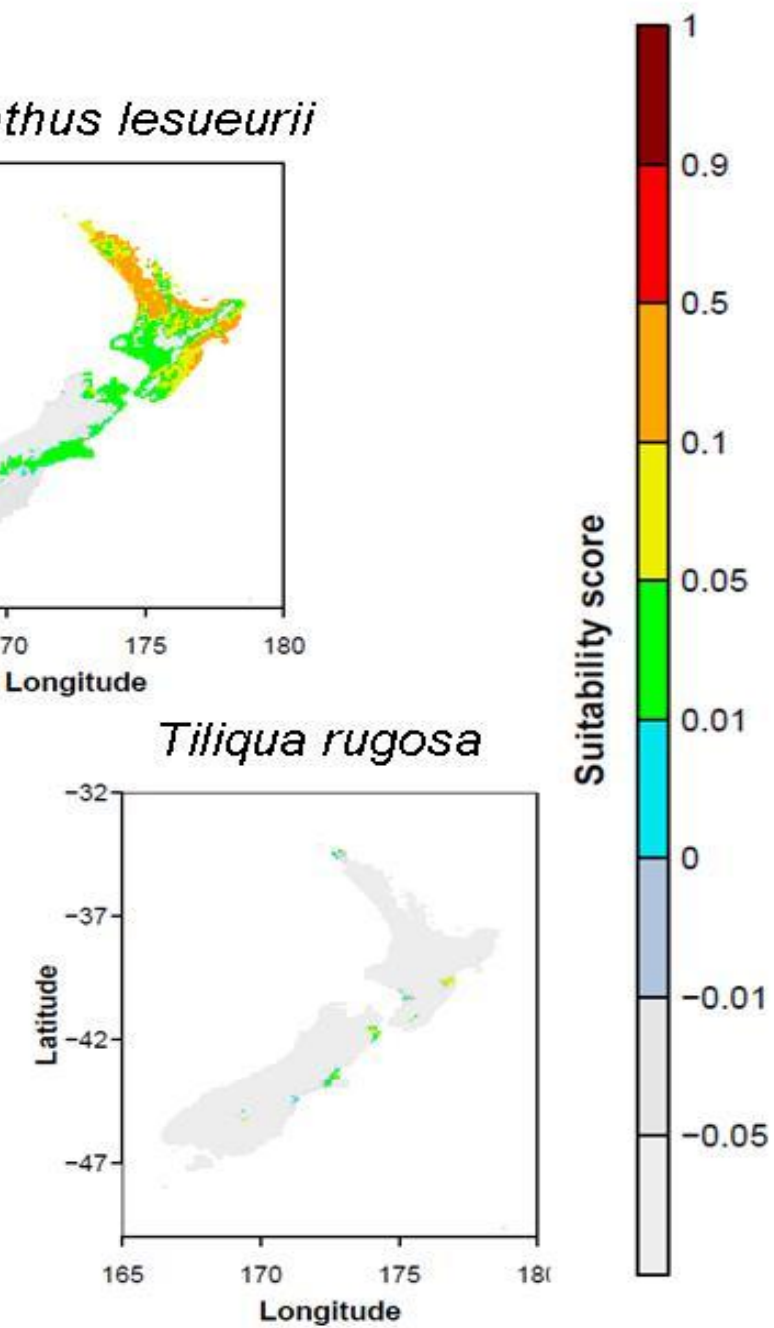


\section{Discussion}

This study investigated the degree of climate match between New Zealand and 11 species of exotic reptile known to exist in captivity in this country in an effort to elucidate the establishment risk posed by these species in event of accidental escape or deliberate release from captivity. There was a wide range in New Zealand suitability scores, from a high score of 0.99 for Tiliqua nigrolutea to a low score of 0.03 for Pogona vitticeps. In regards to the amount of area of New Zealand with climatic suitability $>0.1, T$. scincoides had the highest proportion with 0.45 . For $T$. rugosa and $P$. vitticeps, none of New Zealand was predicted to have suitability $>0.1$.

\section{Climatic factors important in predicting distribution range}

For Chelodina longicollis, the most suitable New Zealand site received a score of 0.4 based on the multimodel average, lower than that of the best performing model, model “j”. Several models predicted high New Zealand suitability scores (suitability $\geq 0.7$ ) (e.g., models "e", "f", “i”" and "j"). The best performing models incorporated mean annual temperature and daily maximum temperatures, suggesting that these factors may be important in predicting the potential range of snake-neck turtles.

The most suitable New Zealand site for Chinemys reevesii received a score of 0.069 based on the multimodel average, a higher score than that predicted by the best performing model, model "k". Several models (“b”, "e", "f", “g”, "h", “i”, and “j”) predicted a very high New Zealand suitability score $(0.99-1)$. All of the climatic variables investigated were incorporated into these models, suggesting that there is not one single climatic factor that dominates over the others in defining the potential distribution of Reeves turtles. 


\section{Chapter 4: Predicting exotic reptile distributions via bioclimatic models}

The most suitable New Zealand site for Testudo graeca based on the multimodel average received a score of 0.16 , higher than that of the best performing model, model "l”. Models which predicted higher New Zealand suitability scores (models "f", "h", "i" and "j") incorporated all of the climate variables other than mean summer temperatures, indicating that this may be an important factor in predicting the potential range of Greek tortoises. Testudo hermanni received a New Zealand suitability score of 0.17 , higher than that predicted score of the best performing model, model "k". Models " $\mathrm{f}$ " and " $\mathrm{h}$ ", which incorporated winter temperatures, predicted much higher suitability scores. Similarly to $T$. graeca, this suggests that summer temperatures are important in defining the distributional limits for these two species of tortoise. Figures 22a and 23a, however, suggests that precipitation levels are crucial in determining the suitability. Although New Zealand's best sites fall near the optimum of the climate envelope in relation to MAXAVG and MINAVG, they are probably drier than the optimum suggested by model "b".

The best performing model for Pogona vitticeps, model "c", generated a similar New Zealand suitability score as the multimodel average. Models "a" and "b", however, which considered average winter and summer temperatures, generated much higher suitability scores. This suggests that daily minimum and maximum temperatures experienced in New Zealand may be less suitable than the seasonal averages with respect to the potential range of inland bearded dragons in New Zealand. For P. barbata, New Zealand's most suitable site received a score of 0.37 based on the multimodel average. This score was lower than that obtained from the best performing model, model "f” (0.87). Model “i”, which incorporated mean annual temperature, produced a higher suitability score of 0.95 , suggesting while the 
mean annual temperature in New Zealand may be suitable for coastal bearded dragons, the seasonal and daily minimum and maximum temperatures may be less favourable. Inspection of Figure 29a might suggest that New Zealand summer temperatures are not high enough.

For Eublepharis macularius, New Zealand's most suitable site received a score of 0.17 based on the multimodel average, lower than that predicted by the best performing model, model "a". Models "h" and "f", which incorporated minimum temperatures, predicted much higher New Zealand suitability scores, indicating that maximum temperatures may be an important factor limiting the potential range of leopard geckos in New Zealand. Figure 32a supports this idea as the best New Zealand sites are within the range of MINAVG values occupied in other countries, but at the lower end of the occupied MAXAVG (summer) temperatures.

The best New Zealand site for Physignathus lesueurii received a suitability score of 0.26 based on the multimodel average. This was similar to that of the best performing model, model "d". The models which predicted high New Zealand suitability scores (models "f" and "j") were not highly weighted and did not include climate variables relating to summer temperature, suggesting that these factors may limit the potential range of waterdragons in New Zealand, but not around their native range.

For Tiliqua scincoides, New Zealand's most suitable site received a score of 0.39 , the same as that of the best performing model, model "g". Models "f" and " $h$ " produced much higher suitability scores (1). Both of these models considered only winter temperatures and rainfall, suggesting that summer temperatures may be limiting factors in the distribution of common blue-tongue skinks in New Zealand. With the exception of model "k", all models predicted very high New Zealand 
suitability scores (0.9-1) for blotched blue-tongue skinks (T. nigrolutea). According to the multimodel average, $T$. rugosa received a New Zealand suitability score of 0.07 , higher than that of the best performing model, model " $k$ ". Models that included mean annual temperature among their climate variables (models "i”" and "j””) were highly weighted for T. nigrolutea and T. rugosa, suggesting that this is an important variable for predicting range limits of these species (Figures 39 and 41). In contrast, summer temperatures (MAXAVG and MAXMAX) were more important for predicting the distribution of T. scincoides (Figure 37). Previous studies investigating distributional limits of blue-tongue skinks conclude that the ranges of $T$. scincoides and T. rugosa in Australia are restricted due to their lower tolerance for cool temperatures during the winter months (Hancock and Thompson 1997). In this study, however, model "g", which incorporated mean daily maximum temperatures in the hottest month (MAXMAX), was important in the multimodels for all three species of blue-tongued skink investigated in this study, suggesting that daily maximum temperatures should be considered when predicting the potential distribution of these species in New Zealand.

The high New Zealand suitability score for Tiliqua nigrolutea (0.99) is not surprising. Blotched blue-tongue skinks are naturally found in cool, wet areas in Tasmania, which has a higher climate match to New Zealand than, for example, inland Australia. It is unknown if blotched blue-tongue skinks exist in the pet trade, but as they appear to be able to hybridise with $T$. scincoides (NSW National Parks and Wildlife Service 2010) (and T. scincoides are common in the pet trade), further investigation regarding their status is recommended. 


\section{Other factors to consider when predicting establishment risk}

A high New Zealand suitability score does not mean that all of the country is suitable for establishment, as the suitability score was based on the relative suitability of the best site in New Zealand. For example, according to the bioclimatic model, the species with the highest New Zealand Suitability Score, Tiliqua nigrolutea (0.99), would find only $25 \%$ of New Zealand to have a suitability greater than 0.1 . Meanwhile, Tiliqua scincoides has a lower New Zealand Suitability score (0.39), yet almost half of the country is predicted to have a suitability greater than 0.1 . As expected, however, species with a low peak suitability score are also generally predicted to have a restricted range of suitable area within New Zealand (e.g. Pogona vitticeps, Chinemys reevesii, Tiliqua rugosa, Eublepharis macularius, Testudo graeca, and T. hermanni).

It is important to remember that a high climate match score does not guarantee that a species will establish in an area. There are many other biotic and abiotic factors to consider, including the availability of suitable shelter and food resources, freedom from disease and/or competitors (Bomford et al. 2009). Additionally, some species may have a wider tolerance to different climate variables as not every species has been introduced to areas encompassing the extent of their climatic tolerances. For example, a climate-matching study investigating the potential range of invasive pythons (Python molurus bivittatus, an invasive pest in southern Florida) in the continental USA predicted that much of the lower portion of the country may be climatically suitable for this species (Rodda et al. 2009). Recently, however, a large proportion of captive pythons held in outdoor pens (supplemented with heated refugia) in north-central Florida died during the winter months as a result of cold temperatures, 
suggesting that their cold tolerance may not be as highly developed as previously thought (Avery et al. 2010).

The climatic factors that best define a species distribution in and around its native range (and which received a high weighting) may not be the ones that are most limiting in New Zealand. Moreover, the choice of which variables to include in a model makes huge differences to the predicted New Zealand Suitability Score. The climate variable of mean annual temperature was regularly in the set of highly weighted models. Models which included mean annual temperature and winter temperature variables typically predicted higher New Zealand suitability than models incorporating summer temperatures. This suggests that, in general, the prediction of New Zealand suitability for reptiles should be based on summer mean and maximum temperatures, as these appear to be the most relevant climatic variables. In other words, winters do not appear to be too cold for most introduced reptiles, but the summers are often not warm enough.

\section{Conservation Implications}

Although Tiliqua nigrolutea received the highest New Zealand suitability score, T. scincoides had the largest proportion of New Zealand predicted to have a suitability $>0.1$ (that is, the proportion of New Zealand with sites believed to be climatically better than $10 \%$ of sites incorporated into the model representing its native range). This may be more concerning, in a biosecurity context, than a species with a higher climatic suitability that may be restricted to a smaller area. It is highly recommended that pet stores and breeders selling $T$. scincoides provide potential owners with information regarding secure enclosures and emphasize that these animals should not be released or allowed to escape into the wild. Incorporating both 
climatic suitability and the proportion of New Zealand with a suitability $>0.1$, the species predicted to have the lowest risk of establishment in New Zealand are Eublepharis macularius, Testudo hermanni, T. graeca, Tiliqua rugosa, Chinemys reevesii, and Pogona vitticeps.

Areas of New Zealand that were most commonly predicted to be climatically suitable for exotic reptiles were the northern portion of the North Island and the eastern coast of the South Island. Interestingly, neither Tiliqua nigrolutea nor $T$. rugosa, which are prohibited in the Auckland region, are predicted to have any climatic suitability in that area.

Results from this study may be useful for regional councils to help determine if regulations regarding the keeping certain species may be appropriate for their areas. Climate matching is often considered to be a first step in the investigation of the establishment potential of a species of interest (Ficetola et al. 2007), from which further investigation can be conducted. The results from this study are used in Chapter 7 to produce a more comprehensive risk assessment for exotic reptiles in New Zealand. 


\section{Literature cited}

Auckland Regional Council (2007). Regional Pest Management Strategy 2007-2012 Auckland, New Zealand, Auckland Regional Council: Pages 119-120.

Avery, M., R. Engeman, K. Keacher, J. Humphrey, W. Bruce, T. Mathies and R. Mauldin (2010). "Cold weather and the potential range of invasive Burmese pythons." Biological Invasions DOI 10.1007/s10530-010-9761-4.

Bertolero, A., J. Nougarede, M. Cheylan and A. Marin (2007). "Breeding traits of Hermann's tortoise Testudo hermanni hermanni in two western populations." Amphibia-Reptilia 28: 77-85.

Bomford, M., F. Kraus, S. Barry and E. Lawrence (2009). "Predicting establishment success for alien reptiles and amphibians: a role for climate-matching." Biological Invasions 11: 713-724.

Burne, C. (2009). The ultimate guide to keeping Australian dragons successfully in New Zealand. Napier, New Zealand, GEON Print.

Cogger, H. (1975). Reptiles and amphibians of Australia. Sydney, Australia, Reed Party Books.

De Vosjoli, P., B. Viets, R. Tremper and R. Klingenberg (2004). The Leopard Gecko Manual. Santee, California, USA, Advanced Vivarium Systems.

Ficetola, G., W. Thuiller and C. Miaud (2007). "Prediction and validation of the potential global distribution of a problematic alien invasive species - the American bullfrog." Diversity and Distributions 13: 476-485.

Forsyth, D., R. Duncan, M. Bomford and G. Moore (2004). "Climatic suitability, lifehistory traits, introduction effort, and the establishment and spread of introduced mammals in Australia." Conservation Biology 18(2): 557-569.

Hancock, L. and M. Thompson (1997). "Distributional limits of Eastern blue-tongue lizards Tiliqua scincoides, blotched blue-tongue lizards T. nigrolutea and shingleback lizards T. rugosa (Gray) in New South Wales." Australian Zoologist 30(3): 340-345.

Hijmans, R., S. Cameron, J. Parra, P. Jones and A. Jarvis (2005). "Very high resolution interpolated climate surfaces for global land areas." International Journal of Climatology 25(1965-1978).

Kikillus, K. H., K. M. Hare and S. Hartley (2010). "Minimizing false-negatives when predicting the potential distribution of an invasive species: a bioclimatic envelope for the red-eared slider at global and regional scales." Animal Conservation 13(Suppl. 1): 1-11 (doi:10.1111/j.1469-1795.2008.00299.x).

Kolar, C. and D. Lodge (2001). "Progress in invasion biology: predicting invaders." Trends in Ecology and Evolution 16(4): 199-204. 
Kraus, F. (2009). Alien reptiles and amphibians: a scientific compendium and analysis, Springer Netherlands.

Lever, C. (2003). Naturalized reptiles and amphibians of the world. New York, USA, Oxford University Press.

New, M., M. Hulme and P. D. Jones (1999). "Representing twentieth century spacetime climate variability. Part I: development of a 1961-90 mean monthly terrestrial climatology." Journal of Climate 12(3): 829-856.

NSW National Parks and Wildlife Service (2010). "NSW native animal keepers' species list 2010." Retrieved 3 June, 2010, from http://www.environment.nsw.gov.au/resources/nature/CurrentSpeciesList.pdf.

Orenstein, R. (2001). Turtles, tortoises and terrapins: survivors in armor. New York, USA, Firefly Books.

Pimentel, D. (2002). Introduction: Non-native species in the world. Biological Invasions: Economic and environmental costs of alien plant, animal, and microbe species. D. Pimentel. Boca Raton, Florida, USA, CRC Press.

Rodda, G., C. Jarnevich and R. Reed (2009). "What parts of the US mainland are climatically suitable for invasive alien pythons spreading from Everglades National Park?" Biological Invasions 11: 241-252.

Sikder, I., S. Mal-Sarkar and T. Mal (2006). "Knowledge-based risk assessment under uncertainty for species invasion." Risk Analysis 26(1): 239-252.

Wiltshier, B. (2000). The Greek spur-thighed tortoise (Testudo graeca): Its care and management. Auckland, New Zealand, Premier Print Services Ltd. 


\title{
Chapter 5:
}

\section{Developmental degree-day models to assess the establishment potential of red-eared slider turtles and other exotic reptiles in New Zealand}

\begin{abstract}
Invasive pest species are a significant threat to biodiversity. The release of unwanted pets is a means by which many exotic species have become established in areas outside of their native range. Exotic pet reptiles are often released and survive in New Zealand (especially red-eared slider turtles, Trachemys scripta elegans) but data detailing whether these species can successfully reproduce and establish selfsustaining populations are limited. Using published data on incubation conditions, I formulated degree-day models for seven exotic reptile species most commonly encountered in the New Zealand pet trade. I then recorded soil temperatures at 16 locations in northern New Zealand to determine whether natural soil temperatures fulfill the degree-day model predictions. Three of the seven species that were investigated accrued a sufficient number of degree-days in at least one location. Favourable microsites, as well as predicted increases in temperature with climate change, may produce higher soil temperatures and increase the potential for successful embryonic development. While soil temperatures are extremely important in the incubation of reptile eggs, other factors must be considered when predicting range limits of a potentially invasive species, such as soil moisture content and juvenile survival. Nonetheless, the ability to successfully reproduce would increase the possibility of self-sustaining populations of exotic reptiles in New Zealand. These
\end{abstract}


techniques can easily be applied to other species whose development is temperaturedependent.

\section{Introduction}

Exotic species that successfully invade areas outside of their native range are often associated with detrimental economic and ecological effects in their new environment (Pimentel 2002). Thus, it is often more cost-effective to determine if a species can establish before it has the opportunity to do so, rather than to attempt eradication at a later date (Mack et al. 2000; Manchester and Bullock 2000). Predictive models, such as climate matching (comparing the climate "overlap" in the native range of a species to an area of interest, (e.g. (Forsyth et al. 2004; Rodda et al. 2009) and physiological models (which examine if certain environments can allow for proper function of temperature-dependent processes, such as growth and development, e.g. (Hartley and Lester 2003) are a useful way in which to identify areas that may be susceptible to invasion by a species of interest.

Cool-temperate New Zealand is home to a rich assemblage of endemic reptiles, including tuatara (Sphenodon spp.), skinks (Oligosoma spp.), and geckos (Hoplodactylus spp. and Naultinus spp.) as well as migratory/ vagrant sea-snakes and sea turtles (Daugherty et al. 1990; Gill and Whitaker 2001; Chapple et al. 2009). In addition, one species of Australian skink has naturalised (Lampropholis delicata) (Gill et al. 2001) and a number of exotic reptile species are present in the New Zealand pet trade - releases of which are commonly reported (see Chapter 2). This "pet release pathway" is a means by which many species of exotic reptile have become established outside of their native range (Kraus 2009). Invasive reptiles, 
however, are often overlooked as they can be small and cryptic, and/ or their effects on their new environment may not be immediately noticeable (Kraus 2007).

This study uses published information to develop degree-day models of temperature-dependent embryonic/egg development for the most commonly traded species of oviparous exotic reptile kept as pets in New Zealand (see Chapter 2 and Appendices 1-8). Using these data, I investigate the establishment potential of these seven species by determining whether successful incubation of eggs is likely under current environmental conditions. Degree-day models are a type of physiological model often used for species whose development is temperature-dependent in order to help predict timing of pest outbreaks or geographic limits of distribution (e.g., (Broufas and Koveos 2000; Hartley and Lester 2003; Baek et al. 2008). Reptile eggs are dependent on environmental conditions in order to complete successfully embryonic development (Birchard 2004). Warmer incubation temperatures typically result in a shorter development time and quicker hatching than cooler incubation temperatures (Ackerman and Lott 2004). As reptile egg incubation at constant temperatures is rare in the wild (Birchard 2004), a degree-day model will help to identify a baseline temperature and the amount of "thermal units" above this temperature that are required to successfully complete development of the selected organism.

\section{Methods}

\section{Study species}

Of the species of exotic reptile available in the New Zealand pet trade, the most commonly encountered are: red-eared slider turtles (Trachemys scripta elegans), snake-neck turtles (Chelodina longicollis), Reeves turtles (Chinemys reevesii), Greek 
tortoises (Testudo graeca), bearded dragons (Pogona vitticeps and P. barbata), leopard geckos (Eublepharis macularius), and waterdragons (Physignathus lesueurii). (See Appendix for additional information). Red-eared slider turtles are most abundant and affordable, and are the most common escapees into the wild (Kikillus et al. 2010) (also see Chapter 2). This freshwater turtle, native to the Mississippi Valley area of the United States of America, has established invasive populations in numerous countries as a result of deliberately released or escaped pets (Lever 2003; Kraus 2009) and is classified as one of the "World's Worst Invaders" (Invasive Species Specialist Group (ISSG) 2004). Red-eared sliders generally produce between three and 24 eggs per clutch, in nests approximately $10 \mathrm{~cm}$ deep and are capable of producing up to three clutches per year (Thornton 1999; Invasive Species Specialist Group (ISSG 2006; O'Keeffe 2006). Feral RES exist throughout New Zealand (Hoskins 2006; Dykes 2007; Kikillus et al. 2010) but it is unknown if environmental conditions are suitable for the turtles to breed successfully and thus establish selfsustaining populations.

In addition to RES, three other species of chelonian were investigated: snakeneck turtles (Chelodina longicollis), Reeves turtles (Chinemys reevesii), and Greek tortoises (Testudo graeca), as well as several types of lizard commonly available for purchase in New Zealand: bearded dragons (Pogona barbata and P. vitticeps were combined for the purposes of this analysis), leopard geckos (Eublepharis macularius), and waterdragons (Physignathus lesueurii). Although popular pets in New Zealand, blue-tongue skinks (Tiliqua scincoides) were excluded from the analysis as they are viviparous. 


\section{Data sources and analysis}

Developmental periods and temperature data were collected from published studies that incubated eggs at a constant temperature (see Supplementary Table 1). Mean development time in days (D) and mean incubation temperature (T) were used in the linearised Law of Total Effective Temperature equation (Ikemoto and Takai 2000):

$$
\mathbf{D T}=\mathbf{k}+\mathbf{t}_{\mathbf{0}} \mathbf{D}
$$

where $\mathrm{D}=$ mean development time, $\mathrm{T}=$ mean ambient temperature, $\mathrm{t}_{0}=\mathrm{a}$ baseline temperature of theoretically zero development, and $\mathrm{k}=\mathrm{a}$ thermal constant for development measured in units of degree-days. Data points were plotted onto a graph and a straight line fitted via a reduced major axis regression of DT vs. D, as recommended by Ikemoto and Takai (2000). The values of $k$ and $t_{0}$ were then estimated from the intercept and slope of the resulting graph. We checked the literature for information on upper limits that might invalidate the use of a degree-day model without an upper developmental limit. For example, turtle embryos generally cease development and die at constant incubation temperatures above $33^{\circ} \mathrm{C}$ (Congdon and Gibbons 1990). The relevant temperatures for application of the degree-day models are from the lower lethal limit (presumed to be someway below the theoretical baseline) to the upper limit. In cases where information from published studies was unavailable, hobbyist/breeder websites were consulted for mean incubation temperatures and duration of development. Additionally, as few records were available for waterdragons (Physignathus lesueurii), incubation data from a closely related species, the Asian waterdragon ( $P$. cocincinus) were incorporated into the degree-day model. 


\section{Degree-day measurements from the environment}

To apply the degree-day model results for RES in the field, dataloggers (TidbiT® v2 Temp, Onset Computer Corporation, Bourne, Massachusetts, USA) were deployed in 16 sites around northern New Zealand between 2007 and 2010 (Table 2). Sites in the Auckland region (\#1-7) were selected with the help of Auckland Regional Council biosecurity officers in areas where RES have been observed living in the wild. Sites outside of the Auckland region (\# 9-14) were chosen based on results of a previous study which highlighted climatically-suitable areas for RES in New Zealand (Kikillus et al. 2010). Individual dataloggers were also deployed in Wellington, lower North Island (not considered climatically suitable for RES (Kikillus et al. 2010) but where they are often released) (See Chapter 2), and Sydney, Australia (an area where RES have become established) (Burgin 2006), for comparative purposes likely to represent upper and lower extremes of breeding potential. Datalogger deployment sites were situated on flat to north-facing slopes which received full sun and within $0.5 \mathrm{~km}$ of a freshwater source (lake, river, etc.), with the exception of datalogger \#8, which was opportunistically deployed within a reptile exhibit at a zoo, and datalogger \#15, which was deployed in a shaded area where a female RES had been observed exhibiting nesting behaviours. Dataloggers were buried at a depth of $10 \mathrm{~cm}$ (average RES nesting depth) and recorded temperature at hourly intervals for at least one year. Although datalogger deployment sites were chosen with RES in mind, the soil temperatures measured by these devices in New Zealand were also applied to the degree-day models of other species of exotic reptile present within the New Zealand pet trade to investigate potential incubation temperatures that these animals might encounter within the New Zealand 
environment. Upon retrieval, datalogger information was downloaded via HOBOware ${ }^{\circledR}$ Lite Version 2.3.0.

As reptile eggs cannot develop indefinitely at suboptimal temperatures (Birchard 2004), we needed to specify a maximum time frame in which degree-days could be accumulated. To determine the maximum allowable period, we selected the longest successful incubation period for each species from the data underlying Appendix 11: Supplementary Table 1. The temperature time series recorded by the dataloggers were examined and sites that met the temperature requirements denoted by the degree-day model within the specified time frame were classified as potential breeding sites.

\section{Results}

\section{Degree-day models}

A total of 17 records of incubation lengths and temperatures for RES were obtained from literature sources, and included into the model (Figure 1 and Appendix 11: Supplementary Table 1). According to the points fitted into the reduced major axis regression, the summary model indicated that 502 ( $\pm 12.8 \mathrm{SE})$ degree-days above a developmental threshold of $20.2( \pm 0.2 \mathrm{SE}){ }^{\circ} \mathrm{C}$ were required for complete development of RES embryos (Figure 2). Seven records of incubation lengths and temperatures from published literature and breeder/ hobbyist websites were incorporated into the snake-neck turtle model, 14 for Reeves turtles, 5 for Greek tortoises, 16 for bearded dragons, 9 for leopard geckos, and 8 for waterdragons. (Appendix 11: Supplementary Table 1 and Supplementary Figures 1 and 2). 
Figure 1: Mean development time (days) vs. mean incubation temperature $\left({ }^{\circ} \mathrm{C}\right)$ for red-eared slider turtles (Trachemys scripta elegans).

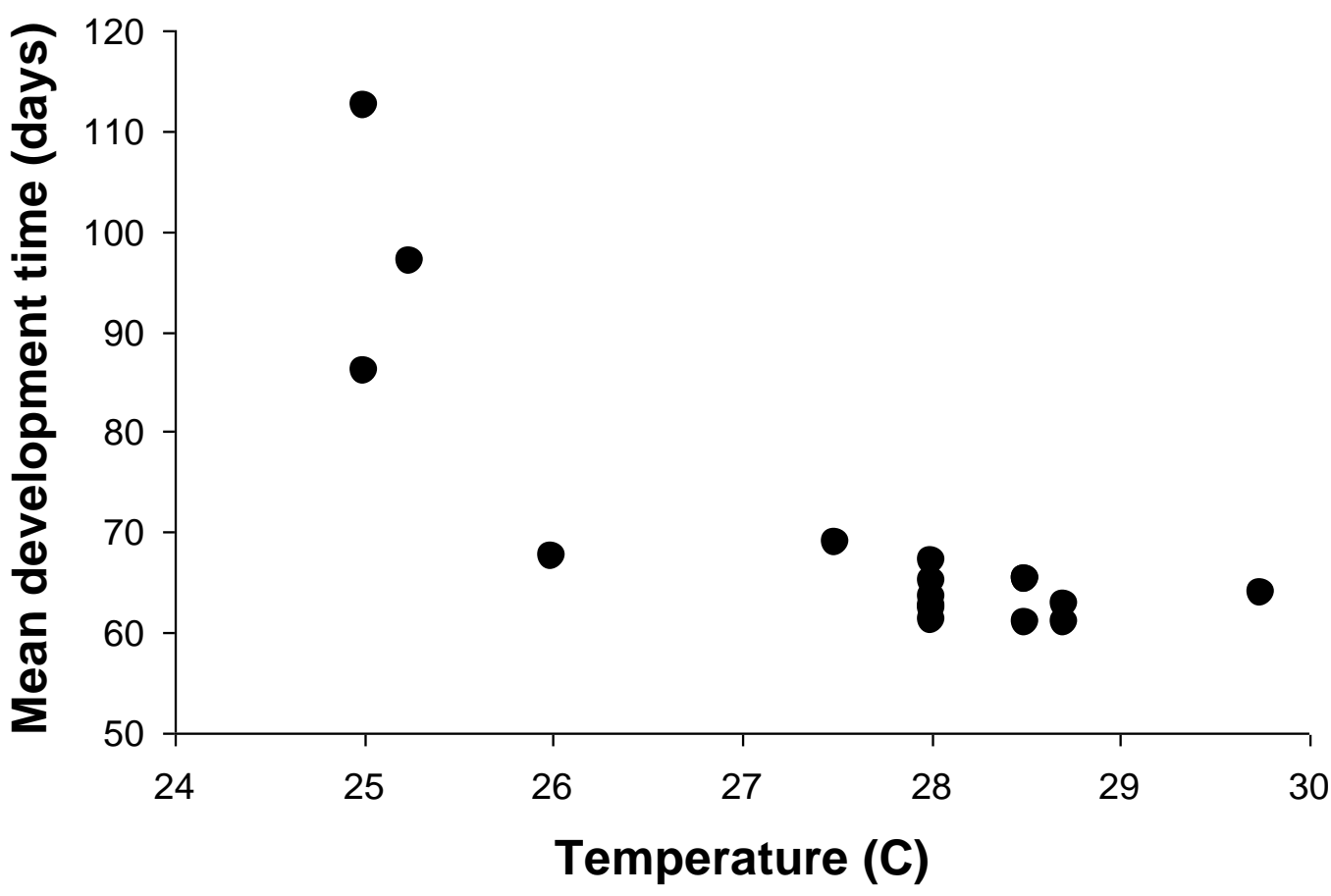

Figure 2: Reduced Major Axis Regression plotting mean development time (days) * mean incubation temperature $\left({ }^{\circ} \mathrm{C}\right.$ ) against mean development time (days) for production of both sexes of the red-eared slider (Trachemys scripta elegans).

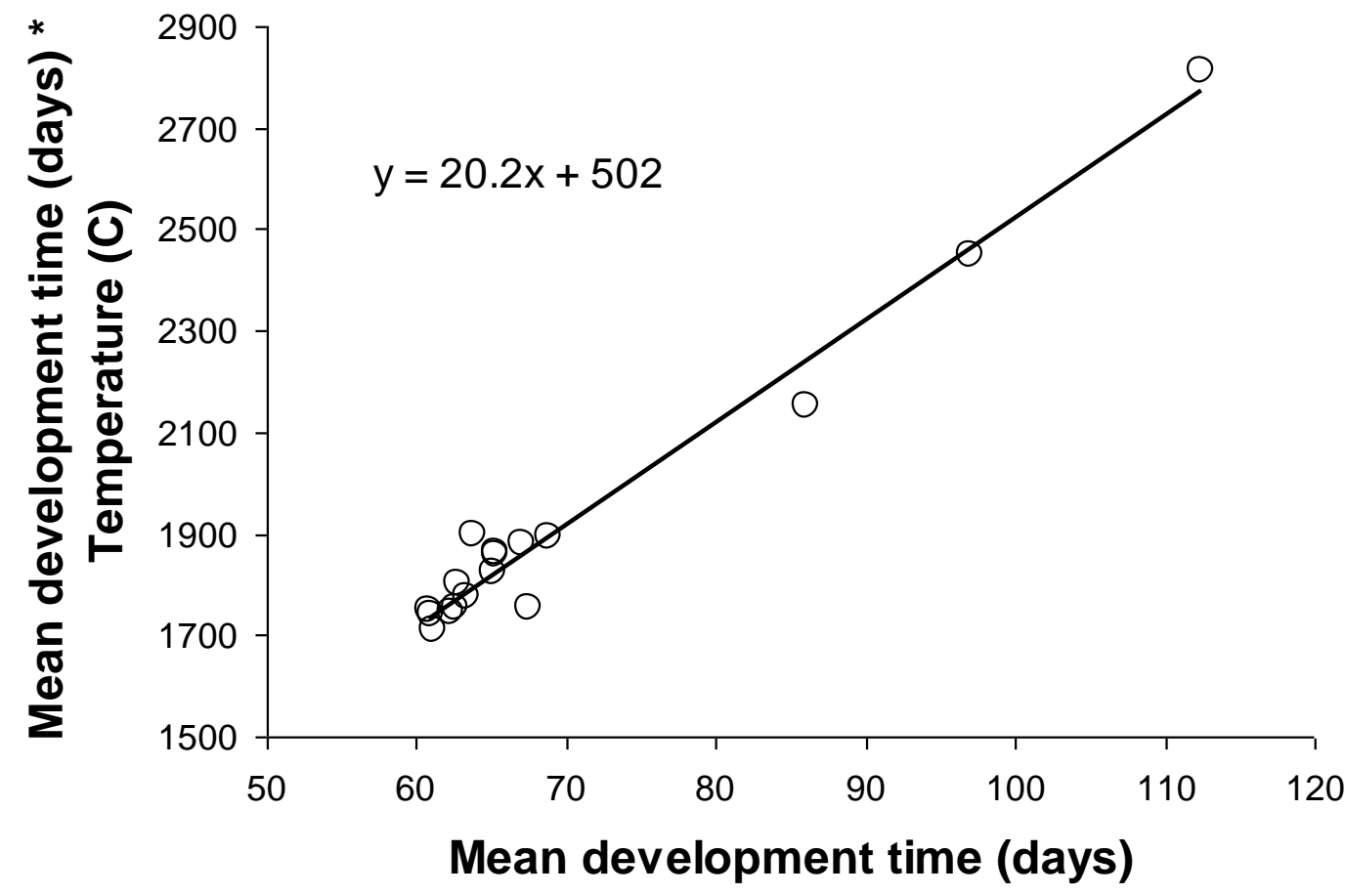




\section{Degree-day measurements from the environment}

Based on the data used to formulate the degree-day model predictions (See Appendix 11: Supplementary Table 1), we selected the maximum timeframes to accrue degree-days as 112 days for RES, 108 days for snake-neck turtles, 92 days for Reeves turtles, 105 days for Greek tortoises, 75 days for bearded dragons, 72 days for leopard geckos, and 78 days for waterdragons.

Dataloggers deployed throughout New Zealand accumulated between 20 and 608 degree-days above a threshold of $20.2^{\circ} \mathrm{C}$ for RES, which should be compared with the modeled requirement of 502 degree-days in the model. The Wellington logger (low suitability site) accumulated 97 degree-days, while the Sydney logger (high suitability site) accumulated 722 degree-days.

The results from the dataloggers suggested that snake-neck turtles and Reeves turtles could find suitable nesting temperatures at least one of the locations where the dataloggers were buried within New Zealand. Greek tortoises, bearded dragons, leopard geckos, and waterdragons did not accrue a sufficient number of degree-days within the specified time frame at any of the New Zealand study sites. Results from all sites are listed in Tables 1 and 2. 
Table 1: Results from degree-day models for exotic reptiles available in the New Zealand pet trade.

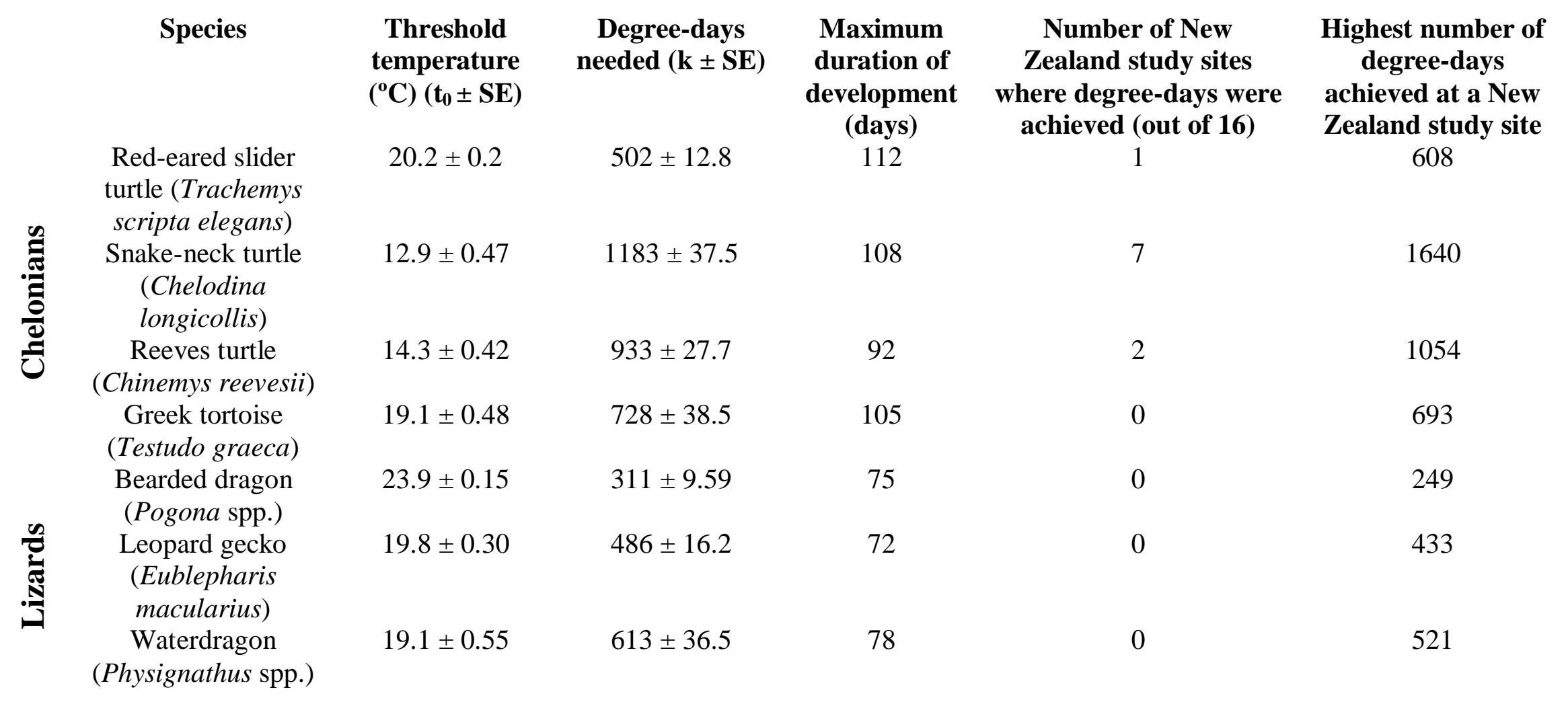


Table 2: Sites of datalogger deployment and accumulated degree-days for each species for each site. Asterisks indicate that the degree-day requirements modelled for the species were exceeded at that particular site.

\begin{tabular}{|c|c|c|c|c|c|c|c|c|c|}
\hline $\begin{array}{c}\text { Datalogger } \\
\#\end{array}$ & Site & $\begin{array}{c}\text { Geographic } \\
\text { Coordinates } \\
\text { (WGS84) }\end{array}$ & $\begin{array}{c}\text { Red-eared } \\
\text { slider turtle } \\
\text { (Trachemys } \\
\text { scripta } \\
\text { elegans) } \\
\end{array}$ & $\begin{array}{c}\begin{array}{c}\text { Snake-neck } \\
\text { turtle }\end{array} \\
\text { (Chelodina }^{\text {Chelodlis) }} \\
\text { longicollis }^{2}\end{array}$ & $\begin{array}{l}\text { Reeves turtle } \\
\text { (Chinemys } \\
\text { reevesii) })^{3}\end{array}$ & $\begin{array}{c}\text { Greek } \\
\text { tortoise } \\
(\text { Testudo } \\
\text { graeca })^{4}\end{array}$ & $\begin{array}{c}\text { Bearded } \\
\text { dragon } \\
(\text { Pogona } \\
\text { spp. })^{5}\end{array}$ & $\begin{array}{c}\text { Leopard } \\
\text { gecko } \\
\text { (Eublepharis }^{\text {Eacularius) }}{ }^{6}\end{array}$ & $\begin{array}{c}\text { Waterdragon } \\
\text { (Physignathus } \\
\text { spp. })^{7}\end{array}$ \\
\hline 1 & $\begin{array}{l}\text { Henderson Creek, } \\
\text { Auckland }\end{array}$ & $\begin{array}{l}36^{\circ} 52^{\prime} 18.4^{\prime \prime} \mathrm{S} \\
174^{\circ} 38^{\prime} 05^{\prime \prime} \mathrm{E}\end{array}$ & 21 & 835 & 485 & 59 & 0 & 31 & 58 \\
\hline 2 & $\begin{array}{l}\text { Lake Wainamu, } \\
\text { Auckland }\end{array}$ & $\begin{array}{l}36^{\circ} 53^{\prime} 17^{\prime \prime} \mathrm{S} \\
174^{\circ} 27^{\prime} 52^{\prime \prime} \mathrm{E}\end{array}$ & 169 & 1057 & 645 & 217 & 4 & 143 & 196 \\
\hline 3 & $\begin{array}{l}\text { Upper Nihotupu } \\
\text { Auxiliary Dam, } \\
\text { Auckland }\end{array}$ & $\begin{array}{l}36^{\circ} 55^{\prime} 57.2^{\prime \prime} \mathrm{S} \\
174^{\circ} 33^{\prime} 26.1^{\prime \prime} \mathrm{E}\end{array}$ & 138 & 834 & 492 & 185 & 36 & 113 & 144 \\
\hline 4 & $\begin{array}{l}\text { KareKare, } \\
\text { Auckland }\end{array}$ & $\begin{array}{l}36^{\circ} 59^{\prime} 21.7^{\prime \prime} \mathrm{S} \\
174^{\circ} 28^{\prime} 35.3^{\prime \prime} \mathrm{E}\end{array}$ & 483 & $1480 *$ & 998* & 588 & 146 & 405 & 487 \\
\hline 5 & $\begin{array}{l}\text { Auckland Botanic } \\
\text { Gardens }\end{array}$ & $\begin{array}{l}37^{\circ} 00^{\prime} 39.99^{\prime \prime} \mathrm{S} \\
174^{\circ} 54^{\prime} 25.3^{\prime \prime} \mathrm{E}\end{array}$ & 58 & 894 & 530 & 117 & 0.67 & 70 & 108 \\
\hline 6 & $\begin{array}{l}\text { Botany Downs, } \\
\text { Auckland }\end{array}$ & $\begin{array}{l}36^{\circ} 56^{\prime} 13.2^{\prime \prime} \mathrm{S} \\
174^{\circ} 54^{\prime} 26.4^{\prime \prime} \mathrm{E}\end{array}$ & 266 & $1251 *$ & 781 & 365 & 43 & 249 & 314 \\
\hline 7 & $\begin{array}{l}\text { Lakeside Park, } \\
\text { Western Springs, } \\
\text { Auckland }\end{array}$ & $\begin{array}{l}36^{\circ} 51^{\prime} 56.9 ” \mathrm{~S} \\
174^{\circ} 43^{\prime} 16^{\prime \prime} \mathrm{E}\end{array}$ & $608 *$ & $1640 *$ & $1054 *$ & 693 & 249 & 433 & 521 \\
\hline 8 & Auckland Zoo & $\begin{array}{l}36^{\circ} 51^{\prime} 42.7^{\prime \prime} \mathrm{S} \\
174^{\circ} 43^{\prime} 13.0^{\prime \prime} \mathrm{E}\end{array}$ & 246 & $1201 *$ & 758 & 342 & 32 & 210 & 277 \\
\hline 9 & $\begin{array}{l}\text { Coromandel } \\
\text { peninsula }\end{array}$ & $\begin{array}{l}37^{\circ} 06^{\prime} 17.7^{\prime \prime} \mathrm{S} \\
175^{\circ} 46^{\prime} 00.7^{\prime \prime} \mathrm{E}\end{array}$ & 84 & 1003 & 601 & 177 & 0.04 & 90 & 141 \\
\hline 10 & $\begin{array}{l}\text { Waharau } \\
\text { Regional Park }\end{array}$ & $\begin{array}{l}37^{\circ} 02^{\prime} 33.8^{\prime \prime} \mathrm{S} \\
175^{\circ} 17^{\prime} 21.1 ” \mathrm{E}\end{array}$ & 339 & $1350 *$ & 847 & 439 & 86 & 304 & 370 \\
\hline 11 & Whangarei & $\begin{array}{l}35^{\circ} 42^{\prime} 37.3^{\prime \prime} \mathrm{S} \\
174^{\circ} 19^{\prime} 48.7^{\prime \prime} \mathrm{E}\end{array}$ & 233 & $1208 *$ & 748 & 334 & 21 & 225 & 286 \\
\hline
\end{tabular}


Chapter 5: Assessing establishment potential via degree-day models

\begin{tabular}{|c|c|c|c|c|c|c|c|c|c|}
\hline 12 & Kaikohe & $\begin{array}{l}35^{\circ} 24{ }^{\prime} 21.3^{\prime \prime} \mathrm{S} \\
173^{\circ} 47^{\prime} 49.5^{\prime \prime} \mathrm{E}\end{array}$ & 190 & 1053 & 676 & 269 & 40 & 191 & 238 \\
\hline 13 & Rotorua & $\begin{array}{l}38^{\circ} 20^{\prime} 11.0^{\prime \prime} \mathrm{S} \\
176^{\circ} 23^{\prime} 13.4^{\prime \prime} \mathrm{E}\end{array}$ & 193 & 1074 & 681 & 274 & 32 & 180 & 228 \\
\hline 14 & $\begin{array}{l}\text { Kai Iwi Lakes, } \\
\text { Dargaville }\end{array}$ & $\begin{array}{l}35^{\circ} 47^{\prime} 55.2^{\prime \prime} \mathrm{S} \\
173^{\circ} 37^{\prime} 32.3^{\prime \prime} \mathrm{E}\end{array}$ & 399 & $1433 *$ & 869 & 497 & 75 & 338 & 409 \\
\hline 15 & Hamilton Zoo & $\begin{array}{l}37^{\circ} 46^{\prime} 27.0^{\prime \prime} \mathrm{S} \\
175^{\circ} 12^{\prime} 50.0^{\prime \prime} \mathrm{E}\end{array}$ & 22 & 356 & 263 & 46 & 0.40 & 30 & 46 \\
\hline 16 & Wellington & $\begin{array}{l}41^{\circ} 17^{\prime} 38.8^{\prime \prime} \mathrm{S} \\
174^{\circ} 44^{\prime} 59.9^{\prime \prime} \mathrm{E}\end{array}$ & 97 & 695 & 459 & 139 & 24 & 110 & 138 \\
\hline 17 & Sydney, Australia & $\begin{array}{l}33^{\circ} 54^{\prime} 03.4^{\prime \prime} \mathrm{S} \\
151^{\circ} 14^{\prime} 17.2^{\prime \prime} \mathrm{E}\end{array}$ & 722* & 1848* & $1180 *$ & 808* & 324* & $583 *$ & $660^{*}$ \\
\hline
\end{tabular}

Targets: ${ }^{1} 502$ degree-days (dd) within 112 days, ${ }^{2} 1183$ dd within 108 days, ${ }^{3} 933$ dd within 92 days, ${ }^{4} 728$ dd within 105 days, ${ }^{5} 311$ dd within 75 days, ${ }^{6} 486$ dd within 72 days, ${ }^{7} 613$ dd within 78 days. 


\section{Discussion}

In this study, degree-day models for successful embryonic development of seven species of exotic reptile found in the New Zealand pet trade were formulated, and model results were applied to conditions encountered in the New Zealand environment. The minimum requirements for successful embryonic development and hatching were met for all three species of freshwater aquatic turtle at one or more of the New Zealand study sites tested. Thus, these species could potentially breed in the wild and establish wild populations if released.

\section{Red-eared slider turtles}

Although the majority of datalogger sites in New Zealand did not accumulate enough degree-days to incubate RES eggs according to our model, one site in Auckland experienced 608 degree-days; more than the minimum needed as indicated by our model. Red-eared sliders inhabit the lake in this park (Chillingworth 2007) and have been observed attempting to nest here (Mitchell 2007). The higher temperatures achieved at this site may be due to a large boulder, at which the datalogger was buried near the base of, and may have acted as a heat sink, keeping the surrounding soil warmer than usual. When selecting a nest site, female reptiles seek out thermally-favourable areas (Birchard 2004), and therefore may choose a site such as this one to lay their eggs. To date, the only confirmed record of RES successfully breeding outdoors in NZ is in an outdoor exhibit at a zoo (Feldman 1992). In this instance, a concrete wall was believed to have acted as a heat sink which presumably exposed the developing eggs to higher temperatures than they would have normally experienced. 
Like many reptiles, RES exhibit temperature-dependent sex determination; females are produced at higher temperatures (above approximately $30^{\circ} \mathrm{C}$ ) and males are produced at cooler temperatures (below approximately $28^{\circ} \mathrm{C}$ ), with both sexes produced at a pivotal temperature around $29^{\circ} \mathrm{C}$ ) (Congdon and Gibbons 1990; Etchberger et al. 1991; Dodd et al. 2006; Dodd et al. 2006). As data included into the RES degree-day model encompassed both male and female producing temperatures, our predictions for RES are valid for the production of both sexes in this species. If it was found that New Zealand conditions could only produce male RES hatchlings, it would not constitute a self-sustaining population. This may still be a concern, however, as with the constant release of unwanted pet RES (Hoskins 2006) and escapes from captivity (Kikillus, unpublished data), including females with the ability to store sperm (O'Keeffe 2006), the wild population would be artificially and regularly supplemented.

As some additional sites within New Zealand are close to reaching the number of degree-days indicated by the model (Table 2), it is possible that RES may be produced in these locations if future years are slightly warmer. Temperatures in the upper North Island were slightly above normal in 2007 and 2008, but slightly below normal in 2009 (NIWA 2008; NIWA 2009; NIWA 2010). Additionally, as females can travel over $1.5 \mathrm{~km}$ from the water to nest (Morreale and Gibbons 1986), other potential nesting sites should be investigated. Further validation of the degree-day models and their implications for the establishment success or failure of reptiles in the New Zealand pet trade requires incubating eggs in the laboratory at the temperature profiles recorded by our dataloggers. 


\section{Other exotic reptile species}

Dataloggers were deployed in sites most relevant to RES, as they are the most common exotic reptile pet in New Zealand (see Chapter 2) and previous studies have identified climatically suitable areas for RES in New Zealand (Kikillus et al. 2010). However, these potential nesting sites are also relevant to the other freshwater turtles included in this study, snake-neck turtles and Reeves turtles, which also excavate flask-shaped nests near water bodies (Dayi and Chunshan 1988; Palmer-Allen et al. 1991; Ernst et al. 1997). Snake-neck turtle embryos are able to withstand a considerable variation in temperature and still hatch normally (Goode and Russell 1968). The average temperatures recorded in natural nests is approximately $20^{\circ} \mathrm{C}$, but can range between $12.5^{\circ} \mathrm{C}$ and $32^{\circ} \mathrm{C}$ (Parmenter 1985). In the lab, snake-neck turtle eggs incubated at a temperature constantly below $24^{\circ} \mathrm{C}$ do not complete development, therefore eggs in the wild appear to take advantage of the periods when temperatures are above this threshold and conducive for embryonic development (Palmer-Allen et al. 1991). As snake-neck turtles fulfilled degree-day model predictions for $44 \%$ of the New Zealand study sites, further research into this species is warranted. There have, however, been very few reports of lost snake-neck turtles in New Zealand (See Appendix 2). Snake-neck turtles are more expensive than RES, therefore owners may be less likely to allow them to escape captivity. Further research is also needed focusing on the nest sites selection of the other reptile species, specifically lizards. The datalogger sites selected for this study are unlikely to be utilised by exotic reptiles found in arid regions, such as bearded dragons, leopard geckos, and Greek tortoises, but may be suitable for waterdragons, which live near freshwater sources. In their native range, female waterdragons at high altitude locations appear to nest at shallower depths than those at low altitude locations, and similarly, waterdragons in 
drier areas tend to dig deeper nest chambers than those in areas where more soil moisture content is present (Doody 2009). Further research is needed on this species' potential nest site selection in New Zealand.

In this study, the "search window" (time allowed for degree-day accumulation) was based on development rates of eggs incubated at constant temperatures. Studies have shown that eggs incubated at fluctuating temperatures can take longer to hatch than those incubated at constant temperatures (Les et al. 2009), therefore if we were to expand our "search window", more species would have accumulated sufficient degree-days in more locations. Nonetheless, even with our conservative time-frames, multiple exotic reptile species may encounter temperatures sufficient for successful egg incubation within the New Zealand environment.

\section{Successful incubation requirements}

While the thermal environment is vital in the development of reptile eggs, several other factors that must be taken into account before concluding that exotic reptiles have the ability to breed and establish wild populations in New Zealand. Soil moisture content is an important factor which influences water uptake and loss by eggs; if conditions are too dry, the eggs will desiccate (Congdon and Gibbons 1990; Belinsky et al. 2004). For example, some researchers consider that the soil conditions in New Zealand are too dry to allow proper egg development of RES (Feldman 2009). Also, established invasive mammals prey upon native wildlife and eggs (King 2005) and may destroy the nests and eggs before they complete development. Additionally, while adult RES are considered to be hardy animals capable of surviving winters in New Zealand (Hoskins 2006), the survival rate of juvenile RES is unknown. In regards to temperature requirements, captive adult RES are often kept in outdoor 
ponds in New Zealand, but it is recommended to rear juveniles indoors for the first few years of their life as they are not believed to be able to survive in outdoor conditions at a young age (Thornton 1999; Burne 2000). Adult RES are also more commonly reported "lost" or "missing" than juvenile RES by pet owners (see Chapter 2). If air and soil temperatures rise as predicted in the future (Solomon et al. 2007) more sites may be capable of providing sufficient heat for the development of RES eggs and the survival of hatchlings. It is also important to remember that not every egg in a natural nest may experience the same temperatures as the others. A temperature gradient can be found within nests, with temperatures at the top of the nest generally warmer than those at the bottom (Birchard 2004). In natural snakeneck turtle nests, a difference of almost $6^{\circ} \mathrm{C}$ has been recorded between the top and bottom eggs (Palmer-Allen et al. 1991).

Metabolic activity of the developing eggs may also increase the surrounding temperatures (Burger 1976; Ackerman and Lott 2004), and in nests with large clutches, the eggs at the core of the nest can be substantially warmer than those along the periphery (Birchard 2004). Therefore, our temperature recordings are only a representation of temperatures that may be experienced by developing eggs; further research involving actual nests is needed.

\section{Conservation Implications}

This study is broadly consistent with a bioclimatic model for RES predicting which areas may be most climatically suitable (Kikillus et al. 2010). A physiological model such as this one provides a complement to bioclimatic model and gives an understanding of the suitability of particular habitats and microsites, based on a specified physiological requirement. In conclusion, certain microsites in northern 
New Zealand appear to provide suitable soil temperatures for egg incubation of at least three exotic reptile species: red-eared slider turtles, snake-neck turtles, and Reeves turtles. However, further research of potential nest conditions, sex ratios, juvenile survival, and potential climate change are needed in order to determine if these or other exotic reptiles are indeed capable of establishing self-sustaining populations in New Zealand. The degree-day model used in this study has been previously utilised to predict range limits of other species in New Zealand, and can be applied to further species that are dependent on temperature conditions in order to successfully complete development. 


\section{Literature cited}

Ackerman, R. A. and D. B. Lott (2004). Thermal, hydric and respiratory climate of nests. Reptilian incubation: Environment, evolution and behaviour. D. C. Deeming. Nottingham, United Kingdom, Nottingham University Press: 15-44.

Baek, S., K. Cho, Y. H. Song and J.-L. Lee (2008). "Degree-day based models for forecasting the flight activity of adult Helicoverpa assulta (Lepidoptera: Noctuidae) in hot pepper fields." International Journal of Pest Management 54(4): 295-300.

Belinsky, A., R. A. Ackerman, R. Dmi'el and A. Ar (2004). Water in reptilian eggs and hatchlings. Reptilian incubation: Environment, evolution and behaviour. D. C. Deeming. Nottingham, United Kingdom, Nottingham University Press.

Birchard, G. F. (2004). Effects of incubation temperature. Reptilian incubation: Environment, evolution and behaviour. D. C. Deeming. Nottingham, United Kingdom, Nottingham University Press: 103-124.

Broufas, G. D. and D. S. Koveos (2000). "Threshold temperature for post-diapause development and degree-days to hatching of winter eggs of the European red mite (Acari: Tetranychidae) in northern Greece." Environmental Entomology 29(4): 710713.

Burger, J. (1976). "Temperature relationships in nests of the northern diamondback terrapin, Malaclemys terrapin terrapin." Herpetologica 32: 412-418.

Burgin, S. (2006). "Confirmation of an established population of exotic turtles in urban Sydney." Australian Zoologist 33(3): 379-384.

Burne, C. (2000). The ultimate guide to keeping freshwater turtles successfully in New Zealand. Napier, New Zealand, Brebner Print.

Chapple, D., P. Ritchie and C. Daugherty (2009). "Origin, diversification, and systematics of the New Zealand skink fauna (Reptilia: Scincidae)." Molecular Phylogenetics and Evolution 52(2): 470-487.

Chillingworth, M. (2007). Personal Communication: September 6, 2007. Auckland Zoo. Auckland, New Zealand.

Congdon, J. and J. Gibbons (1990). Turtle eggs: their ecology and evolution. Life History and Ecology of the Slider Turtle. J. Gibbons. Washington, DC, USA, Smithsonian Institution Press.

Daugherty, C., G. Patterson, C. Thorn and D. French (1990). "Differentiation of the members of the New Zealand Leiolopisma nigriplantare species complex (Lacertilia: Scincidae)." Herpetological Monographs 4: 61-76.

Dayi, L. and L. Chunshan (1988). "Studies on the breeding ecology of the tortoise, Chinemys reevesii (Gray)." Acta hydrobiologica sinica 1988: 3. 
Dodd, K., C. Murdock and T. Wibbels (2006). "Interclutch variation in sex ratios produced at pivotal temperature in the red-eared slider, a turtle with temperaturedependent sex determination." J. Herpetology 40(4): 544-549.

Dodd, K., C. Murdock and T. Wibbels (2006). "Interclutch variation in sex ratios produced at pivotal temperature in the red-eared slider, a turtle with temperaturedependent sex determination." Journal of Herpetology 40(4): 544-549.

Doody, J. (2009). "Superficial lizards in cold climates: Nest site choice along an elevational gradient." Austral Ecology 34: 773-779.

Dykes, M. (2007). Red-eared slider turtle a potential hazard. Manawatu Standard. Palmerston North, New Zealand. November 10, 2007.

Ernst, C., R. Altenburg and R. Barbour (1997). Turtles of the World, Available online: http://ip30.eti.uva.nl/bis/turtles.php?menuentry=inleiding.

Etchberger, C., J. Phillips, M. Ewert, C. Nelson and H. Prange (1991). "Effects of oxygen concentration and clutch on sex determination and physiology in red-eared slider turtles (Trachemys scripta)." Journal of Experimental Zoology 258: 394-403.

Feldman, M. (1992). "Can turtles reproduce in New Zealand? ." Moko 1992: 14-16.

Feldman, M. (2009). Personal Communication: December 13, 2009.

Forsyth, D., R. Duncan, M. Bomford and G. Moore (2004). "Climatic suitability, lifehistory traits, introduction effort, and the establishment and spread of introduced mammals in Australia." Conservation Biology 18(2): 557-569.

Gill, B., D. Bejakovich and A. Whitaker (2001). "Records of foreign reptiles and amphibians accidentally imported to New Zealand." New Zealand Journal of Zoology 28: $351-359$.

Gill, B. and T. Whitaker (2001). New Zealand Frogs and Reptiles. Auckland, New Zealand, David Bateman.

Goode, J. and J. Russell (1968). "Incubation of eggs of three species of chelid tortoises, and notes on their embryological development." Australian Journal of Zoology 16: 749-761.

Hartley, S. and P. Lester (2003). "Temperature-dependent development of the Argentine ant, Linepithema humile (Mayr) (Hymenoptera: Formicidae): a degree-day model with implications for range limits in New Zealand." New Zealand Entomologist 26: 91-100.

Hoskins, G. (2006). Personal Communication: November 14, 2006. Auckland, New Zealand, Auckland Regional Council. 
Ikemoto, T. and K. Takai (2000). "A new linearized formula for the Law of Total Effective Temperature and the evaluation of line-fitting methods with both variables subject to error." Environmental Entomology 29(4): 671-682.

Invasive Species Specialist Group (ISSG (2006). Retrieved July 12, 2006, from www.issg.org/database/species/ecology.asp?si=71\&ver=print

Invasive Species Specialist Group (ISSG) (2004). 100 of the World's Worst Invasive Alien Species.

Kikillus, K. H., K. M. Hare and S. Hartley (2010). "Minimizing false-negatives when predicting the potential distribution of an invasive species: a bioclimatic envelope for the red-eared slider at global and regional scales." Animal Conservation 13(Suppl. 1): 1-11 (doi:10.1111/j.1469-1795.2008.00299.x).

King, C., Ed. (2005). The handbook of New Zealand mammals: Second edition. Melbourne, Australia, Oxford University Press.

Kraus, F. (2007). Using pathway analysis to inform prevention strategies for alien reptiles and amphibians. Managing Vertebrate Invasive Species Symposium, National Wildlife Research Center, Fort Collins, Colorado, USA, USDA/ APHIS/ WS.

Kraus, F. (2009). Alien reptiles and amphibians: a scientific compendium and analysis, Springer Netherlands.

Les, H., R. Paitz and R. Bowden (2009). "Living at extremes: Development at the edges of viable temperature under constant and fluctuating conditions." Physiological and Biochemical Zoology 82(2): 105-112.

Lever, C. (2003). Naturalized reptiles and amphibians of the world. New York, USA, Oxford University Press.

Mack, R., D. Simberloff, W. Lonsdale, H. Evans, M. Clout and F. Bazzaz (2000). "Biotic invasions: causes, epidemiology, global consequences, and control." Ecological Applications 10(3): 689-710.

Manchester, S. and J. Bullock (2000). "The impacts of non-native species on UK biodiversity and the effectiveness of control." Journal of Applied Ecology 37: 845864.

Mitchell, M. (2007). Personal Communication: September 5, 2007. Auckland Regional Council. Auckland, New Zealand.

Morreale, S. J. and J. W. Gibbons (1986). Habitat suitability index models: Slider turtle. U.S. Fish Wildl. Serv. Biol. Rep. 82: 14.

NIWA (2008). "National Institute of Water and Atmospheric Research: Annual Climate Summaries: 2007." Retrieved May 18, 2010, from http://www.niwa.co.nz/our-science/climate/publications/all/cs/annual/aclimsum 07. 
NIWA (2009). "National Institute of Water and Atmospheric Research: Annual Climate Summaries: 2008." May 18, 2010, from http://www.niwa.co.nz/ourscience/climate/publications/all/cs/annual/aclimsum_08.

NIWA (2010). "National Institute of Water and Atmospheric Research: Annual Climate Summaries: 2009." Retrieved May 18, 2010, from http://www.niwa.co.nz/our-science/climate/publications/all/cs/annual/2009.

O'Keeffe, S. (2006). "Red-eared slider turtle." Retrieved May 3, 2007, from http://www.nrw.qld.gov.au/pests/pest_animals/declared/red_eared_slider.html.

Palmer-Allen, M., F. Beynon and A. Georges (1991). "Hatchling sex ratios are independent of temperature in field nests of the Long-necked turtle, Chelodina longicollis (Testudinata: Chelidae)." Wildlife Research 18: 225-231.

Parmenter, C. J. (1985). Reproduction and survivorship of Chelodina longicollis (Testudinata: Chelidae). Biology of Australasian Frogs and Reptiles. G. Grigg, R. Shine and H. Ehmann. Chipping Norton, NSW, Australia, Surrey Beatty \& Sons Pty Ltd. .

Pimentel, D., Ed. (2002). Biological Invasions: Economic and environmental costs of alien plant, animal, and microbe species. Boca Raton, Florida, USA, CRC Press LLC.

Rodda, G., C. Jarnevich and R. Reed (2009). "What parts of the US mainland are climatically suitable for invasive alien pythons spreading from Everglades National Park?" Biological Invasions 11(2): 241-252.

Solomon, S., D. Qin, M. Manning, Z. Chen, M. Marquis, K. Averyt, M. Tignor and H. Miller, Eds. (2007). Contribution of Working Group I to the Fourth Assessment Report of the Intergovernmental Panel on Climate Change. Cambridge, United Kingdom, Cambridge University Press.

Thornton, T. (1999). Keeping red-eared turtles in New Zealand. Warkworth, New Zealand, TJ's Books. 


\title{
Chapter 6:
}

\section{Salmonella prevalence and detected serovars associated with captive exotic reptiles in New Zealand ${ }^{2}$}

\begin{abstract}
AIM: To investigate the prevalence of Salmonella in captive introduced reptile species in New Zealand and identify the serovars associated with this population. Our hypothesis was that Salmonella prevalence in captive exotic reptiles in New Zealand would be higher than that found in wild New Zealand reptiles and similar to that found in captive reptiles overseas. Further we hypothesised that the captive exotic reptiles in New Zealand would carry a wider diversity of Salmonella serotypes than wild native reptiles.
\end{abstract}

METHODS: Cloacal swabs were obtained from 378 captive exotic reptiles, representing 24 species, residing in 25 collections throughout New Zealand. Samples were cultured for Salmonella and suspected colonies were serotyped by ESR. Epidemiological information was gathered to identify risk factors for infection including reptile species, age and sex class, group size, observations of hygiene protocols, the type of captive institute, and whether the enclosures were indoors or outdoors.

\footnotetext{
${ }^{2}$ Based on KH Kikillus, BD Gartrell, and E Motion (in review) Salmonella prevalence and detected serovars associated with captive exotic reptiles in New Zealand. New Zealand Veterinary Journal.
} 
RESULTS: $11.4 \%$ of the reptiles sampled tested positive for Salmonella. Estimated true prevalence of Salmonella in exotic reptiles in New Zealand is within the range of $12-25 \%$ at the $95 \%$ CI. Significant risk factors for Salmonella infection included reptile species $(\mathrm{p}<0.001$; odds ratio $=0.76)$ and group size $(\mathrm{p}=0.006$; odds ratio $=$ 0.59). Lizards tested positive for Salmonella more often than chelonians. Agamid lizards tested positive more often than any other family group, with an estimated true prevalence within the range of $56-100 \%$ at the $95 \%$ CI. Surprisingly, animals held singly or in groups of 2-5 had a higher prevalence of Salmonella infection than those held in larger groups. Six Salmonella serovars from subspecies I and two from subspecies II were isolated. The most commonly isolated serovar was Salmonella Onderstepoort (30.2\%), followed by $S$. Thompson (20.9\%), S. Potsdam (14\%), $S$. Wangata (14\%), S. Infantis (11.6\%), and $S$. Eastbourne (2.3\%). All of the subspecies I serovars have been previously reported in both reptiles and humans in New Zealand, and include serovars previously associated with disease in humans.

CONCLUSIONS AND CLINICAL RELEVANCE: The prevalence of Salmonella in exotic reptiles detected in this study is much lower than those for reptiles overseas but higher than prevalence reported for wild New Zealand reptiles. Although no novel serovars were identified, we recommend segregating native and exotic reptiles within collections. Veterinarians and reptile keepers are advised to follow hygiene protocols developed to minimise reptile-associated Salmonellosis.

\section{ABBREVIATIONS:}

CDC Center for Disease Control

ERMA Environmental Risk Management Authority

ESR Institute of Environmental Science and Research Ltd. 
MAFBNZ Ministry of Agriculture and Forestry Biosecurity New Zealand XLD Xylose lysine deoxycholate

LIA Lysine-Iron agar

TSI Triple sugar Iron

KEY WORDS: Reptile, lizard, turtle, cloacal swabs, zoonosis, Salmonella, prevalence, serovars, New Zealand

\section{Introduction}

Salmonella infections affect more humans and animals than any other disease (Woodward et al. 1997). There are estimated to be 3 billion human cases worldwide every year (Cooke et al. 2007). Salmonella is responsible for economic losses in New Zealand, with Salmonella Brandenburg implicated in outbreaks of sheep and cattle abortions and human disease in the South Island (Clark et al. 2004; Baker et al. 2007). In New Zealand, Salmonella Typhimurium has been a cause of significant mortality in both introduced and native birds (Alley et al. 2002; Ewen et al. 2007).

Reptiles have long been recognised as a reservoir of Salmonella, and in some studies up to $90 \%$ of reptiles are estimated to carry and shed the bacteria in their faeces asymptomatically (Chiodini and Sundberg 1981; Woodward et al. 1997). Salmonella can be spread amongst reptiles via faeces, contaminated soil, and eggs may become exposed whilst passing through the cloaca (Chiodini and Sundberg 1981; Mitchell and Shane 2000). Outbreaks of reptile associated salmonellosis are commonly reported in people (Chiodini and Sundberg 1981; Schroter et al. 2004; Harris et al. 2009). Wild reptiles may act as reservoirs of Salmonella for livestock. For example, native New Zealand geckos and skinks are thought to have been the source of a Salmonella Saintpaul infection in sheep in the late 1960s (McInnes 1971). 
The keeping of exotic reptiles is a popular hobby in New Zealand, however reptiles are no longer legally imported for the pet trade. The importation of the most common exotic reptile pet, the red-eared slider turtle (Trachemys scripta elegans) was halted in 1965 due to concern that the turtles may be bringing novel serovars of Salmonella into the country (Feldman 2005). More recently, several green iguanas (Iguana iguana), were confiscated from their owners, declared to be a new organism in New Zealand by the Environmental Risk Management Authority (ERMA), and euthanased on the basis of carrying Salmonella Mountpleasant, which at that time was considered to be exotic to New Zealand (Bingham 2006; Anonymous 2010a).

There has been research conducted on the Salmonella carriage rates of wild native New Zealand reptiles (Gartrell et al. 2007; Middleton et al. 2010), however the Salmonella carriage rates of captive exotic reptiles in New Zealand is unknown. Sightings of escaped or deliberately released exotic reptiles, primarily red-eared slider turtles, are commonly reported in New Zealand (Kikillus et al. 2010). As Salmonella bacteria are extremely hardy (Otokunefor et al. 2003) and are capable of remaining viable for several months in water and soil, and for over two years in faeces (Chiodini and Sundberg 1981), it is suspected that exotic reptiles may act as a reservoir of Salmonella for native species and humans in New Zealand.

The aim of this study was to determine prevalence of Salmonella in captive exotic reptiles in New Zealand and the Salmonella serovars associated with this population. Our hypothesis was that Salmonella prevalence in captive exotic reptiles in New Zealand would be higher than that found in wild New Zealand reptiles 
(Middleton et al. 2010) and similar to that found in captive reptiles overseas (Chiodini and Sundberg 1981; Geue and Loschner 2002; Chen et al. 2010). Further we hypothesised that the captive exotic reptiles in New Zealand would carry a wider diversity of Salmonella serotypes than wild native reptiles.

\section{Materials and methods}

We identified 120 pet stores, private breeders/collections and zoos that were believed to hold exotic reptiles throughout the North and South Islands of New Zealand. These were approached for involvement in the study by letter and follow up phone call and 25/120 (20.8\%) agreed to take part. During 2008 and 2009, 378 reptiles were sampled from 5 pet stores, 12 private collections/ reptile breeders, and 8 zoos/wildlife parks throughout New Zealand. Cloacal swabs (Copan Diagnostics, 2175 Sampson Ave., Suite 124, Corona, CA 92879, USA) taken from captive exotic reptiles on the premises.

Epidemiological information collected from each institution included species, age, and sex of animals, group size within enclosures, whether the enclosures were indoors or outdoors, the type of institution (private holder, pet store or zoological institute), whether other reptile species (including native reptiles) were kept at the same institute. We also recorded whether the reptile keepers were observed to use hand-washing or disinfection between handling animals as a simple measure of hygiene protocols. 


\section{Chapter 6: Salmonella in exotic reptiles}

Participation in the study was voluntary and confidential. Victoria University of Wellington Animal Ethics approval was obtained for sampling reptiles (\#2006R18). Swabs were kept refrigerated and submitted to the laboratory for processing within 5 days, where they were inoculated onto MacConkey agar and XLD agar with Novobiocin (Fort Richard Laboratories, Auckland, New Zealand). Swabs were then inoculated into $2.5 \mathrm{ml}$ of sterile saline which was then divided equally and inoculated into Tetrathionate broth and Selenite Cystine broth (Fort Richard Laboratories). The MacConkey and XLD with Novobiocin agar plates were examined after overnight incubation $\left(37^{\circ} \mathrm{C}\right.$, in normal atmosphere for $18-24$ hours) for Non-Lactose fermenting colonies and red colonies with black centres, respectively. Any suspect colonies from either agar were isolated and emulsified in one drop of sterile saline on a microscope slide, tested for agglutination with Polyvalent Salmonella antisera (O and H antigens), and subcultured into Lysine-Iron agar (Corrente et al.) and Triple sugar Iron agar slopes (TSI) (Fort Richard Laboratories). Suspect colonies were also subcultured onto Columbia sheep blood agar, MacConkey agar, and a Nutrient agar slope (Fort Richard Laboratories) to check for purity. Incubation was again at $37^{\circ} \mathrm{C}$ in normal atmosphere for 18-24 hours. The Tetrathionate and Selenite Cystine broths were subcultured after incubation onto a new XLD with Novobiocin plate and incubated for a further 18-24 hours. Any suspect colonies were subjected to the tests above. Any colonies that resulted in glucose fermentation and Hydrogen sulfide production on TSI slopes, and a positive lysine decarboxylase reaction on LIA, as well as agglutination with Polyvalent Salmonella antisera were submitted to the Institute of Environmental Science and Research Ltd. (ESR) for confirmation and serotyping (Table 1). Salmonella subspecies I were identified as named serovars. Salmonella 
subspecies II do not have specific names. In total, 378 individuals from 24 species were sampled and assayed.

\section{Statistical analysis}

The prevalence rates of Salmonella were calculated (Thrusfield 2005) assuming that the Salmonella culture was $50 \%$ sensitive and $98 \%$ specific (Bager \& Petersen 1991). True prevalence (P) was estimated from test prevalence (PT) using the equation $\mathrm{P}=(\mathrm{PT}+$ specificity -1$) /($ sensitivity + specificity -1$)$.

Ninety-five percent confidence intervals (95\% CI) are reported, where: $95 \% \mathrm{CI}=\mathrm{P} \pm 1.96 \sqrt{ }$ variance, and

Variance $=[\mathrm{PT}(1-\mathrm{PT})] /\left[\mathrm{n}(\text { sensitivity }+ \text { specificity }-1)^{2}\right]$, where $n=$ sample size. An overall apparent prevalence as well as an estimated true prevalence was calculated.

A logistic regression was carried out using EpiInfo 3.5.1 (Centers for Disease Control and Prevention, United States Department of Health and Human Services, Atlanta, Georgia, USA) to assess the significance of epidemiological factors (institute, institute type, age class, group size, hygiene observations, indoor vs outdoor enclosures) on the risk of Salmonella infection. All institutes kept multiple species of reptile so this factor was not included in the analysis.

Prevalence was compared between lizards and chelonians (turtles) and also between family groups using chi-squared analysis. Chameleons and geckos were 


\section{Chapter 6: Salmonella in exotic reptiles}

excluded from the analysis between family groups due to the low sample size of these subsets. For groups in which no Salmonella was detected, the Detection of Disease component of Win Episcope 2.0 (Thrusfield et al. 2001) was used to calculate the 95\% confidence range for the maximum possible prevalence. As no records of total numbers of exotic reptiles in New Zealand exist, estimates were made for the purpose of this analysis. Gekkonidae were estimated at 75 individuals and Chamaeleonidae at 25 individuals. The frequency of Salmonella infection within group sizes was analysed using chi-squared analysis.

We compared the prevalence of Salmonella in the exotic reptiles in this study to Middleton et al. (2010) results in native reptiles using chi-squared analysis.

\section{Results}

Forty-three of 378 captive exotic reptiles (11.4\%) were positive for Salmonella on a single cloacal sample. The estimated true prevalence ranged from $12 \%-25 \%(95 \% \mathrm{CI})$. Logistic regression (Table 2) showed that the factors measured did not fully explain the outcome of Salmonella infection (Likelihood ratio $=69.088$, $\mathrm{df}=7, \mathrm{p}<0.001)$ but that reptile species $(\mathrm{p}<0.001$; odds ratio $=0.76)$ and group size $(\mathrm{p}=0.02$; odds ratio $=0.65)$ were significant risk factors for Salmonella infection. Ten of the $24(41.7 \%)$ reptile species tested were positive. Although chelonians (turtles) outnumbered lizards in this study (263 vs. 115), there was a significantly higher prevalence of Salmonella in lizards than chelonians (27\% for lizards, and $4 \%$ for chelonians; $\left.\chi^{2}=44.3, \mathrm{df}=1, \mathrm{p}<0.001\right)$. 
Table 1: The prevalence and type of serovar of Salmonella isolated from captive exotic reptiles within New Zealand. The final two columns refer to Salmonella subspecies II isolates identified as a) 40: g,[m],[s],t : [1,5] and b) 40: g,t : - .

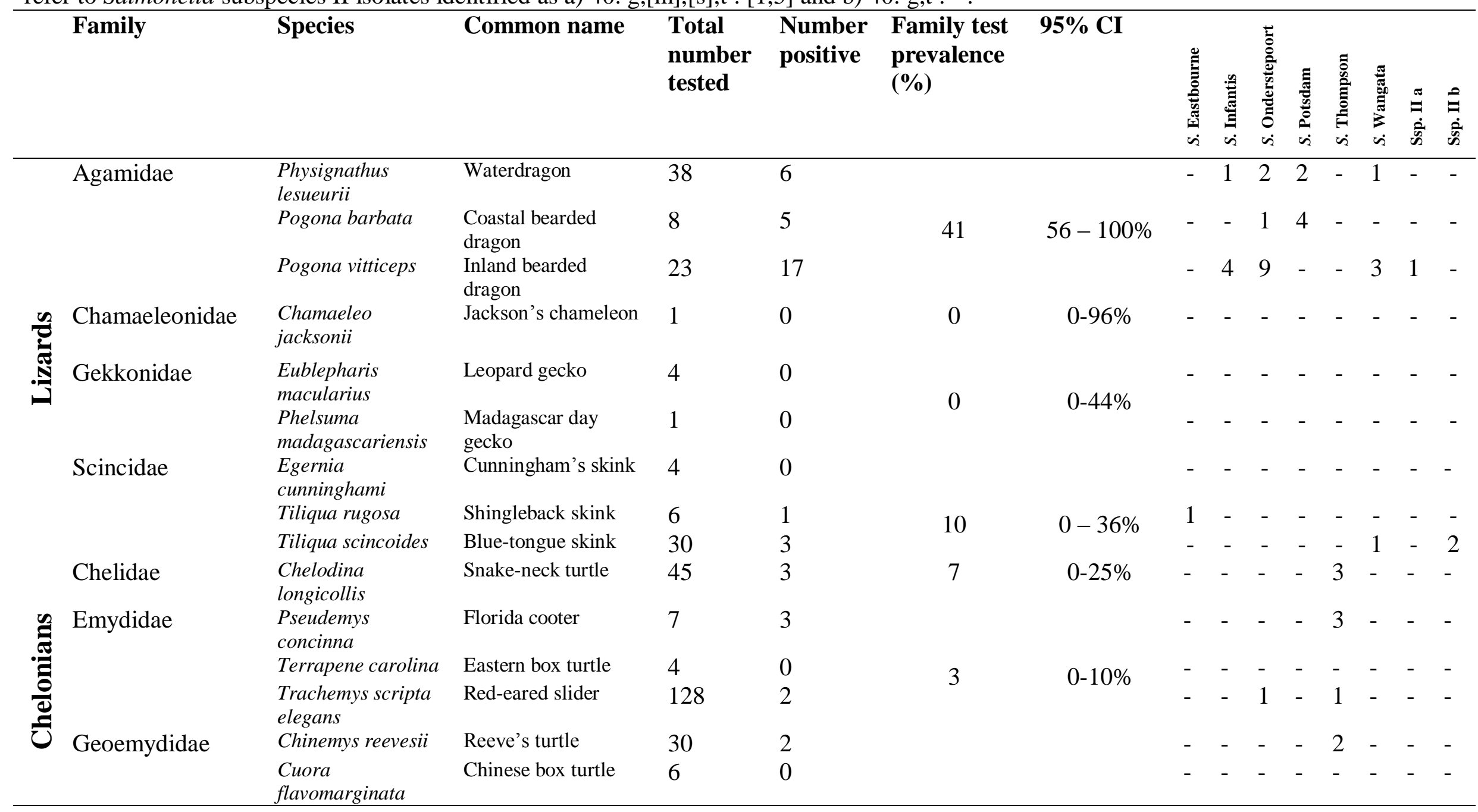




\section{Chapter 6: Salmonella in exotic reptiles}

\begin{tabular}{|c|c|c|c|c|c|c|c|c|c|c|c|c|c|c|}
\hline & Cuora amboinensis & Asian box turtle & 2 & 0 & & & - & - & - & - & - & - & - & - \\
\hline & $\begin{array}{l}\text { Cyclemys atripons } \\
\text { (?) }\end{array}$ & Leaf turtle & 8 & 0 & 4 & $0-17 \%$ & - & - & - & - & - & - & - & - \\
\hline \multirow[t]{7}{*}{ Testudinidae } & $\begin{array}{l}\text { Geochelone } \\
\text { chilensis }\end{array}$ & Chaco tortoise & 1 & 0 & & & - & - & - & - & - & - & - & - \\
\hline & $\begin{array}{l}\text { Geochelone } \\
\text { denticulata }\end{array}$ & $\begin{array}{l}\text { Yellow-footed } \\
\text { tortoise }\end{array}$ & 2 & 0 & & & - & - & - & - & - & - & - & - \\
\hline & $\begin{array}{l}\text { Geochelone } \\
\text { elegans }\end{array}$ & Star tortoise & 2 & 0 & 3 & $0-14 \%$ & - & - & - & - & - & - & - & - \\
\hline & $\begin{array}{l}\text { Geochelone } \\
\text { pardalis }\end{array}$ & Leopard tortoise & 2 & 0 & & & - & - & - & - & - & - & - & - \\
\hline & $\begin{array}{l}\text { Gopherus } \\
\text { berlandieri }\end{array}$ & Texas tortoise & 3 & 0 & & & - & - & - & - & - & - & - & - \\
\hline & Testudo graeca & Greek tortoise & 14 & 1 & & & - & - & - & - & - & 1 & - & - \\
\hline & Testudo hermanni & Hermanns tortoise & 9 & 0 & & & - & - & - & - & - & - & - & - \\
\hline
\end{tabular}


There were significant differences in prevalence of Salmonella between family groups (Table $1 ; \chi^{2}=73.9, \mathrm{df}=5, \mathrm{p}<0.001$ ). Agamid lizards had the highest rate of Salmonella carriage, with $41 \%$ (28 of 69) of the swabs testing positive and an estimated true prevalence in the range of $56 \%-100 \%$ (95\% CI). Two family groups in which Salmonella was not detected were the Gekkonidae (represented by 4 Leopard geckos, Eublepharis macularius, and 1 Madagascar day gecko, Phelsuma madagascariensis), and the Chamaeleonidae (represented by a single Jackson's chameleon, Chamaeleo jacksonii), but these families had a very small number of individuals tested. Incorporating these negative results with a total population estimate and a $95 \%$ confidence interval, the maximum possible prevalence of Salmonella that this study failed to detect could be up to $44 \%$ for Gekkonidae and $96 \%$ for Chamaeleonidae.

There was a significant difference in the prevalence of Salmonella infection according to the group size within an enclosure $\left(\chi^{2}=28.65, \mathrm{df}=4, \mathrm{p}<0.001\right)$. Counter-intuitively, the prevalence of Salmonella infection was higher in solitary reptiles $(38.5 \%, 10 / 26)$ than those kept in groups of $2-5(13.9 \%, 23 / 142)$; groups of 6$10(9.7 \%, 6 / 62)$; groups of $11-15(0 \%, 0 / 16)$ or in groups greater than $15(3.7 \%$ 4/105).

Six Salmonella subspecies I serovars and two Salmonella subspecies II were isolated (Table 1). The most commonly isolated serovar was Salmonella Onderstepoort (30.2\%), followed by $S$. Thompson (20.9\%), S. Potsdam (14\%), S. Wangata (14\%), S. Infantis (11.6\%), and S. Eastbourne (2.3\%). All of the subspecies I serovars have been previously recorded in both reptiles and humans in New Zealand 
(Anonymous 2010); these records, however, do not consistently distinguish between native and exotic reptiles. Salmonella subspecies II do not have specific names, and this type naturally does not express a second phase flagella antigen. The two isolates of subspecies II were characterised by serology as Salmonella subspecies II 40 : g,t : and Salmonella subspecies II 40: $\mathrm{g},[\mathrm{m}],[\mathrm{s}], \mathrm{t}:[1,5]$. This is the first report of the latter serovar in New Zealand.

While the majority of specimens were sampled once, we had the opportunity to retest 5 Florida cooter turtles (Psuedemys concinna). Three turtles which had tested positive for Salmonella the first time tested negative one year later. The remaining two turtles tested negative on both visits.

The prevalence of Salmonella in captive exotic reptiles in this study was significantly higher $\left(\chi^{2}=15.7, \mathrm{df}=1, \mathrm{p}<0.001\right)$ than the previously reported rates in wild native reptiles (Middleton et al. 2010). 
Table 2: The results of unconditional logistic regression for the outcome of Salmonella infection against the risk factors of institute, institute type, age class, group size, hygiene observations, and indoor vs outdoor enclosures from a survey of 378 exotic reptiles kept in 25 captive institutes in New Zealand.

\begin{tabular}{llllllll}
\hline Term & Odds Ratio & $\mathbf{9 5 \%}$ & C.I. & Coefficient & S. E. & Z-Statistic & P-Value \\
\hline Age_class & 0.6225 & 0.3687 & 1.0512 & -0.474 & 0.2673 & -1.7731 & 0.0762 \\
Group_size & $\underline{0.6526}$ & $\underline{0.4542}$ & $\underline{0.9377}$ & -0.4268 & 0.1849 & -2.3081 & $\underline{0.021}$ \\
Hygiene_observed & 0.6061 & 0.2089 & 1.7586 & -0.5007 & 0.5435 & -0.9212 & 0.3569 \\
Indoor & 0.4095 & 0.1674 & 1.0017 & -0.8929 & 0.4564 & -1.9562 & 0.0504 \\
Institute_type & 0.73 & 0.4781 & 1.1145 & -0.3147 & 0.2159 & -1.4578 & 0.1449 \\
Institution_Key & 1.01 & 0.9453 & 1.0791 & 0.0099 & 0.0338 & 0.2935 & 0.7691 \\
Species & $\underline{0.7645}$ & $\underline{0.6913}$ & $\underline{0.8454}$ & -0.2686 & 0.0514 & -5.2288 & $\underline{0.0000}$ \\
CONSTANT & $*$ & $*$ & $*$ & 4.2223 & 1.5425 & 2.7373 & $\underline{0.0062}$ \\
\hline
\end{tabular}




\section{Discussion}

This study found the estimated true prevalence of Salmonella in exotic reptiles in New Zealand was much lower than reported prevalence of Salmonella in reptiles overseas, which can be over 90\% (Koopman and Janssen 1973; Chiodini and Sundberg 1981; Woodward et al. 1997), but significantly higher than the prevalence reported in native reptiles in New Zealand (Gartrell et al. 2007; Middleton et al. 2010). The diversity of Salmonella serovars isolated in our study differs from those found in wild native lizards by Middleton et al. (2010), who isolated eleven serovars of Salmonella enterica including S. Bousso, S. Warragul, S. Mississippi, S. Mana, and S. Saintpaul. The only serovar in common to both studies was $S$. Infantis. All Salmonella serotypes identified in this study have been previously reported in both reptiles and humans in New Zealand (Anonymous 2010a), however the ESR database does not differentiate between native and exotic reptiles.

This study isolated several serovars of Salmonella with known pathogenicity to humans, including $S$. Infantis, which is one of the most common Salmonella serovars isolated from both humans and non-human sources in New Zealand (Broughton et al. 2010). A review of ESR records shows that in New Zealand, Salmonella Onderstepoort has been isolated only once in humans from a 3 month old child and apart from a food isolate 16 years ago, has otherwise only been isolated from reptiles (Anonymous 2010a). Salmonella Wangata has only been isolated in New Zealand in reptiles since 2008 and has only been isolated from 9 human samples (Anonymous 2010a). Salmonella Thompson consistently ranks as one of the top ten most common serotypes isolated from humans worldwide (Galanis et al. 2006). In 


\section{Chapter 6: Salmonella in exotic reptiles}

New Zealand, Salmonella Thompson is commonly found in human, poultry and bovine samples (Anonymous 2010a). Salmonella Potsdam is commonly isolated from reptiles overseas (Hidalgo-Vila et al. 2008) and is the most common strain found in aquatic turtles in Europe (Hidalgo-Vila et al. 2007). In New Zealand, S. Potsdam has only been isolated from reptiles and one ovine sample, and human cases in New Zealand are commonly associated with overseas travel (Anonymous 2010a). Salmonella Eastbourne isolates in New Zealand have mostly been from reptiles with the exceptions of one ovine and thirteen human samples. No human isolates have been reported since 2004 (Anonymous 2010a).

Of the Salmonella serovars detected in this study, only $S$. Infantis and $S$. Thompson have been implicated in reptile deaths overseas (Johnson-Delaney 2006). Surprisingly, we found no evidence of some common Salmonella serovars widespread in New Zealand such as $S$. Typhimurium DT160 (wild birds) or $S$. Brandenburg (livestock and gulls). We also found no evidence of $S$. Mountpleasant, which has been previously detected in captive green iguanas in New Zealand, and was used as circumstantial evidence for an overseas origin of the reptiles.

Salmonella subspecies II isolates are considered to be commensals of poikilothermic vertebrates such as reptiles and only rarely cause disease in humans (Katribe et al. 2009). In New Zealand, S. subspecies II are isolated predominantly from reptiles or environmental samples (Anonymous 2010a).

Consistent with several studies overseas, more lizards than chelonians in our study tested positive for Salmonella (de Sá and Solari 2001; Pfleger et al. 2003). 


\section{Chapter 6: Salmonella in exotic reptiles}

Surprisingly, we found a low prevalence of Salmonella in red-eared slider turtles (Trachemys scripta elegans) (1.5\%). In a similar study of pet reptiles in Brazil, redeared slider turtles constituted the majority of Salmonella- positive chelonians (93.3\%) (de Sá and Solari 2001), and in the early 1970s, red-eared slider turtles were linked to over a quarter of a million cases of salmonellosis in humans in the United States (Jacobsen 2007). Due to the high numbers of human Salmonella infections attributed to reptile pets overseas, the United States has banned the sale of pet turtles under 4 inches $(10.2 \mathrm{~cm}$ ) in length since 1975 (Anonymous 2010b). It was believed that young children may have perceived tiny turtles as desirable objects and were therefore more likely to handle them (Mitchell and Shane 2001). It was assumed that larger turtles would be less appealing for children and thus less likely to infect them with Salmonella (Johnson-Delaney 2006). Today, American pet stores are trying to circumvent the ban by giving away small turtles to customers who purchase turtle habitats (Grady 2005) or sell them as "educational animals", which are not covered by the pet ban (Mitchell and Shane 2001). Although this change in legislation aimed to lessen the likelihood of direct contact between infected reptiles and young children, reptile-associated salmonellosis can just as easily be acquired via indirect contact (Mermin et al. 1997; Friedman et al. 1998). Allowing a pet reptile to roam free throughout the house or washing reptile cages in kitchen areas have been linked to Salmonella infections in humans that have not had direct contact with the reptile (Mermin et al. 1997; Willis et al. 2002). Given the prevalence of Salmonella in exotic reptiles within New Zealand found in this study, we suggest that veterinarians and reptile keepers should educate pet owners about reptile-associated salmonellosis. Children less than 5 years of age and immunocompromised people are at higher risk 
of more serious complications from reptile associated salmonellosis (Mermin et al. 2004).

The limitations of this study include the sampling design, the assumptions inherent in the true prevalence statistics and the difficulties inherent in comparing prevalence studies that use different methodology. Our sampling design was predicated by the need for voluntary and confidential inclusion in the study. Possible biases in our sample include our reliance on publicly available information to identify reptile keepers and that participants volunteering for the study may have been less likely to hold illegally imported animals. Some of the assumptions required for the estimation of true prevalence are also open to question. The sensitivity of cloacal sampling for the detection of asymptomatic Salmonella carriage varies widely. In the absence of specific studies in reptiles, we chose $50 \%$ sensitivity based on a study in pigs (Bager and Petersen 1991) because that has been used in previously published prevalence studies of Salmonella in New Zealand reptiles (Gartrell et al. 2007; Middleton et al. 2010). Our estimates for the total population size of captive exotic reptiles in New Zealand are also based on publicly available sources and may be flawed. Finally, the comparison of our results between the previously published data on reptiles must be tempered by the knowledge that differing microbial culture methodology was used, which has been shown to influence the sensitivity of Salmonella cultures (Bager and Petersen 1991; Corrente et al. 2004; Bauwens et al. 2006).

Reptiles can be intermittent shedders of Salmonella, which can make detection difficult (Kelsey et al. 1997). It is thought that stress is a factor which 
makes reptiles more likely to excrete the bacteria (Chiodini and Sundberg 1981). Pfleger et al. (2003) found it difficult to repeat results with samples from individual animals. Similarly, we found inconsistent results with the few animals that we sampled twice. The three Florida cooter turtles (Psuedemys concinna) which tested positive for Salmonella the first time and negative the next year, had, in the meantime, undergone an enclosure renovation and, based on research done by their owner, were being fed a new vegetable-based diet which was deemed more appropriate for the species. It is possible that the new setup and diet contributed to their lack of excretion of Salmonella on the second sampling visit.

The treatment of reptiles for Salmonella is controversial (Mitchell and Shane 2001). Due to the intermittent excretion, it is difficult to determine if the bacteria have indeed been eliminated (Chiodini and Sundberg 1981) and there are concerns that treatment may also lead to antibiotic-resistant strains of Salmonella (D'Aoust et al. 1990). As many reptiles carry Salmonella with no apparent ill effects, it has been suggested that it is part of the normal bacterial flora of these animals (McCoy and Seidler 1973). Importantly, reptiles are not the only organisms which can act as vectors of Salmonella and possibly introduce novel serovars into New Zealand. Mammals (including humans), birds, and fish are all capable of carrying the bacteria and transmitting it to other organisms (Tillotson et al. 1997; Seepersadsingh and Adesiyun 2003). It is likely that human visitors to a free-living island population of the endangered New Zealand passerine, Notiomystis cincta (hihi), were responsible for the introduction of a fatal Salmonella Typhimurium DT195 infection in a number of the birds (Ewen et al. 2007). Situations such as this imply that global human travellers, and perhaps even migratory birds, seem to be more likely candidates to 
introduce novel strains of Salmonella into New Zealand than exotic reptiles. If reptiles are to be imported, however, it is recommended that they undergo a Salmonella screening to identify any serovars that may not yet have been recorded in New Zealand.

The epidemiological factors assessed in this study did not fully explain the outcome of Salmonella infection in the captive exotic reptiles, however we identified species of reptile and group size to be the most important risk factors of those we assessed. Counter intuitively, reptiles kept singly or in small groups (2-5 animals) were more likely to be infected with Salmonella. The underlying pathophysiological explanation for this result is unknown and worthy of further investigation. Some further suggested risk factors to consider may include seasonality of sampling, health history and origin of sampled animals, feed type used, and other aspects of management such as enclosure size, biosecurity, exposure to wild animals and rodents. These aspects of captive management have been shown in other reptiles to facilitate the transmission of Salmonella within reptile collections (Mitchell and Shane 2001; Pfleger et al. 2003).

Many reptile keepers in New Zealand keep both native and exotic reptiles. Restoration of reptile biodiversity by translocation is a commonly used conservation technique in New Zealand (Towns and Ferreira 2001) and the use of captive stocks to replenish wild reptile populations has been advocated (Santos et al. 2009). Based on the diversity of Salmonella serovars and the high prevalence rates in captive exotic reptiles identified in this study, we recommend that, as a minimum, native and exotic 
reptiles should be separated in captive collections and biosecurity measures used to minimise the risk of transmission of novel Salmonella serovars to native reptiles.

\section{Acknowledgements}

We thank the many owners of exotic reptiles in New Zealand that allowed us to sample their collections. Sample collection procedures were approved by the Victoria University of Wellington (VUW) Animal Ethics Committee (\#2006R18). Salmonella cultures were carried out by New Zealand Veterinary Pathology, Palmerston North and Hamilton. Funding was provided by VUW, the New Zealand Wildlife Health Centre, Palmerston North, the Centre for Biodiversity and Restoration Ecology, Wellington, and the Ian Swingland Scholarship Fund. Also thanks to Andrew Smith for fieldwork assistance, and Danielle Middleton, Kelly Hare, the VUW Herpetological Hatchet group, and 3 anonymous reviewers for providing comments to greatly improve this manuscript. 


\section{Literature cited}

Alley MR, Connolly JH, Fenwick SG, Mackereth GF, Leyland MJ, Rogers LE, Haycock M, Nicol C, Reed CEM. An epidemic of salmonellosis caused by Salmonella Typhimurium DT160 in wild birds and humans in New Zealand. New Zealand Veterinary Journal 50, 170-6, 2002

Anonymous. Enteric Reference Laboratory. http://www.surv.esr.cri.nz/enteric_reference/enteric_reference.php (accessed January 7, 2010). Environmental Science and Research, Auckland, New Zealand, 2010a

Anonymous. Centre for Veterinary Medicine: Salmonella and Turtle Safety. http://www.fda.gov/AnimalVeterinary/GuidanceComplianceEnforcement/Co mplianceEnforcement/ucm090573.htm (accessed August 31, 2010). U.S. Food and Drug Administration, Silver Spring, MD, USA, 2010b

Bager F, Petersen J. Sensitivity and specificity of different methods for the isolation of Salmonella from pigs. Acta veterinaria scandinavica 32, 473-81, 1991

Baker MG, Thornley CM, Lopez LD, Garrett NK, Nicol CM. A recurring salmonellosis epidemic in New Zealand linked to contact with sheep. Epidemiology and Infection 135, 76-83, 2007

Bauwens L, Vercammen F, Bertrand S, Collard JM, De Ceuster S. Isolation of Salmonella from environmental samples collected in the reptile department of Antwerp Zoo using different selective methods. Journal of Applied Microbiology 101, 284-9, 2006

Bingham P. Quarterly report of investigations of suspected exotic diseases. Surveillance 33, 17-23, 2006

Broughton E, Heffernan H, Cloes C. Salmonella enterica serotypes and antibiotic susceptibility in New Zealand, 2002-2007. Epidemiology and Infection 138, $322-9,2010$

Chen CY, Chen WC, Chin SC, Lai YH, Tung KC, Chiou CS, Hsu YM, Chang CC. Prevalence and antimicrobial susceptibility of salmonellae isolates from reptiles in Taiwan. Journal of Veterinary Diagnostic Investigation 22, 44-50, 2010

Chiodini R, Sundberg J. Salmonellosis in reptiles: A review. American Journal of Epidemiology 113, 494-9, 1981

Clark R, Nicol C, Marchant R, Swanney S, Gill J, Holmes J, Leyland M, Davies P. Salmonella Brandenburg - emergence of a new strain affecting stock and humans in the South Island of New Zealand. New Zealand Veterinary Journal $52,26-36,2004$ 
Cooke F, Threlfall E, Wain J. Current trends in the spread and occurrences of human salmonellosis: Molecular typing and emerging antibiotic resistance. In: Rhen M, Maskell D, Mastroeni P, Threlfall J (eds). Salmonella: Molecular Biology and Pathogenesis. Pp 1-34. Cromwell Press, Norfolk, UK, 2007

Corrente M, Madio A, Friedrich KG, Greco G, Desario C, Tagliabue S, D'Incau M, Campolo M, Buonavoglia C. Isolation of Salmonella strains from reptile faeces and comparison of different culture media. Journal of Applied Microbiology 96, 709-15, 2004

D'Aoust JY, Daley E, Crozier M, Sewell AM. Pet turtles: A continuing international threat to public health. American Journal of Epidemiology 132, 233-8, 1990

de Sá IVA, Solari CA. Salmonella in Brazilian and imported pet reptiles. Brazilian Journal of Microbiology 32, 293-7, 2001

Ewen J, Thorogood R, Nicol C, Armstrong D, Alley M. Salmonella typhimurium in hihi, New Zealand. Emerging Infectious Diseases 13, 788-90, 2007

Feldman M. The Red-eared slider turtle (Trachemys scripta elegans) in New Zealand. In: '13th Australasian Vertebrate Pest Conference '. Wellington, New Zealand Pp 96-101. Landcare Research, New Zealand, 2005

Friedman C, Hoffman R, DeWitt W. An outbreak of salmonellosis among children attending a reptile exhibit at a zoo. The Journal of Pediatrics 132, 802-7, 1998

Galanis E, Wong D, Patrick M, Binsztein N, Cieslik A, Chalermchaikit T, AidaraKane A, Ellis A, Angulo F, Wegener H. Web-based surveillance and global Salmonella distribution, 2000-2002. Emerging Infectious Diseases 12, 381-8, 2006

Gartrell B, Youl J, King C, Bolotovski I, McDonald W, Nelson N. Failure to detect Salmonella species in a population of wild tuatara (Sphenodon punctatus). New Zealand Veterinary Journal 55, 134-6, 2007

Geue L, Loschner U. Salmonella enterica in reptiles of German and Austrian origin. Veterinary Microbiology 84, 79-91, 2002

Grady D. Tiny pet turtles return; Salmonella does, too. In: New York Times. (New York, New York, USA) March 15, 2005

Harris JR, Bergmire-Sweat D, Schlegel JH, Winpisinger KA, Klos RF, Perry C, Tauxe RV, Sotir MJ. Multistate Outbreak of Salmonella Infections Associated With Small Turtle Exposure, 2007-2008. Pediatrics 124, 1388-94, 2009

Hidalgo-Vila J, Díaz-Paniagua C, de Frutos-Escobar C, Jiménez-Martínez C, PérezSantigosa N. Salmonella in free-living terrestrial and aquatic turtles. Veterinary Microbiology 119, 311-5, 2007 
Hidalgo-Vila J, Díaz-Paniagua C, Pérez-Santigosa N, de Frutos-Escobar C, HerreroHerrero A. Salmonella in free-living exotic and native turtles and in pet exotic turtles from SW Spain. Research in Veterinary Science 85, 449-52, 2008

Jacobsen ER. Bacterial diseases of reptiles. In: Jacobsen ER (ed) Infectious Diseases and Pathology of Reptiles. Pp 461-526. CRC Press, Boca Raton, Florida, USA, 2007

Johnson-Delaney W. Reptile zoonoses and threats to public health. In: Mader DR (ed) Reptile Medicine and Surgery. Pp 20-32. Saunders Elsevier, St. Louis, Missouri, USA, 2006

Katribe E, Bogomolnaya LM, Wingert H, Andrews-Polymenis H. Subspecies IIIa and IIIb Salmonellae are defective for colonization of murine models of Salmonellosis compared to Salmonella enterica subsp I serovar Typhimurium. Journal of Bacteriology 191, 2843-50, 2009

Kelsey J, Ehrlich M, Henderson S. Exotic reptile bites. American Journal of Emergency Medicine 15, 536-7, 1997

Kikillus K, Hare K, Hartley S. Minimizing false-negatives when predicting the potential distribution of an invasive species: a bioclimatic envelope for the red-eared slider at global and regional scales. Animal Conservation 13, 1-11, 2010

Koopman J, Janssen F. The occurrence of salmonellas and lactose-negative Arizonas in reptiles in The Netherlands, and a comparison of three enrichment methods used in their isolation. The Journal of Hygiene 71, 363-71, 1973

McCoy RH, Seidler R. Potential pathogens in the environment: Isolation, enumeration, and identification of seven genera of intestinal bacteria associated with small green pet turtles. Applied Microbiology 25, 534-8, 1973

McInnes H. Salmonella saintpaul infection of sheep with lizards as possible reservoirs. New Zealand Veterinary Journal 19, 163-4, 1971

Mermin J, Hoar J, Angulo F. Iguanas and Salmonella Marina infection in children: A reflection of the increasing incidence of reptile-associated salmonellosis in the United States. Pediatrics 99, 399-402, 1997

Mermin J, Hutwagner L, Vugia D, Shallow S, Daily P, Bender J, Koehler J, Marcus R, Angulo FJ. Reptiles, amphibians, and human Salmonella infection: A population-based, case-control study. Clinical Infectious Diseases 38, S253S61, 2004

Middleton D, Minot E, Gartrell B. Salmonella enterica serovars in lizards of New Zealand's offshore islands. New Zealand Journal of Ecology 34, 27-52, 2010 
Mitchell MA, Shane SM. Preliminary findings of Salmonella spp. in captive green iguanas (Iguana iguana) and their environment. Preventative Veterinary Medicine 45, 297-304, 2000

Mitchell MA, Shane SM. Salmonella in reptiles. Seminars in Avian and Exotic Pet Medicine 10, 25-35, 2001

Otokunefor T, Kindzeka B, Ibiteye I, Osuji G, Obi F, Jack A. Salmonella in gut and droppings of three pest lizards in Nigeria. World Journal of Microbiology and Biotechnology 19, 545-8, 2003

Pfleger S, Benyr G, Sommer R, Hassl A. Pattern of Salmonella excretion in amphibians and reptiles in a vivarium. International Journal of Hygiene and Environmental Health 206, 53-9, 2003

Santos T, Perez-Tris J, Carbonell R, Telleria JL, Diaz JA. Monitoring the performance of wild-born and introduced lizards in a fragmented landscape: Implications for ex situ conservation programmes. Biological Conservation 142, 2923-30, 2009

Schroter M, Roggentin P, Hofmann J, Speicher A, Laufs R, Mack D. Pet snakes as a reservoir for Salmonella enterica subsp diarizonae (serogroup IIIb): a prospective study. Applied and Environmental Microbiology 70, 613-5, 2004

Seepersadsingh N, Adesiyun A. Prevalence and antimicrobial resistance of Salmonella spp. in pet mammals, reptiles, fish aquarium water, and birds in Trinidad. Journal of Veterinary Medicine 50, 488-93, 2003

Thrusfield MV. Describing disease occurrence. In: Veterinary Epidemiology, 3rd edition. Pp 46-74. Blackwell Science, Oxford, UK, 2005

Thrusfield MV, Ortega C, de Blas I, Noordhuizen JP, Frankena K. Win Episcope 2.0: Improved epidemiological software for veterinary medicine. Veterinary Record 148, 567-72, 2001

Tillotson K, Savage C, Salman M, Gentry-Weeks C, Rice D, Fedorka-Cray P, Hendrickson D, Jones R, Nelson A, Traub-Dargatz J. Outbreak of Salmonella Infantis infection in a large animal veterinary teaching hospital. Journal of the American Veterinary Medical Association 211, 1554-7, 1997

Towns DR, Ferreira SM. Conservation of New Zealand lizards (Lacertilia : Scincidae) by translocation of small populations. Biological Conservation 98, 211-22, 2001

Willis C, Wilson T, Greenwood M. Pet reptiles associated with a case of salmonellosis in an infant were carrying multiple strains of Salmonella. Journal of Clinical Microbiology 40, 4802-3, 2002

Woodward D, Khakhria R, Johnson W. Human salmonellosis associated with exotic pets. Journal of Clinical Microbiology 35, 2786-90, 1997 


\title{
Chapter 7:
}

\section{Overall establishment risk assessment of exotic reptiles in New Zealand}

\begin{abstract}
Overseas, invasive reptiles are associated with both economic impacts and negative effects on native fauna. This study uses a modified Australian risk assessment model to investigate the establishment risk of twelve species of exotic reptile known to exist in captivity in New Zealand. By incorporating, and assigning a relative score, to the factors of 1) Climate match, 2) History of exotic populations elsewhere, 3) Taxonomic class, and 4) Propagule pressure (factors proven to be important in successful invasions), the establishment risk of exotic reptiles was able to be investigated and compared between species. Blotched blue-tongue lizards (Tiliqua nigrolutea) and red-eared slider turtles (Trachemys scripta elegans) were found to pose the highest establishment risk in New Zealand, and Reeves turtles (Chinemys reevesii), inland bearded dragons (Pogona vitticeps), leopard geckos (Eublepharis macularius), and shingleback skinks (Tiliqua rugosa), the least. Redeared slider turtles (RES) are the most popular and affordable exotic reptile pet in New Zealand and the only species known to be regularly released into the local environment. For this reason, efforts to reduce the amount of releases, as well as the removal of feral individuals from the environment need to be made priorities. It is important that a balance be found between realistic biosecurity concerns for New Zealand and the benefits of keeping exotic reptiles. Regulatory actions, such as a
\end{abstract}




\section{Chapter 7: Exotic reptile establishment risk}

permitting process and/or microchipping of exotic reptile pets may help to prevent the release of other species into the wild, and hence prevent their potential establishment.

\section{Introduction}

Pest risk assessments generally focus on preventing the establishment of an alien species in a particular area (Andersen 2007). While "the scientific discipline of risk assessment is in its infancy" (Andersen et al. 2004), risk assessments are often used to decide which potential pests to focus management efforts upon. They also may provide justification for the allocation of scarce resources. Although these predictions are associated with a level of uncertainty (Sikder et al. 2006), it is often more desirable and cost-effective to attempt to identify potential invaders than to control a species once it has become established (Manchester and Bullock 2000). Eradication of introduced species is costly (Ruesink et al. 1995) and success is not guaranteed.

Conducting risk assessments for exotic reptiles can be challenging as often only limited information regarding many species is available (Kraus 2009). In Australia, the risk from exotic reptiles was previously assessed via a generic risk analysis used for all exotic vertebrates (Bomford 2003), however in 2005, this risk assessment model was tailored specifically to exotic reptiles and amphibians (Bomford et al. 2005). In this new model, the authors discussed several factors which may be related to the establishment of invasive reptiles (such as broad environmental tolerances, ability to live in human-disturbed habitats, female able to colonize an area by herself) and identified four key factors which appear to be consistently associated with the successful introduction of exotic reptiles into new habitats: 1) "Propagule pressure" (the number of founding individuals and/or release events), 2) "Climate 


\section{Chapter 7: Exotic reptile establishment risk}

match" (the degree of similarity between a species native range and the area investigated), 3) "History of exotic populations elsewhere" (under the assumption that if a species has proven it is capable of invading an area outside of its native range, it may likely be able to invade additional areas), and 4) "Taxonomic group" (as some groups of reptiles have become invasive more than others).

A study of non-native constrictor snakes in the continental USA incorporated factors such as "total maximum size" (assuming that larger species may pose a higher risk) and "fecundity" (the highest known clutch or litter size, assuming that animals with higher reproductive output may pose a greater establishment threat than species with lower reproductive output) (Reed 2005). Reed (2005) also suggested that the use of additional ecological information (e.g., age at maturity) would be useful data to incorporate into a risk assessment. This information, however, is not always available for wild populations and data from captive collections may not be transferrable to animals living outside of captivity.

In Florida, USA, however, researchers did attempt to incorporate such variables into a reptilian risk assessment (Fujisaki et al. 2010). These included "total body size", "number of years required to reach sexual maturity", "clutch size", "frequency of reproduction", and "possible parthenogenesis", among others. The authors admit that there were gaps in the knowledge and obtaining this information was difficult. While this information was not insignificant, the authors found better performing predictors to include taxonomic class, degree of climate match, and human-related variables, such as "manageability" and "price” (Fujisaki et al. 2010).

Human-related variables were also incorporated in a study which investigated the drivers of the exotic reptile pet trade in South Africa (van Wilgen et al. 2010). Researchers considered factors such as aesthetic appeal (e.g., colour, patterns, 


\section{Chapter 7: Exotic reptile establishment risk}

interesting features, etc.), manageability, and sale price. As alien reptiles are often introduced to new locales by humans (i.e., via the pet trade) (Kraus 2009), it is reasonable to incorporate human-related variables. If a species is not perceived as a good pet (perhaps for reasons such as difficulty to maintain or manage) it is less likely to become abundant (van Wilgen et al. 2010).

New Zealand has a reputation for its unique wildlife, a high proportion of which is endemic (Wilson 2004). The native reptiles include numerous species of lizard, the only extant member of the Order Rhynchocephalia, and migratory sea snakes and sea turtles (Jewell 2008; Chapple and Hitchmough 2009). One species of exotic reptile, the small Australian skink, Lampropholis delicata, has already established in New Zealand (Gill et al. 2001). Worldwide, invasive reptiles have displaced native reptiles through direct predation and competition (Savidge 1988;

Cole et al. 2005). They are also capable of introducing disease (Burridge and Simmons 2003) and precipitating major changes in ecological communities, including extinctions (Rodda et al. 1997; Wiles et al. 2003).

This study uses an Australian risk assessment procedure (Bomford et al. 2005) adapted here to predict the establishment risk of exotic reptiles present in captivity in New Zealand. For those exotic reptiles currently within New Zealand that are found to have the ability to establish wild populations, appropriate and cost-effective management actions can be taken to avoid negative consequences to the environment and economy. On the other hand, for those species found to pose no threat to New Zealand, commercial breeders will be able to safely supply reptiles to the lucrative local pet trade without further regulation. 


\section{Methods}

\section{Study species}

Today, the New Zealand exotic reptile trade is restricted to $\sim 10$ species (Chapter 1), and these were investigated in this risk assessment. These are the redeared slider turtle (Trachemys scripta elegans; RES), inland bearded dragon (Pogona vitticeps), common blue-tongue skink (Tiliqua scincoides), snake-neck turtle (Chelodina longicollis), waterdragon (Physignathus lesueurii), Reeves turtle (Chinemys reevesii), coastal bearded dragon (Pogona barbata), Greek tortoise (Testudo graeca), Hermanns tortoise (T. hermanni), and leopard gecko (Eublepharis macularius). Two additional species which are known to exist in New Zealand zoos, but whose status within the New Zealand pet trade is unclear, the blotched bluetongue skink (Tiliqua nigrolutea) and the shingleback skink (T. rugosa) were also included. These species have recently been classified as a "Surveillance Pest" (meaning prohibition of the sale, breeding, and exhibition) and as a "pest when not held in secure confinement", respectively, in the Auckland region (Auckland Regional Council 2007). More information regarding the general biology of these species is presented in detail in Appendices 1-8. While these species of exotic reptile are present within New Zealand, there has been no integrated or comparative risk assessment of these species. 


\section{Chapter 7: Exotic reptile establishment risk}

\section{Selection of criteria and methods for risk assessment}

As the information required for the Bomford et al. (2005) model is readily available for all of the species of exotic reptile traded in New Zealand, and as the area in which this risk assessment was performed is geographically closest to New Zealand, this analysis model (with some modifications, see below) was chosen to be applied to the twelve species of exotic reptile outlined above. The model incorporated the following factors: 1) climate match, 2) history of exotic populations elsewhere, and 3) taxonomic family (see below for more details). Although Bomford et al. (2005) discusses the importance of propagule pressure to invasion success, it was not included in their risk assessment as information regarding this is seldom available. Some risk assessments for exotic reptiles address the issue of propagule pressure by incorporating the number of specimens imported into a particular area annually as it provides a better understanding of the number of animals being traded (e.g., (Reed 2005; Fujisaki et al. 2010). New Zealand is unique, however, in that it no longer allows the importation of exotic reptiles. For example, imports of red-eared slider turtles (Trachemys scripta elegans) were halted in 1965 due to the concern that they might introduce novel strains of Salmonella into New Zealand (Feldman 2005). Exotic reptiles that were legally present in the country before the Hazardous Substances and New Organisms Act 1996 (HSNO) can be bred and traded without regulation. Therefore, I modified the existing protocol to include a measure of propagule pressure which was assigned on the basis of animals sold and number of reported releases into the environment (See Chapters 1 and 2 and Appendices 1-8).

The first three key factors in predicting establishment risk were assigned a score based on methods developed by Bomford et al. (2005), which were then added to a "Propagule Pressure Risk Score" (see below) to reach an "Establishment Risk 
Score". This score is then compared to the score range to determine the

Establishment Risk Rank (Table 1). The ranges of the Establishment Risk score are based on Bomford et al. (2005), however for this analysis, the top five score ranges were increased by ten points in order to allow for the extra factor of propagule pressure.

The equation used to determine the risk score is:

Score A + Score B + Score C + Score D = Establishment Risk Score

Where:

Score A = Climate Match Risk Score (0 - 100)

Score B = Exotic Elsewhere Risk Score $(0-30)$

Score C = Taxonomic Family Risk Score $(0-30)$

Score D = Propagule Pressure Risk Score $(0-50)$

Table 1: Method for converting Establishment risk scores to Establishment Risk ranks. Modified from Bomford et al. (2005).

\begin{tabular}{ccc}
\hline $\begin{array}{c}\text { Establishment Risk } \\
\text { Score range (A + B + C) } \\
\text { after Bomford et al. }\end{array}$ & $\begin{array}{c}\text { Establishment Risk Score } \\
\text { range }(\mathbf{A}+\mathbf{B}+\mathbf{C}+\mathbf{D})\end{array}$ & Establishment Risk Rank \\
$\mathbf{( 2 0 0 5 )}$ & & \\
\hline$<20$ & $<20$ & Very Low \\
$20-45$ & $20-55$ & Low \\
$46-60$ & $56-70$ & Moderate \\
$61-84$ & $71-94$ & High \\
$85-115$ & $95-125$ & Very High \\
$>115$ & $>125$ & Extreme \\
\hline
\end{tabular}

The "Climate Match Risk Score" was obtained from the bioclimatic modelling results for each species (See Chapter 4 and Appendix 10). A "relative New Zealand suitability score", with a value between 0 (no match) and 1 (perfect match), was obtained from the result of the weighted multi-model average, then converted to a percentage value by multiplying by 100 , and used as "Score $\mathrm{A}=$ Climate match risk score" in the equation above. 


\section{Chapter 7: Exotic reptile establishment risk}

The "Exotic Elsewhere Risk Score" of Bomford et al. (2005) uses the following guidelines:

- $\quad$ A species that has "established a breeding self-sustaining exotic population in another country" is assigned 30 points

- A species that has "been introduced into another country and for which records of it exist in the wild, but for which it is uncertain if a breeding selfsustaining exotic population has established" is assigned 15 points

- A species that has "not established an exotic population, including species not known to have been introduced elsewhere" is assigned $\mathbf{0}$ points

For the New Zealand risk assessment, I chose to define "another country" as "another jurisdiction", as many Australian species have been moved throughout Australia and established in areas in which they were not believed to have existed before (e.g., Tiliqua rugosa on South Australian offshore islands) (Sarre et al. 1990). Although still within the same country (and often near their native range), this conservative standpoint considers any reported introduction of a species into the wild regardless of the area.

Based on previous research of successful and failed introductions of reptiles and amphibians, Bomford et al. (2005) assigned Taxonomic Family Risk Scores based on the number of successful introductions per group. Table 2 shows the scores given to the reptilian groups present within New Zealand and investigated in this analysis. 
Table 2: Taxonomic Family Risk Scores assigned to some reptile families by Bomford et al. (2005).

\begin{tabular}{lll}
\hline \multicolumn{1}{c}{ Family } & \multicolumn{1}{c}{$\begin{array}{c}\text { Relevant species in the New Zealand pet } \\
\text { trade }\end{array}$} & $\begin{array}{c}\text { Taxonomic } \\
\text { Family Risk Score }\end{array}$ \\
\hline Gekkonidae & leopard gecko (Eublepharis macularius) & 30 \\
Agamidae & $\begin{array}{l}\text { bearded dragon (Pogona vitticeps } \text { and } P . \\
\text { barbata) } \\
\text { waterdragon (Physignathus lesueurii) }\end{array}$ & 30 \\
Testudinidae & $\begin{array}{l}\text { Greek tortoise (Testudo graeca) } \\
\text { Hermanns tortoise (T. hermanni) }\end{array}$ & 15 \\
Scincidae & $\begin{array}{l}\text { common blue-tongue skink (Tiliqua scincoides) } \\
\text { blotched blue-tongue skink (T. nigrolutea) } \\
\text { shingleback skink (T. rugosa) }\end{array}$ & 15 \\
Emydidae & red-eared slider (Trachemys scripta elegans) & 15 \\
Chelidae & snake-neck turtle (Chelodina longicollis) & 10 \\
Geoemydidae & Reeves turtle (Chinemys reevesii) & 0 \\
\hline
\end{tabular}

For the "Propagule Pressure Risk Score", I devised the following guidelines applicable to the New Zealand pet trade based on the number of online sales and reported losses during the period between October 2007 and October 2009 (See Chapters 1 and 2 and Appendices 1-8).

- A species which is known to be regularly released into the New Zealand environment and common in the pet trade is assigned $\mathbf{5 0}$ points

- A species which has at least one reported release of a single individual into the wild and/or is common in the pet trade is assigned 25 points

- A species which has no reported releases and/or is uncommon or nonexistent in the pet trade is assigned $\mathbf{1 0}$ points

- A species not present in the country and never previously recorded entering the country is assigned $\mathbf{0}$ points

A species was considered "common" if $>90$ animals were sold within the timeframe investigated. Similarly, an animal was classified as "uncommon" if $<25$ 


\section{Chapter 7: Exotic reptile establishment risk}

specimens were sold during the same period. No species received a "Propagule Pressure Risk Score" of 0 , as once a species is present in a particular country or jurisdiction, there is no such thing as a "zero escape risk" (Shine et al. 2000). A summary graph and table were constructed to visualise the results and to compare species (Figure 1 and Table 3).

\section{Results}

$\underline{\text { Red-eared slider turtle (Trachemys scripta elegans) }}$

Red-eared sliders received a New Zealand Suitability Score of 0.19 based on the multimodel average (the "conservative dataset (confirmed breeding location records only) was used in this analysis). (See Chapter 3 and Appendix 10). This corresponds to a "Climate Match Risk Score" of 19 for the Bomford et al. (2005) risk assessment model. As red-eared sliders have been introduced throughout the world and established invasive populations in numerous countries (Lever 2003; Ernst and Lovich 2009), they received an "Exotic Elsewhere Risk Score" of 30. Based on the Bomford model's taxonomic classification table (Table 2), red-eared sliders received a "Taxonomic Family Risk Score" of 15. Red-eared sliders were assigned a "Propagule Pressure Risk Score" of 50, as they are common in the pet trade and are regularly released into the local environment.

Establishment risk score $(A+B+C+D)=(19+30+15+50)=\mathbf{1 1 4}=$ Very High Inland bearded dragon (Pogona vitticeps)

Based on the multimodel average (See Chapter 4), Pogona vitticeps received a New Zealand suitability score of 0.03 , which translated to a "Climate Match Risk Score" of 3. No records of any introductions of Pogona vitticeps outside of their 


\section{Chapter 7: Exotic reptile establishment risk}

native range could be found; therefore they were assigned a score of 0 for the "Exotic Elsewhere Risk Score". According to taxonomic classification, inland bearded dragons received a "Taxonomic Family Risk Score" of 30. Inland bearded dragons were assigned a "Propagule Pressure Risk Score" of 25, as at least one specimen has been reported to escape into the environment (see Appendix 5) and they are considered common in the New Zealand pet trade.

Establishment risk score $(\mathrm{A}+\mathrm{B}+\mathrm{C}+\mathrm{D})=(3+0+30+25)=\mathbf{5 8}=$ Moderate

\section{Blue-tongue skink (Tiliqua scincoides)}

Blue-tongue skinks received a New Zealand Suitability Score of 0.39, giving them a "Climate Match Risk Score" of 39. This species is listed on a database for the "Florida Invasive Species Partnership" (Invasive.org 2010), but no details regarding the location or impacts of any alien populations are given. Tiliqua scincoides has also been reported to be translocated throughout Australia in produce shipments (O'Dwyer et al. 2000), and therefore receives an "Exotic Elsewhere Risk Score" of 15. Finally, according to Bomford et al. (2005)'s taxonomic table (Table 2), the Family Scincidae receives a Taxonomic Family Risk Score of 15. Common blue-tongue skinks were assigned a "Propagule Pressure Risk Score" of 25 points as they are considered to be common in the pet trade.

Establishment Risk Score $(\mathrm{A}+\mathrm{B}+\mathrm{C}+\mathrm{D})=(39+15+15+25)=\mathbf{9 4}=\mathbf{H i g h}$ Snake-neck turtle (Chelodina longicollis)

According to the multimodel average (Chapter 4), snake-neck turtles received a New Zealand Suitability Score of 0.40, giving them a "Climate Match Risk" Score of 40. There are reports that Chelodina longicollis has been introduced to Tasmania 


\section{Chapter 7: Exotic reptile establishment risk}

(Low 2002), however an exact location or breeding status is unclear, therefore snakeneck turtles were given an "Exotic Elsewhere Risk Score" of 15 points. Using the information from Bomford et al. (2005), the Family Chelidae receives a "Taxonomic Family Risk" Score of 10. Snake-neck turtles were assigned a "Propagule Pressure Risk Score" of 25 as at least one specimen has been reported to have escaped into the environment (see Appendix 2) and they are considered common in the New Zealand pet trade.

Establishment risk score $(\mathrm{A}+\mathrm{B}+\mathrm{C}+\mathrm{D})=(40+15+10+25)=\mathbf{9 0}=\mathbf{H i g h}$

\section{Waterdragon (Physignathus lesueurii)}

Based on the multimodel average (Chapter 4), Physignathus lesueurii received a New Zealand Suitability Score of 0.26 , which translates to a "Climate Match Risk Score" of 26. Low (2002) reports that waterdragons are now living in the Melbourne area after being "set free by someone along the Yarra". Details regarding breeding status are not given, therefore waterdragons were assigned an "Exotic Elsewhere Risk Score" of 15 points. According to Table 2, waterdragons receive a "Taxonomic Family Risk Score" of 30. Waterdragons were assigned a "Propagule Pressure Risk Score" of 25 as they are considered common in the pet trade.

Establishment risk score $(A+B+C+D)=26+15+30+25=96=$ Very High

\section{$\underline{\text { Reeves turtle (Chinemys reevesii) }}$}

Reeves turtles received a New Zealand Suitability Score of 0.07 (Chapter 4), which translates to a "Climate Match Risk Score" of 7. Reeves turtles have been introduced into North America, but reports do not elaborate on if these animals are breeding, or on any potential impacts caused by these animals. Many reports are of 


\section{Chapter 7: Exotic reptile establishment risk}

single individuals thought to be released pets. (Fuller and Foster 2000). For these reasons, Chinemys reevesii are assigned an "Exotic Elsewhere Risk Score" of 15. Based on Table 2, Reeves turtles receive a "Taxonomic Family Risk Score" of 0. Reeves turtles were assigned a "Propagule Pressure Risk Score" of 10 as they are considered uncommon in the pet trade.

Establishment risk score $(\mathrm{A}+\mathrm{B}+\mathrm{C}+\mathrm{D})=(7+15+0+10)=\mathbf{3 2}=$ Low

\section{Coastal bearded dragon (Pogona barbata)}

In Chapter 4, coastal bearded dragons received a New Zealand Suitability Score of 0.37, which translates to a "Climate Match Risk Score" of 37. One specimen, a captive pet, was reportedly released onto Heron Island in Australia (Mather and Bennett 1984). Although it did not survive, published evidence of an introduction outside of its native range meant that Pogona barbata was assigned an "Exotic Elsewhere Risk Score" of 15 points. According to the taxonomic categories outlined in Table 2, coastal bearded dragons were assigned a "Taxonomic Family Risk Score" of 30. Coastal bearded dragons were assigned a "Propagule Pressure Risk Score" of 10 as they are considered uncommon in the pet trade.

Establishment risk score $(\mathrm{A}+\mathrm{B}+\mathrm{C}+\mathrm{D})=(37+15+30+10)=\mathbf{9 2}=\mathbf{H i g h}$

\section{Greek tortoise (Testudo graeca)}

Based on the multimodel average (Chapter 4), Greek tortoises received a New Zealand Suitability Score of 0.16, which translates to a "Climate Match Risk Score" of 16. Testudo graeca has been introduced into areas outside of its native range and become established (Lever 2003), and is therefore assigned an "Exotic Elsewhere Risk Score" of 30. Utilising the information in Table 2, Greek tortoises are assigned 
a "Taxonomic Family Risk Score" of 15. Greek tortoises were assigned a "Propagule Pressure Risk Score" of 10 as they are considered uncommon in the pet trade.

Establishment risk score $(\mathrm{A}+\mathrm{B}+\mathrm{C}+\mathrm{D})=(16+30+15+10)=\mathbf{7 1}=\mathbf{H i g h}$

\section{Hermanns tortoise (Testudo hermanni)}

Similar to Testudo graeca, T. hermanni received a New Zealand Suitability score of 0.17 , which corresponds to a "Climate Match Risk Score" of 17 . Hermanns tortoises have also been introduced into areas outside of their native range, although in many areas their breeding status is uncertain. In northern France, however, north of the species' native range, Lever (2003) reports of a "thriving colony"; therefore $T$. hermanni received an "Exotic Elsewhere Risk Score" of 30. Also similar to $T$. graeca, T. hermanni received a "Taxonomic Family Risk Score" of 15. Hermanns tortoises were assigned a "Propagule Pressure Risk Score" of 10 as they are considered uncommon in the pet trade.

Establishment risk score $(\mathrm{A}+\mathrm{B}+\mathrm{C}+\mathrm{D})=(17+30+15+10)=\mathbf{7 2}=\mathbf{H i g h}$

\section{Leopard gecko (Eublepharis macularius)}

In Chapter 4, leopard geckos received a New Zealand Suitability Score of 0.18, corresponding to a "Climate Match Risk Score" of 18 in the modified Bomford model As no records of the introduction of leopard geckos into areas outside of their could be found, they received an "Exotic Elsewhere Risk Score" of 0. Based on their taxonomic family classification, Eublepharis macularius received a "Taxonomic Family Risk Score" of 30. Leopard geckos were assigned a "Propagule Pressure Risk Score" of 10 as they are considered uncommon in the pet trade.

Establishment risk score $(\mathrm{A}+\mathrm{B}+\mathrm{C}+\mathrm{D})=(18+0+30+10)=\mathbf{5 8}=$ Moderate 


\section{$\underline{\text { Blotched blue-tongue skink (Tiliqua nigrolutea) }}$}

Of all of the species of exotic reptile investigated in Chapter 4, Tiliqua nigrolutea had the highest New Zealand Suitability Score (0.99). This corresponded to a "Climate Match Risk Score" of 99. There do not appear to be any reports of blotched blue-tongue skinks being introduced to areas outside of their native range; therefore they were assigned an "Exotic Elsewhere Risk Score" of 0. According to Table 2, members of the Scincidae family receive a "Taxonomic Family Risk Score" of 15. Blotched blue-tongue skinks were assigned a "Propagule Pressure Risk Score" of 10 as they are considered uncommon (and possibly non-existent) in the New Zealand pet trade.

Establishment risk score $(A+B+C+D)=(99+0+15+10)=\mathbf{1 2 4}=$ Very High

\section{Shingleback skink (Tiliqua rugosa)}

Based on the bioclimatic modelling performed in Chapter 4, shingleback skinks received a New Zealand Suitability Score of 0.07 , which corresponds to a "Climate Match Risk Score" of 7. Shingleback skinks are believed to have been introduced to offshore islands of the Yorke Peninsula in South Australia (Sarre et al. 1990). Although these areas are close to the mainland, where Tiliqua rugosa exists naturally, evidence of successful introductions elsewhere earns shingleback skinks an "Exotic Elsewhere Risk Score" of 30. Based on the information in Table 2, Scincidae receive a "Taxonomic Family Risk Score" of 15. Shingleback skinks were assigned a "Propagule Pressure Risk Score" of 10 as they are considered uncommon in the New Zealand pet trade.

\footnotetext{
Establishment risk score $(\mathrm{A}+\mathrm{B}+\mathrm{C}+\mathrm{D})=(7+30+15+10)=\mathbf{6 2}=$ Moderate
} 
Table 3: Breakdown of scores for each component for all species of exotic reptile investigated by a modified Bomford et al. (2005) establishment risk assessment.

\begin{tabular}{|c|c|c|c|c|c|c|}
\hline Species & $\begin{array}{c}\text { Score } \\
\text { A: } \\
\text { Climate } \\
\text { Match } \\
\text { Risk } \\
\text { Score }\end{array}$ & $\begin{array}{c}\text { Score B: } \\
\text { Exotic } \\
\text { Elsewhere } \\
\text { Risk } \\
\text { Score }\end{array}$ & $\begin{array}{c}\text { Score C: } \\
\text { Taxonomic } \\
\text { Family } \\
\text { Risk Score }\end{array}$ & $\begin{array}{c}\text { Score D: } \\
\text { Propagule } \\
\text { Pressure } \\
\text { Risk } \\
\text { Score }\end{array}$ & $\begin{array}{c}\text { Establishment } \\
\text { Risk Score (A } \\
\text { + B + C + D) }\end{array}$ & $\begin{array}{c}\text { Establishment } \\
\text { Risk Rank }\end{array}$ \\
\hline $\begin{array}{l}\text { Red-eared } \\
\text { slider turtle } \\
\text { (Trachemys } \\
\text { scripta } \\
\text { elegans) }\end{array}$ & 19 & 30 & 15 & 50 & 114 & Very High \\
\hline 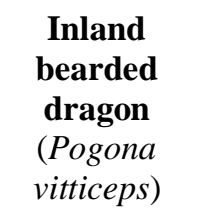 & 3 & 0 & 30 & 25 & 58 & Moderate \\
\hline $\begin{array}{l}\text { Blue-tongue } \\
\text { skink } \\
\text { (Tiliqua } \\
\text { scincoides) }\end{array}$ & 39 & 15 & 15 & 25 & 94 & High \\
\hline $\begin{array}{c}\text { Snake-neck } \\
\text { turtle } \\
\text { (Chelodila } \\
\text { longicollis) }\end{array}$ & 40 & 15 & 10 & 25 & 90 & High \\
\hline $\begin{array}{c}\text { Naterdragon } \\
\text { Physignathus } \\
\text { lesueurii) }\end{array}$ & 26 & 15 & 30 & 25 & 96 & Very High \\
\hline $\begin{array}{l}\text { Reeves turtle } \\
\text { (Chinemys } \\
\text { reevesii) }\end{array}$ & 7 & 15 & 0 & 10 & 32 & Low \\
\hline $\begin{array}{c}\text { Coastal } \\
\text { bearded } \\
\text { dragon } \\
\text { (Pogona } \\
\text { barbata) }\end{array}$ & 37 & 15 & 30 & 10 & 92 & High \\
\hline $\begin{array}{c}\text { Greek } \\
\text { tortoise } \\
\text { (Testudo } \\
\text { graeca) }\end{array}$ & 16 & 30 & 15 & 10 & 71 & High \\
\hline $\begin{array}{c}\text { Hermanns } \\
\text { tortoise } \\
\text { (Testudo } \\
\text { hermanni) }\end{array}$ & 17 & 30 & 15 & 10 & 72 & High \\
\hline $\begin{array}{c}\text { Leopard } \\
\text { gecko } \\
\text { Eublepharis } \\
\text { macularius) }\end{array}$ & 18 & 0 & 30 & 10 & 58 & Moderate \\
\hline
\end{tabular}


Chapter 7: Exotic reptile establishment risk

\begin{tabular}{ccccccc}
$\begin{array}{c}\text { Blotched } \\
\text { blue-tongue } \\
\text { skink } \\
\text { (Tiliqua } \\
\text { nigrolutea) }\end{array}$ & 99 & 0 & 15 & 10 & 124 & Very High \\
$\begin{array}{c}\text { Shingleback } \\
\text { skink } \\
\text { (Tiliqua } \\
\text { rugosa) }\end{array}$ & 7 & 30 & 15 & 10 & 62 & Moderate \\
\hline
\end{tabular}


Figure 1: Summary of Establishment Risk Scores for 12 exotic reptile species within New Zealand using a modified Bomford et al. (2005) risk assessment.

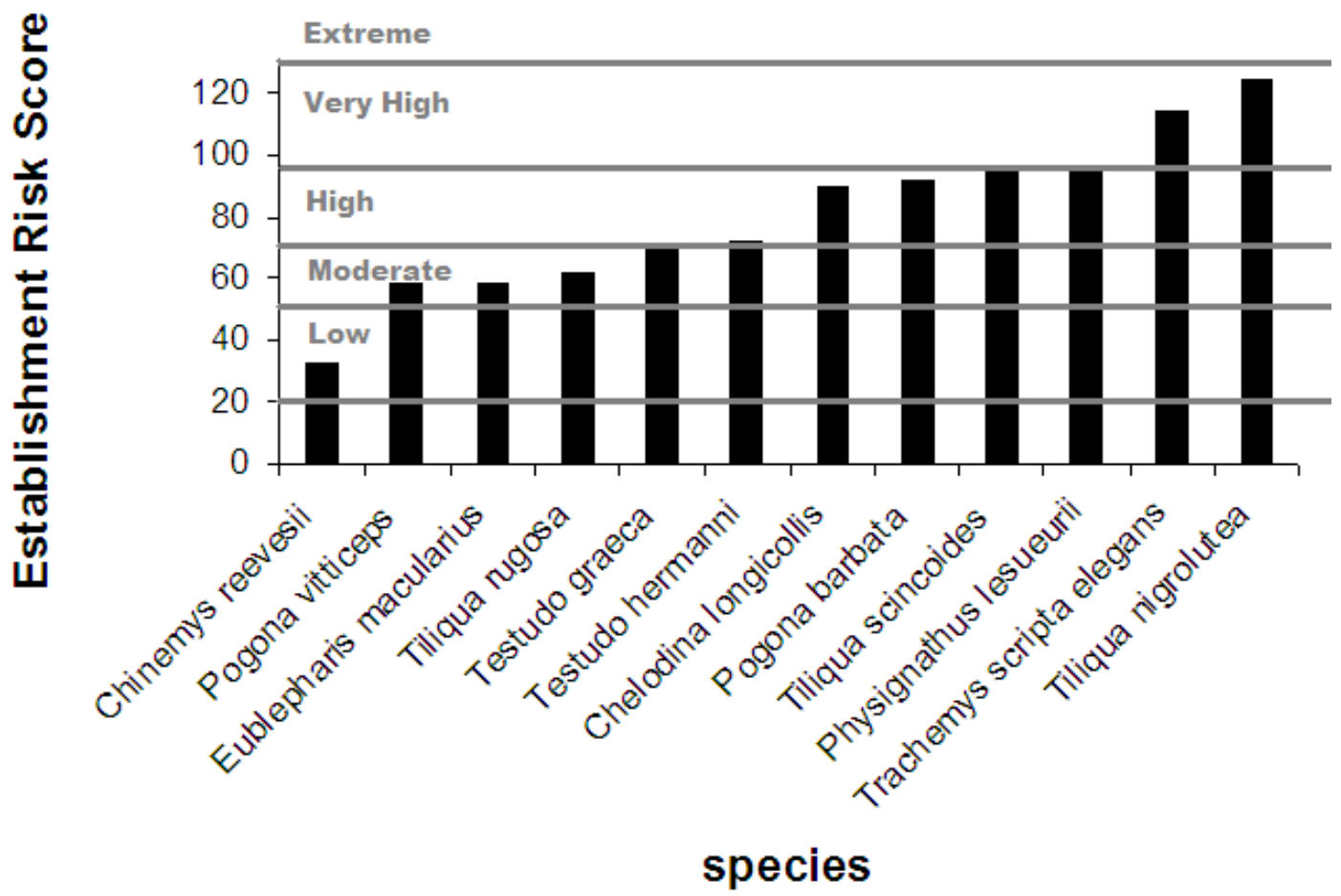

\section{Discussion}

Of the twelve species of exotic reptile investigated via this risk assessment, eight of them have "High" to "Very High" establishment risk. Blotched blue-tongue skinks (Tiliqua nigrolutea), red-eared slider turtles (Trachemys scripta elegans), and waterdragons (Physignathus lesueurii) are predicted to pose the highest establishment risk in New Zealand, and Reeves turtles (Chinemys reevesii), the least. The risk assessment methods outlined here provide a protocol for exotic reptiles in New Zealand and are based on four factors consistently found to be associated with invasive reptiles in many risk assessments: the degree of climate match, a history of exotic populations outside of a species' native range, and taxonomic class, and degree of propagule pressure (Bomford et al. 2005). 


\section{Chapter 7: Exotic reptile establishment risk}

\section{Establishment risk of exotic reptiles in New Zealand}

For red-eared slider turtles, the "conservative dataset" (confirmed breeding records) was used to obtain the Establishment Risk Score (See Chapter 3 and Appendix 10 for details), as successful reproduction is a crucial component of establishing a self-sustaining population. If the "liberal dataset" (all location records) is analysed via this risk assessment, the Establishment Risk Score is increased to "Extreme". This, however, may be an overestimate, as the "liberal dataset" used in the bioclimatic model included location records where feral RES were known to exist, but where breeding was unconfirmed. Non-breeding populations of RES, however, may still impact the environment, as they are long-lived, have the ability to store sperm (Gist and Jones 1989), and feral populations may be regularly supplemented by released pets. Overseas, established exotic populations of RES are reported to outcompete native species for resources (Cadi and Joly 2004), therefore the continued removal of feral exotic reptiles from the New Zealand environment is recommended

The "lower risk" species (those that fell into the categories of "Low" and "Moderate" in the risk assessment) (Reeves turtles, inland bearded dragons, leopard geckos, and shingleback skinks) owe their relatively low scores to their low degree of climate match to New Zealand. Further research on their temperature tolerances is suggested.

Tortoises (Greek tortoises and Hermanns tortoises) were pushed into the "High Risk" category based on their history of successful introductions elsewhere. Areas where these tortoises have been introduced, however, are close in both geographic proximity and climatic conditions to their native range. If the "Exotic Elsewhere Risk Score" for these tortoises was reduced to 0, they would fall into the "Low Risk" category. Additionally, as tortoises are so scarce and valued in New 


\section{Chapter 7: Exotic reptile establishment risk}

Zealand, any wild populations of tortoises in New Zealand would likely be quickly captured by collectors.

Snake-neck turtles, common blue-tongue skinks, and coastal bearded dragons all received fairly similar scores; all fell into the "High Risk" category. Waterdragons, however, only just made it into the "Very High" establishment risk category. All of these species received an "Exotic Elsewhere Risk Score" of 15 as they have been reported to have been introduced into other areas within Australia. It could be argued that these introductions are close in proximity to their native range and should be interpreted with caution. However, if the "Exotic Elsewhere Risk Score" was dropped to 0 for these 4 species, all classifications would stay the same, with the exception of waterdragons, which would drop down to the "High Risk" category. Snake-neck turtles received a "Propagule Pressure Risk Score" of 25 based on the reports of a three individuals being lost into the New Zealand environment (See Appendix 2). If the "Propagule Pressure Risk Score" was dropped to the lowest level score for this species (in addition to an "Exotic Elsewhere Risk Score" of 0), snakeneck turtles would fall into the "Moderate" risk category.

The blotched blue-tongue skink received the highest risk score, based primarily on the high degree of climate match between New Zealand and its native range. It has recently been classified as a "Surveillance Pest" (meaning restrictions on keeping, breeding, and exhibition) in the Auckland area (Auckland Regional Council 2007). While this species is kept in New Zealand zoos, it is unknown if any are in private hands. The status of the blotched blue-tongue skink within the New Zealand pet trade needs to be clarified. 


\section{Chapter 7: Exotic reptile establishment risk}

\section{Other factors to consider in risk analyses}

Propagule pressure is a vital factor in the establishment of invasive populations (Simberloff 1989; Williamson 1996; Duncan 1997), but information regarding this is often unavailable and/or difficult to quantify (Simberloff 1989). I included a measure of propagule pressure relevant to New Zealand into the Bomford et al. (2005) risk assessment based on records of exotic reptile sales and reported losses. In Chapter 2, I investigated the online trade in New Zealand of red-eared slider turtles (Trachemys scripta elegans), and found an average of almost 800 turtles sold per year. Although these numbers do not reflect pets sold privately or through pet stores, it does give us a minimum number of animals present within the country. In comparison to all of the other species of exotic reptile in the New Zealand pet trade (see Appendices 2-8 for online sales information), red-eared sliders are, by far, the most numerous, most affordable, and easiest to obtain. They are also the only species known to be regularly released into the New Zealand environment.

If only climatic suitability is considered, the blotched blue-tongue skink would hold the highest risk of establishment. However, just because a species may have a high degree of climate match, it doesn't necessarily mean that all of the country is suitable for its establishment. In Chapter 4, the New Zealand suitability score was based on the relative suitability of the best site in New Zealand. According to the bioclimatic model, the species with the highest New Zealand Suitability Score, Tiliqua nigrolutea (0.99), would find only $25 \%$ of New Zealand to have a suitability greater than 0.1 (meaning the proportion of New Zealand with sites believed to be climatically better than $10 \%$ of sites incorporated into the model representing its native range). Meanwhile, Tiliqua scincoides has a lower New Zealand Suitability score (0.39), yet almost half of the country is predicted top have a 


\section{Chapter 7: Exotic reptile establishment risk}

suitability greater than 0.1 . From a biosecurity context, a species with a lower degree of climate match, but with a larger area of suitable habitat may be more concerning than a species with a high degree of climate match that may be concentrated in a particular area.

Human-related variables, although interesting, were not included in this risk assessment. Price was found to be an important factor when investigating the drivers of the South African reptile trade (van Wilgen et al. 2010). Exotic reptiles in New Zealand are considerably more expensive than the same species overseas. For example, leopard geckos (Eublepharis macularius) in New Zealand can command over 1,000 NZD, whereas in the USA they can be purchased for less than 20 USD ( 29 NZD). Similarly Hermanns tortoises (Testudo hermanni) in New Zealand can cost over 6,000 NZD when available, whereas in the USA they are abundant and cost $\sim 120$ USD ( 174 NZD). Additionally green iguanas (Iguana iguana) sell for less than 15 USD ( 22 NZD) in the USA, whereas collectors in New Zealand paid 5,000 NZD each before they were declared a "New Organism" and subsequently confiscated and destroyed (Kikillus, personal observation; (Anonymous 2007) (also see Appendices 7 and 8). Reptile enthusiasts that pay such high prices for their pets would likely seek to protect their investment by providing secure enclosures and less likelihood of intentional releases. In contrast, pet owners with "cheaper" and "abundant" species may be less likely to provide adequate housing and be more likely to release their pets when they lose the desire and/or ability to maintain it (van Wilgen et al. 2010). This appears to be relevant to New Zealand as well, as more than 50 RES were reported lost or missing between October 2007 and October 2009 (See Chapter 2), compared to only three snake-neck turtles and two inland bearded dragons (which are more expensive than RES) (See Appendices 2 and 5). 


\section{Chapter 7: Exotic reptile establishment risk}

Risk assessments are always associated with a level of uncertainty (Sikder et al. 2006); they assume that species and environmental conditions do not change over time (Keller and Drake 2009). In regards to climate envelopes, it must be acknowledged that not every species may have been exposed to all climate parameters that it is able to tolerate (Williamson 1996). Bomford et al. (2005) also remind us that the Exotic Elsewhere Risk Score and Taxonomic Family Risk Score must be interpreted with caution as not every species or taxonomic family has had the opportunity to establish elsewhere. The only way to be certain of the establishment potential of exotic reptiles in New Zealand is to release founding populations and see if they successfully establish. Predictive modelling and risk assessments allow us to avoid this "Fool's choice" (Reed 2005) and enable us to investigate establishment potential in a rapid, cost-effective manner. Although there are many factors that may be important in conducting risk assessments for potential invaders, a simple, quantitative method, as developed by Bomford et al. (2005) is a useful tool to begin an investigation on a potentially invasive species. Based on the scores achieved in this risk assessment, further research on the species of interest may be warranted.

\section{Future research directions}

Combining the use of both correlative and mechanistic models (See Chapters 3,4 , and 5), allows for the investigation of the potential distribution of exotic reptiles in New Zealand. The degree-day study in Chapter 5 suggested that thermal conditions in northern New Zealand may be sufficient for at least three species of exotic reptile (red-eared slider turtles, Reeves turtles, and snake-neck turtles) to incubate developing eggs. Further research involving artificial nests, future climate 


\section{Chapter 7: Exotic reptile establishment risk}

change, juvenile survival and sex ratios is suggested to confirm if successful reproduction of these species is possible in New Zealand.

With regards to potential impacts that alien reptiles may pose to native species, specifically the possibility of exotic reptiles transferring pathogens to native species, I investigated the Salmonella carriage rate of hundreds of captive exotic reptiles throughout New Zealand in Chapter 6. While higher than that of native reptiles, the Salmonella carriage rate of exotic reptiles in New Zealand is lower than that of exotic reptiles overseas. All of the serovars identified had been previously recorded in both reptiles and humans in New Zealand. One species, the inland bearded dragon (Pogona vitticeps) had a significantly higher rate of Salmonella than other species investigated. If exotic reptiles were to be imported in the future, it is recommended that they be screened for Salmonella to ensure that strains novel to New Zealand are not introduced.

If we consider Williamson's “10:10 rule” (Williamson and Brown 1986) which states that, in the case of Britain, 10\% of introduced species become established and, of these, $\sim 10 \%$ become a pest. If applied to the New Zealand situation, there are $\sim 10$ species known to be present with the pet trade, therefore we may expect 1 of these to become established. However, this species would have an approximately $10 \%$ chance of becoming a pest. Williamson admits the " $10: 10$ rule" is not exact and that "modified, isolated places" are more susceptible to invasion (Williamson 1993). Invasive species are also often subject to a "lag time", meaning that they may exist in the environment at low levels and then exponentially increase and become a problem (Crooks and Soulé 1999). Red-eared sliders have been present in New Zealand for decades (importation was halted in 1965) and some 
researchers feel that "they would already be a problem if they were ever going to be" (Feldman 2005).

As released red-eared sliders are known to exist within the New Zealand environment, the continued removal of feral individuals is recommended. Interestingly, the red-eared slider was previously classified as "Absolutely Protected" under the New Zealand Wildlife Act, however recent legislative changes have changed their status to "Not protected" (Wilkinson 2010). The removal of feral individuals from the New Zealand environment will also allow an opportunity for dietary analysis research to be conducted, which may provide information on what the turtles are subsisting on in the wild and provide a better understanding of their potential impacts.

\section{Recommendations to prevent the establishment of exotic reptiles in New Zealand}

It may be possible to suggest exotic reptile keepers to switch their focus to keeping native herpetofauna (which are subject to regulatory permits), however, with no freshwater turtles native to New Zealand, it may prove difficult for the New Zealand public to give up this interesting group of animals. Sale of exotic reptiles is also a lucrative business, and if bans were put in place, compensation issues may arise (Feldman 2005). The exotic reptile trade in New Zealand is already highly restricted in regards to the number of species available in comparison to other countries, such as South Africa, European Union countries, and the USA. Thus, methods are needed to control accidental and deliberate releases of exotic reptiles into the environment. Some methods which may work in New Zealand include public education and regulations imposed by regional councils, such as a permitting system and microchipping. 


\section{Chapter 7: Exotic reptile establishment risk}

Education of pet owners is an easy and cost-effective method to reduce the number of animals released into the wild (Wittenberg and Cock 2001). A good model is the "Habitattitude ${ }^{\mathrm{TM}}$ " program in the United States. It is a national initiative developed by the Aquatic Nuisance Species (ANS) Taskforce, the US Fish and Wildlife Service, the Pet Industry Joint Advisory Council, and the National Oceanic and Atmospheric Administration (NOAA) National Sea Grant College program (http://www.habitattitude.net). Habitattitude ${ }^{\mathrm{TM}}$ provides pet stores and other partners with information for customers to prevent the release of unwanted pets and plants. There are three major components to the program: 1) to educate consumers to make wise pet choices, 2) to provide resources enabling high standards in animal care and maintenance, and 3) to encourage pet owners to choose among several alternatives to the release of their pet (Reaser and Meyers 2007). A similar program, if instated in New Zealand and aligned with pet shops and exotic reptile breeders, may help educate the public and prevent the intentional release of unwanted pet reptiles.

Ownership permits are often utilised in areas which have a large number of established alien reptiles. In 2007, Florida, USA, instated a permit system for redeared slider turtle ownership. Red-eared sliders already in an owner's possession were allowed to remain, but restrictions were placed on breeding (Florida Fish and Wildlife Conservation Commission 2010). Interestingly, albino or unusually marked turtles were exempt from the permitting process, probably as they were considered "more valuable" than normally coloured turtles to their owners and were less likely to be discarded. In 2010, permits for red-eared sliders stopped being issued. In an effort to prevent euthanasia of unwanted pets, herpetological groups are advocating sending unwanted red-eared sliders to a "turtle sanctuary" within their native range (Suncoast Herpetological Society 2010). 


\section{Chapter 7: Exotic reptile establishment risk}

Microchipping is a common technique used to identify many pets, such as domestic cats and dogs (Lord et al. 2008). It is also feasible to use this technology with reptiles: wild reptiles in population studies are often identified via this technique (Moore et al. 2007), as are captive reptiles in large collections (Hoser 1995). If this procedure were implemented in the New Zealand exotic reptile trade it could serve two purposes: providing an extra measure of security in the case of theft of valuable animals, and providing the ability to track down owners who have intentionally or accidentally released their pets. Pet owners may be more reluctant to dispose of unwanted pet reptiles into the local environment if there is a chance that the animal may be tracked back to them.

In conclusion, while some species appear to have a fairly low risk of establishment based on the risk assessment performed above, there are several species that warrant further investigation in regards to climatic tolerances and reproductive ability in New Zealand. As no exotic reptiles are imported for the New Zealand pet trade, it is imperative to focus on preventing introductions of animals that are already present within captivity. Public education must be made a priority to ensure that New Zealand pet owners understand that they must provide secure enclosures for exotic species and that the release of unwanted animals is not an option. However, accidents can happen, and an increase in public awareness regarding which agency to contact in the event of a feral exotic reptile sighting may also help to prevent establishment. In the event that exotic reptiles do find their way into the wild, a rapid response to remove them would be needed. Many areas with established pest reptiles, such a Florida and Guam, have dedicated phone hotlines to report an exotic reptile sighting and "Rapid Response Groups" to assess the situation (Campbell 2007; 


\section{Chapter 7: Exotic reptile establishment risk}

Stanford and Rodda 2007). Red-eared slider turtles are the most abundant and easily obtainable species, and the only ones known to be regularly released into the New Zealand environment. Therefore efforts to prevent further introductions of this species, as well as removal of feral individuals from the environment, should be of high importance. Some restrictions on keeping certain species have already been implemented in some areas, such as the ban on keeping blue-tongue lizards (Tiliqua spp.) in the Auckland region. Additionally, as it is virtually impossible to trace the origin of a released or escaped pet, microchipping of exotic reptiles may help to identify their source and, if penalties are instated, hold liable those responsible for their release. However, as the exotic reptile trade in New Zealand is already perceived by many hobbyists as being very limited in comparison to other countries, drastic changes in legislation may encourage illegal importation/smuggling of new specimens. This phenomenon has been recorded overseas (Ferrior 2009), therefore the implementation of a "blanket ban" on all exotic reptile species in New Zealand is not recommended.

Exotic reptiles within the pet trade can only pose a threat to New Zealand if 1) local conditions are suitable for their survival and proliferation, and 2) if they are given the opportunity to establish (i.e., released into the wild). A species with a high climate match to New Zealand cannot pose a high establishment risk if it is confined securely in captivity. A balance between biosecurity concerns for New Zealand and the benefits of allowing exotic reptiles to be kept in captivity needs to be found. Benefits include the educational value and satisfaction that many people derive from keeping unusual pets. This experience may generate a greater awareness of global biodiversity and an appreciation of the uniqueness of New Zealand fauna (which in most cases cannot be kept as pets). At this time, it appears red-eared sliders are the 


\section{Chapter 7: Exotic reptile establishment risk}

only species which are regularly released into the wild. Better education for potential pet owners from pet stores and breeders may help to alleviate this problem. The instatement of a permitting/microchipping system for species deemed high risk by regional councils may prevent other popular species from developing a similar reputation as a "disposable pet". A compromise such as this may appease both New Zealand biosecurity concerns and address the concerns held by exotic reptile keepers in New Zealand. 


\section{Literature cited}

Andersen, M. (2007). "The roles of risk assessment in the control of invasive vertebrates." Wildlife Research 35: 242-248.

Andersen, M., H. Adams, B. Hope and M. Powell (2004). "Risk Assessment for invasive species." Risk Analysis 24(4): 787-793.

Anonymous (2007). "Reptile Sting." Retrieved February 6, 2007, from http://www.stuff.co.nz/print/3901023a6004.html.

Auckland Regional Council (2007). Regional Pest Management Strategy 2007-2012 Auckland, New Zealand, Auckland Regional Council: Pages 119-120.

Bomford, M. (2003). Risk Assessment for the import and keeping of exotic vertebrates in Australia. Bureau of Rural Sciences. Canberra, Australia.

Bomford, M., F. Kraus, M. Braysher, L. Walter and L. Brown (2005). Risk assessment model for the import and keeping of exotic reptiles and amphibians. Department of Environment and Heritage, Bureau of Rural Sciences, Canberra, Australia.

Burridge, M. and L. Simmons (2003). "Exotic ticks introduced into the United States on imported reptiles from 1962 to 2001 and their potential roles in international dissemination of diseases." Veterinary Pathology 113: 289-320.

Cadi, A. and P. Joly (2004). "Impact of the introduction of the red-eared slider (Trachemys scripta elegans) on survival rates of the European pond turtle (Emys orbicularis)." Biodiversity and Conservation 13: 2511-2518.

Campbell, T. (2007). The role of early detection and rapid response in thwarting amphibian and reptile introductions in Florida. Managing Vertebrate Invasive Species, Fort Collins, Colorado, USA, USDA APHIS Wildlife Services, National Wildlife Research Center.

Chapple, D. and R. Hitchmough (2009). "Taxonomic instability of reptiles and frogs in New Zealand: information to aid the use of Jewell (2008) for species identification." New Zealand Journal of Zoology 36: 59-71.

Cole, N., C. Jones and S. Harris (2005). "The need for enemy-free space: The impact of an invasive gecko on island endemics." Biological Conservation 125: 467-474.

Crooks, J. and M. Soulé (1999). Lag times in population explosions of invasive species: Causes and implications. Invasive Species and Biodiversity Management. O. Sandlund, P. Schei and A. Viken. Dordrecht, The Netherlands, Kluwer Academic Publishers.

Duncan, R. (1997). "The role of competition and introduction effort in the success of Passeriform birds introduced to New Zealand." The American Naturalist 149(5): 903915. 
Ernst, C. and J. Lovich (2009). Turtles of the United States and Canada. Baltimore, Maryland, USA, The Johns Hopkins University Press.

Feldman, M. (2005). The red-eared slider turtle (Trachemys scripta elegans) in New Zealand. 13th Australasian Vertebrate Pest Conference Wellington, New Zealand, Landcare Research, New Zealand.

Ferrior, P. (2009). The economics of agricultural and wildlife smuggling. United States Department of Agriculture/ Economic Research Service. ERR-81.

Florida Fish and Wildlife Conservation Commission (2010). "Captive Wildlife Categories." Retrieved May 29, 2010, from http://myfwc.com/RULESANDREGS/Rules CaptiveCategories.htm\#concern.

Fujisaki, I., K. Hart, F. Mazzotti, K. Rice, S. Snow and M. Rochford (2010). "Risk assessment of potential invasiveness of exotic reptiles imported to south Florida." Biological Invasions DOI 10.1007/s10530-009-9667-1.

Fuller, P. and A. Foster (2000). "Chinemys reevesii. USGS Nonindigenous aquatic species database." Retrieved June 1, 2010, from http://nas.er.usgs.gov/queries/FactSheet.aspx?SpeciesID=1228

Gill, B., D. Bejakovich and A. Whitaker (2001). "Records of foreign reptiles and amphibians accidentally imported to New Zealand." New Zealand Journal of Zoology 28: $351-359$.

Gist, D. and J. Jones (1989). "Sperm storage within the oviduct of turtles." Journal of Morphology 199: 379-384.

Hoser, R. (1995). "Record keeping for reptiles." Pantherosaurus 1.

Invasive.org (2010). "Florida Invasive Species Partnership,." Retrieved May 29, 2010, from http://www.invasive.org/species/list.cfm?id=77.

Jewell, T. (2008). A Photographic Guide to Reptiles and Amphibians of New Zealand. Auckland, New Zealand, New Holland Publishers Ltd.

Keller, R. and J. Drake (2009). Trait-based risk assessments for invasive species. Bioeconomics of invasive species: Integrating ecology, economics, policy, and management. R. Keller, D. Lodge, M. Lewis and J. Shogren. New York, New York, USA, Oxford University Press: 44-62.

Kraus, F. (2009). Alien reptiles and amphibians: a scientific compendium and analysis, Springer Netherlands.

Lever, C. (2003). Naturalized reptiles and amphibians of the world. New York, USA, Oxford University Press. 
Lord, L., M. Pennell, W. Ingwerson and R. Fisher (2008). "Sensitivity of commercial scanners to microchips of various frequencies implanted in dogs and cats." Journal of the American Veterinary Medical Association 233(11): 1729-1735.

Low, T. (2002). The new nature. Camberwell, Victoria, Australia, Penguin Group.

Manchester, S. and J. Bullock (2000). "The impacts of non-native species on UK biodiversity and the effectiveness of control." Journal of Applied Ecology 37: 845864.

Mather, P. and I. Bennett, Eds. (1984). A coral reef handbook: a guide to the fauna, flora and geology of Heron Island and adjacent reefs and cays. Brisbane, Australia, The Australian Coral Reef Society.

Moore, J., J. Hoare, C. Daugherty and N. Nelson (2007). "Waiting reveals waning weight: Monitoring over 54 years shows a decline in body condition of a long-lived reptile (tuatara, Sphenodon punctatus)." Biological Conservation 135: 181-188.

O'Dwyer, T., W. Buttemer and D. Priddel (2000). "Inadvertent translocation of amphibians in the shipment of agricultural produce into New South Wales: its extent and conservation implications." Pacific Conservation Biology 6: 40-45.

Reaser, J. and N. Meyers (2007). Habitattitude ${ }^{\mathrm{TM}}$ : Getting a backbone about the pet release pathway. Managing Vertebrate Invasive Species, Fort Collins, Colorado, USA, USDA APHIS Wildlife Services, National Wildlife Research Center.

Reed, R. (2005). "An ecological risk assessment of nonnative boas and pythons as potentially invasive species in the United States." Risk Analysis 25(3): 753-766.

Rodda, G., T. Fritts and D. Chiszar (1997). "The disappearance of Guam's wildlife." Bioscience 47(9): 565-574.

Ruesink, J., I. Parker, M. Groom and P. Kareiva (1995). "Reducing the risks of nonindigenous species introductions." Bioscience 45(7): 465-477.

Sarre, S., S. Schwaner and A. Georges (1990). "Genetic variation among insular populations of the sleepy lizard, Trachydosaurus rugosus Gray (Squamata: Scincidae)." Australian Journal of Zoology 38: 603-616.

Savidge, J. (1988). "Food habits of Boiga irregularis, an introduced predator on Guam." Journal of Herpetology 22(3): 275-282.

Shine, C., N. Williams and L. Gündling (2000). A guide to designing legal institutional frameworks on alien invasive species. Gland, Switzerland, IUCN.

Sikder, I., S. Mal-Sarkar and T. Mal (2006). "Knowledge-based risk assessment under uncertainty for species invasion." Risk Analysis 26(1): 239-252. 
Simberloff, D. (1989). Which insect introductions succeed and which fail? Biological Invasions: A Global Perspective. J. Drake, H. Mooney, F. di Castriet al. Chichester, UK, John Wiley and Sons.

Stanford, J. and G. Rodda (2007). The brown treesnake rapid response team. Managing Vertebrate Invasive Species, Fort Collins, Colorado, USA, USDA APHIS Wildlife Services, National Wildlife Research Center.

Suncoast Herpetological Society (2010). "Red-eared sliders." Retrieved June 5, 2010, from http://www.kingsnake.com/suncoastherpsociety/SHSHome.htm.

van Wilgen, N., J. Wilson, J. Elith, B. Wintle and D. Richardson (2010). "Alien invaders and reptile traders: what drives the live animal trade in South Africa?" Animal Conservation 13(Suppl. 1): 1-9.

Wiles, G., J. Bart, R. Beck Jr. and C. Augon (2003). "Impacts of the brown tree snake: Patterns of decline and species persistence in Guam's avifauna." Conservation Biology 17(5): 1350-1360.

Wilkinson, K. (2010). "Protection status changes to Wildlife Act." Retrieved June 10, 2010, from

http://www.beehive.govt.nz/release/protection+status+changes+wildlife+act.

Williamson, M. (1993). "Invaders, weeds and the risk from genetically manipulated organisms." Experientia 49: 219-224.

Williamson, M. (1996). Biological Invasions. London, UK, Chapman and Hall.

Williamson, M. and K. Brown (1986). "The analysis and modelling of British invasions." Philosophical Transactions of the Royal Society of London B 314: 505522.

Wilson, K. (2004). Flight of the Huia: Ecology and conservation of New Zealand's frogs, reptiles, birds and mammals. Christchurch, New Zealand, Canterbury University Press.

Wittenberg, R. and M. Cock (2001). Invasive alien species. How to address one of the greatest threats to biodiversity: A toolkit of best prevention and management practices. CAB International. Wallingford, Oxon, UK: 215 pages. 


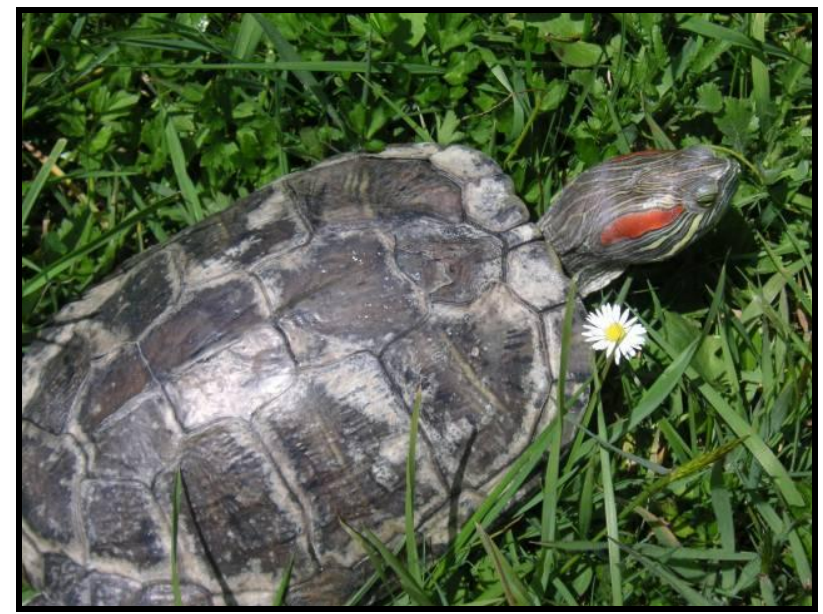

Red-eared sliders are a popular pet, not only in New Zealand, but around the world. They are the most affordable (from 40 NZD) and easily obtained exotic reptiles in the New Zealand pet trade. More than 1500 red-eared sliders were sold on the New Zealand online auction site TradeMe (www.trademe.co.nz) between October 2007 and October 2009. Many are purchased as hatchlings, with their owners often unaware of the maximum size that they may attain. Adult turtles can become aggressive and are often released into local waterways by owners who have lost the ability or desire to care for them.

\section{Native Range}

Red-eared sliders are native to the Mississippi valley area of the United States of America, being found from the state of Ohio down into the Gulf of Mexico.

\section{Habitat Type}

Although described as a "habitat generalist", red-eared sliders prefer slow-moving waters (ideally $0.5 \mathrm{~m}$ to $2 \mathrm{~m}$ deep), with soft, muddy bottoms, and availability of suitable basking sites.

\section{Temperature preferences}

Similar to habitat conditions, red-eared sliders can tolerate a wide range of temperature exposure. Water temperatures of about $18^{\circ} \mathrm{C}$ are required in their native range for growth and feeding in the spring. They prefer temperatures between $25-29^{\circ}$ $\mathrm{C}$, but can withstand much colder temperatures. Red-eared sliders tend to hibernate during the winter months and have been known to survive harsh winters where temperatures dropped below $-10^{\circ} \mathrm{C}$ for extended periods. If they come into direct contact with snow/ ice while hibernating underground, however, it may prove fatal. Red-eared sliders are able to successfully overwinter in the wild in the Auckland region in New Zealand. 
Red-eared sliders can also thrive in warmer than normal conditions. A study in America found that sliders living in a heated lake grew faster and matured earlier than sliders in an unheated lake. Sliders will also seek out warmer temperatures when they have a full stomach, which may help to aid digestion.

\section{Reproductive Information}

\section{Breeding}

Sexual maturity seems to be size-related, not necessarily age related (i.e. larger turtles tend to breed sooner than smaller turtles). It averages around 3-4 years of age, or when males' shell length reaches about $10 \mathrm{~cm}$ and the females $17 \mathrm{~cm}$. Adult redeared sliders exhibit extreme sexual dimorphism: Males are smaller than females and have elongated claws on their front feet. They also tend to have thicker tails than females and a concave shape to their plastron (bottom portion of shell). Males tend to move been aquatic habitats more than females. This is attributed to searching for mates and tends to increase in frequency as the male gets older.

Hibernation, or at least a winter cooling, is a trigger for breeding. Female sliders are able to store sperm for several years. Some turtles are capable of producing 70 fertile eggs per year for five years after a single mating! Red-eared sliders that have established exotic populations in the southern hemisphere have adapted to breed in the seasonal equivalents of their northern hemisphere counterparts.

\section{Nesting}

In early spring, females begin to look for suitable nesting sites. They have been known to travel $0.4-1.6 \mathrm{~km}$ from the nearest water source to select nesting sites in open, unshaded areas (meadows, dirt roads, forest clearings, etc.) and tend to dig "jug-shaped" nests ranging from 10-25 cm deep. Clutches range from three to 24 eggs, but average around 11. Larger turtles tend to produce larger clutches and larger eggs than smaller turtles. Females are capable of laying three clutches per year. In parts of their native range, females seem to exhibit fidelity to their nesting sites, but it is unknown if they are returning to the site where they were hatched. In some areas, imported red fire ants have been recorded destroying nests.

\section{Incubation/ Hatchlings}

According the Invasive Species Specialist Group, red-eared slider turtle eggs require incubation temperatures between $22^{\circ}-33^{\circ} \mathrm{C}$ for $55-80$ days. Like many reptiles, redeared sliders exhibit “Temperature-Dependent Sex Determination", in which male hatchlings are produced at lower incubation temperatures (below approximately $28^{\circ} \mathrm{C}$ ) and females produced at higher incubation temperatures (above approximately $30^{\circ} \mathrm{C}$ ), with both sexes produced when eggs are incubated at a constant temperature around $29^{\circ} \mathrm{C}$. In their native range, hatchling turtles will often remain underground over the winter months and emerge from their nests the following spring. The benefit of a springtime emergence from nests is the prospect of resources being available for a longer period of time than if the turtles were to emerge directly from the nest after hatching. Environmental changes (such as a rise in soil temperatures) are thought to trigger hatchling emergence. 
Hatchling turtles have some degree of freeze-tolerance, with animals in one study surviving as long as 30 hours at $-2^{\circ} \mathrm{C}$. In another study, hatchlings survived freezing at $-4^{\circ} \mathrm{C}$ for four hours, but none revived after eight hours.

\section{Diet}

Juvenile slider turtles are highly carnivorous, and as they grow to adulthood their diet preferences change to include more vegetable matter. Overall, they are considered to be opportunistic omnivores. In the wild their diet may include invertebrates, aquatic plants, carrion, tadpoles, fish, and birds. Slider turtles are often attracted to movement and will pursue live prey.

\section{Maximum Size}

Female red-eared sliders are larger than males; they can reach approximately $30 \mathrm{~cm}$ and $18 \mathrm{~cm}$, respectively.

\section{Naturalised Distribution}

Due to the release of unwanted pets, red-eared sliders have been introduced to all of the 48 contiguous U.S. states, as well as Hawaii. This has resulted in established populations in some states. Also through the pet trade, red-eared sliders have established breeding populations on all continents except for Antarctica. Countries in which red-eared sliders have established include: France, Italy, Spain, Japan, South Korea, Taiwan, South Africa, Brazil, Guam, and Australia. It is now considered to be the most widespread freshwater turtle in the world and is classified as of the "World's Worst Invasive Alien Species" by the World Conservation Union's (IUCN) Invasive Species Specialist Group.

\section{New Zealand Distribution}

Although the importation of red-eared sliders into New Zealand was halted in 1965, local breeders contribute approximately 2,000 turtles annually to the New Zealand pet trade. There are numerous reports of escapes from captivity and many turtles are known to exist in the wild in New Zealand. The majority of the known feral sliders in New Zealand are located in the upper North Island, which is the most climaticallysuitable area for this species.

\section{Possible negative effects to New Zealand}

In parts of Europe where red-eared sliders have established, they negatively impact native freshwater turtles. In Australia, farm dams inhabited by slider turtles have been found to be devoid of native turtles, fish, and crayfish, possibly indicating that sliders were negatively affecting native wildlife. As New Zealand does not have any freshwater turtles, this issue is not relevant; however, there are concerns that redeared sliders could have a detrimental effect on aquatic vegetation and animal life in New Zealand. For these reasons, red-eared sliders have been classified as both a Research Organism (a species requiring more research into its potential impacts) and 
as a pest "only where they are not held in secure containment" by the Auckland Regional Council.

\section{Associated Diseases}

Red-eared sliders, like many reptiles, are often asymptomatic carriers of Salmonella bacteria, which can be easily transferred to humans if hygiene protocols are not followed. Although human cases of reptile-associated salmonellosis are generally not severe, there have been reported cases of septicaemia and meningitis, sometimes fatal, associated with infections.

\section{Lifespan}

In the wild, juvenile red-eared sliders have a high mortality rate, but adults tend to be quite hardy and can live for 25-30 years. Lifespans of captive red-eared sliders tend to be longer.

\section{Other relevant information}

Red-eared sliders are banned in the European Union and Australia, and large fines are issued if a slider turtle is found in your possession. In Florida, USA (an area outside of the sliders' native range in which they have established), permits are required for anyone purchasing a slider as a pet. Interestingly, albino turtles and those exhibiting unusual colour variations are exempt as they are "unique and unlikely to be wantonly discarded". The United States has banned the sale of pet turtles less than 4 inches $(10.2 \mathrm{~cm})$ in length since 1975 due to the high numbers of human Salmonella infections attributed to reptile pets overseas. It was believed that young children may have perceived tiny turtles as desirable objects and were therefore more likely to handle them. It was assumed that larger turtles would be less appealing for children and thus less likely to infect them with Salmonella. Today, American pet stores are trying to circumvent the ban by giving away small turtles to customers who purchase turtle habitats or sell them as "educational animals", which are not covered by the pet ban. Although this change in legislation aimed to lessen the likelihood of direct contact between infected reptiles and young children, reptile-associated salmonellosis can just as easily be acquired via indirect contact. Allowing a pet reptile to roam free throughout the house or washing reptile cages in kitchen areas have been linked to Salmonella infections in humans that have not had direct contact with the reptile. Over 30 years have passed since the U.S. ban on the trade in small turtles was enacted. While the ban is believed to have been responsible for an initial decline in reptileassociated salmonellosis in humans, it seems that, over time, many people have forgotten that reptiles are potential carriers of the bacteria. In 2007-2008, pet reptiles were linked to a salmonellosis outbreak which sickened over 100 people in 34 states. The Association of Reptile and Amphibian Veterinarians in combination with the Center for Disease Control have published guidelines for veterinarians and reptile keepers to minimise reptile-associated Salmonellosis. (http://www.arav.org/ ECOMARAV//timssnet/arav publications/arav publications.cfm). Given the high prevalence of Salmonella in exotic reptiles within New Zealand found in this study, it is suggested that veterinarians and reptile keepers should be familiar with these guidelines. 


\section{References}

Anonymous (2004) Invading Turtles. Feral Herald: Newsletter of the Invasive Species Council. 1(7): 8.

Anonymous (2004, November 5) Urgent turtle ban to protect native plants and animals. The New Zealand Herald. Available Online: http://www.nzherald.co.nz/section/story.cfm?c id=1\&objectid=3607463

Aresco, MJ (2004) Reproductive ecology of Pseudemys floridana and Trachemys scripta (Testudines: Emydidae) in northwestern Florida. Journal of Herpetology. 38(2): 249-256.

Associated Press (2009) Pet turtles sickened children in 34 states. Retrieved 19 October, 2009, from http://www.msnbc.msn.com/id/33369885/ns/healthkids and parenting/

Auckland Regional Council (ARC) (2006) Proposed Auckland Regional Pest Management Strategy 2007-2012. Auckland, New Zealand. Pages 113-115.

Bringsøe, H (2006) NOBANIS- Invasive alien species fact sheet- Trachemys scriptaFrom: Online database of the North European and Baltic Network on Invasive Alien Species- NOBANIS. www.nobanis.org (accessed April 12, 2007).

Bouchard, S and K Bjorndal (2005) Microbial fermentation in juvenile and adult pond sliders, Trachemys scripta. Journal of Herpetology. 39(2): 321-324.

Burgin, S (2006) Confirmation of an established population of exotic turtles in urban Sydney. Australian Zoologist. 33(3): 379-384.

Burne, C (2000) The ultimate guide to keeping freshwater turtles successfully in New Zealand. Brebner Print, Napier.

Cadi A, Delmas V, Prévot-Julliard A, Joly P, Pieau C, and M Girondot (2004) Successful reproduction of the introduced slider turtle (Trachemys scripta elegans) in the South of France. Aquatic Conservation: Marine and Freshwater Ecosystems. 14: 237-246.

Cadi, A and P Joly (2004) Impact of the introduction of the red-eared slider (Trachemys scripta elegans) on the survival rates of the European pond turtle (Emys orbicularus). Biodiversity and Conservation. 13: 2511-2518.

Cagle, F (1944) Activity and winter changes of hatchling Pseudemys. Copeia. 1944(2): 105-109.

Chen, T and K Lue (1998) Ecological notes on feral populations of Trachemys scripta elegans in northern Taiwan. Chelonian Conservation and Biology. 3(1): 87-90. 
Churchill, T and K Storey (1992) Responses to freezing exposure of hatchling turtles Trachemys scripta elegans: Factors influencing the development of freeze tolerance by reptiles. Journal of experimental Biology. 167: 221-233.

Connor, M (1992) The Red-eared slider, Trachemys scripta elegans. Tortuga Gazette. 28(4): $1-3$.

Dodd, K, Murdock, C, and T Wibbels (2006) Interclutch variation in sex ratios produced at pivotal temperature in the Red-eared slider, a turtle with temperaturedependent sex determination. Journal of Herpetology. 40(4): 544-549.

Dreslik, M, Kuhns, A, and C Phillips (2005) Structure and composition of a Southern Illinois freshwater turtle assemblage. Northeastern Naturalist. 12(2): 173-186.

Ernst, C (1990) "Systematics, taxonomy, variation, and geographic distribution of the slider turtle". In Gibbons, JW (Ed.) Life history and ecology of the slider turtle. Smithsonian Institution Press. Washington DC, USA. Pages 57-67.

Ernst, C, Lovich, J, and R Barbour (1994) Turtles of the United States and Canada. Smithsonian Institution Press, Washington D.C., USA.

Ernst, C and J Lovich (2009) Turtles of the United States and Canada: Second Edition. The Johns Hopkins Press. Baltimore, Maryland, USA.

Feldman, M (1992) Can turtles reproduce in New Zealand? Moko. 1992: 14-16.

Feldman, M (2005) The Red-eared slider (Trachemys scripta elegans) in New Zealand. Proceedings of the $13^{\text {th }}$ Australasian Vertebrate Pest Conference. Wellington, New Zealand. May 2-6, 2005.

Filoramo, NI and FJ Janzen (2002) An experimental study of the influence of embryonic water availability, body size, and clutch on survivorship of neonatal redeared sliders, Trachemys scripta elegans. Herpetologica. 58(1): 67-74.

Florida Fish and Wildlife Conservation Commission (FWC) (2007) News Release. Retrieved 20 July, 2007, from http://myfwc.com/Whatsnew/07/statewide/nonnativerules.html.

Friedman, C, Torigian, C, Shillam, P, Hoffman, R, Heltzel, D, Beebe, J, Malcolm, G, DeWitt, W, Huttwagner, L, and P Griffin (1998) An outbreak of salmonellosis among children attending a reptile exhibit at a zoo. The Journal of Pediatrics. 132(5): 802807.

Gatten, R (1974) Effect of nutritional status on the preferred body temperature of the turtles Pseudemys scripta and Terrapene ornata. Copeia. 1974(4): 912-917.

Gibbons JW (1990) “The Slider turtle”. In Gibbons JW (Ed.) Life history and ecology of the slider turtle. Smithsonian Institution Press. Washington DC, USA. Pages 3-18. 
Gibbons JW and JE Lovich (1990) Sexual dimorphism in turtles with emphasis on the slider turtle (Trachemys scripta). Herpetological Monographs. 4: 1-29.

Grady, D (15 March, 2005) Tiny pet turtles return: Salmonella does, too. New York Times. New York, New York, USA.

Hoskins, G (14 November, 2006) Personal Communication. Auckland Regional Council.

Invasive Species Specialist Group (ISSG) (2006):

www.issg.org/database/species/ecology.asp?si=71\&ver=print (accessed July 12, 2006).

Johnson-Delaney, W (2006) "Reptile zoonoses and threats to public health". In Mader D (Ed.) Reptile Medicine and Surgery. Saunders Elsevier. St. Louis, Missouri, USA.

Kikillus, KH, Hare, KM, and S Hartley (2010) Minimizing false-negatives when predicting the potential distribution of an invasive species: a bioclimatic envelope for the red-eared slider at global and regional scales. Animal Conservation.

13(Supplement 1): 1-11.

Lever, C (2003) Naturalized reptiles and amphibians of the world. Oxford University Press, New York.

Ligon, D (2007) Natural History Notes: Trachemys scripta elegans (Red-eared slider). Predation. Herpetological Review. 38(2): 201-202.

Luiselli, L, Capula, M, Capizzi, D, Filippi, E, Jesus, V, and C Anibaldi (1997) Problems for conservation of pond turtles (Emys orbicularis) in central Italy: is the introduced red-eared turtle (Trachemys scripta) a threat? Chelonian Conservation and Biology. 2(3): 417-419.

Mermin, J, Hoar, B, and F Angulo (1997) Iguanas and Salmonella Marina infection in children: A reflection of the increasing incidence of reptile-associated salmonellosis in the United States. Pediatrics. 99(3): 399-402.

Mitchell, MA and SM Shane (2001) Salmonella in reptiles. Seminars in Avian and Exotic Pet Medicine. 10(1): 25-35.

Morreale, SJ and JW Gibbons (1986) Habitat suitability index models: Slider turtle. U.S. Fish Wildl. Serv. Biol. Rep. 82(10.125): 14 pp.

Nagano, N, Oana, S, Nagano, Y, and Y Arakawa (2006) A severe Salmonella enterica serotype Paratyphi B infection in a child related to a pet turtle, Trachemys scripta elegans. Japanese Journal of Infectious Disease. 59: 132-134.

Newbery, R (1984) The American Red-eared terrapin in South Africa. African Wildlife. 38(5): 186-189. 
O'Keeffe, S (3 May, 2007) Personal Communication. Queensland Government Department of Natural Resources and Water.

Orenstein, R (2001) Turtles, tortoises and terrapins: survivors in armor. Firefly Books, New York, USA.

Packard GC, Packard MJ, Lang JW, and JK Tucker (1999) Tolerance for freezing in hatchling turtles. Journal of Herpetology. 33(4): 536-543.

Parmenter, C (1980) Effects of food availability and water temperature on the feeding ecology of pond sliders (Chrysemys s. scripta) Copeia. 1980(3): 503-514.

Pendlebury, P (3 May, 2007) Personal Communication. Reptrans UK.

Platt, S and L Fontenot (1992) The Red-eared slider, Trachemys scripta elegans (Weid) in South Korea. Bulletin of the Chicago Herpetological Society. 27(5): 113114.

Prevot-Julliard, A, Gousset, E, Archinard, C, Cadi, A, and M Girondot (2007) Pets and invasion risks: is the slider turtle strictly carnivorous? Amphibia-Reptilia. 28: 139-143.

Queensland Department of Natural Resources website: http://www.nrw.qld.gov.au/pests/pest_animals/declared/red_eared_slider.html (accessed May 3, 2007).

Smith, H (1956) Handbook of amphibians and reptiles of Kansas. University of Kansas. Lawrence, Kansas, USA.

Thomas RB, Vogrin N, and R Altig (1999) Sexual and seasonal differences in behavior of Trachemys scripta (Testudines: Emydidae). Journal of Herpetology. 33(3): 511-515.

Thornhill, G (1982) Comparative reproduction of the turtle, Chrysemys scripta elegans, in heated and natural lakes. Journal of Herpetology. 16(4): 347-353.

Thornton, T (1999) Keeping red-eared turtles in New Zealand. TJ's Books. Warkworth, New Zealand.

Tuberville TD, Gibbons JW, and JL Greene (1996) Invasion of new aquatic habitats by male freshwater turtles. Copeia. 1996(3): 713-715.

Tucker JK and D Moll (1997) Growth, reproduction, and survivorship in the redeared turtle, Trachemys scripta elegans, in Illinois, with conservation implications. Chelonian Conservation and Biology. 2(3): 352-357.

Tucker JK and GC Packard (1998) Overwinter survival by hatchling sliders (Trachemys scripta) in west-central Illinois. Journal of Herpetology. 32(3): 431-434. 
Tucker JK (2001a) Clutch frequency in the red-eared slider (Trachemys scripta elegans). Journal of Herpetology. 35(4): 664-668.

Tucker JK (2001b) Nesting Red-eared sliders (Trachemys scripta elegans) exhibit fidelity to their nesting areas. Journal of Herpetology. 35(4): 661-664.

U.S. Food and Drug Administration (2007) "CVM and the regulation of turtles" Retrieved 16 October, 2007, from http://www.fda.gov/cvm/turtles.htm.

Wibblels, T, Cowan, J, and R LeBoeuf (1998) Temperature-Dependent Sex Determination in the Red-eared slider turtle, Trachemys scripta. The Journal of Experimental Zoology. 281: 409-416.

Willis, C, Wilson, T, Greenwood, M, and L Ward (2002) Pet reptiles associated with a case of salmonellosis in an infant were carrying multiple strains of Salmonella. Journal of Clinical Microbiology. 40(12): 4802-4803. 


\section{Appendix 2: Snake-neck turtle (Chelodina longicollis)}

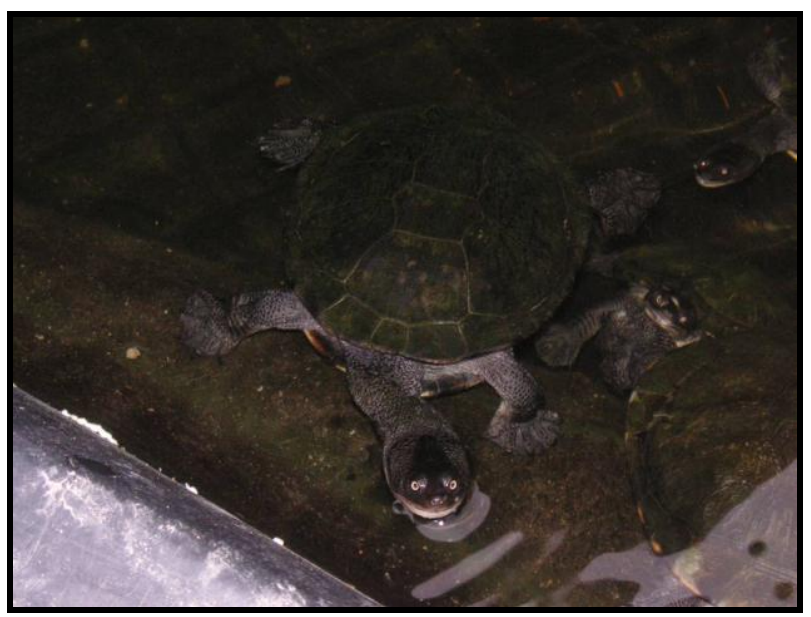

Although not quite as popular as red-eared slider turtles, snake-neck turtles are a common type of reptile pet in New Zealand. They are readily available from pet stores and online auction sites, such as TradeMe (www.trademe.co.nz), where they range between 100-150 NZD.

\section{Native Range}

Snake-neck turtles are native to south-eastern Australia, being found from Townsville (Queensland) down to Adelaide (South Australia).

\section{Habitat Type}

In the wild, snake-neck turtles can be found in permanent lakes and rivers, or even artificial habitats such as farm dams. They are also known to exploit ephemeral swamps, likely to take advantage of their high invertebrate densities. Snake-necks have the ability to burrow into soil, leaf litter, and sediment in order to aestivate when water sources dry up.

\section{Temperature preferences}

While some reptile keepers recommend maintaining captive snake-neck turtle at temperatures between $24^{\circ} \mathrm{C}-28^{\circ} \mathrm{C}$, they are actually classified as a "cold climate turtle". In the wild, snake-neck turtles have been observed being active and feeding in water temperatures of $12^{\circ} \mathrm{C}$, and surfacing in water temperatures of $8.3^{\circ} \mathrm{C}$.

\section{Reproductive Information}

\section{Breeding}

In the wild, males tend to reach sexual maturity before females. Males generally reach maturity when their shell length is approximately $15 \mathrm{~cm}$ long (usually after about their seventh winter), whereas females generally reach maturity when their shell length is about $17 \mathrm{~cm}$ long (usually after about their tenth or eleventh winter). 
While males are reported to attain a smaller size than females, possess longer thicker tails and a concave plastron, it can still be extremely difficult to differentiate sexes visually.

\section{Nesting}

In their native range, snake-neck turtles nest in spring or early summer. Females prefer to nest following a heavy rain and by moonlight. They deposit over ten eggs into a flask-shaped nest approximately $10 \mathrm{~cm}$ deep. As with red-eared sliders, larger snake-neck turtles tend to produce larger clutches and larger eggs than smaller snakenecks. In South Australia, many nests are destroyed by invasive foxes.

\section{Incubation/ Hatchlings}

Snake-neck turtle embryos are able to withstand a considerable variation in temperature and still hatch normally. The average temperatures recorded in natural nests is approximately $20^{\circ} \mathrm{C}$, but can range between $12.5^{\circ} \mathrm{C}$ and $32^{\circ} \mathrm{C}$. In the lab, snake-neck turtle eggs do not develop below $24^{\circ} \mathrm{C}$, therefore eggs in the wild appear to take advantage of the periods when temperatures are above this threshold and conducive for embryonic development. The incubation period in natural nests in New South Wales, Australia, was found to average 116 days, whereas nests in Victoria take up to 145 days for eggs to hatch. When eggs were brought into the laboratory for artificial incubation at a constant temperature of $30^{\circ} \mathrm{C}$, they hatched in about 70 days. Snake-neck turtles do not appear to exhibit Temperature-Dependent Sex Determination.

\section{Diet}

Snake-neck turtles are carnivorous and have been recorded to feed upon a diverse diet of fish, amphibians, crustaceans, invertebrates, snails, and carrion. Although they are aquatic, snake-neck turtles have been observed feeding on land and gut contents have revealed terrestrial insects.

\section{Maximum Size}

Snake-neck turtles can reach a maximum size of 25-30 inches. Males are reported to be slightly smaller than females.

\section{Naturalised Distribution}

Snake-neck turtles have reportedly been introduced into Tasmania, however no details regarding location or breeding status are given.

\section{New Zealand Distribution}

"Many specimens" of snake-neck turtles were brought into New Zealand in the 1800s, some of which were part of a "large consignment" for the South Seas Exhibition in Dunedin in 1889. There have been no reports of established populations of these turtles in New Zealand, however single individuals have been captured. One 
specimen captured in Wellington Harbour was thought to have been released from a nearby boat. In 2009, three snake-neck turtles were reported missing in the Auckland area.

The online trade of snake-neck turtles in New Zealand was monitored over a two year period. Adults and juveniles comprised similar amounts of sales; $43 \%$ and $46 \%$, respectively. (See Figure 1 and Table 1).

Figure 1: Numbers and age brackets of snake-neck turtle (Chelodina longicollis) sales by season (October 2007- October 2009) from www.trademe.co.nz. Summer $=$ December - February, spring $=$ September - November, autumn $=$ March - May, and winter $=$ June - August. Juvenile $=<1$ year, Subadult $=1-2$ years, Adult $=>2$ years. $\mathrm{N}=127$.

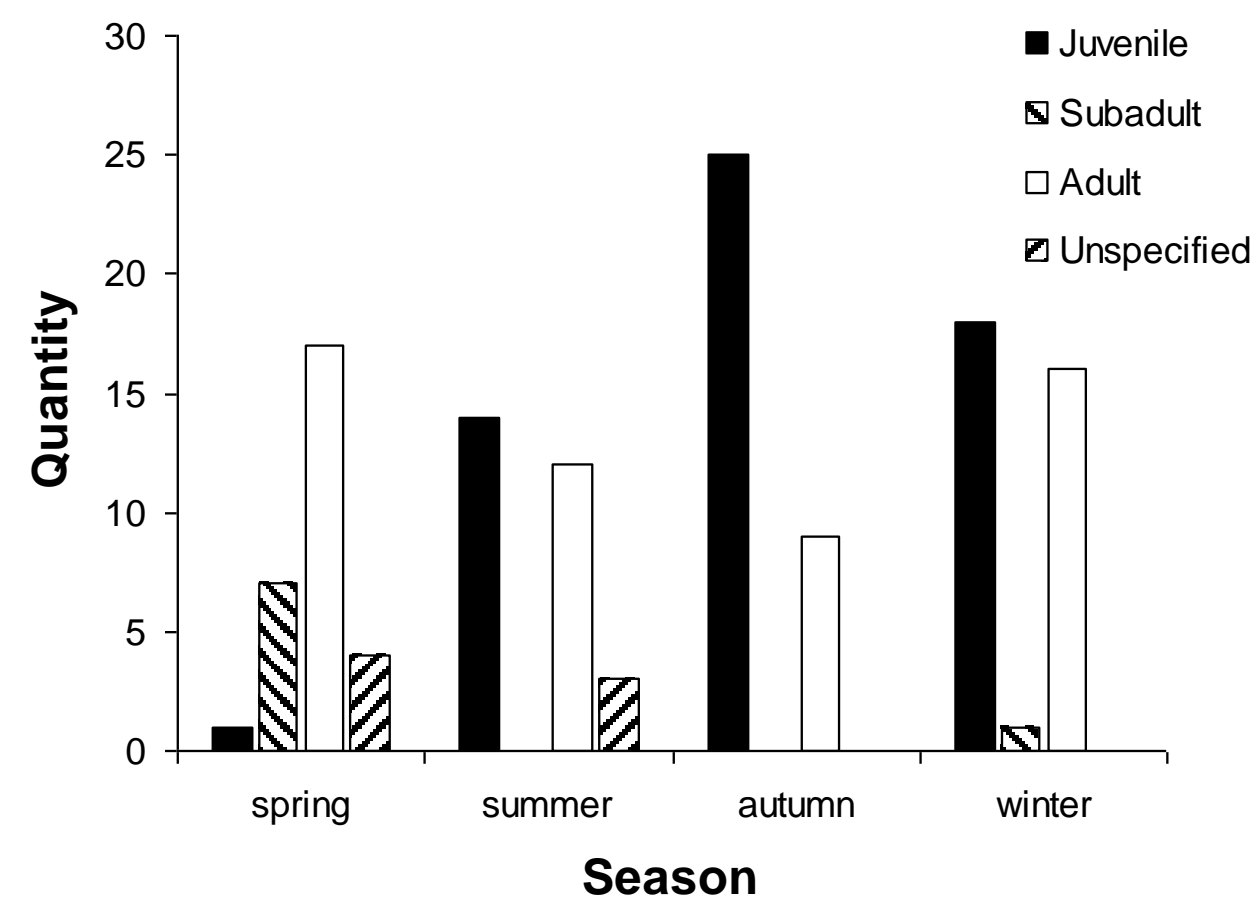

Table 1: Sex and age bracket of snake-neck turtles (Chelodina longicollis) sold on TradeMe (October 2007-October 2009). (Juvenile $=<1$ year, Subadult $=1-2$ years, Adult $=>2$ years).

\begin{tabular}{lccccc}
\hline Sex & \multicolumn{2}{c}{ Age bracket } & \multicolumn{2}{c}{ Total } \\
& Adult & Juvenile & Subadult & Unspecified & \\
\hline Female & 10 & 0 & 2 & 0 & 12 \\
Male & 11 & 0 & 0 & 0 & 11 \\
Unspecified & 33 & 58 & 6 & 7 & 104 \\
Total & 54 & 58 & 8 & 7 & $\mathbf{1 2 7}$
\end{tabular}




\section{Possible negative effects to New Zealand}

As snake-neck turtles are carnivorous and capable of pursuing relatively swift prey, such as fish and shrimps, their potential impact on New Zealand's aquatic fauna is of concern.

\section{Associated Diseases}

Like many reptiles, snake-neck turtles are capable of carrying Salmonella bacteria, which is easily transferred to humans.

\section{Lifespan}

Snake-neck turtles are believed to live for over 35 years in the wild. Captive turtles likely live longer.

\section{Other relevant information}

As wild snake-necks live in an ever-changing environment in which water sources often dry up, they are fairly tolerant to desiccation. They are able to spend extended periods on land and often navigate overland to find new water sources and are believed to use the sun as a compass. Dehydrated turtles are able to rehydrate themselves by absorbing water through their cloaca.

\section{References}

Burne, C. (2000) The ultimate guide to keeping freshwater turtles successfully in New Zealand. Brebner Print, Napier.

Chessman, B. (1984a) Food of the snake-necked turtle, Chelodina longicollis (Shaw) (Testudines: Chelidae) in the Murray Valley, Victoria and New South Wales. Australian Wildlife Research. 11: 573-578.

Chessman, B. (1984b) Evaporative water loss from three South-eastern Australian species of freshwater turtles. Australian Journal of Zoology. 32: 649-655.

Chessman, B. (1988a) Habitat preferences of freshwater turtles in the Murray Valley, Victoria and New South Wales. Australian Wildlife Research. 15: 485-491.

Chessman, B. (1988b) Seasonal and diel activity of freshwater turtles in the Murray Valley, Victoria and New South Wales. Australian Wildlife Research. 15: 267-276.

Cogger H (1975) Reptiles and amphibians of Australia. Reed Party Books, Sydney, Australia.

Doody, J., Osborne, W., Bourne, D., Rennie, B., and Sims, R. (2004) Vertebrate biodiversity on Australian rice farms: an inventory of species, variation among farms, and proximate factors explaining that variation. Rural Industries Research and Development Corporation. Australia. 
Ernst, C., Altenburg, R., and Barbour, R. (1997) Turtles of the World. Available online: http://ip30.eti.uva.nl/bis/turtles.php

Ezaz, T, Valenzuela, N, Grützner, F, Miura, I, Georges, A, Burke, R, and J Marshall Graves (2007) An XX/XY sex microchromosome system in a freshwater turtle, Chelodina longicollis (Testudines: Chelidae) with genetic sex determination. Chromosome Research. 14: 139-150.

Georges, A., Norris, R., and Wensing, L. (1986) Diet of the freshwater turtle, Chelodina longicollis (Testudines: Chelidae) from the coastal dune lakes of the Jervis Bay Territory. Australian Wildlife Research. 13: 301-308.

Georges, A. (1988) Sex determination is independent of incubation temperature in another Chelid turtle, Chelodina longicollis. Copeia. 1988(1): 248-254.

Goode, J. and Russell, J. (1968) Incubation of eggs of three species of chelid tortoises, and notes on their embryological development. Australian Journal of Zoology. 16: 749-761.

Graham, T., Georges, A., and McElhinney, N. (1996) Terrestrial orientation by the Eastern long-necked turtle, Chelodina longicollis, from Australia. Journal of Herpetology. 30(4): 467-477.

Low, T (2002) The new nature. Penguin Group. Camberwell, Victoria, Australia.

Orenstein, R. (2001) Turtles, tortoises and terrapins: survivors in armor. Firefly Books, New York, USA.

Palmer-Allen, M., Beynon, F., and Georges, A. (1991) Hatchling sex ratios are independent of temperature in field nests of the Long-necked turtle, Chelodina longicollis (Testudinata: Chelidae). Wildlife Research. 18: 225-231.

Parker, L. (1999) Chelodina longicollis Information Sheet. http://www.jcu.edu.au/school/tbiol/zoology/herp/Chelodinalongicollis.PDF (accessed September 17, 2007).

Parmenter, C. J. (1985) Reproduction and survivorship of Chelodina longicollis (Testudinata: Chelidae). In Grigg, G., Shine, R., and Ehmann, H. (Eds) Biology of Australasian Frogs and Reptiles. Surrey Beatty \& Sons Pty Ltd. Chipping Norton, NSW, Australia.

Robb, J (1980) New Zealand Amphibians and Reptiles. William Collins Publishers Ltd. Auckland, New Zealand.

Seebacher, F., Sparrow, J., and Thompson, M. (2004) Turtles (Chelodina longicollis) regulate muscle metabolic enzyme activity in response to seasonal variation in body temperature. Journal of Comparative Physiology B. 174: 205-210. 
Thompson, M. (1983) Populations of the Murray River tortoise, Emydura (Chelodina): the effect of egg predation by the red fox, Vulpes vulpes. Australian Wildlife Research. 10: 363-371.

Thompson, S. (2003) Eastern Long-necked turtle Chelodina longicollis. World Chelonian Trust. Available Online:

http://www.chelonia.org/Articles/easternlongneck.htm (accessed April 15, 2008).

Thornton, T. (1999) Keeping red-eared turtles in New Zealand. TJ's Books.

Warkworth, New Zealand.

West, JA (1979) The occurrence of some exotic reptiles and amphibians in New Zealand. Herpetofauna. 10: 4-9.

Wilson S. and Swan G. (2003) A complete guide to reptiles of Australia. New Holland Publishers, Sydney, Australia. 


\section{Appendix 3: Reeves turtle (Chinemys reevesii)}

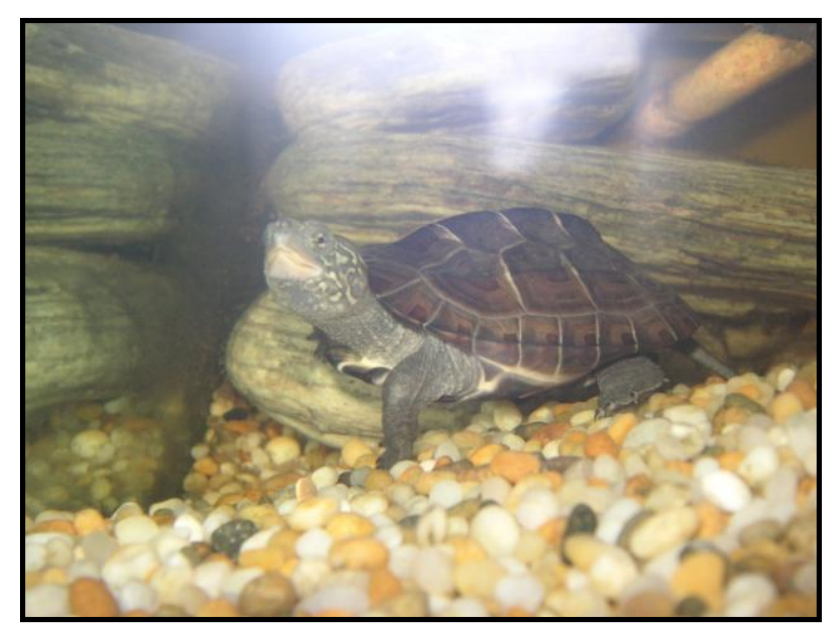

Reeves turtles are the most expensive freshwater turtle pet available in New Zealand, commanding a price of approximately 300 NZD. They are popular pets as they are advertised to "become tamer and more friendly" than red-eared sliders.

\section{Native Range}

Reeves turtles are naturally found in Asia, primarily Japan, Korea, Taiwan, Hong Kong, and China.

\section{Habitat Type}

Reeves turtles prefer soft-bottomed, shallow waters found in ponds and canals.

\section{Temperature preferences}

In captivity, Reeves turtles are usually maintained in water temperatures $\sim 21-22^{\circ} \mathrm{C}$.

\section{Reproductive Information}

\section{Breeding}

Full grown male Reeves turtles are smaller than mature females and possess a longer and thicker tail. Courtship and mating occur in spring.

\section{Nesting}

In their native range, nesting occurs in June and July. As with all chelonians, Reeves turtles deposit eggs in a nest dug into the soil. They are capable of producing up to three clutches per season, and clutches usually contain 4-9 eggs. 


\section{Incubation/ Hatchlings}

In laboratory experiments, eggs incubated at a constant temperature of $29^{\circ} \mathrm{C}$ hatched in about 67 days, whereas eggs incubated at a constant temperature of $33^{\circ} \mathrm{C}$ exhibited a shorter incubation period of about 62 days. Wild Reeves turtle hatchlings in Japan overwinter in the nest and emerge the following spring.

\section{Diet}

As omnivores, Reeves turtles consume fish, amphibians, invertebrates, aquatic vegetation, and fruits.

\section{Maximum Size}

Male Reeves turtles can reach approximately $15 \mathrm{~cm}$, while females can reach approximately $20 \mathrm{~cm}$.

\section{Naturalised Distribution}

Reeves turtles have been introduced into North America, but reports do not elaborate on if these animals are breeding, or on any potential impacts caused by these animals. Many reports are of single individuals thought to be released pets. A specimen has also been found on Russia's Bering Island; however it is thought to likely have washed over from Japan.

\section{New Zealand Distribution}

To date, there have been no reports of established populations of these turtles in New Zealand.

The online trade in Reeves turtles in New Zealand was monitored over a two year period. The majority of turtles sold were adults (62\%). (See Figure 1 and Table 1). 
Figure 1: Numbers and age brackets of Reeves turtle (Chinemys reevesii) sales by season (October 2007- October 2009) from www.trademe.co.nz. Summer $=$ December - February, spring = September - November, autumn $=$ March - May, and winter $=$ June - August. Juvenile $=<1$ year, Subadult $=1-2$ years, Adult $=>2$ years. $N=21$.

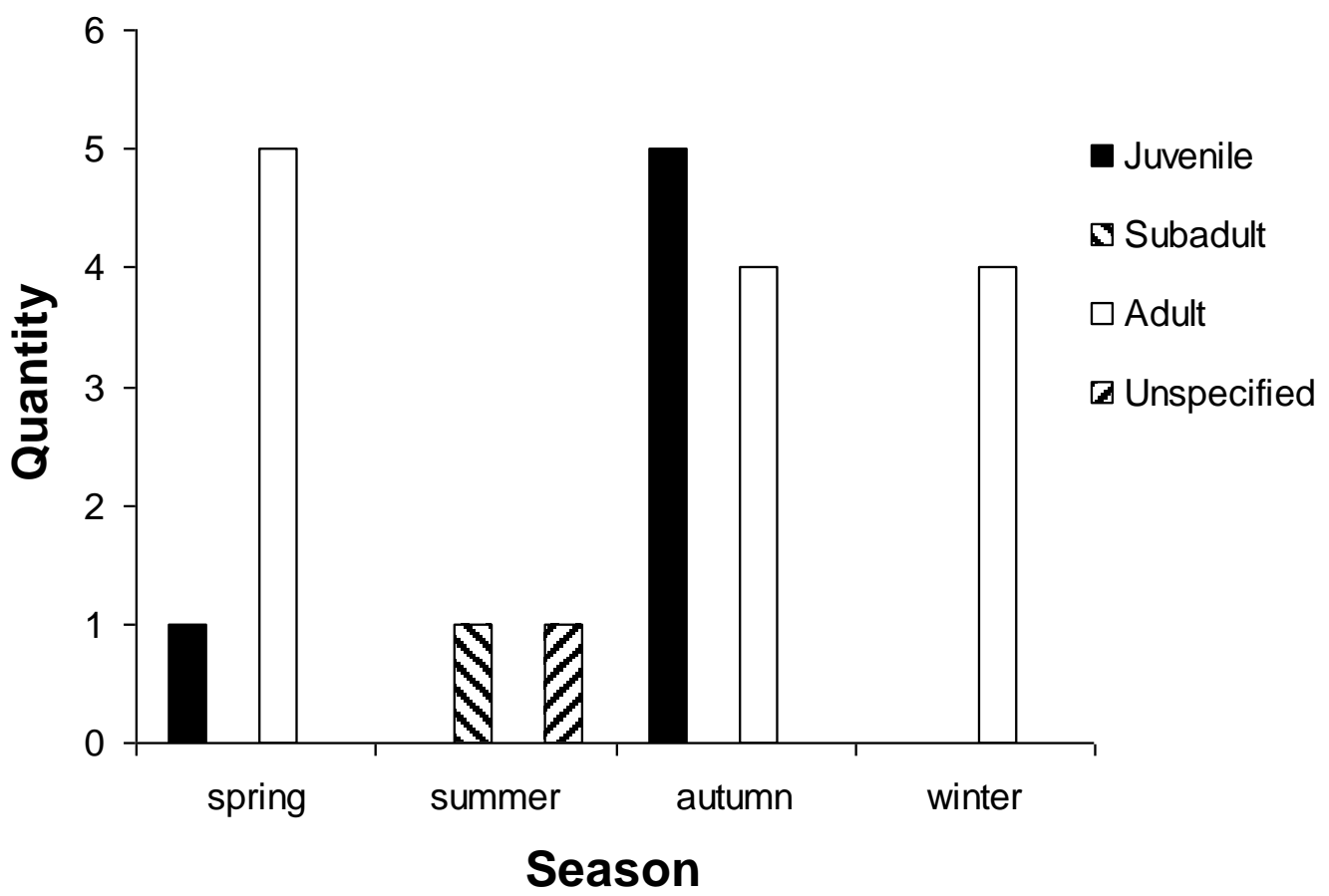

Table 1: Sex and age bracket of Reeves turtles (Chinemys reevesii) sold on TradeMe (October 2007October 2009). (Juvenile $=<1$ year, Subadult $=1-2$ years, Adult $=>2$ years).

\begin{tabular}{lccccc}
\hline Sex & \multicolumn{2}{c}{ Age bracket } & \multicolumn{2}{c}{ Total } \\
& Adult & Juvenile & Subadult & Unspecified & \\
\hline Female & 2 & 0 & 0 & 0 & 2 \\
Male & 4 & 0 & 0 & 0 & 4 \\
Unspecified & 7 & 6 & 1 & 1 & 15 \\
Total & 13 & 6 & 1 & 1 & $\mathbf{2 1}$ \\
\hline
\end{tabular}

\section{Possible negative effects to New Zealand}

Being omnivorous, it is possible that feral Reeves turtles may consume invertebrates, small vertebrates, and aquatic vegetation.

\section{Associated Diseases}

Like many reptiles, Reeves turtles are capable of carrying Salmonella bacteria, which is easily transferred to humans. 


\section{Lifespan}

Reeves turtles can live $\sim 30-50+$ years in captivity.

\section{Other relevant information}

Once common in its native range, numbers of Reeves turtles, especially those in China, have declined due to poaching for food and the pet trade. They are rarely seen for sale in Asian markets nowadays, and New Zealand has implemented breeding programs to ensure this species' survival.

Research has been done in the turtles' native range which recommends using Reeves turtles as a natural biocontrol method for invasive apple snails (Pomacea canaliculata) in Japanese rice fields.

\section{References}

Burne, C (2000) The ultimate guide to keeping freshwater turtles successfully in New Zealand. Brebner Print, Napier.

Endless Exotics (2010) Reeves turtle.

http://www.endlessexotics.com/ReevesTurtle.html (accessed 1 June, 2010).

Ernst, C, Altenburg, R., and Barbour, R. (1997) Turtles of the World. Available online: http://ip30.eti.uva.nl/bis/turtles.php

Fuller, P and A Foster (2000) Chinemys reevesii. USGS Nonindigenous aquatic species database, Gainesville, Florida, USA.

http://nas.er.usgs.gov/queries/FactSheet.aspx?SpeciesID=1228 (accessed 1 June, 2010).

Kirkpatrick, D (1991) The Reeves Turtle, Chinemys reevesii: An alternative to sliders and painted turtles. Reptile and Amphibian Magazine. Nov/Dec 1991: 2-7.

Orenstein, R (2001) Turtles, tortoises and terrapins: survivors in armor. Firefly Books, New York, USA.

Reptile City. Japanese Reeves turtles. http://www.reptilecity.com/Merchant2/ merchant.mvc?Screen=PROD\&Store_Code=reptiles\&Product_Code=CS6I (accessed 1 June, 2010).

Thornton, T (1999) Keeping red-eared turtles in New Zealand. TJ's Books. Warkworth, New Zealand.

Wang, P, Ma, W, Lu, B, and W You (1995) Studies on the physiological ecology of incubation in Chinemys reevesii eggs. Asiatic Herpetological Research. 6: 151-156.

Yoshie, H and Y Yusa (2008) Effects of predation on the exotic freshwater snail Pomaceae canaliculata (Caenogastropoda: Ampullariidae) by the indigenous turtle Chinemys reevesii. Applied Entomology and Zoology. 43(4): 475-482. 


\section{Appendix 4: Blue-tongue skink (Tiliqua spp.)}

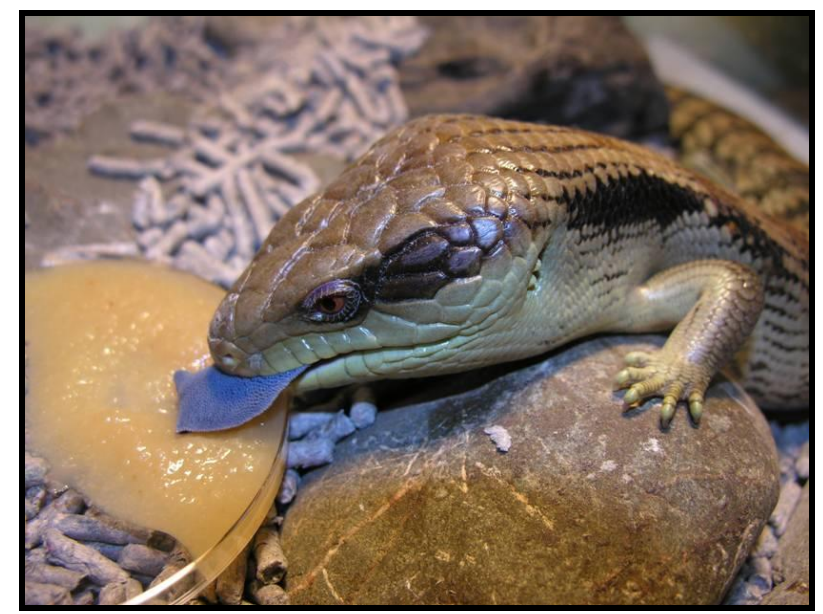

A popular exotic pet lizard in New Zealand is the common blue-tongue skink (Tiliqua scincoides). They are readily available from pet stores and online auction sites, such as TradeMe (www.trademe.co.nz), where they range between 200-700 NZD.

Another type of blue-tongue lizard, the shingleback skink (Tiliqua rugosa), are rarely seen offered for sale in New Zealand (in 2006 one was advertised by "The Turtle and Reptile Farm" for 3,500 NZD, however the website for this organisation no longer exists). A third variety, known as the blotched blue-tongue skink (Tiliqua nigrolutea) is present in New Zealand zoos, but it is unclear if this species is found in the local pet trade. The information below applies to the common blue-tongue skink, unless otherwise noted.

\section{Native Range}

Common blue-tongue skinks are naturally found in eastern and northern Australia, where they are present in the suburbs of all capital cities. Blotched blue-tongue skinks are naturally found in cooler areas of Australia than the common blue-tongue skinks, such as the Blue Mountains of New South Wales and in Tasmania. Shingleback skinks are found throughout the southern half of Australia.

\section{Habitat Type}

Common blue-tongue skinks thrive in urban habitats. Studies have found that bluetongue skinks maintain discrete home ranges and return to the same sleeping areas each night.

\section{Temperature preferences}

The preferred body temperature of the blue-tongue skink is between $30^{\circ}-37^{\circ} \mathrm{C}$, but they have been recorded to be active at temperatures as low as $15^{\circ} \mathrm{C}$.

As blotched blue-tongue skinks are found in cooler areas than common blue-tongue skinks, they are active at cooler temperatures. 


\section{Reproductive Information}

\section{Breeding}

None of the species of blue-tongue skinks exhibit sexual dimorphism. Blue-tongue skinks are viviparous (live-bearing). Some shingleback skinks appear to mate for life, with partners reuniting each spring, while others swap partners, sometimes within the same season.

\section{Nesting}

Gravid females tend to select a safe site and remain there during gestation. This is thought to help protect the mother and provide a safe haven for baby lizards.

\section{Incubation/ Hatchlings}

Females can produce up to 25 young in a litter, which grow rapidly and mature in two to three years.

Shingleback skinks produce a much lower number of young per year than common blue-tongue skinks: an average of two babies per female.

\section{Diet}

Blue-tongue skinks are omnivorous and have been recorded to consume berries, fruits, carrion, eggs, invertebrates, and small vertebrates. Lizards living in an urban area were found to have watermelon seeds and chicken bones in their digestive tract.

\section{Maximum Size}

Adult blue-tongue skinks can reach a length of up to $50 \mathrm{~cm}$.

\section{Naturalised Distribution}

The common blue-tongue skink is listed on a database for the "Florida Invasive Species Partnership" (http://www.invasive.org/species/list.cfm?id=77), but no details regarding the location or impacts of any alien populations are given. It has also been reported to be translocated throughout Australia in produce shipments. Shingleback skinks are believed to have been introduced to offshore islands of the Eyre and Yorke Peninsulas, just off the mainland of South Australia, where they occur naturally.

\section{New Zealand Distribution}

Although a newspaper article reports the naturalisation of blue-tongue skinks in New Zealand (http://www.times.co.nz/cms/news/2006/06/art100012060.php), the locations of these populations are unable to be confirmed. Very occasionally, an escaped or released pet is found. The Auckland Regional Council (ARC) has recently classified blue-tongue skinks (Tiliqua scincoides and T. nigrolutea) as "Surveillance" pests. This would prohibit the sale, breeding, and exhibition of these lizards. This change in legislation does not restrict the keeping of existing blue-tongue skinks for the 
remainder of their natural life. The ARC classifies Shingleback skinks (Tiliqua rugosa) as a pest "only when not held within secure containment".

The online trade in common blue-tongue skinks in New Zealand was monitored for a two year period. The majority of skinks sold were juveniles (59\%). (See Figure 1 and Table 1).

Figure 1: Numbers and age brackets of blue-tongue skinks (Tiliqua scincoides) sales by season (October 2007- October 2009) from www.trademe.co.nz. Summer = December - February, spring = September - November, autumn $=$ March - May, and winter $=$ June - August. Juvenile $=<1$ year, Subadult $=1-2$ years, Adult $=>2$ years. $N=134$.

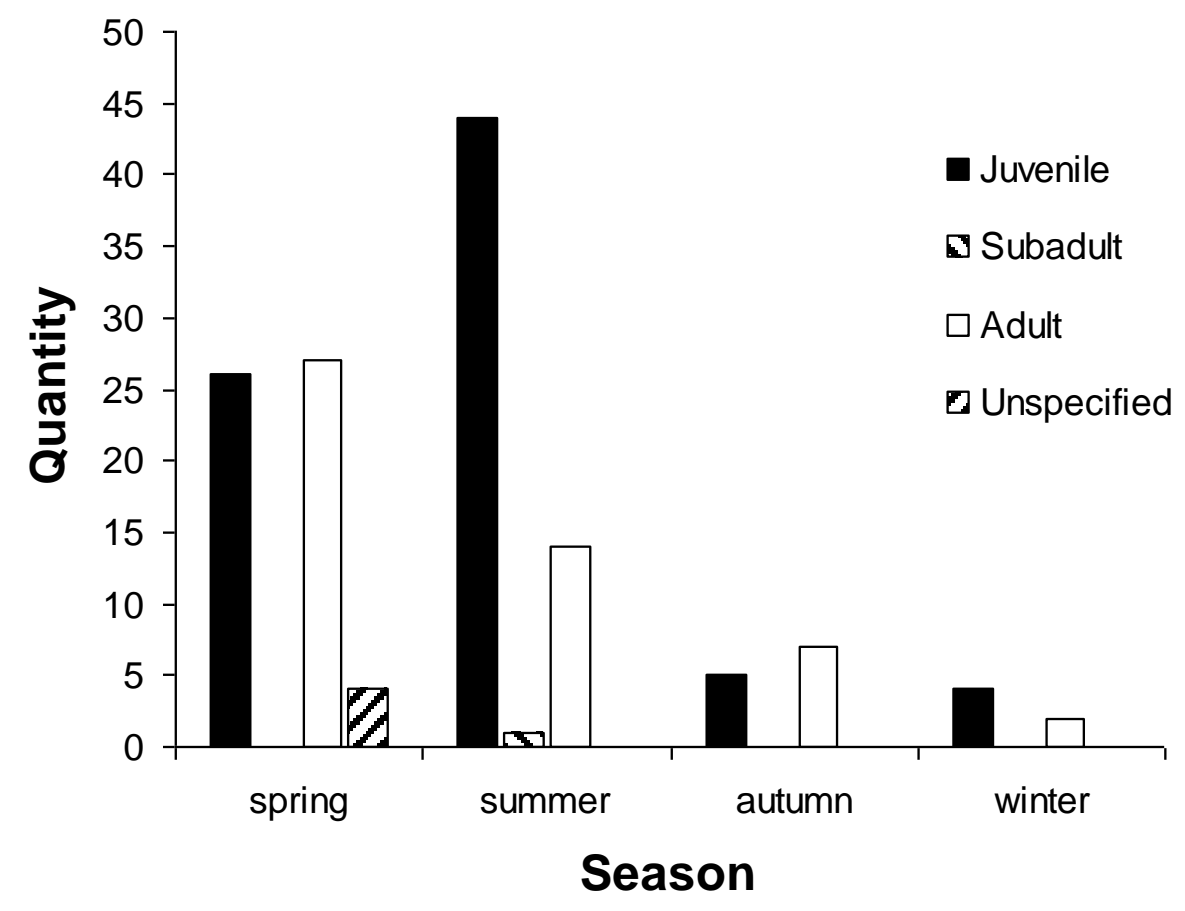

Table 1: Sex and age bracket of blue-tongue skinks (Tiliqua scincoides) sold on TradeMe (October 2007-October 2009). (Juvenile $=<1$ year, Subadult $=1-2$ years, Adult $=>2$ years).

\begin{tabular}{lccccc}
\hline Sex & \multicolumn{2}{c}{ Age bracket } & \multicolumn{2}{c}{ Total } \\
& Adult & Juvenile & Subadult & Unspecified & \\
\hline Female & 18 & 0 & 0 & 0 & 18 \\
Male & 15 & 0 & 0 & 0 & 15 \\
Unspecified & 17 & 79 & 1 & 4 & 101 \\
Total & 50 & 79 & 1 & 4 & $\mathbf{1 3 4}$ \\
\hline
\end{tabular}




\section{Possible negative effects to New Zealand}

As blue-tongue skinks in their native range have been observed knocking bird eggs out of nests and consuming them, their ability to affect birdlife in areas where they are introduced is feasible. Concerns listed by the ARC include the potential for predation of native wildlife, such as birds and smaller lizards and the potential for disease transmission to native species. As blue-tongue skinks have a long life span, populations may persist for some time, even in the absence of recruitment.

\section{Associated Diseases}

In New Zealand, the first reported incidence of a snake mite, Ophionyssus natricis, was from a blue-tongue skink held in a zoo. Overseas, blue-tongue skinks have been reported to suffer from "toe-rot" (progressive digital necrosis) from which researchers isolated Staphylococcus epidermidis, Bacillus spp., and Trichophyton terrestre. Endoparasites found within blue-tongue skinks include Strongylurus paronai, a gastric roundworm. Additionally, as with many reptiles, blue-tongue skinks have been known to harbour Salmonella bacteria in their gut, which is transferable to humans if hygiene practices are not followed.

\section{Lifespan}

Blue-tongue skinks can live for over 30 years in captivity.

\section{Other relevant information}

Recently a climate match assessment on blue-tongue skinks in New Zealand was performed by Landcare Research. The authors concluded that "climate within New Zealand is likely to be suitable" for both Tiliqua scincoides and T. nigrolutea (Barker and Harris, unpublished report, date unspecified). They cautioned that this did not mean that blue-tongue skinks would certainly establish, as there are many other limiting factors involved, such as food availability, presence of predators, and habitat suitability.

\section{References}

Angus, R (1994) Nest Predation by a Blue-tongued lizard. Australian Birds. 27(3): 87.

Auckland Regional Council (ARC) (2007) Auckland Regional Pest Management Strategy 2007-2012. Auckland, New Zealand. Pages 117-120.

Barker, G and R Harris (date unspecified) Risk of bluetongue lizards, Tiliqua scincoides and Tiliqua nigrolutea establishing in New Zealand - Climate assessment using BIOSECURE. Landcare Research. Unpublished report.

Bartholomew, G, Tucker, V, and A Lee (1965) Oxygen consumption, thermal conductance, and heart rate in the Australian skink Tiliqua scincoides. Copeia. 2: 169-173. 
Bull CM (1987) A population study of the viviparous Australian lizard, Trachydosaurus rugosus (Scincidae). Copeia. 3: 749-757.

Bull CM and MJ Freake (1999) Home range fidelity in the Australian sleepy lizard, Tiliqua rugosa. Australian Journal of Zoology. 47: 125-132.

Cabanac, M, Hammel, T, and J Hardy (1967) Tiliqua scincoides: Temperaturesensitive units in lizard brain. Science. 158: 1050-1051.

Christian, K, Webb, J, and T Schultz (2003) Energetics of bluetongue lizards (Tiliqua scincoides) in a seasonal tropical environment. Oecologia. 136: 515-523.

Cogger H (1975) Reptiles and amphibians of Australia. Reed Party Books, Sydney, Australia.

Fergusson, B and G Algar (1986) Home range and activity patterns of pregnant female skinks, Tiliqua rugosa. Australian Wildlife Research. 13: 287-294.

Hazell, S, Eamens, G, and R Perry (1985) Progressive digital necrosis in the Eastern Blue-tongued skink, Tiliqua scincoides (Shaw). Journal of Wildlife Diseases. 21(2):186-188.

Heath, A (1986) First occurrence of the reptile mite, Ophionyssus natricis (Acari: Dermanyssidae) in New Zealand. New Zealand Veterinary Journal. 34(5): 78-79.

Hollingsworth, J and K Hollingsworth (1994) Captive care sheet, Species: Bluetongue skink. Retrieved May 30, 2010 from http://www.livefood.co.uk/zbluetskink.htm.

Koenig, J, Shine, R, and G Shea (2001) The ecology of an Australian reptile icon: how do blue-tongued lizards (Tiliqua scincoides) survive in suburbia? Wildlife Research. 28: 215-227.

Koenig, J, Shine, R, and G Shea (2002) The dangers of life in the city: Patterns of activity, injury and mortality in suburban lizards (Tiliqua scincoides). Journal of Herpetology. 36(1): 62-68.

McKenna, P (2003) An annotated checklist of ecto- and endoparasites of New Zealand reptiles. Surveillance. 30(3): 18-25.

O'Dwyer, T, Buttemer, W, and D Priddel (2000) Inadvertent translocation of amphibians in the shipment of agricultural produce into New South Wales: its extent and conservation implications. Pacific Conservation Biology. 6: 40-45.

Paré, J, Sigler, L, Rosenthal, K, and D Mader (2006) "Microbiology: Fungal and bacterial diseases of reptiles". In Mader (Ed.) Reptile medicine and surgery. Elsevier Inc. St. Louis, Missouri, USA. 
Pfleger, S, Benyr, G, Sommer, R, and A Hassl (2003) Pattern of Salmonella excretion in amphibians and reptiles in a vivarium. International Journal of Hygiene and Environmental Health. 206: 53-59.

Rose, K (2005) Common diseases of urban wildlife: Reptiles. The Australian Registry of Wildlife Health. Zoological Parks Board of New South Wales.

Sarre, S, Schwaner, T, and A Georges (1990) Genetic variation among insular populations of the sleepy lizard, Trachydosaurus rugosus Gray (Squamata:

Scincidae). Australian Journal of Zoology. 38: 603-616.

Satrawaha R and CM Bull (1981) The area occupied by an omnivorous lizard, Trachydosaurus rugosus. Australian Wildlife Research. 8: 435-42.

Sugrue, C (2006, June 22) Exotic pets under scrutiny. Howick and Pakuranga Times. Available Online: http://www.times.co.nz/cms/news/2006/06/art100012060.php

Torr, G (1999) True Blue. Australian Geographic. 55: 52-68.

Turner, G (2001) Keeping blue-tongue lizards. Australian Reptile Keeper Publications. Bendigo, Victoria, Australia.

Wilson S and G Swan (2005) A complete guide to reptiles of Australia. New Holland Publishers, Sydney, Australia. 


\section{Appendix 5: Bearded dragon (Pogona spp.)}

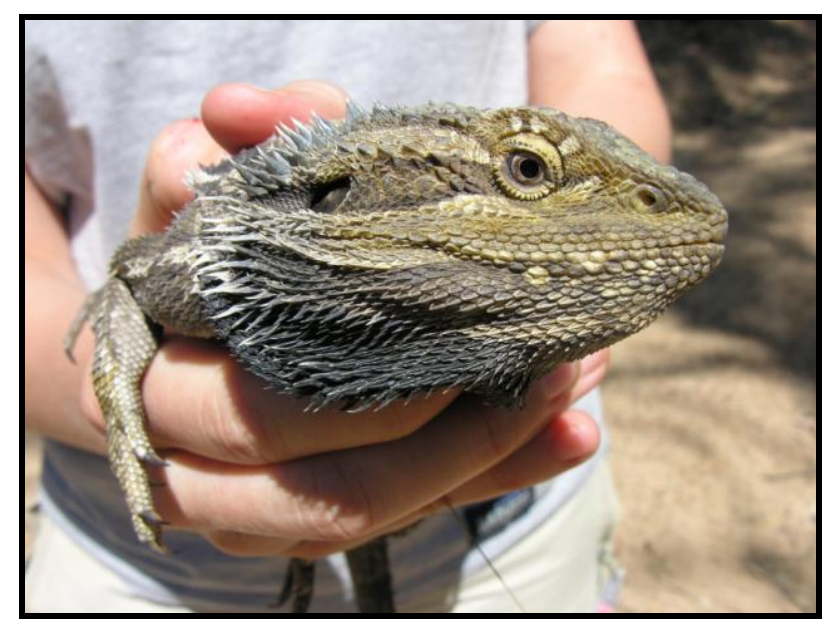

Two species of bearded dragon are available in the New Zealand pet trade: the inland bearded dragon (Pogona vitticeps) and the coastal bearded dragon ( $P$. barbata). They are extremely similar in appearance to each other but can be distinguished by the shape of the scales on the back of the head. In New Zealand, inland bearded dragons are readily available, while coastal bearded dragons appear more difficult to source. Juvenile bearded dragons are frequently offered on online auction websites (e.g. TradeMe) for 300-500 NZD. Adult dragons, especially those with unusual colourings, tend to command higher prices, closer to 1,000 NZD.

\section{Native Range}

Bearded dragons are native to Australia. As their name implies, inland bearded dragons are native to inland Australia, whereas coastal bearded dragons are found along the eastern coast of Australia.

\section{Habitat Type}

Inland bearded dragons are naturally found in arid or semi-arid woodland and shrubland areas. Coastal bearded dragons are found in cool temperate open forest and woodland areas.

\section{Temperature preferences}

Inland bearded dragons are native to hot, dry desert areas and require specialised equipment (e.g. heat lamps) to survive in New Zealand. Coastal bearded dragons are gaining in popularity in the New Zealand pet trade as they are able to withstand lower temperatures and higher humidity than inland bearded dragons, making them more appealing for New Zealand reptile enthusiasts, which often prefer to keep their animals outdoors. 


\section{Reproductive Information}

\section{Breeding}

Male bearded dragons have a thicker tail base, a wider cloacal fold, and more distinct femoral and preanal pores than females. Bearded dragons mate in spring.

\section{Nesting}

Being oviparous, bearded dragons can lay up to 35 eggs at a time in a hole dug in the ground. They are capable of producing multiple clutches.

\section{Incubation/ Hatchlings}

Incubation at a temperature of $26^{\circ} \mathrm{C}$ will cause fertile eggs to hatch in approximately 90 days. Bearded dragons do not appear to exhibit temperature-dependent sex determination.

\section{Diet}

Bearded dragons are omnivorous, consuming invertebrates, small vertebrates, and vegetation.

\section{Maximum Size}

Adult bearded dragons can reach a length of up to $58 \mathrm{~cm}$ from nose to tail tip.

\section{Naturalised Distribution}

Bearded dragons do not appear to have established invasive populations outside of their native range.

\section{New Zealand Distribution}

There are currently no records of bearded dragons living in the wild in New Zealand. One inland bearded dragon was reported missing in the Auckland region in 2008 and another in 2009.

Online sales of bearded dragons in New Zealand were recorded over a two year period (October 2007- October 2009). The majority of bearded dragons sold were juveniles (56\% for inland bearded dragons and $83 \%$ for coastal bearded dragons). (See Figures $1 \& 2$ and Table $1 \& 2$ ). 
Figure 1: Numbers and age brackets of inland bearded dragons (Pogona vitticeps) sales by season (October 2007- October 2009) from www.trademe.co.nz. Summer $=$ December - February, spring $=$ September - November, autumn $=$ March - May, and winter $=$ June - August. Juvenile $=<1$ year, Subadult $=1-2$ years, Adult $=>2$ years. $N=144$.

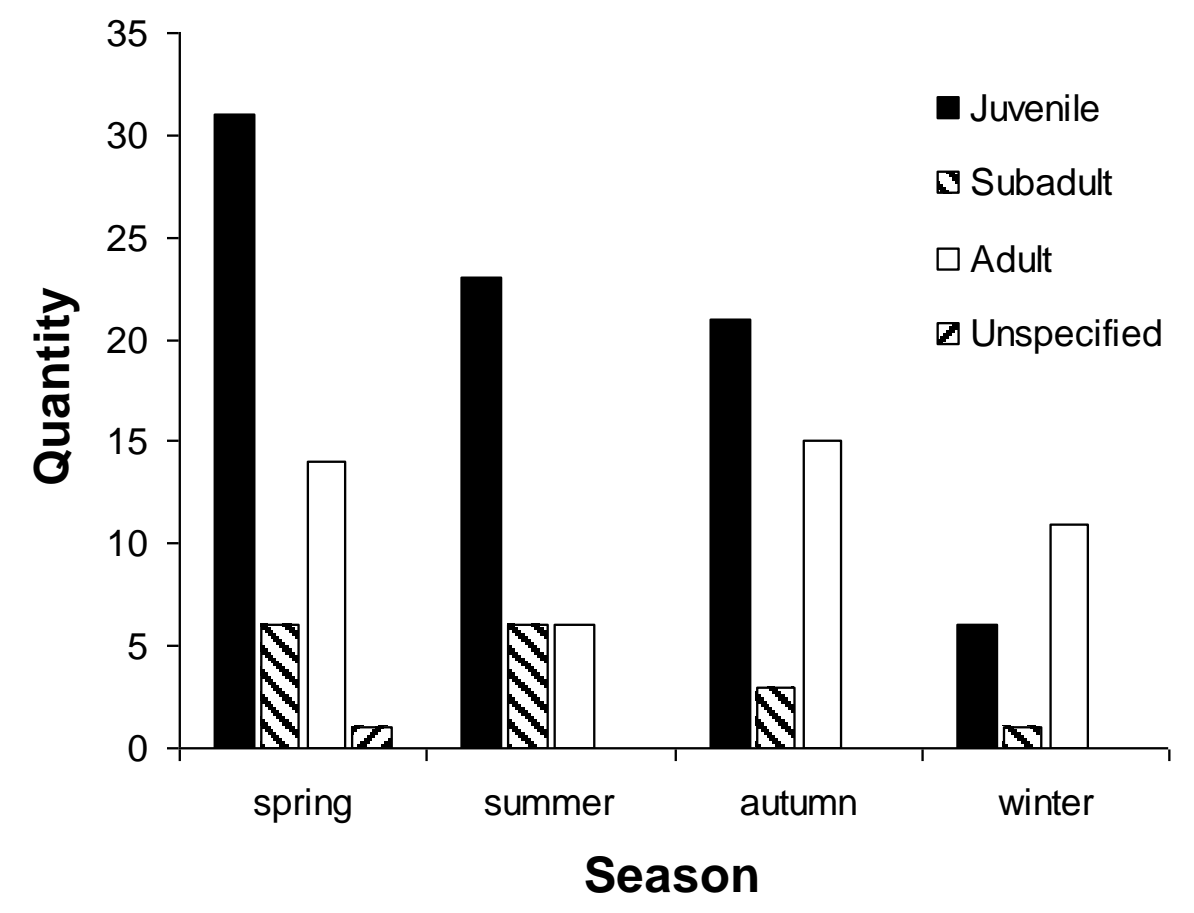

Table 1: Sex and age bracket of inland bearded dragons (Pogona vitticeps) sold on TradeMe (October 2007-October 2009). (Juvenile $=<1$ year, Subadult $=1-2$ years, Adult $=>2$ years .

\begin{tabular}{lccccc}
\hline Sex & \multicolumn{2}{c}{ Age bracket } & \multicolumn{2}{c}{ Total } \\
& Adult & Juvenile & Subadult & Unspecified & \\
\hline Female & 20 & 2 & 3 & 0 & 25 \\
Male & 23 & 8 & 9 & 0 & 40 \\
Unspecified & 3 & 71 & 4 & 1 & 79 \\
Total & 46 & 81 & 16 & 1 & $\mathbf{1 4 4}$ \\
\hline
\end{tabular}


Figure 2: Numbers and age brackets of coastal bearded dragons (Pogona barbata) sales by season (October 2007- October 2009) from www.trademe.co.nz. Summer $=$ December - February, spring $=$ September - November, autumn $=$ March - May, and winter $=$ June - August. Juvenile $=<1$ year, Subadult $=1-2$ years, Adult $=>2$ years. $N=18$.

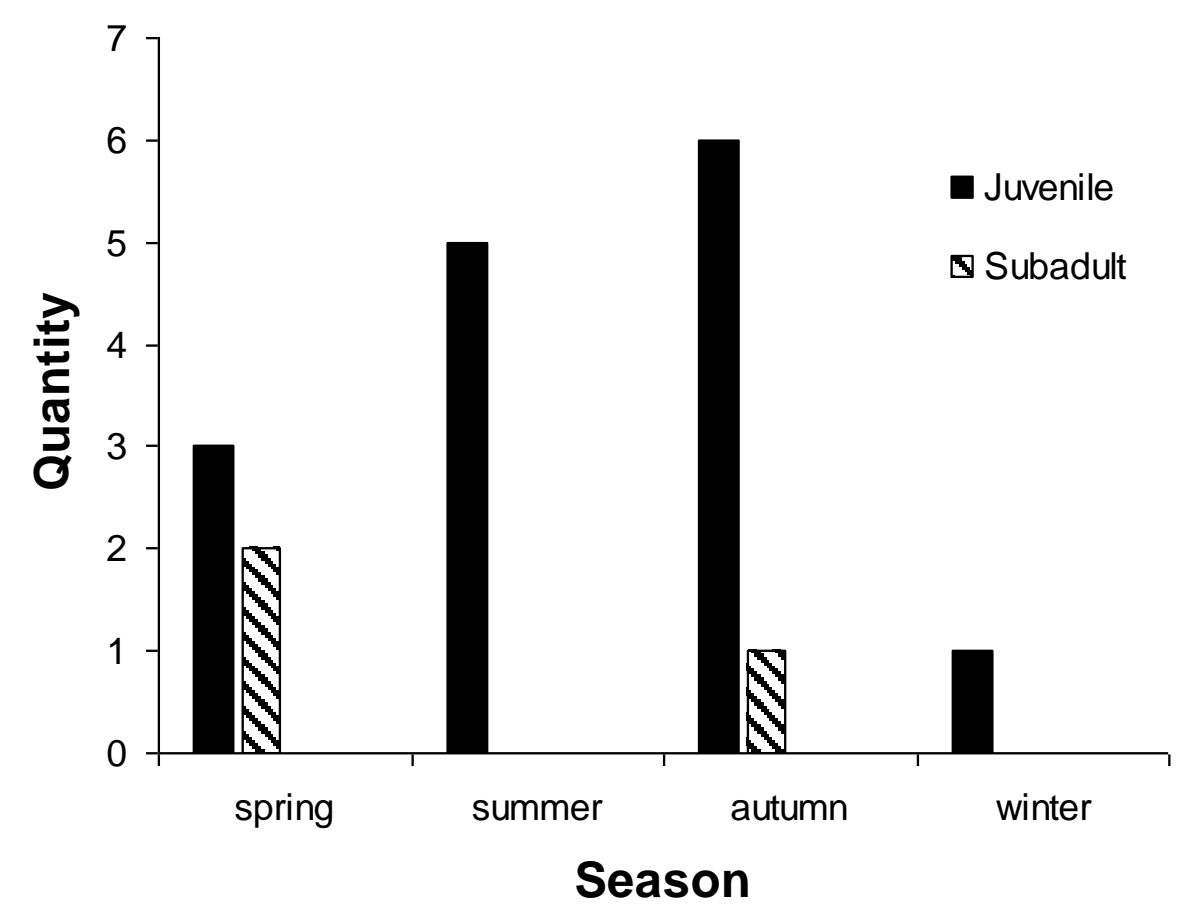

Table 2: Sex and age bracket of coastal bearded dragons (Pogona barbata) sold on TradeMe (October 2007-October 2009). (Juvenile $=<1$ year, Subadult $=1-2$ years, Adult $=>2$ years).

\begin{tabular}{lccccc}
\hline Sex & \multicolumn{2}{c}{ Age bracket } & \multicolumn{2}{c}{ Total } \\
& Adult & Juvenile & Subadult & Unspecified & \\
\hline Female & 0 & 0 & 0 & 0 & 0 \\
Male & 0 & 0 & 1 & 0 & 1 \\
Unspecified & 0 & 15 & 2 & 0 & 17 \\
Total & 0 & 15 & 3 & 0 & $\mathbf{1 8}$ \\
\hline
\end{tabular}

\section{Possible negative effects to New Zealand}

Bearded dragons are classified by the Auckland Regional Council (ARC) as both a "Research Organism" and as a pest "only where they are not held in secure containment". The ARC states concerns of competition with native species for food or other resources.

\section{Associated Diseases}

The potential for disease transmission to other reptiles is associated with bearded dragons. Bearded dragons are susceptible to adenovirus infections, which are characterised by hepatitis, gastrointestinal problems, and death. In most cases, it is 
juvenile dragons that are affected, however adenovirus infections have also proven to be fatal in adult dragons; for this reason, bearded dragons with "chronic subclinical infections have been suggested as a potential risk to other reptiles".

Bearded dragons are also susceptible to a variety of skin conditions. The "CANV" (Chrysosporium anamorph of Nannizziopsis vriesii) is the source of an infection consistently found in captive bearded dragons overseas associated with "Yellow Fungal Disease". The Dermatophilus congolensis bacterium also affects bearded dragons, causing skin lesions and abscesses. Bearded dragons are also susceptible to coccidiosis. Additionally, as with all reptiles, bearded dragons have been known to harbour Salmonella bacteria in their gut, which can be transmissible to humans and other organisms.

\section{Lifespan}

In captivity, healthy bearded dragons can live for up to fifteen years.

\section{Other relevant information}

Many lizards, including bearded dragons, possess a low-grade venom, which can leave reptile owners with prolonged swelling and bleeding after suffering a bite from their pet.

\section{References}

Auckland Regional Council (ARC) (2007) Auckland Regional Pest Management Strategy 2007-2012. Auckland, New Zealand. Pages 117-120.

Cannon, M (2003) Husbandry and veterinary aspects of the bearded dragon (Pogona spp.) in Australia. Seminars in Avian and Exotic Pet Medicine. 12(4): 205-214.

Cogger, H (1975) Reptiles and amphibians of Australia. Reed Party Books, Sydney, Australia.

de Vosjoli, P, Mailloux, R, Donoghue, S, Klingenberg, R, and J Cole (2009) The bearded dragon manual. Advanced Vivarium Systems, Irvine, California, USA.

Ezaz, T, Quinn, A, Miura, I, Sarre, S, Georges, A, J Marshall Graves (2005) The dragon lizard Pogona vitticeps has ZZ/ZW micro-sex chromosomes. Chromosome Research. 13: 763-776.

McAllister, C., Upton, S., Jacobson, E., and Kopit, W. (1995) A description of Isospora amphiboluri (Apicomplexa: Eimeriidae) from the inland bearded dragon, Pogona vitticeps (Sauria: Agamidae). Journal of Parasitology. 81(2): 281-284.

Paré, J., Sigler, L., Rosenthal, K., and Mader, D. (2006) "Microbiology: Fungal and bacterial diseases of reptiles". In Mader (Ed.) Reptile medicine and surgery. Elsevier Inc. St. Louis, Missouri, USA. 
Pfleger, S., Benyr, G., Sommer, R., and Hassl, A. (2003) Pattern of Salmonella excretion in amphibians and reptiles in a vivarium. International Journal of Hygiene and Environmental Health. 206: 53-59.

Ritchie, B. (2006) Virology. In Mader, D. (Ed) Reptile Medicine and Surgery, Second Edition. Saunders Elsevier. St. Louis, Missouri, USA.

Rose, K (2005) Common diseases of urban wildlife: Reptiles. The Australian Registry of Wildlife Health. Zoological Parks Board of New South Wales.

Singleton, C. B., Mitchell, M., Riggs, S., and Figueroa, O. (2003) Evaluating oregano as a coccidiocide in the inland bearded dragon (Pogona vitticeps). Proceedings of the Association of Reptilian and Amphibian Veterinarians. Minneapolis, Minnesota, USA.

Wilson S. and Swan G. (2005) A complete guide to reptiles of Australia. New Holland Publishers, Sydney, Australia.

Young, E (2005) The pet shop never mentioned venom. New Scientist. 188(2526): 10. 


\section{Appendix 6: Australian waterdragon (Physignathus lesueurii)}

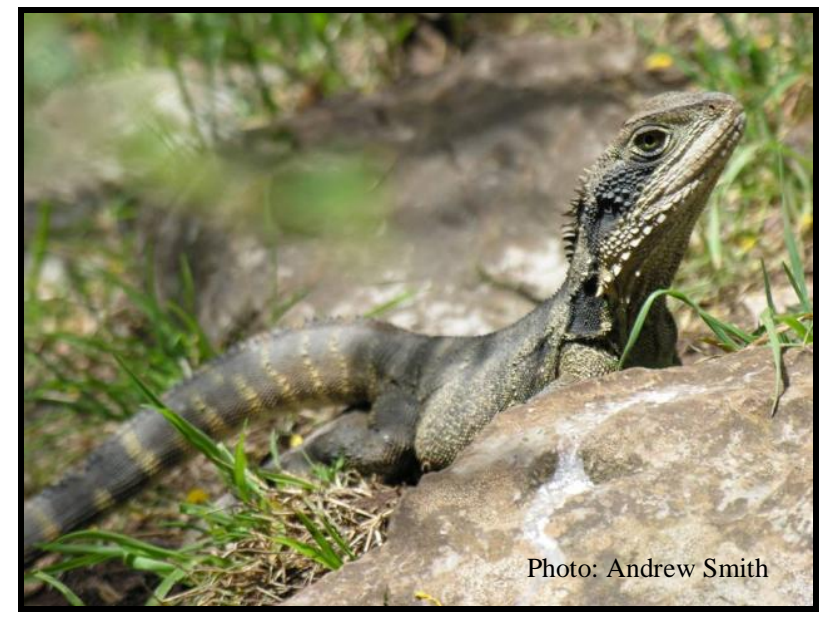

Waterdragons are the largest species of exotic lizard available in the New Zealand pet trade. They retail from between 400-1000 NZD.

\section{Native Range}

Waterdragons are native to the eastern portion of Australia, ranging from Cape York to Victoria. Males are highly territorial during the breeding season.

\section{Habitat Type}

As their name implies, waterdragons are found near water bodies and are powerful swimmers. They are often found in tree branches overhanging the water, which enables them to drop down to the safety of the water when disturbed. Adults can remain under water for over an hour. They are also known to thrive in urban areas. In Australia, this species has even been found "in very polluted rivers frolicking between the floating garbage".

\section{Temperature preferences}

Waterdragons have broad environmental tolerances, being found in both tropical and temperate areas, as well as at a variety of elevations (sea level to 1,250 meters above sea level).

\section{Reproductive Information}

\section{Breeding}

Male waterdragons are larger overall than females and have a larger head and crest. Males also tend to be more colourful than females, with a dark stripe behind the eye and red colouration on their throats and stomachs. Although sperm storage has not been documented in this species, a closely related species, the Asian waterdragon (Physignathus cocincinus) has the capability to store sperm for over 580 days after mating. 


\section{Nesting}

In their native range, waterdragons are capable of laying up to three clutches per year. Nests consist of an excavated chamber (approximately $10 \mathrm{~cm}$ deep) in an open, sunny area.

\section{Incubation/ Hatchlings}

Clutches contain between 4-12 eggs and hatch within 60-120 days. As with many egg-laying reptiles, incubation length is related to temperature, with eggs incubated at warmer temperatures hatching sooner than those incubated at cooler temperatures. In the wild, waterdragon eggs are subjected to a variance of nest temperatures, with nests in Sydney being exposed to daily temperature fluctuations of $12^{\circ} \mathrm{C}$.

Waterdragons have Temperature-Dependent Sex Determination, with females produced at "hot and cool" temperatures (below $25^{\circ} \mathrm{C}$ or above $28^{\circ} \mathrm{C}$ ) and males produced at "intermediate" temperatures.

\section{Diet}

Waterdragons are omnivorous, feeding on a variety of insects, small vertebrates, crustaceans, snails, berries, and fruits. They hunt for food both on land and in the water.

\section{Maximum Size}

Waterdragons are capable of reaching over one meter in length (including tail) and weighing $0.9 \mathrm{~kg}$.

\section{Naturalised Distribution}

Waterdragons have been introduced into the Melbourne areas of Fairfield and Kew from their native range to the east.

\section{New Zealand Distribution}

Within New Zealand, waterdragons have bred successfully in an outdoor enclosure at Auckland Zoo, therefore it would not be unreasonable to assume that they may successfully reproduce within the New Zealand environment and establish sustainable populations.

The online trade of waterdragons in New Zealand was monitored over a two year period. The majority of waterdragons sold were juveniles (79\%). (See Figure 1 and Table 1). 
Figure 1: Numbers and age brackets of waterdragon (Physignathus lesueurii) sales by season (October 2007- October 2009) from www.trademe.co.nz. Summer = December - February, spring = September - November, autumn $=$ March - May, and winter $=$ June - August. Juvenile $=<1$ year, Subadult $=1-2$ years, Adult $=>2$ years. $\mathrm{N}=98$.

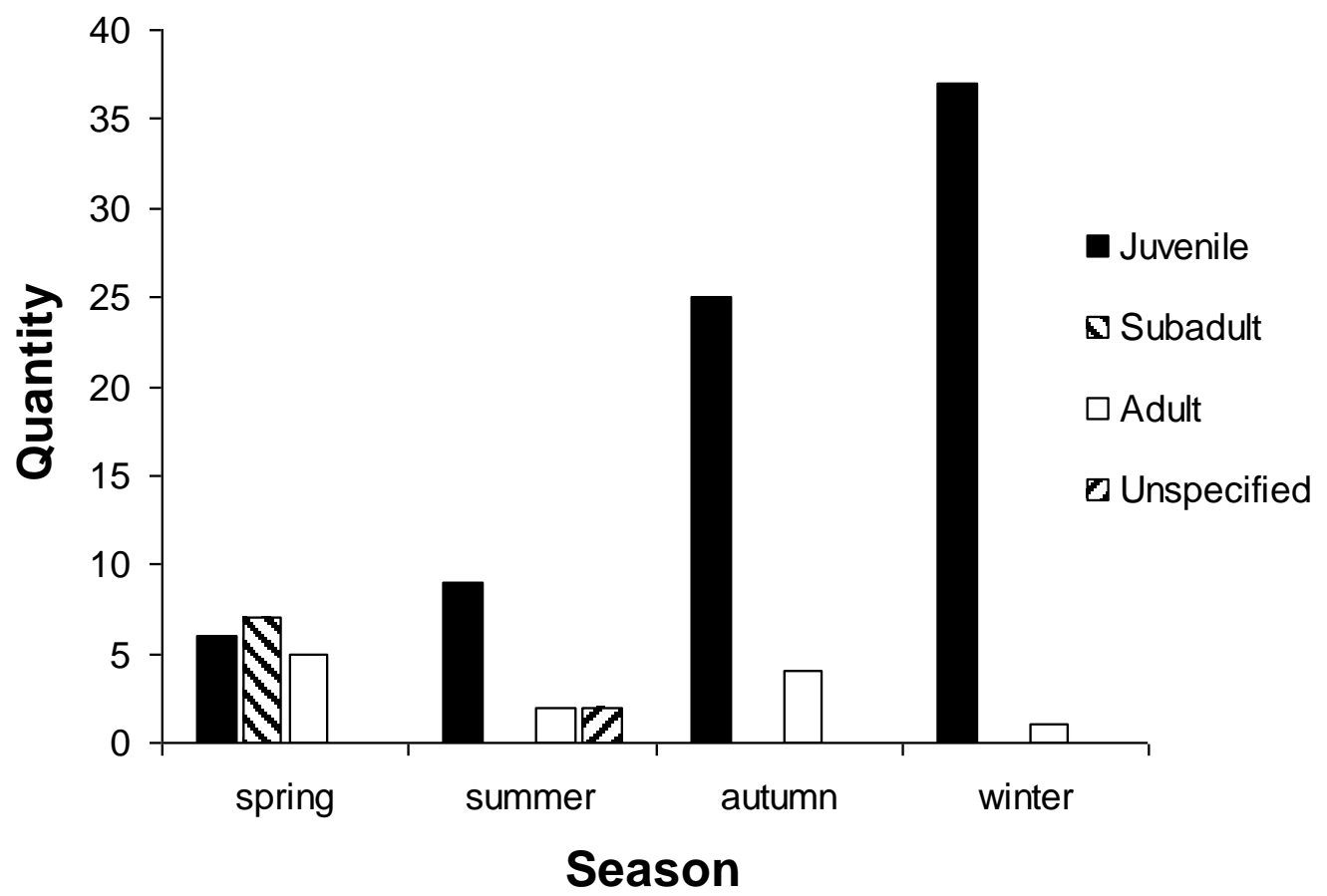

Table 1: Sex and age bracket of waterdragons (Physignathus lesueurii) sold on TradeMe (October 2007-October 2009). (Juvenile $=<1$ year, Subadult $=1-2$ years, Adult $=>2$ years).

\begin{tabular}{lccccc}
\hline Sex & \multicolumn{2}{c}{ Age bracket } & \multicolumn{2}{c}{ Total } \\
& Adult & Juvenile & Subadult & Unspecified & \\
\hline Female & 7 & 3 & 6 & 2 & 18 \\
Male & 4 & 9 & 1 & 0 & 14 \\
Unspecified & 1 & 65 & 0 & 0 & 66 \\
Total & 12 & 77 & 7 & 2 & $\mathbf{9 8}$ \\
\hline
\end{tabular}

\section{Possible negative effects to New Zealand}

Predation of native species (i.e. birds, lizards) appears to be the most likely threat posed by these lizards if they were to establish in New Zealand. Within New Zealand, waterdragons are classified as both a "Research Organism" and as a pest "only where they are not held in secure containment". 


\section{Associated Diseases}

Endoparasites reported from waterdragons include Strongylurus paronai, a gastric roundworm and microsporidia. Various nematodes are also often associated with wild waterdragons, including Abbreviata physignathi and Spinicauda fluviatica, for which the waterdragon is the only known host. Also, as with all reptiles, waterdragons are capable of carrying and transmitting Salmonella bacteria.

\section{Lifespan}

Waterdragons have been reported to live for over 25 years in captivity.

\section{References}

Auckland Regional Council (ARC) (2007) Auckland Regional Pest Management Strategy 2007-2012. Auckland, New Zealand. Pages 117-120.

Cogger H (1975) Reptiles and amphibians of Australia. Reed Party Books, Sydney, Australia.

Cuervo, JJ and R Shine (2007) Hues of a dragon's belly: morphological correlates of ventral coloration in water dragons. Journal of Zoology. 273: 298-304.

Doody, S., Guarino, E., Georges, A., Corey, B., Murray, G., and Ewert, M. (2006) Nest site choice compensates for climate effects on sex ratios in a lizard with environmental sex determination. Evolutionary Ecology. 20: 307-330.

Harlow, PS and MF Harlow (1997) Captive reproduction and longevity in the eastern water dragon (Physignathus lesueurii). Herpetofauna. 27:14-19.

Harlow, PS (2001) The ecology of sex-determining mechanisms in Australian agamid lizards. PhD thesis. Macquarie University, Sydney, Australia.

Hay, M (1972) The breeding of Physignathus lesueurii in captivity. Herpetofauna. 5: 2-3.

Henderson, L (6 September, 2007) Personal Communication. Auckland Zoo.

Jones, H (2007) Nematodes from the water dragon, Physignathus lesueurii (Reptilia: Agamidae) in Australia, with a description of Spinicauda fluviatica, sp. nov. (Nematoda: Heterakoidea). Australian Journal of Zoology. 55: 161-168.

Kast, J. (2007) Prolonged sperm storage in the Asian Water Dragon (Physignathus cocincinus). Herpetological Review. 38(2): 172.

Langerwerf, B (2006) Water Dragons. T.F.H. Publications, Inc. Neptune City, New Jersey, USA.

Low, T (2002) The new nature. Penguin Group. Camberwell, Victoria, Australia. 
Maruyama, K and T Langkilde (1999) Physignathus lesueurii Information Sheet. http://www.jcu.edu.au/school/tbiol/zoology/herp/Physignathuslesueuri.pdf (accessed 23 March, 2010).

Rose, K. (2005) Common diseases of urban wildlife: Reptiles. The Australian Registry of Wildlife Health. Zoological Parks Board of New South Wales.

Thompson, M. (1993) Estimate of the population structure of the Eastern water dragon, Physignathus lesueurii (Reptilia: Agamidae), along riverside habitat. Wildlife Research. 20: 613-619.

Wilson S. and Swan G. (2005) A complete guide to reptiles of Australia. New Holland Publishers, Sydney, Australia. 


\section{Appendix 7: Tortoises (Testudo spp.)}

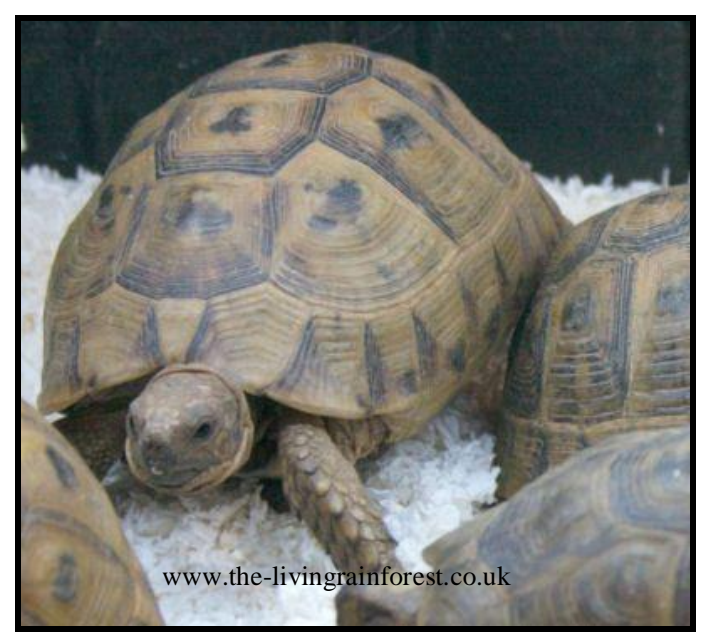

While popular overseas, pet tortoises are relatively rare in New Zealand. When they are available for sale, they can command over 6,000 NZD a piece. Species known to exist in New Zealand include Greek tortoises (Testudo graeca) and Hermanns tortoises (T. hermanni). During the period from October 2007 and October 2009, only six Greek tortoises and one Hermanns tortoise were sold on www.trademe.co.nz with a total value of 21,620 NZD. (See Table 1). Greek tortoises are listed as "Vulnerable" and Hermanns tortoises are listed as "Near Threatened" by the IUCN.

\section{Native Range}

Greek tortoises are native to southeastern Europe, northern Africa, and the Middle East. Hermanns tortoises are naturally found in Europe and the Balkans.

\section{Habitat Type}

Within their native ranges, both Greek and Hermanns tortoises are usually found on dry, sloping hillsides or plateaus covered in scrub vegetation or woodland.

\section{Temperature preferences}

Tortoises prefer areas of low humidity. In the wild, tortoises thermoregulate so that their body temperature is often higher than the ambient temperature.

\section{Reproductive Information}

\section{Breeding}

Adult male Greek tortoises tend to be larger and more muscular than females, whereas male Hermanns tortoises tend to be smaller than females. Males of both species also have a more concave plastron than females. Upon awakening from hibernation, the males pursue the females in an elaborate courtship display which involves circling the females and ramming their carapace. Hermanns tortoises reach sexual maturity at approximately 10 years of age. 


\section{Nesting}

Like all chelonians, female tortoises will deposit eggs in a hole dug in the ground.

\section{Incubation/ Hatchlings}

Greek tortoise eggs incubated at a constant temperature of $29^{\circ} \mathrm{C}$ hatch in $\sim 83$ days. Within New Zealand, Robb (1980) reports that eggs laid by Greek tortoises exhibited at the Ti Point Wildlife Park in the North Island have not hatched successfully.

\section{Diet}

Tortoises are primarily herbivorous. In captivity they are maintained on fruits and vegetables, however in the wild they have been observed occasionally consuming slugs and carrion.

\section{Maximum Size}

In the wild, different tortoise populations obtain dramatically different sizes. For example, straight carapace lengths of Greek tortoises can range in size from $15.5 \mathrm{~cm}$ to $25.5 \mathrm{~cm}$, however an adult male tortoise was found in Romania which a carapace measuring $30.1 \mathrm{~cm}$.

\section{Naturalised Distribution}

In other parts of the world, both Greek and Hermanns tortoises have been deliberately introduced into areas outside of their native range. Established populations of these tortoises are currently found in Spain, Malta, northern France, the Balearic Islands, and Corsica. Attempts have also been made to introduce Hermanns tortoises into Austria, although they are not confirmed to have successfully established.

\section{New Zealand Distribution}

The number of tortoises in private collections in New Zealand is unknown, and due to their rarity, collectors often do not publicise that they own tortoises due to the concern of theft. There are no known wild populations of these animals in New Zealand. 
Table 1: Sex and age bracket of Greek tortoises (Testudo graeca) sold on TradeMe (October 2007October 2009). (Juvenile $=<1$ year, Subadult $=1-2$ years, Adult $=>2$ years .

\begin{tabular}{lccccc}
\hline Sex & \multicolumn{2}{c}{ Age bracket } & \multicolumn{2}{c}{ Total } \\
& Adult & Juvenile & Subadult & Unspecified & \\
\hline Female & 2 & 1 & 0 & 0 & 3 \\
Male & 0 & 0 & 0 & 0 & 0 \\
Unspecified & 0 & 3 & 0 & 0 & 3 \\
Total & 2 & 4 & 0 & 0 & $\mathbf{6}$ \\
\hline
\end{tabular}

\section{Associated Diseases}

Like all reptiles, tortoises are able to carry and transmit Salmonella bacteria.

Tortoises are also known to carry intestinal worms, such as Ascarids and Trichurids.

\section{Lifespan}

Tortoises are a long-lived species capable of living well over 50 years. Reports of tortoises outliving their owners are not uncommon.

\section{References}

Cogălniceanu, D., Samoilă, C., Tudor, M., and O. Tallowin (2010) An extremely large spur-thighed tortoise male (Testudo graeca) from Măcin Mountains National Park, Romania. Herpetology Notes. 3: 45-48.

Connor, M. (1993) Hermanns tortoise, Testudo hermanni. Tortuga Gazette. 29(8): 1-3.

Lever, C (2003) Naturalized reptiles and amphibians of the world. Oxford University Press, New York.

Grange reptiles (2010) Hermanns tortoise care sheet. Available online at: http://www.grangereptiles.co.uk/csheets/caresheets/Hermans_Tortoise_Care_Sheet.p $\underline{\mathrm{df}}$

Highfield, A (2010) Notes on the systematics and ecology of Testudo hermanni GMELIN 1789. The Tortoise Trust. Available online at:

http://www.tortoisetrust.org/articles/sysherm.html

Lapid, R., Nir, N., Snapir, N., and B. Robinzon (2004) Reproductive traits in the spur-thighed tortoise (Testudo graeca terrestris): new tools for the enhancement of reproductive success and survivorship. Theriogenology. 61(6): 1147-1162.

Longepierre, S. Hailey, A., and C. Grenot (2001) Home range area in the tortoise Testudo hermanni in relation to habitat complexity: implications for conservation of biodiversity. Biodiversity and Conservation. 10: 1131-1140. 
Petco Animal Supplies (2004) Greek tortoise (Testudo graeca) Care sheet. Available online at: http://www.petco.com/caresheets/turtles/Tortoise Greek.pdf

Robb, J (1980) New Zealand Amphibians and Reptiles. William Collins Publishers, Ltd. Auckland, New Zealand.

van Dijk, P. Corti, C., Mellado, V., and M. Cheylan (2004) Testudo graeca. In: IUCN 2010. IUCN Red List of Threatened Species. Version 2010.1. www.iucn.org. Accessed 26 June, 2010.

van Dijk, P. Corti, C., Mellado, V., and M. Cheylan (2004) Testudo hermanni. In: IUCN 2010. IUCN Red List of Threatened Species. Version 2010.1. www.iucn.org. Accessed 26 June, 2010.

Wiltshier, B (2000) The Greek Spur-thighed tortoise (Testudo graeca) Its care and management. Premier Print Services Ltd. Auckland, New Zealand. 


\section{Appendix 8: Leopard gecko (Eublepharis macularius)}

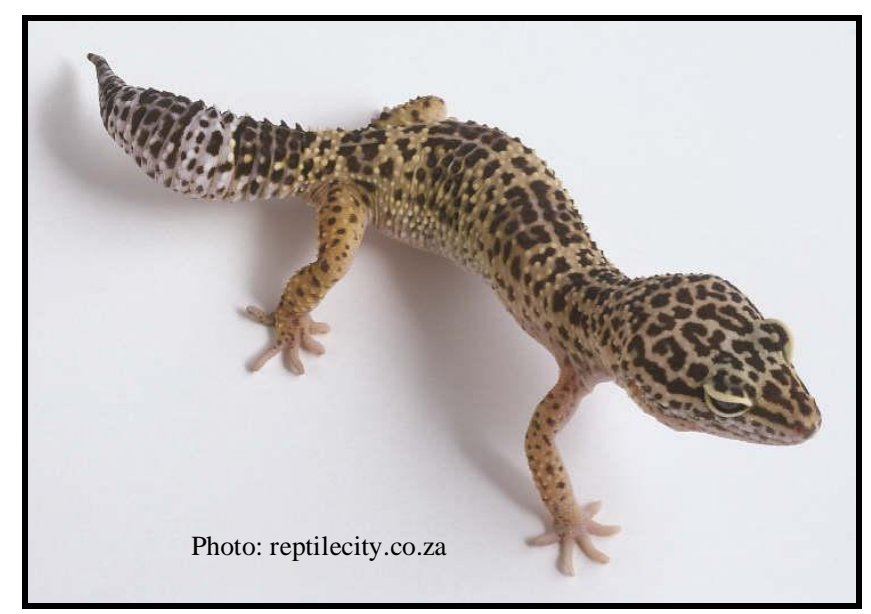

While leopard geckos have been present in zoological collections in New Zealand for many years, they are a relatively recent arrival on the New Zealand pet scene. They began appearing on the online auction site, TradeMe (www.trademe.co.nz) in late 2009, and can command over 1,500 NZD a piece. In May 2010, they began appearing in Auckland-area pet stores, advertised at 890 NZD. Allegedly, the majority of leopard geckos in New Zealand are females, making males very valuable to hobbyists and breeders.

\section{Native Range}

Leopard geckos are naturally found in the desert areas of Afghanistan, Pakistan, and India.

\section{Habitat Type}

In the wild, leopard geckos can be found in rocky desert and grassland areas. They are also found in mountainous areas at high altitudes (2100+ $\mathrm{m}$ above sea level). Gecko burrows and shelters can experience high humidity.

\section{Temperature preferences}

In captivity, leopard geckos are recommended to be maintained between $29-31^{\circ} \mathrm{C}$, but it is advised to have a "warm end" and "cool end" of the terrarium. This will allow the lizard to thermoregulate.

\section{Reproductive Information}

\section{Breeding}

Leopard geckos exhibit slight sexual dimorphism. Males can be differentiated from females by the presence of 2 hemipenal bulges on the underside of the base of the tail. Males also have a row of visible pre-anal pores above the cloaca. Sexual maturity is 
size-dependent (generally when a gecko reaches 35 grams) and usually reached between 10 and 24 months.

\section{Nesting}

Leopard geckos are capable of producing several clutches, consisting of two eggs per clutch, per year.

\section{Incubation/ Hatchlings}

Like many reptiles, leopard geckos exhibit temperature-dependent sex determination. There are no recorded constant incubation temperatures that produce exclusively males. At a constant incubation temperature of $26^{\circ} \mathrm{C}$, only females are produced, at $30^{\circ}, \sim 25 \%$ males are produced, and at $32.5^{\circ} \mathrm{C}, \sim 75 \%$ males are produced.

\section{Diet}

Leopard geckos are insectivorous. In captivity they are primarily maintained on mealworms and crickets, although baby "pinkie" mice are occasionally given.

\section{Maximum Size}

Adults can reach a length of approximately $20.5 \mathrm{~cm}$.

\section{Naturalised Distribution}

Leopard geckos are not reported to have been introduced into areas outside of their native range.

\section{New Zealand Distribution}

There are no records of feral leopard geckos existing in New Zealand. Due to the high monetary value associated with these geckos in the New Zealand pet trade, any feral individuals would likely be removed from the environment by collectors.

\section{Possible negative effects to New Zealand}

Being insectivorous, it is possible that leopard geckos may prey upon native invertebrates. They might also compete for resources with native geckos.

\section{Associated Diseases}

In captivity, leopard geckos are often susceptible to coccidiosis. Also, as with all reptiles, they are capable of harbouring and transmitting Salmonella bacteria.

\section{Lifespan}

In captivity, leopard geckos can live up to 30 years. Males tend to live longer than females. 


\section{Other relevant information}

Overseas, leopard geckos are considered a "beginner's pet", as they are easy to care for and cheap to acquire (from 20 USD). In New Zealand they are in high demand, and due to the limited number of geckos available in the pet trade, especially males, asking prices can be as high as 2,500 NZD.

\section{References}

De Vosjoli, P, Viets, B, Tremper, R, and R Klingenberg (2004) The Leopard Gecko Manual. Advanced Vivarium Systems, Santee, California, USA.

Federation of New Zealand Aquatic Societies (2009) Leopard gecko Caresheet. Available at: http://fnzas.org.nz/fishroom/viewtopic.php? $\mathrm{f}=40 \& \mathrm{t}=42518 \&$ sid $=48 \mathrm{a} 8 \mathrm{e} 5047 \mathrm{bf} 9 \mathrm{eda} 4675628 \mathrm{bfa} 3 \mathrm{bad} 304$

Janes, D and M Wayne (2006) Evidence for a genotype x environment interaction in sex-determining response to incubation temperature in the leopard gecko, Eublepharis macularius. Herpetologica. 62(1): 56-62. 


\section{Appendix 9: Supplementary Information for Chapter 3}

(Minimizing false-negatives when predicting the potential distribution of an invasive species: a bioclimatic envelope for the red-eared slider at global and regional scales)

Supplementary Table 1: Sources of red-eared slider (Trachemys scripta elegans) confirmed breeding records ("conservative dataset") used to generate a global distribution map of the species. An excel spreadsheet of the geographical coordinates is available from the author.

Country/ Island
Australia
Bahamas
Bermuda
British Virgin Islands
France
Guadeloupe
Guam
Italy
Japan
New Zealand
Puerto Rico
Saipan
Spain
Taiwan
USA

\section{References}

(Burgin 2006, 2007)

(Invasive Species Specialist Group (ISSG) 2006)

(Lever 2003)

(Perry et al. 2007)

(Cadi et al. 2004; Prévot-Julliard et al. 2007)

(Lever 2003)

(Lever 2003)

(Ficetola 2008)

(Lever 2003)

(Feldman 1992)

(United States Geological Survey (USGS) 2005)

(Lever 2003)

(Lever 2003)

(Chen \& Lue 1998)

(Cagle 1942, 1944; Brown 1950; Smith 1956; Clarke 1958;

Mahmoud \& Lavenda 1969; Rosen \& Marquardt 1978;

Thornhill 1982; Gibbons 1990; Connor 1992; Janzen et al. 1992; Tucker et al. 1995; Rose \& Manning 1996; Thomas et al. 1997; Cash \& Holberton 1999; Filoramo \& Janzen 1999; Marlen \& Fischer 1999; Thomas et al. 1999; Tucker et al. 1999; Tucker \& Warner 1999; Dreslik 2000; Bowden et al. 2002; Etchberger et al. 2002; Freedberg et al. 2004; Aresco 2005; LeClere 2005; Stone \& Babb 2005; United States Geological Survey (USGS) 2005; Dodd et al. 2006; Tryfonas et al. 2006; Avery et al. 2007; Glorioso \& Pruett 2007; Ligon 2007; Petzing et al. 2007; Rosenzweig et al. 2007) 
Supplementary Table 2: Sources of red-eared slider (Trachemys scripta elegans) location records where breeding status is unknown or unconfirmed ("liberal dataset") used to generate a global distribution map of the species. All records from the conservative dataset were also included into the "liberal dataset" for analyses. An excel spreadsheet of the geographical coordinates is available from the author.

\begin{tabular}{|c|c|}
\hline Country/ Island & References \\
\hline Australia & (Burgin 2007; Abrahams 2007, February 9) \\
\hline Bahrain & (Lever 2003) \\
\hline Belgium & (Lever 2003) \\
\hline Brazil & (www.instituohorus.org.br) \\
\hline British Virgin Islands & (Perry et al. 2007) \\
\hline Canada & $\begin{array}{l}\text { (United States Geological Survey (USGS) 2005; Rideau } \\
\text { River Biodiversity Project 2007) }\end{array}$ \\
\hline Cayman Islands & (Lever 2003) \\
\hline Chile & (Iriarte et al. 2005; Mundaca 2008) \\
\hline Czech Republic & (Lever 2003) \\
\hline Denmark & (Bringsøe 2006) \\
\hline $\begin{array}{l}\text { Federated States of } \\
\text { Micronesia }\end{array}$ & (Invasive Species Specialist Group (ISSG) 2006) \\
\hline Finland & (Global Biodiversity Information Facility 2008) \\
\hline France & (Cadi \& Joly 2004; Prévot-Julliard et al. 2007) \\
\hline Germany & $\begin{array}{l}\text { (Bringsøe 2006; Global Biodiversity Information Facility } \\
\text { 2008) }\end{array}$ \\
\hline Guam & (Global Biodiversity Information Facility 2008) \\
\hline Israel & (Lever 2003) \\
\hline Italy & $\begin{array}{l}\text { (Luiselli et al. 1997; Invasive Species Specialist Group } \\
\text { (ISSG) 2006; Ficetola 2008) }\end{array}$ \\
\hline Japan & $\begin{array}{l}\text { (Ebisujima et al. 2003; Global Biodiversity Information } \\
\text { Facility 2008) }\end{array}$ \\
\hline Korea & (Platt \& Fontenot 1992) \\
\hline Mexico & (Global Biodiversity Information Facility 2008) \\
\hline New Zealand & $\begin{array}{l}\text { (Thomas \& Hartnell 2000; New Zealand Department of } \\
\text { Conservation (DoC) 2007; Auckland Regional Council } \\
\text { (ARC) 2007, September 4) }\end{array}$ \\
\hline Nicaragua & (Global Biodiversity Information Facility 2008) \\
\hline Panama & (Global Biodiversity Information Facility 2008) \\
\hline Poland & $\begin{array}{l}\text { (Bringsøe 2006; Invasive Species Specialist Group (ISSG) } \\
\text { 2006) }\end{array}$ \\
\hline Scotland & 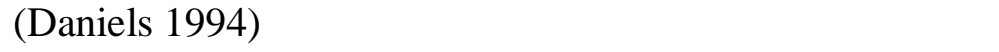 \\
\hline Singapore & $\begin{array}{l}\text { (Ng et al. 2005; Global Biodiversity Information Facility } \\
\text { 2008) }\end{array}$ \\
\hline Spain & (Lever 2003; Segurado 2008, July 21) \\
\hline South Africa & (Newbery 1984) \\
\hline Surinam & (Global Biodiversity Information Facility 2008) \\
\hline
\end{tabular}


Sweden

USA

Vietnam

Wales

\section{References}

Abrahams H 2007, February 9. Dog sniffs out waterways threat. Retrieved August 8, 2008 http://helenabrahams.com/media27.html

Anon. 2007, May 4. Santa Cruz Sentinel. Santa Cruz, California.

Aresco M 2005. The effect of sex-specific terrestrial movements and roads on the sex ratio of freshwater turtles. Biol. Conserv. 123: 37-44.

Auckland Regional Council (ARC) 2007, September 4.

Avery H, Spotila J, Bien W 2007. Effects of wetland fragmentation on freshwater turtle populations in the Delaware Estuary. Delaware Estuary Science Conference.

Bone L 1975. Eimeria pseudemydis Lainson, 1968, from the red-eared turtle, Pseudemys scripta elegans, in Arkansas. J. Wildl. Dis. 11: 290-291.

Bowden R, Ewert M, Nelson C 2002. Hormone levels in yolk decline throughout development in the red-eared slider turtle (Trachemys scripta elegans). Gen. Comp. Endocr. 129: 171-177.

Bringsøe H 2006. NOBANIS -- Invasive Alien Species Fact Sheet -- Trachemys scripta. Online Database of the Northern European and Baltic Network on Invasive Alien species -- NOBANIS.

Brown B 1950. An annotated check list of the reptiles and amphibians of Texas. Waco, Texas, USA, Baylor University.

Burgin S 2006. Confirmation of an established population of exotic turtles in urban Sydney. Aust. Zool. 33: 379-384.

Burgin S 2007. Status report on Trachemys scripta elegans: Pet terrapin or Australia's pest turtle? In: Lunney D, Eby P, Hutchings P, Burgin S ed. Pest or Guest: The Zoology of Overabundance. Sydney, Australia, Royal Zoological Society of New South Wales. 
Cadi A, Joly P 2004. Impact of the introduction of the red-eared slider (Trachemys scripta elegans) on the survival rates of the European pond turtle (Emys orbicularis). Biodiversity Conserv. 13: 2511-2518.

Cadi A, Delmas V, Prévot-Julliard A-C, Joly P, Pieau C, Girondot M 2004. Successful reproduction of the introduced slider turtle (Trachemys scripta elegans) in the South of France. Aquat. Conserv.: Marine and Freshwater Ecosystems 14: 237246.

Cagle F 1942. Turtle populations in southern Illinois. Copeia 1942: 155-162.

Cagle F 1944. Activity and winter changes of hatchling Pseudemys. Copeia 1944: 105-109.

Cash W, Holberton R 1999. Effects of exogenous corticosterone on locomotor activity in the Red-eared slider turtle, Trachemys scripta elegans. J. Exp. Zool. 284: 637-644.

Chen T-H, Lue K-Y 1998. Ecological notes on feral populations of Trachemys scripta elegans in northern Taiwan. Chelonian Conserv. Biol. 3: 87-90.

Clarke R 1958. An ecological study of reptiles and amphibians in Osage County, Kansas. Emporia, Kansas, USA, Graduate Division of the Kansas State Teachers College.

Conner C, Douthitt B, Ryan T 2005. Descriptive ecology of a turtle assemblage in an urban landscape. Am. Midl. Nat. 153: 428-435.

Connor M 1992. The Red-eared slider, Trachemys scripta elegans. Tortuga Gazette 28: $1-3$.

Daniels T 1994. Red-eared terrapin at Loch Ardinning, Milngavie (v.c. 86). Glasgow Naturalist 22: 133-134.

Dodd K, Murdock C, Wibbels T 2006. Interclutch variation in sex ratios produced at pivotal temperature in the Red-eared slider, a turtle with temperature-dependent sex determination. J. Herpetol. 40: 544-549.

Dreslik M 2000. Early season basking in the red-eared slider, Trachemys scripta. Trans. Ill. Acad. Sci. 93: 215-220.

Ebisujima A, Isaki K, Okada T 2003. The observation of a red-eared slider in a hydrology study site. Osaka, Japan, Osaka Prefectural Higashisumiyoshi Technical High School.

Etchberger C, Ewert M, Phillips J, Nelson C 2002. Carbon dioxide influences environmental sex determination in two species of turtle. Amphib.-reptil. 23: 169-175.

Feldman M 1992. Can turtles reproduce in New Zealand? Moko 1992: 14-16. 
Ficetola G 2008. From introduction to establishment of alien species: bioclimatic differences between presence and reproduction localities in the slider turtle. Diversity Distrib. D.O.I.: 10.1111/j.1472-4642.2008.00516.x.

Filoramo N, Janzen F 1999. Effects of hydric conditions during incubation on overwintering hatchlings of the red-eared slider turtle (Trachemys scripta elegans). $J$. Herpetol. 33: 29-35.

Freedberg S, Stumpf A, Ewert M, Nelson C 2004. Developmental environment has long-lasting effects on behavioural performance in two turtles with environmental sex determination. Evol. Ecol. Res. 6: 739-747.

Gibbons JW 1990. Life history and ecology of the slider turtle. Washington, D.C., USA, Smithsonian Institution Press.

Global Biodiversity Information Facility 2008. GBIF Data Portal.

Glorioso B, Pruett J 2007. New records for amphibians and reptiles from Trousdale County, Tennessee. Herpetol. Rev. 38: 247-248.

Instituto Horus (2008). Retrieved March 9, 2009.

http://www.institutohorus.org.br/download/fichas/Trachemys_scripta.htm

Invasive Species Specialist Group (ISSG) 2006. Ecology of Trachemys scripta elegans. Retrieved June 14, 2006

www.issg.org/database/species/ecology.asp?si=71\&ver=print

Iriarte JA, Lobos G, Jaksic F 2005. Invasive vertebrate species in Chile and their control and monitoring by governmental agencies. Rev. Chil. Hist. Nat. 78(143-154).

Janzen F, Paukstis G, Brodie III E 1992. Observations on basking behavior of hatchling turtles in the wild. J. Herpetol. 26: 217-219.

LeClere J 2005. Red-eared slider- Trachemys scripta. September 12, 2007, from http://www.herpnet.net/Iowa-

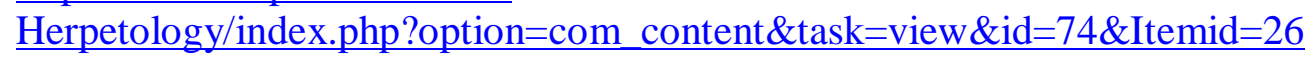

Lever C 2003. Naturalized Reptiles and Amphibians of the World. New York, USA, Oxford University Press.

Ligon D 2007. Trachemys scripta elegans (Red-eared slider). Predation. Herpetol. Rev. 38: 201-202.

Luiselli L, Capula M, Capizzi D, Filippi E, Jesus VT, Anibaldi C 1997. Problems for conservation of pond turtles (Emys orbicularis) in central Italy: is the introduced redeared turtle (Trachemys scripta elegans) a serious threat? Chelonian Conserv. Biol. 2: 417-419.

Mahmoud I, Lavenda N 1969. Establishment and eradication of food preferences in red-eared turtles. Copeia 1969: 298-300. 
Marlen M, Fischer R 1999. Parental investment in the red-eared slider turtle, Trachemys scripta elegans. J. Herpetol. 33: 306-309.

Michigan Department of Natural Resources 2007. Retrieved September 11, 2007 http://www.michigan.gov/dnr/0,1607,7-153-10370_12145_12201-60650--,00.html

Mundaca E 2008. Personal Communication.

Newbery, R 1984. The American red-eared terrapin in South Africa. Afr. Wildl. 38: 186-189.

New Zealand Department of Conservation (DoC) 2007.

Ng PNK, O'Riordan R, Ramsay N, Chou L 2005. Are red-eared sliders reproducing in Singapore? Fifth World Congress of Herpetology.

Perry G, Owen J, Petrovic C, Lazell J, Egelhoff J 2007. The red-eared slider, Trachemys scripta elegans, in the British Virgin Islands. Appl. Herpetol. 4: 88-89.

Petzing J, Mui J, Dreslik M, Kuhns A, Shepard D, Phillips C, Tucker J, Warner J, Mauger D, Anton T. 2007. Filling in the gaps II: New Illinois amphibian and reptile county records from 2000-2005. Herpetol. Rev. 38: 240-243.

Platt S, Fontenot L 1992. The red-eared slider, Trachemys scripta elegans (Weid) in South Korea. Bull. Chicago Herpetol. Soc. 27: 113-114.

Prévot-Julliard A-C, Gousset E, Archinard C, Cadi A, Girondot M 2007. Pets and invasion risks: is the slider turtle strictly carnivorous? Amphib.-reptil. 28: 139-143.

Rideau River Biodiversity Project 2007. Retrieved September 11, 2007 http://nature.ca/rideau/b/b9a-e.html

Rose F, Manning R 1996. Notes on the biology of the slider, Trachemys scripta elegans (Reptilia: Emydidae), inhabiting man-made cattle ponds in west Texas. Tex. $J$. Sci. 48: 191-206.

Rosen R, Marquardt W 1978. Helminth parasites of the red-eared turtle (Pseudemys scripta elegans) in central Arkansas. J. Parasitol. 64: 1148-1149.

Rosenzweig A, Hatfield J, Trichell J, Rachel M, Antwine M, Lynch B 2007. New distributional records for amphibians and reptiles in northeastern Louisiana. Herpetol. Rev. 38: 243-244.

Segurado P 2008, July 21. Personal Communication.

Smith G 2004. Diel activity patterns of the turtle assemblage of a northern Indiana lake. Am. Midl. Nat. 152: 156-164. 
Smith H 1956. Handbook of amphibians and reptiles of Kansas, Second Edition. Lawrence, Kansas, USA, University of Kansas.

Smith H, Kohler A 1977. A survey of herpetological introductions in the United States and Canada. Trans. Kan. Acad. 80: 1-24.

Stitt E 2005. The Red-eared slider (Trachemys scripta elegans). Sonoran Herpetologist 18: 65-66.

Stone P, Babb M 2005. A test of the annual growth line hypothesis in Trachemys scripta elegans. Herpetologica 61: 409-411.

Thomas M, Hartnell P 2000. An occurrence of a red-eared turtle (Trachemys scripta elegans) in the Waikato River at Hamilton, New Zealand. Herpetofauna 30: 15-17.

Thomas RB, Vogrin N, Altig R 1999. Sexual and seasonal differences in behavior of Trachemys scripta (Testudines: Emydidae). J. Herpetol. 33: 511-515.

Thomas RB, Beckman D, Thompson K, Buhlmann K, Gibbons JW, Moll D 1997. Estimation of age for Trachemys scripta and Deirochelys reticularia by counting annual growth layers in claws. Copeia 1997: 842-845.

Thornhill G 1982. Comparative reproduction of the turtle, Chrysemys scripta elegans, in heated and natural lakes. J. Herpetol. 16: 347-353.

Tryfonas A, Tucker J, Brunkow P, Johnson K, Hussein H, Lin Z-Q 2006. Metal accumulation in eggs of the red-eared slider (Trachemys scripta elegans) in the lower Illinois River. Chemosphere 63: 39-48.

Tucker J, Warner D 1999. Microgeographic variation in response of red-eared slider (Trachemys scripta elegans) embryos to similar incubation environments. J. Herpetol. 33: 549-557.

Tucker J, Maher R, Theiling C 1995. Melanism in the red-eared slider (Trachemys scripta elegans). J. Herpetol. 29: 291-296.

Tucker J, Filoramo N, Janzen F 1999. Size-biased mortality due to predation in a nesting freshwater turtle, Trachemys scripta. Am. Midl. Nat. 141: 198-203.

United States Geological Survey (USGS) 2005. NAS- Nonindigenous Aquatic Species: Trachemys scripta elegans. Retrieved September 10, 2007 http://nas.er.usgs.gov/queries/CollectionInfo.asp?SpeciesID $=1261 \&$

Virginia Department of Game and Inland Fisheries 2008. Red-eared slider (Trachemys scripta elegans). Retrieved September 11, 2007

http://www.dgif.virginia.gov/wildlife/information/?s=030077 
Supplementary Table 3: Comparison of models from Table 1 using the liberal dataset (all red-eared slider (Trachemys scripta elegans) records, (a) Cross-validation indicates performance in predicting withheld, geographically separated, test data (mean of ten partitions), pAUC = partial area under the curve measured where specificity $\geq 0.95$. (b) Performance under self-validation, where all available data was used to make final predictions of suitability. (c) Model weights determined from the number of times models were selected as the best predictive model (i.e., the one with the highest pAUC of the test data). Models in bold account for greater than $50 \%$ of the total weight. (d) Suitability score $=$ rank of New Zealand's most suitable site relative to all the positive location records, based on the modelled probability of occurrence. A score of 0.822 indicates that New Zealand's most suitable site is modelled as being at least as favourable as $82 \%$ of the locations from which RES have been recorded.

\begin{tabular}{|c|c|c|c|c|c|c|}
\hline \multirow[b]{2}{*}{ Model } & \multicolumn{3}{|c|}{ Cross-validation $^{\mathrm{a}}$} & \multicolumn{3}{|c|}{ Final fit $^{b}$} \\
\hline & $\mathbf{A U C}$ & pAUC & $\begin{array}{c}\text { Model } \\
\text { weight }^{\mathrm{c}}\end{array}$ & $\mathbf{A U C}$ & pAUC & $\begin{array}{c}\text { NZ } \\
\text { suitability } \\
\text { score }^{\text {d }}\end{array}$ \\
\hline $\mathrm{a}$ & 0.852 & 0.592 & 0 & 0.899 & 0.634 & 0.489 \\
\hline $\mathrm{b}$ & 0.847 & 0.584 & 0.2 & 0.904 & 0.674 & 0.468 \\
\hline $\mathrm{c}$ & 0.840 & 0.571 & 0 & 0.885 & 0.597 & 0.541 \\
\hline $\mathrm{d}$ & 0.848 & 0.601 & 0 & 0.896 & 0.629 & 0.565 \\
\hline $\mathrm{e}$ & 0.769 & 0.487 & 0 & 0.829 & 0.519 & 0.606 \\
\hline $\mathbf{f}$ & 0.871 & 0.609 & 0.2 & 0.888 & 0.650 & 0.999 \\
\hline $\mathrm{g}$ & 0.764 & 0.448 & 0 & 0.832 & 0.508 & 0.665 \\
\hline $\mathrm{h}$ & 0.862 & 0.595 & 0.1 & 0.875 & 0.608 & 1.000 \\
\hline i & 0.861 & 0.622 & 0.2 & 0.885 & 0.642 & 1.000 \\
\hline $\mathbf{j}$ & 0.862 & 0.620 & 0.3 & 0.886 & 0.638 & 1.000 \\
\hline $\mathrm{k}$ & 0.853 & 0.576 & 0 & 0.905 & 0.690 & 0.625 \\
\hline 1 & 0.847 & 0.534 & 0 & 0.921 & 0.705 & 0.612 \\
\hline $\begin{array}{l}\text { Weighted } \\
\text { multimodel }\end{array}$ & NA & NA & NA & 0.897 & 0.660 & 0.822 \\
\hline
\end{tabular}


Supplementary Figure 1: (a) Red-eared slider (RES; Trachemys scripta elegans) climate envelope of the best model, "model l" (Table 1), fitted to the liberal dataset at three different levels of precipitation: (i) $<300 \mathrm{~mm} /$ year, (ii) 300-1200 mm/year, and (iii) $>1200 \mathrm{~mm} /$ year. Black squares indicate sites with a recorded presence. White dots are sites where RES is presumed absent, but for clarity only a $20 \%$ random sample of all presumed absences have been drawn. Purple diamonds show New Zealand's top ten most suitable RES sites. To calculate predicted probabilities MINMIN (not shown) was set equal to MINAVG minus $5^{\circ} \mathrm{C}$, MAXMAX (not shown) was set equal to MAXAVG plus $5^{\circ} \mathrm{C}$, and MAT (not shown) was set to the average of MINAVG and MAXAVG. (b) Global bioclimatic predictions derived from the weighted multimodel for areas of suitable RES habitat derived from the liberal dataset (unconfirmed RES breeding). The red areas denote a more suitable climate for RES than blue areas. (c) Vertical lines and summary box plots illustrate the distribution of predicted probability of occurrence for all RES occupied sites (top) with the central line equal to the median, boxes extend from the $10^{\text {th }}$ to $90^{\text {th }}$ percentile and whiskers across the full range. These percentiles are used to define a relative suitability score. Below is the distribution of suitability for all sites available in New Zealand. (d) Bioclimatic predictions for areas of suitable RES habitat, derived from weighted multimodel applied to higher resolution climate data of New Zealand and utilising the liberal dataset (unconfirmed breeding records). The red areas denote a more suitable climate than blue areas for RES. (e) Colourcoding for the suitability scale (refer to part (b) and text for details).

(a)

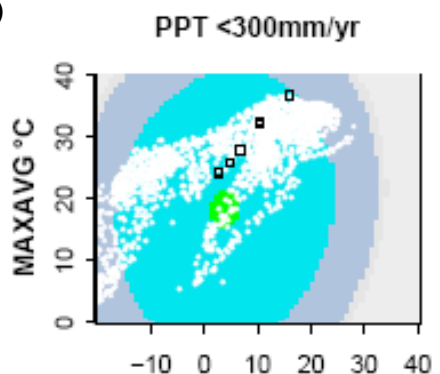

(b)

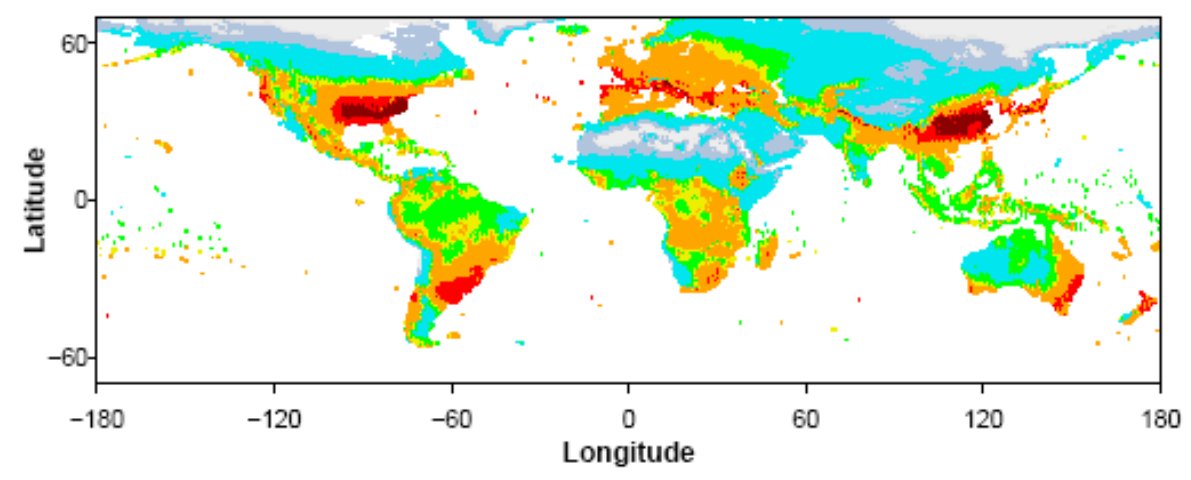

PPT $>1200 \mathrm{~mm} / \mathrm{yr}$

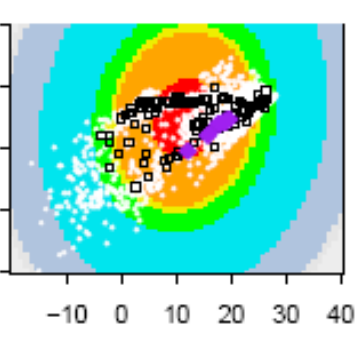

$\begin{array}{ccc}0 & 10 & 20 \\ \text { MINAVG } & \\ & \end{array}$ (e)

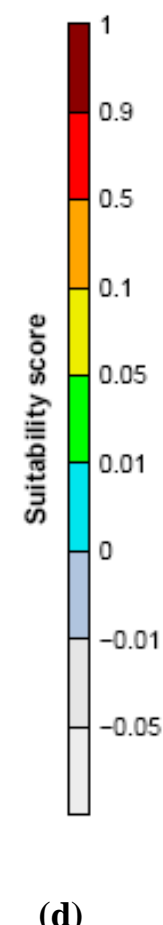

(d) (c)

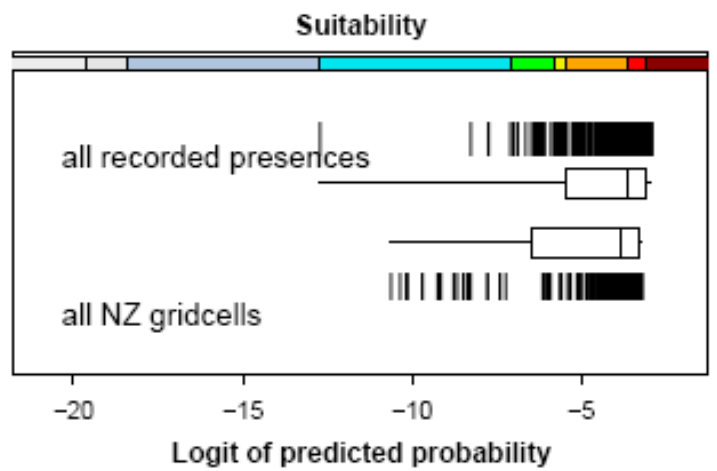

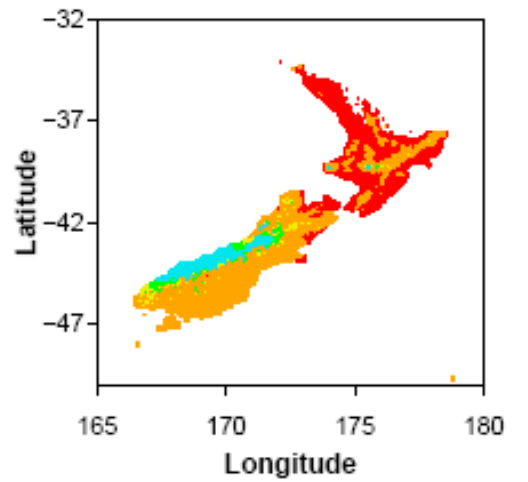




\section{Appendix 10: Supplementary Information for Chapter 4}

(Predicting the potential for exotic reptile establishment in New Zealand using bioclimatic models)

Supplementary Table 1: Sources of exotic reptile location records used to generate a global distribution map of each species.

Species snake-neck turtle

Reeves turtle

(Chinemys reevesii)

Greek tortoise

(Testudo graeca)

Hermanns tortoise

(Testudo hermanni)

bearded dragon

(Pogona vitticeps)

\section{References}

(Doody, Osbourne et al. 2004), (Chessman 1984), (Georges, Norris et al. 1986), (Kennett, Georges et al. 1993), (Goode and Russell 1968), (Thompson 1983), (Chessman 1984), (Jakes, O'Donoghue et al. 2001), (Seebacher, Sparrow et al. 2004), (Georges 1988), (Stott 1987), (Burgin 2007), (Burgin 2006), (Burgin, Emerton et al. 1999), (Chessman 1988), (Graham, Georges et al. 1996), (Ernst, Altenburg et al. 1997), (Morewell National Park 2000), (Lamington National Park 2000), (Wilson and Swan 2003), (Burgin and Renshaw 2008), (Burgin and Ryan 2008), (Roe, Georges et al. 2008), (Pichelin 1995), (Department of Environment Climate Change and Water 2009), (MacDonald 2008), (Brambuk National Park and Visitors Centre 2009), (Organ Pipes National Park 1991), (Friends of Werakata National Park 2009), (Department for Environment and Heritage 2009), (NSW National Parks and Wildlife Service 2009), (Rees, Roe et al. 2009), (Roe, Brinton et al. 2009), (Ryan and Burgin 2007), (Hoser 1982), (Global Biodiversity Information Facility (GBIF) 2010)

(Ebisujima, Isaki et al. 2003), (Ernst, Altenburg et al. 1997), (Tada, Saka et al. 2007), (Yoshie and Yusa 2008), (Tada, Saka et al. 2004), (Morikawa, Kamei et al. 2006), (Lovich, Ernst et al. 1985), (Global Biodiversity Information Facility (GBIF) 2010)

(Barje, Slimani et al. 2005), (Amiranashvili 2000), (Lever 2003), (Rouag, Benyacoub et al. 2007), (El Mouden, Slimani et al. 2006), (Wiltshier 2000), (Global Biodiversity Information Facility (GBIF) 2010)

(Willemsen and Hailey 1999), (Amiranashvili 2000), (Mazzotti, Pisapia et al. 2002), (Bertolero, Carretero et al. 2005), (Corti and Zuffi 2003), (Lever 2003), (Longepierre, Hailey et al. 2001), (Giacalone, Valvo et al. 2009), (Bertolero, Nougarede et al. 2007), (Loy, Ramacciato et al. 2007), (Rugiero and Luiselli 2006)

(Johnston 1979), (Melville and Schulte II 2001), (Ezaz, Quinn et al. 2005), (Seebacher and Franklin 2003), (Cogger 1975), (Wilson and Swan 2003), (Swan and Watharow 2005), (Sullivan, Orgeig et al. 2002), (Wood, 
bearded dragon

(Pogona barbata)

blue-tongue skink

(Tiliqua scincoides)

blotched blue-

tongue skink

(Tiliqua nigrolutea)

shingleback skink

(Tiliqua rugosa)

\section{leopard gecko}

(Eublepharis

macularius)

waterdragon

(Physignathus

lesueurii)
Lopatko et al. 1999), (Global Biodiversity Information Facility (GBIF) 2010)

(Kikillus, personal observation, 2007), (Lamington National Park 2000), (Cree, Amey et al. 2000), (Brattstrom 1971), (Cogger 1975), (Wilson and Swan 2003), (Swan and Watharow 2005), (Swan, Shea et al. 2004), (Brambuk National Park and Visitors Centre 2009), (Organ Pipes National Park 1991), (Friends of Werakata National Park 2009), (Department for Environment and Heritage 2009), (Seebacher and Franklin 2001), (Amey and Whittier 2000), (Queensland Museum 2008), (Oz Animals 2008), (Stawski, Grigg et al. 2006), (Schauble and Grigg 1998), (Global Biodiversity Information Facility (GBIF) 2010)

(Kikillus, personal observation, 2005), (Oakwood and Marquart 2007), (Christian, Webb et al. 2003), (Koenig, Shine et al. 2001), (Angus 1994), (Cogger 1975), (Wilson and Swan 2003), (Brambuk National Park and Visitors Centre 2009), (Organ Pipes National Park 1991), (Friends of Werakata National Park 2009), (NSW National Parks and Wildlife Service 2009), (Global Biodiversity Information Facility (GBIF) 2010)

(Edwards, Jones et al. 2002), (Morewell National Park 2000), (Cogger 1975), (Wilson and Swan 2003), (Swan, Shea et al. 2004), (Brambuk National Park and Visitors Centre 2009), (Department for Environment and Heritage 2009)

(Torr 1999), (Wilson and Swan 2003), (Swan and Watharow 2005), (Swan, Shea et al. 2004), (Ellis, Firth et al. 2006), (Fergusson and Algar 1986), (Bull 1987), (Satrawaha and Bull 1981), (Global Biodiversity Information Facility (GBIF) 2010)

(Ege University Faculty of Science 2010), (Mophidia 2010), (Global Biodiversity Information Facility (GBIF) 2010)

(Doody, Guarino et al. 2006), (Kikillus, personal observation), (Daly 2007), (Lamington National Park 2000), (Thompson 1993), (Cogger 1975), (Wilson and Swan 2003), (Friends of Werakata National Park 2009), (Phillott, Garland et al. 2009), (Doody 2009), (Meek and Avery 2008), (Cuervo and Shine 2007), (Queensland Museum 2008), (Langerwerf 2006), (Global Biodiversity Information Facility (GBIF) 2010) 


\section{References:}

Amey, A. and J. Whittier (2000). "Seasonal patterns of plasma steroid hormones in males and females of the bearded dragon lizard, Pogona barbata." General and Comparative Endocrinology 117: 335-342.

Amiranashvili, N. (2000). "Differences in shell morphology of Testudo graeca and Testudo hermanni, based on material from Bulgaria." Amphibia-Reptilia 21: 67-81.

Angus, R. (1994). "Nest predation by a blue-tongued lizard." Australian Birds 27(3): 87.

Barje, F., T. Slimani, et al. (2005). "Shrewd shrikes and spiny shrubs: a calamity for hatchling Moorish tortoises (Testudo graeca graeca)." Amphibia-Reptilia 26: 113115.

Bertolero, A., M. Carretero, et al. (2005). "An assessment of the reliability of growth rings counts for age determination in the Hermann's tortoise Testudo hermanni." Amphibia-Reptilia 26: 17-23.

Bertolero, A., J. Nougarede, et al. (2007). "Breeding traits of Hermann's tortoise Testudo hermanni hermanni in two western populations." Amphibia-Reptilia 28: 7785.

Brambuk National Park and Visitors Centre (2009). "Grampians National Park: mammals, reptiles, amphibia, fishes, and crustaceans." Retrieved January 7, 2010, from http://www.brambuk.com.au/assets/pdf/GrampiansNationalParkFaunaList.pdf.

Brattstrom, B. (1971). "Social and thermoregulatory behavior of the bearded dragon, Amphibolurus barbatus." Copeia 1971(3): 484-497.

Bull, M. (1987). "A population study of the viviparous Australian lizard, Trachydosaurus rugosus (Scincidae)." Copeia 1987(3): 749-757.

Burgin, S. (2006). "Confirmation of an established population of exotic turtles in urban Sydney." Australian Zoologist 33(3): 379-384.

Burgin, S. (2007). Status report on Trachemys scripta elegans: Pet terrapin or Australia's pest turtles? Pest or Guest: The Zoology of Overabundance. D. Lunney, P. Hutchings and S. Burgin. Mosman, NSW, Australia, Royal Zoological Society of NSW: $1-7$.

Burgin, S., S. Emerton, et al. (1999). "A comparison of sample and total census data for a population of the Eastern longneck turtle, Chelodina longicollis, in a farm dam northwest of Sydney, NSW." Australian Zoologist 31(1): 161-164.

Burgin, S. and A. Renshaw (2008). "Epizoochory, algae and the Australian Eastern long necked turtle, Chelodina longicollis." American Midland Naturalist 160(1): 6168 . 
Burgin, S. and M. Ryan (2008). "Comparison of sympatric freshwater turtle populations from an urbanised Sydney catchment." Aquatic Conservation: Marine and Freshwater Ecosystems 18: 1277-1284.

Chessman, B. (1984). "Evaporative water loss from three south-eastern Australian species of freshwater turtle." Australian Journal of Zoology 32: 649-655.

Chessman, B. (1984). "Food of the snake-necked turtle, Chelodina longicollis (Shaw) (Testudines: Chelidae) in the Murray Valley, Victoria and New South Wales." Australian Wildlife Research 11: 573-578.

Chessman, B. (1988). "Habitat preferences of freshwater turtles in the Murray Valley, Victoria and New South Wales." Australian Wildlife Research 15: 485-491.

Christian, K., J. Webb, et al. (2003). "Energetics of bluetongue lizards (Tiliqua scincoides) in a seasonal tropical environment." Ecophysiology 136: 515-523.

Cogger, H. (1975). Reptiles and amphibians of Australia. Sydney, Australia, Reed Party Books.

Corti, C. and M. Zuffi (2003). "Aspects of population ecology of Testudo hermanni hermanni from Asinara Island, NW Sardinia (Italy, Western Mediterranean Sea): preliminary data." Amphibia-Reptilia 24: 441-447.

Cree, A., A. Amey, et al. (2000). "Lack of consistent hormonal responses to capture during the breeding season of the bearded dragon, Pogona barbata." Comparative Biochemistry and Physiology, Part A 126: 275-285.

Cuervo, J. and R. Shine (2007). "Hues of a dragon's belly: morphological correlates of ventral coloration in water dragons." Journal of Zoology 273: 298-304.

Daly, G. (2007). "Reptiles and amphibians of Wadbilliga National Park and environs on the south coast of New South Wales." Herpetofauna 37(1): 45-62.

Department for Environment and Heritage (2009). "Naracoorte Caves National Park." Checklist of animal species identified from Pleistocene fossil sites of the Naracoorte Caves World Heritage Area. Retrieved January 7, 2010, from http://www.environment.sa.gov.au/parks/sanpr/naracoortecaves/faunalist.html.

Department of Environment Climate Change and Water (2009). "Royal National Park: native animals." Retrieved January 7, 2010, from http://www.environment.nsw.gov.au/NationalParks/parkWildlife.aspx?id=N0030.

Doody, J. (2009). "Superficial lizards in cold climates: Nest site choice along an elevational gradient." Austral Ecology 34: 773-779.

Doody, J., E. Guarino, et al. (2006). "Nest site choice compensates for climate effects on sex ratios in a lizard with environmental sex determination." Evolutionary Ecology 20: $307-330$. 
Doody, J., W. Osbourne, et al. (2004). Vertebrate biodiversity on Australian rice farms: an inventory of species, variation among farms, and proximate factors explaining that variation. Rural Industries Research and Development Corporation. Barton, ACT, Australia.

Ebisujima, A., K. Isaki, et al. (2003). The observation of a red-eared slider in a hydrology study site. Osaka, Japan, Osaka Prefectural Higashisumiyoshi Technical High School.

Edwards, A., S. Jones, et al. (2002). "Multiennial reproduction in females of a viviparous, temperate-zone skink, Tiliqua nigrolutea." Herpetologica 58(4): 407-414.

Ege University Faculty of Science (2010). "Leopard geckos: (Sauria: Eublepharidae) of the world." Retrieved March 7, 2010, from http://sci.ege.edu.tr/ bgocmen/emacularius.html.

El Mouden, E., T. Slimani, et al. (2006). "Testudo graeca graeca feeding ecology in an arid and overgrazed zone in Morocco." Journal of Arid Environments 64: 422-435.

Ellis, D., B. Firth, et al. (2006). "Circadian rhythm of behavioral thermoregulation in the sleepy lizard (Tiliqua rugosa)." Herpetologica 62(3): 259-265.

Ernst, C., R. Altenburg, et al. (1997). "Turtles of the World." Retrieved June 18, 2008, from http://nlbif.eti.uva.nl/bis/turtles.php.

Ezaz, T., A. Quinn, et al. (2005). "The dragon lizard Pogona vitticeps has ZZ/ZW micro-sex chromosomes." Chromosome Research 13: 763-776.

Fergusson, B. and D. Algar (1986). "Home range and activity patterns of pregnant female skinks, Tiliqua rugosa." Australian Wildlife Research 13: 287-294.

Friends of Werakata National Park (2009). "Werakata National Park reptile list." Retrieved January 7, 2010, from http://www.werakata.org.au/Reptiles_List.html.

Georges, A. (1988). "Sex determination is independent of incubation temperature in another chelid turtle, Chelodina longicollis." Copeia 1988(1): 248-254.

Georges, A., R. Norris, et al. (1986). "Diet of the freshwater turtle Chelodina longicollis (Testudines: Chelidae) from the coastal dune lakes of the Jervis Bay territory." Australian Wildlife Research 13: 301-308.

Giacalone, G., M. Valvo, et al. (2009). "Phylogeographic link between Sicilian and Corso-Sardinian Testudo h. hermanni confirmed." Acta Herpetologica 4(2): 119-123.

Global Biodiversity Information Facility (GBIF) (2010). "GBIF Data Portal." Retrieved January 8, 2010, from http://www.gbif.org/.

Goode, J. and J. Russell (1968). "Incubation of eggs of three species of chelid tortoises, and notes on their embryological development." Australian Journal of Zoology 16: 749-761. 
Graham, T., A. Georges, et al. (1996). "Terrestrial orientation by the Eastern longnecked turtle, Chelodina longicollis, from Australia." Journal of Herpetology 30(4): 467-477.

Hoser, R. (1982). "On breeding Australian long-necked tortoises Chelodina longicollis (Shaw), with new cases of captive breeding and comments on more than one annual egg laying season both in the wild and in captivity." Journal of the Northern Ohio Association of Herpetologists 8(1): 15-26.

Jakes, K., P. O'Donoghue, et al. (2001). "Hemoprotozoa of freshwater turtles in Queensland." Journal of Wildlife Diseases 37(1): 12-19.

Johnston, G. (1979). "The eggs, incubation, and young of the bearded dragon Amphibolorus vitticeps." Herpetofauna 11(1): 5-8.

Kennett, R., A. Georges, et al. (1993). "Early developmental arrest during immersion of eggs of a tropical freshwater turtle, Chelodina rugosa (Testudinata: Chelidae), from northern Australia." Australian Journal of Zoology 41: 37-45.

Koenig, J., R. Shine, et al. (2001). "The ecology of an Australian reptile icon: how do blue-tongued lizards (Tiliqua scincoides) survive in suburbia?" Wildlife Research 28 : 215-227.

Lamington National Park (2000). "Reptiles of Lamington National Park." Common snake-necked tortoise, Chelodina longicollis. Retrieved January 7, 2010, from http://lamington.nrsm.uq.edu.au.

Langerwerf, B. (2006). Water Dragons. Neptune City, New Jersey, USA, T.F.H. Publications, Inc.

Lever, C. (2003). Naturalized reptiles and amphibians of the world. New York, USA, Oxford University Press.

Longepierre, S., A. Hailey, et al. (2001). "Home range area in the tortoise Testudo hermanni in relation to habitat complexity: implications for conservation of biodiversity." Biodiversity and Conservation 10: 1131-1140.

Lovich, J., C. Ernst, et al. (1985). "Geographic variation in the Asiatic turtle Chinemys reevesii (Gray) and the status of Geoclemys grangeri Schmidt." Journal of Herpetology 19(2): 238-245.

Loy, A., V. Ramacciato, et al. (2007). "Demography of Eurotestudo hermanni in a mesic area of Central Italy." Amphibia-Reptilia 28: 87-95.

MacDonald, S. (2008). "Stewed Thoughts." Days 2 \& 3: Warrumbungle National Park. Retrieved January 7, 2010, from http://www.stewartmacdonald.com.au/blog/2008/11/days-2-3-warrumbunglenational-park/. 
Mazzotti, S., A. Pisapia, et al. (2002). "Activity and home range of Testudo hermanni in Northern Italy." Amphibia-Reptilia 23: 305-312.

Meek, R. and R. Avery (2008). "Basking in the Australian water dragon Physignathus lesueurii; why do alpha males not respond to operative temperatures in the same way as adults and sub-adults?" Amphibia-Reptilia 29: 257-262.

Melville, J. and J. Schulte II (2001). "Correlates of active body temperatures and microhabitat occupation in nine species of central Australian agamid lizards." Austral Ecology 26(660-669).

Mophidia (2010). "Eublepharis macularius, the leopard gecko." Retrieved March 8, 2010, from http://www.mophidia.com/eublepharis.html.

Morewell National Park (2000). "Plants and Animals." Retrieved June 18, 2008, from http://morwellnp.pangaean.net/cgi-

bin/show_species.cgi?find_this=Chelodina\%20longicollis\&image_size $=0$.

Morikawa, A., N. Kamei, et al. (2006). "The bioconcentration factor of perfluorooctane sulfonate is significantly larger than that of perfluorooctanoate in wild turtles (Trachemys scripta elegans and Chinemys reevesii): An Ai river ecological study in Japan." Ecotoxicology and Environmental Safety 65: 14-21.

NSW National Parks and Wildlife Service (2009). "Fauna of Murramarang National Park." Retrieved January 7, 2010, from http://www.visitdepotbeach.com.au/assets/pdf/faunalistmurramarangnationalpark.pdf.

Oakwood, M. and L. Marquart (2007). "Observations of diet of lace monitors (Varanus varius) in Gosford, New South Wales." Herpetofauna 37(1): 42-44.

Organ Pipes National Park (1991). "Species list." Retrieved January 7, 2010, from http://home.vicnet.net.au/ foopnp/guide/Organ_Pipes_National_Park_Species_Lists. htm.

Oz Animals (2008). "Bearded dragon (Pogona barbata)." Retrieved September 18, 2008, from http://www.ozanimals.com/Reptile/Bearded-Dragon/Pogona/barbata.html.

Phillott, A., S. Garland, et al. (2009). "Eastern water dragons (Physignathus lesueurii) are not important alternate hosts of the frog chytrid fungus Batrachochytrium dendrobatidis." Herpetological Conservation and Biology 4(3): 379-383.

Pichelin, S. (1995). "The taxonomy and biology of the Polystomatidae (Monogenea) in Australian freshwater turtles (Chelidae: Pleurodira)." Journal of Natural History 29: 1345-1381.

Queensland Museum (2008). "Animal factsheets." Retrieved September 18, 2008, from http://www.qm.qld.gov.au/inquiry/factsheets/bearded water dragons 20081127.pdf. 
Rees, M., J. Roe, et al. (2009). "Life in the suburbs: Behavior and survival of a freshwater turtle in response to drought and urbanization." Biological Conservation 142(2009): 3172-3181.

Roe, J., A. Brinton, et al. (2009). "Temporal and spatial variation in landscape connectivity for a freshwater turtle in a temporally dynamic wetland system." Ecological Applications 19(5): 1288-1299.

Roe, J., A. Georges, et al. (2008). "Energy and water flux during terrestrial estivation and overland movement in a freshwater turtle." Physiological and Biochemical Zoology 81(5): 570-583.

Rouag, R., S. Benyacoub, et al. (2007). "Population structure and demography of an Algerian population of the Moorish tortoise, Testudo graeca." Animal Biology 57(3): 267-279.

Rugiero, L. and L. Luiselli (2006). "Ecological modelling of habitat use and the annual activity patterns in an urban population of the tortoise, Testudo hermanni." Italian Journal of Zoology 73(3): 219-225.

Ryan, M. and S. Burgin (2007). "Gone walkabout? Movement of the Eastern longnecked turtle Chelodina longicollis from farm dams in northwest per-urban Sydney (Australia)." Journal of Biological Research - Thessaloniki 8: 119-127.

Satrawaha, R. and M. Bull (1981). "The area occupied by an omnivorous lizard, Trachydosaurus rugosus." Australian Wildlife Research 8: 435-442.

Schauble, C. and G. Grigg (1998). "Thermal ecology of the Australian agamid Pogona barbata." Oecologia 114: 461-470.

Seebacher, F. and C. Franklin (2001). "Control of heart rate during thermoregulation in the heliothermic lizard, Pogona barbata; importance of cholinergic and adrenergic mechanisms." Journal of Experimental Biology 204: 4361-4366.

Seebacher, F. and C. Franklin (2003). "Prostaglandins are important in thermoregulation of a reptile (Pogona vitticeps)." Proceedings of the Royal Society B Supplement 270: S50-S53.

Seebacher, F., J. Sparrow, et al. (2004). "Turtles (Chelodina longicollis) regulate muscle metabolic enzyme activity in response to seasonal variation in body temperature." Journal of Comparative Physiology B: Biochemical, Systemic, and Environmental Physiology 174: 205-210.

Stawski, C., G. Grigg, et al. (2006). "Temperature and the respiratory properties of whole blood in two reptiles, Pogona barbata and Emydura signata." Comparative Biochemistry and Physiology, Part A 143: 173-183.

Stott, P. (1987). "Terrestrial movements of the freshwater tortoise Chelodina longicollis Shaw as monitored with a spool tracking device." Australian Wildlife Research 14: 559-567. 
Sullivan, L., S. Orgeig, et al. (2002). "Regulation of pulmonary surfactant secretion in the developing lizard, Pogona vitticeps." Comparative Biochemistry and Physiology, Part A 133: 539-546.

Swan, G., G. Shea, et al. (2004). A field guide to reptiles of New South Wales. Sydney, Australia, Reed New Holland.

Swan, G. and S. Watharow (2005). Snakes, lizards, and frogs of the Victorian mallee. Collingwood, Victoria, Australia, CSIRO Publishing.

Tada, N., M. Saka, et al. (2007). "A field study on serum vitellogenin levels in male Reeves' pond turtles (Chinemys reevesii) from estrogen-contaminated sites and a reference site." Science of the Total Environment 384: 205-213.

Tada, N., M. Saka, et al. (2004). "Comparative analyses of serum vitellogenin levels in male and female Reeves' pond turtles (Chinemys reevesii) by an immunological assay." Journal of Comparative Physiology B: Biochemical, Systemic, and Environmental Physiology 174: 13-20.

Thompson, M. (1983). "Populations of the Murray River tortoise, Emydura (Chelodina): the effect of egg predation by the red fox, Vulpes vulpes." Australian Wildlife Research 10: 363-371.

Thompson, M. (1993). "Estimate of the population structure of the Eastern water dragon, Physignathus lesueurii (Reptilia: Agamidae), along riverside habitat." Wildlife Research 20: 613-619.

Torr, G. (1999). "True Blue." Australian Geographic 55: 52-68.

Willemsen, R. and A. Hailey (1999). "A latitudinal cline of dark plastral pigmentation in the tortoise Testudo hermanni in Greece." Herpetological Journal 9: 125-132.

Wilson, S. and G. Swan (2003). A complete guide to reptiles of Australia. Sydney, Australia, New Holland Publishers.

Wiltshier, B. (2000). The Greek spur-thighed tortoise (Testudo graeca): Its care and management. Auckland, New Zealand, Premier Print Services Ltd.

Wood, P., O. Lopatko, et al. (1999). "Control of pulmonary surfactant secretion from type II pneumocytes isolated from the lizard Pogona vitticeps." The American Journal of Physiology - Regulatory, Integrative and Comparative Physiology 277: 1705-1711.

Yoshie, H. and Y. Yusa (2008). "Effects of predation on the exotic freshwater snail Pomacea canaliculata (Caenogastropoda: Ampullariidae) by the indigenous turtle Chinemys reevesii (Testudines: Geoemydidae)." Applied Entomology and Zoology 43(4): 475-482. 
Supplementary Figure 1: Red-eared slider turtle (Trachemys scripta elegans) confirmed breeding locations (Chapter 3's “conservative dataset") incorporated into the bioclimatic model.

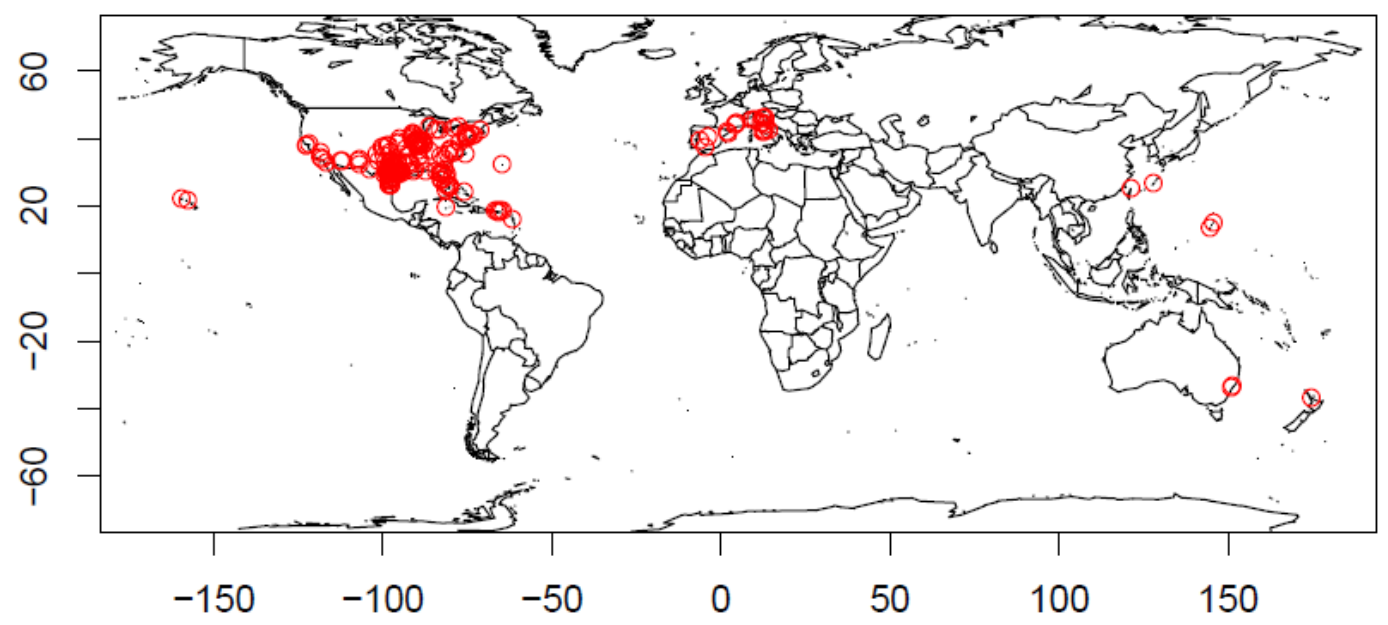


Supplementary Table 2: Comparison of the 12 models from Chapters 3 and 4 for confirmed breeding records (both native and introduced ranges) for the red-eared slider turtle (Trachemys scripta elegans) (i.e. Chapter 3's “conservative dataset"), (a) Cross-validation indicates mean performance in predicting withheld test data, pAUC $=$ partial area under the curve measured where specificity $\geq 0.95$. (b) Performance under self-validation, where all available data was used to make final predictions of suitability. (c) Model weights determined from the mean pAUCs of the ten best models relative to the eleventh best, which was set as the zero-weight baseline value (d) Suitability score $=$ rank of New Zealand's most suitable site relative to all the positive location records, based on the modelled probability of occurrence. A score of 0.19 indicates that New Zealand's most suitable site is modelled as being at least as favourable as $19 \%$ of the locations from which red-eared slider turtles have been recorded to breed successfully. Numbers in parentheses represent the $90 \%$ confidence interval.

\begin{tabular}{|c|c|c|c|c|c|c|}
\hline \multirow[b]{2}{*}{ Model } & \multicolumn{3}{|c|}{ Cross-validation $^{\mathrm{a}}$} & \multicolumn{3}{|c|}{ Final fit $^{\mathrm{b}}$} \\
\hline & $\mathbf{A U C}$ & pAUC & $\begin{array}{l}\text { Model } \\
\text { weight }^{\mathrm{c}}\end{array}$ & $\mathbf{A U C}$ & $\mathbf{p A U C}$ & $\begin{array}{c}\text { NZ } \\
\text { suitability }^{\text {score }} \\
\text { s }^{\text {d }}\end{array}$ \\
\hline $\mathrm{a}$ & 0.921 & 0.698 & 0.099 & 0.938 & 0.764 & 0.102 \\
\hline $\mathrm{b}$ & 0.926 & 0.709 & 0.115 & 0.945 & 0.803 & 0.072 \\
\hline $\mathrm{c}$ & 0.904 & 0.624 & 0 & 0.922 & 0.623 & 0.116 \\
\hline d & 0.917 & 0.700 & 0.103 & 0.936 & 0.753 & 0.193 \\
\hline $\mathrm{e}$ & 0.867 & 0.610 & 0 & 0.883 & 0.683 & 0.057 \\
\hline $\mathrm{f}$ & 0.899 & 0.698 & 0.099 & 0.913 & 0.747 & 0.997 \\
\hline g & 0.870 & 0.628 & 0.005 & 0.886 & 0.683 & 0.313 \\
\hline $\mathrm{h}$ & 0.884 & 0.649 & 0.034 & 0.899 & 0.668 & 0.987 \\
\hline $\mathrm{i}$ & 0.899 & 0.698 & 0.099 & 0.909 & 0.749 & 0.993 \\
\hline $\mathrm{j}$ & 0.899 & 0.687 & 0.085 & 0.910 & 0.736 & 1 \\
\hline $\mathrm{k}$ & 0.929 & 0.752 & 0.173 & 0.946 & 0.837 & 0.153 \\
\hline 1 & 0.944 & 0.763 & 0.188 & 0.963 & 0.840 & 0.140 \\
\hline $\begin{array}{l}\text { Weighted } \\
\text { multi- } \\
\text { model } \\
\text { average }\end{array}$ & NA & NA & NA & 0.956 & 0.844 & $\begin{array}{c}0.197 \\
(\mathbf{0 . 0 7 2}-1)\end{array}$ \\
\hline
\end{tabular}


Supplementary Figure 2: Relative pAUC values based on cross-validation results for each of the 12 models applied to the "conservative dataset" (confirmed breeding) of the red-eared slider turtle (Trachemys scripta elegans). Mean pAUC values for each model are represented by an open circle and median pAUC values are represented by a horizontal line. The model ranked eleventh (i.e., the second-worst, model "f" in this case) was set as the zero weight baseline, from which weightings of the ten best models were calculated (Supplementary Table 2).

\section{pAUC}

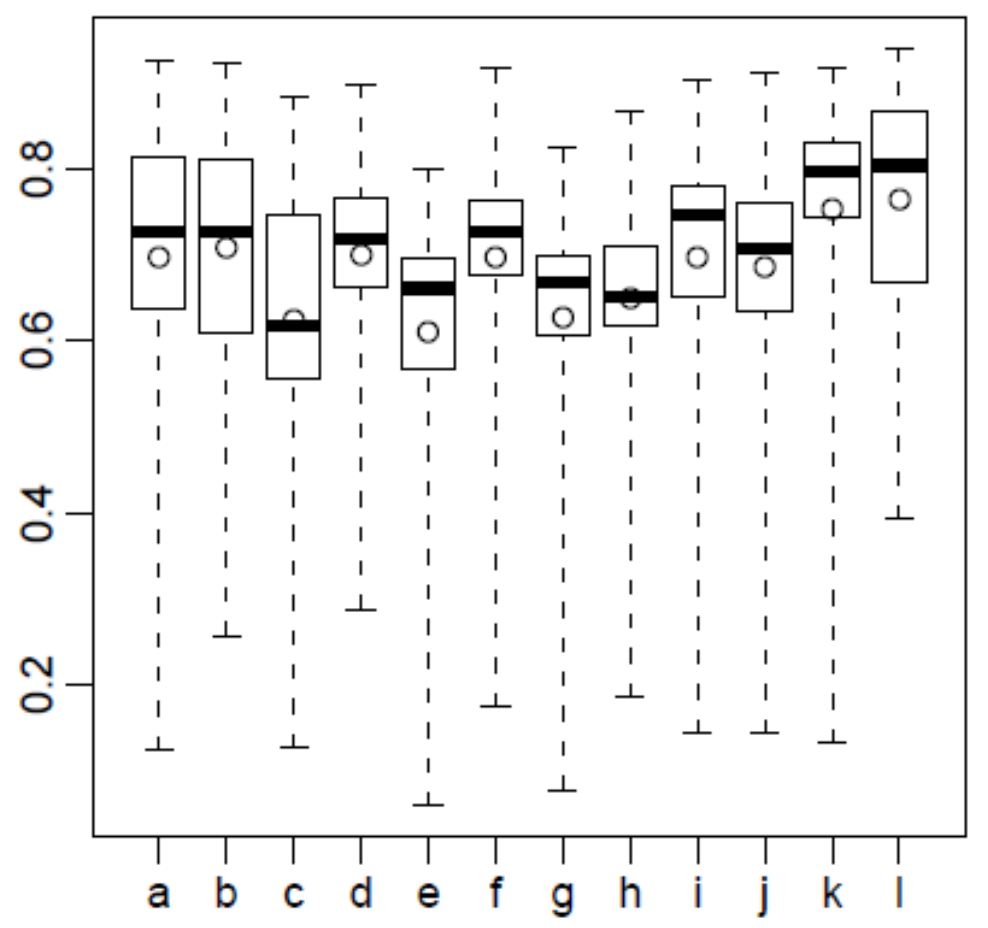

Supplementary Figure 3: "Relative importance" of each of the climatic variables incorporated into the bioclimatic model with regards to Trachemys scripta elegans ("conservative dataset").

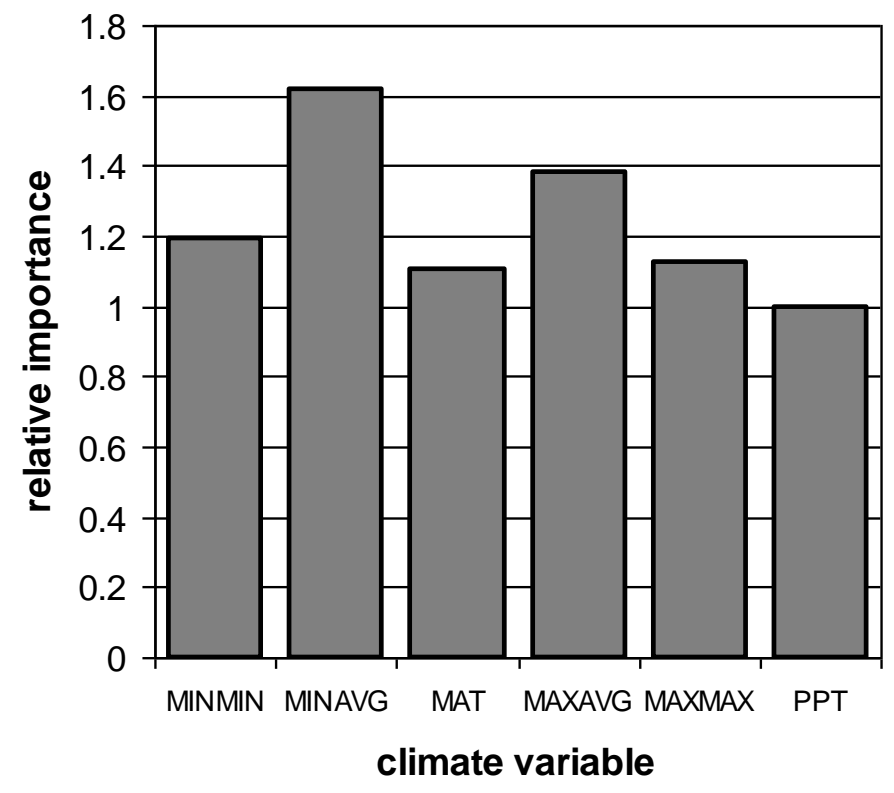


Supplementary Figure 4: (a) Red-eared slider turtle (Trachemys scripta elegans) climate envelope of model "b" (Table 1), fitted to the confirmed breeding ("conservative") dataset at three different levels of precipitation: (i) $<300 \mathrm{~mm} /$ year, (ii) $300-1200 \mathrm{~mm} /$ year, and (iii) $>1200 \mathrm{~mm} /$ year. Black squares indicate sites with a recorded presence. White dots are sites where red-eared sliders are presumed absent, but for clarity only a $20 \%$ random sample of all presumed absences have been drawn. Purple diamonds show New Zealand's top ten most suitable red-eared slider sites. To calculate predicted probabilities MINMIN (not shown) was set equal to MINAVG minus $5^{\circ} \mathrm{C}$, MAXMAX (not shown) was set equal to MAXAVG plus $5^{\circ} \mathrm{C}$, and MAT (not shown) was set to the average of MINAVG and MAXAVG. (b) Global bioclimatic predictions derived from the weighted multimodel for areas of suitable red-eared slider habitat derived from the location record dataset. The red areas denote a more suitable climate for red-eared sliders than blue areas. (c) Vertical lines and summary box plots illustrate the distribution of predicted probability of occurrence for all red-eared slider occupied sites (top) with the central line equal to the median, boxes extend from the $10^{\text {th }}$ to $90^{\text {th }}$ percentile and whiskers across the full range. These percentiles are used to define a relative suitability score. Below is the distribution of suitability for all sites available in New Zealand. (d) Bioclimatic predictions for areas of suitable red-eared slider habitat, derived from weighted multimodel applied to higher resolution climate data of New Zealand. The red areas denote a more suitable climate than blue areas for red-eared sliders. (e) Colour-coding for the suitability scale (refer to part (b) and text for details). 
(a) PPT $<300 \mathrm{~mm} / \mathrm{yr}$

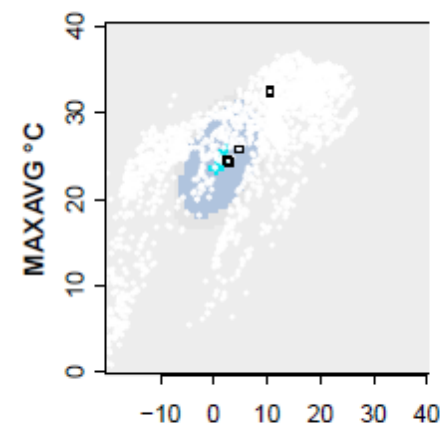

(b)

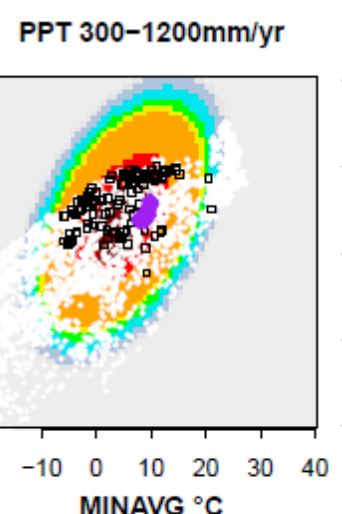

MINAVG ${ }^{\circ} \mathrm{C}$

(e)

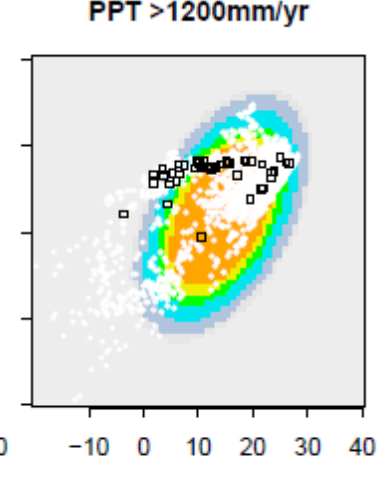

过 0.05

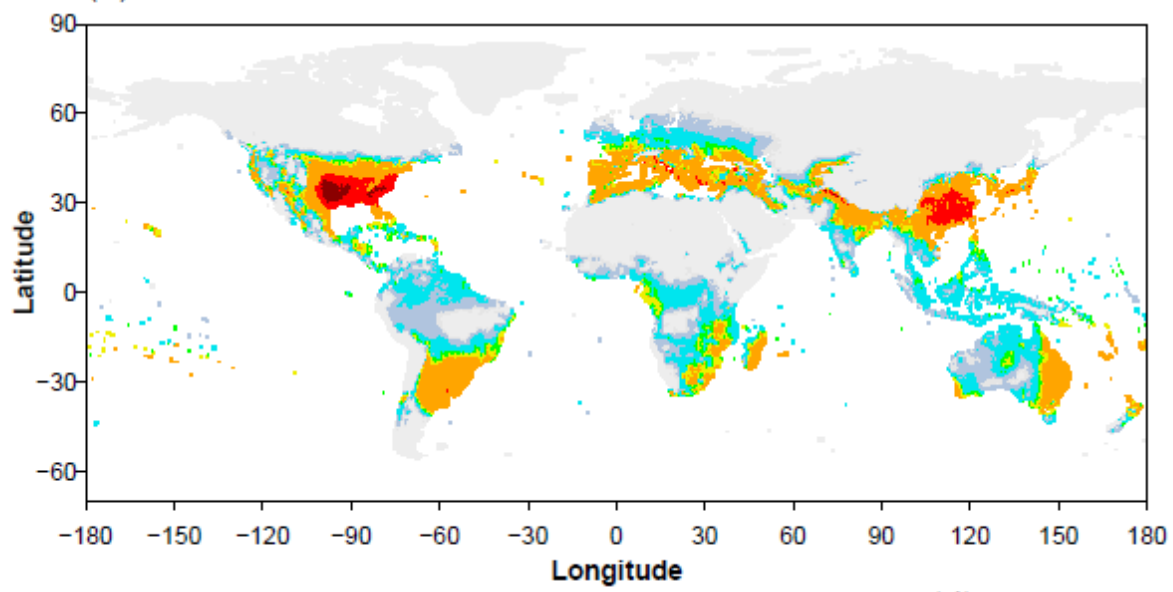

(d)

(c)

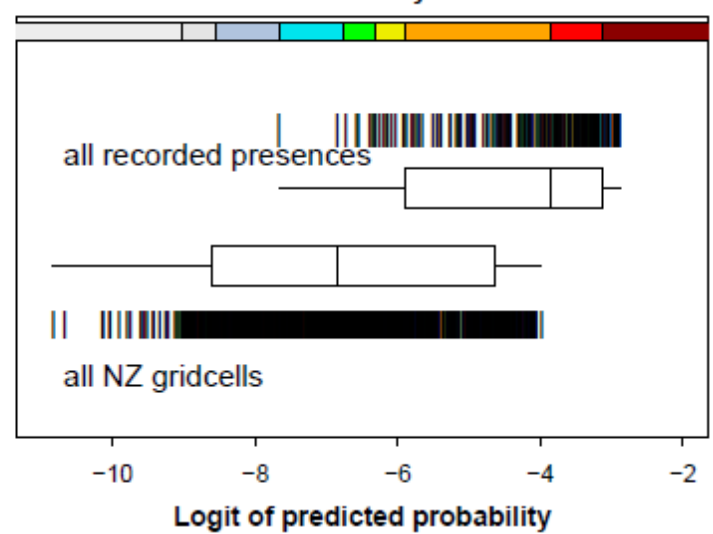

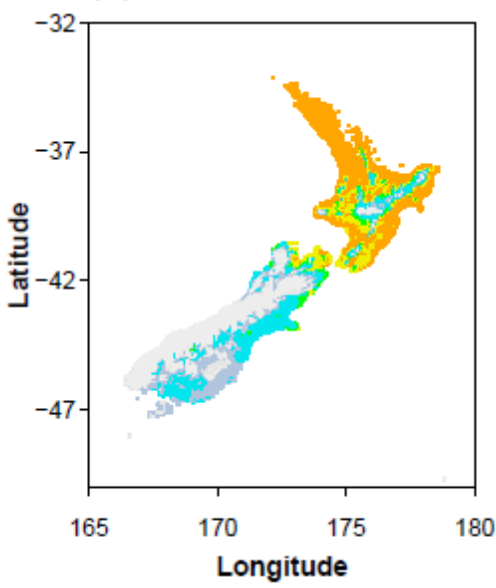


Supplementary Figure 5: Red-eared slider turtle (Trachemys scripta elegans) location records (includes areas where breeding is unconfirmed) (Chapter 3's "liberal dataset") incorporated into the bioclimatic model.

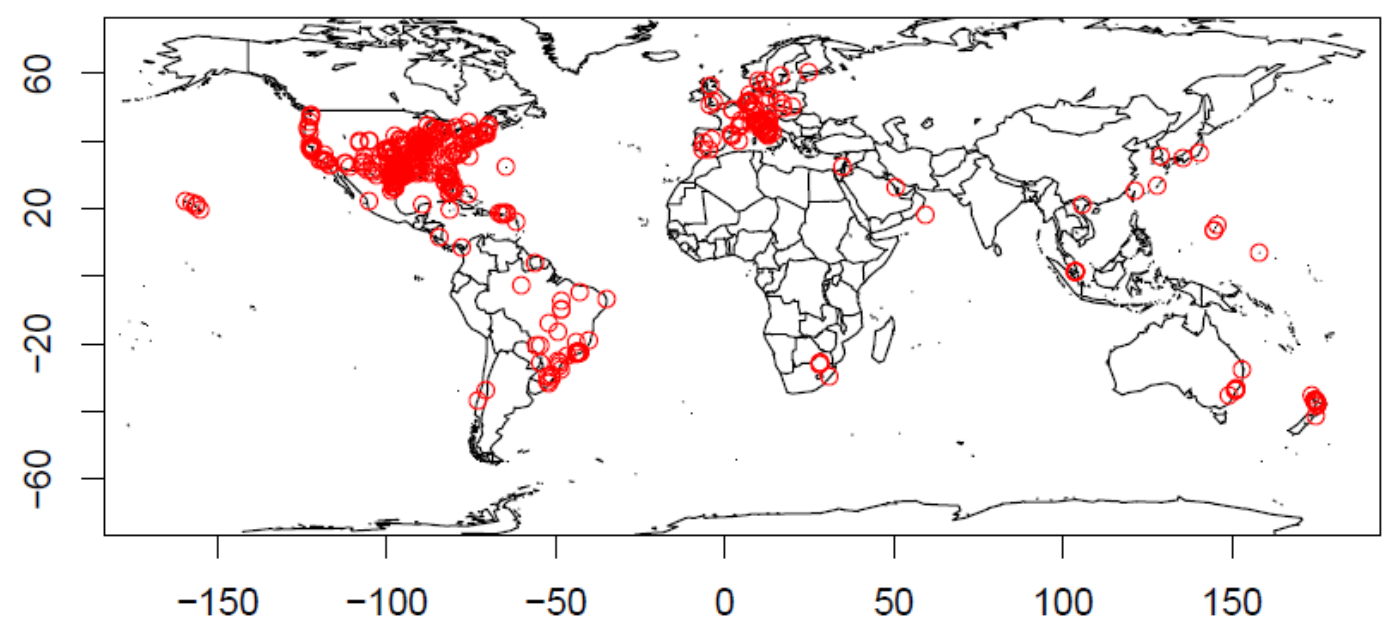


Supplementary Table 3: Comparison of the 12 models from Chapters 3 and 4 for all records for the red-eared slider turtle (Trachemys scripta elegans) (i.e. Chapter 3's "liberal dataset"). Details as described in Supplementary Table 2.

\begin{tabular}{|c|c|c|c|c|c|c|}
\hline \multirow[b]{2}{*}{ Model } & \multicolumn{3}{|c|}{ Cross-validation $^{\mathrm{a}}$} & \multicolumn{3}{|c|}{ Final fit $^{\mathrm{b}}$} \\
\hline & $\mathbf{A U C}$ & pAUC & $\begin{array}{c}\text { Model } \\
\text { weight }^{\mathrm{c}}\end{array}$ & $\mathbf{A U C}$ & pAUC & $\begin{array}{c}\text { NZ } \\
\text { suitability }^{\text {score }} \\
\text { s }^{\text {s. }}\end{array}$ \\
\hline $\mathrm{a}$ & 0.904 & 0.645 & 0.090 & 0.909 & 0.668 & 0.489 \\
\hline $\mathrm{b}$ & 0.906 & 0.669 & 0.114 & 0.913 & 0.704 & 0.468 \\
\hline c & 0.889 & 0.608 & 0.054 & 0.896 & 0.635 & 0.541 \\
\hline d & 0.897 & 0.658 & 0.104 & 0.905 & 0.664 & 0.565 \\
\hline $\mathrm{e}$ & 0.839 & 0.554 & 0 & 0.845 & 0.563 & 0.606 \\
\hline f & 0.894 & 0.656 & 0.101 & 0.898 & 0.682 & 0.999 \\
\hline $\mathrm{g}$ & 0.842 & 0.539 & 0 & 0.848 & 0.554 & 0.665 \\
\hline h & 0.882 & 0.632 & 0.077 & 0.887 & 0.644 & 1 \\
\hline $\mathrm{i}$ & 0.892 & 0.668 & 0.113 & 0.895 & 0.675 & 1 \\
\hline $\mathrm{j}$ & 0.893 & 0.668 & 0.113 & 0.897 & 0.672 & 1 \\
\hline $\mathrm{k}$ & 0.908 & 0.676 & 0.121 & 0.914 & 0.719 & 0.625 \\
\hline 1 & 0.914 & 0.668 & 0.113 & 0.929 & 0.732 & 0.612 \\
\hline $\begin{array}{l}\text { Weighted } \\
\text { multi- } \\
\text { model } \\
\text { average }\end{array}$ & NA & NA & NA & 0.917 & 0.699 & $\begin{array}{c}0.612 \\
(0.47-1)\end{array}$ \\
\hline
\end{tabular}


Supplementary Figure 6: Relative pAUC values based on cross-validation results for each of the 12 models applied to the "liberal dataset" (which includes unconfirmed breeding records) of the red-eared slider turtle (Trachemys scripta elegans). Details as in Supplementary Figure 2.

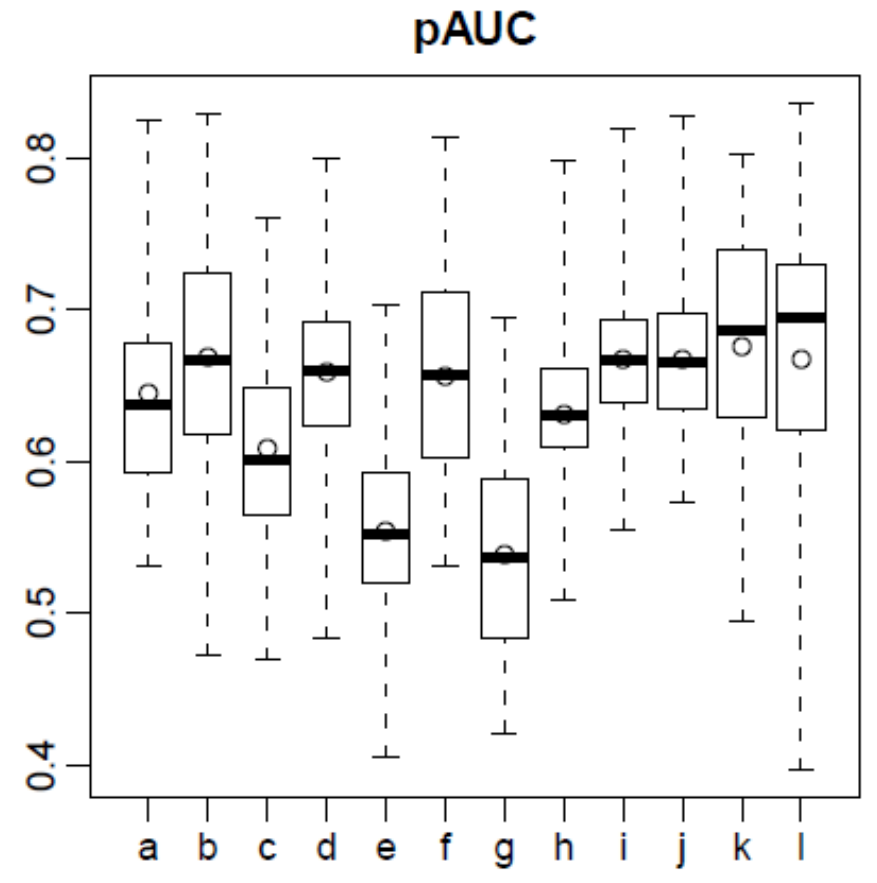

Supplementary Figure 7: "Relative importance" of each of the climatic variables incorporated into the bioclimatic model with regards to Trachemys scripta elegans ("liberal dataset").

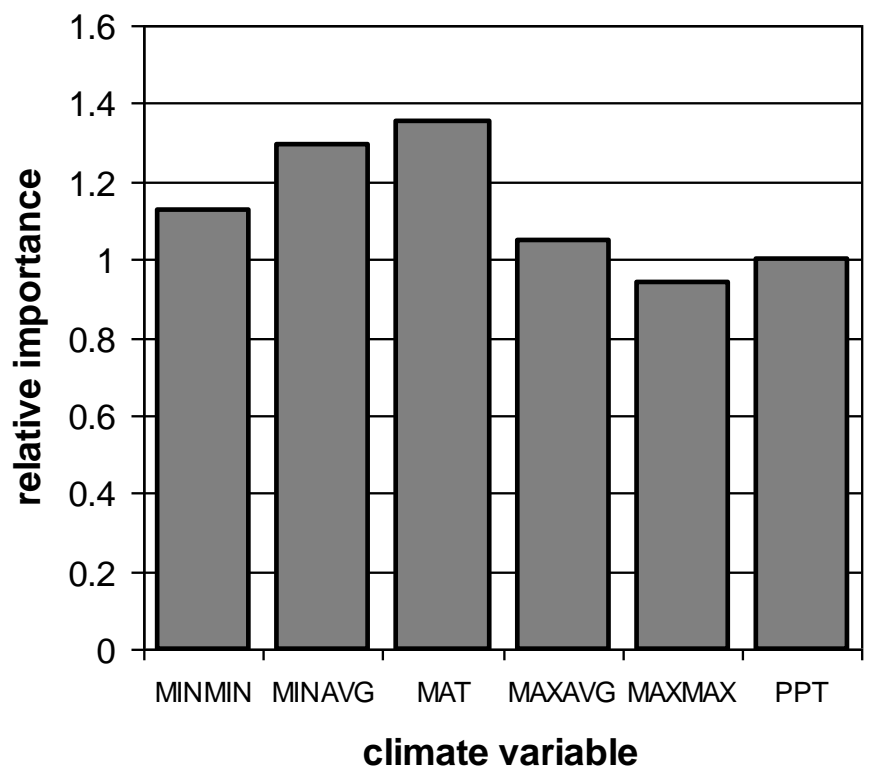


Supplementary Figure 8: Climate envelope and predicted suitability for the red-eared slider turtles (Trachemys scripta elegans) fitted to the "liberal dataset" (all records, including those where breeding is unconfirmed). Details as described in Supplementary Figure 4.

(a) PPT $<300 \mathrm{~mm} / \mathrm{yr}$

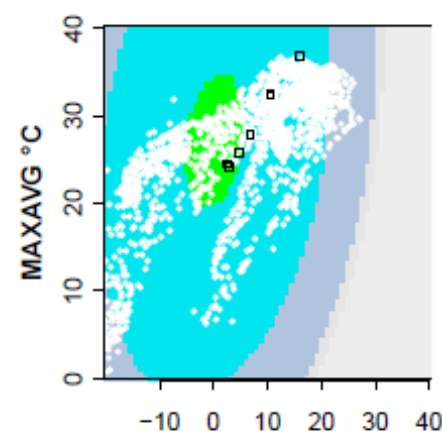

(b)
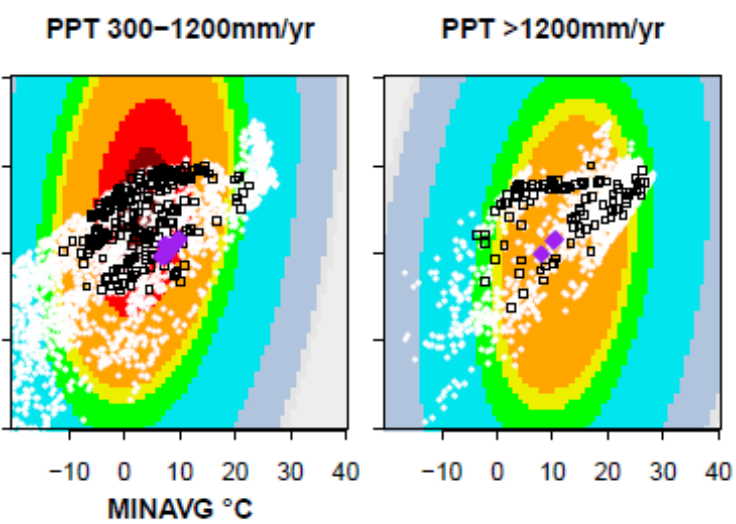

PPT $>1200 \mathrm{~mm} / \mathrm{yr}$

(e)

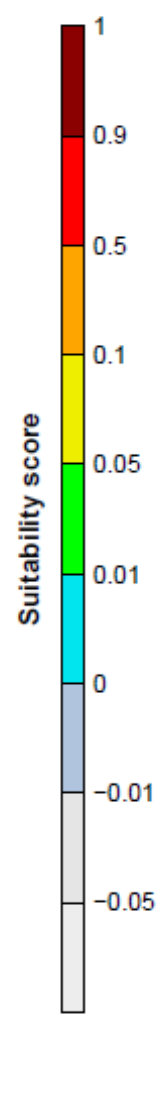

(d) (c)

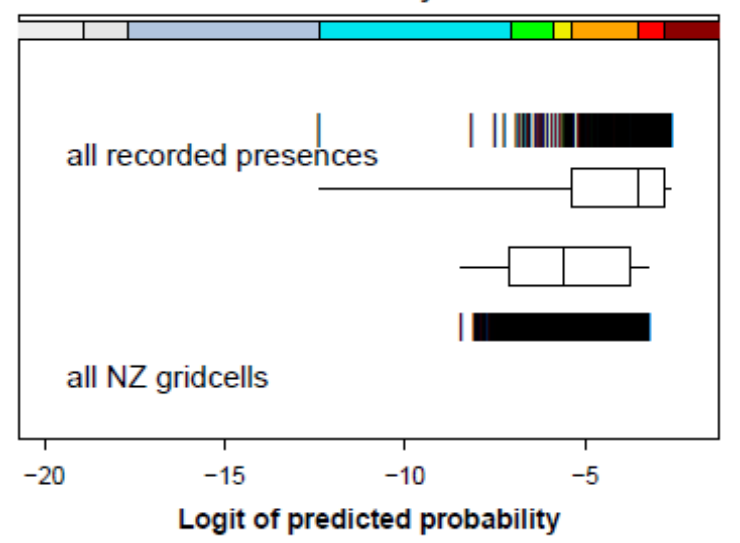

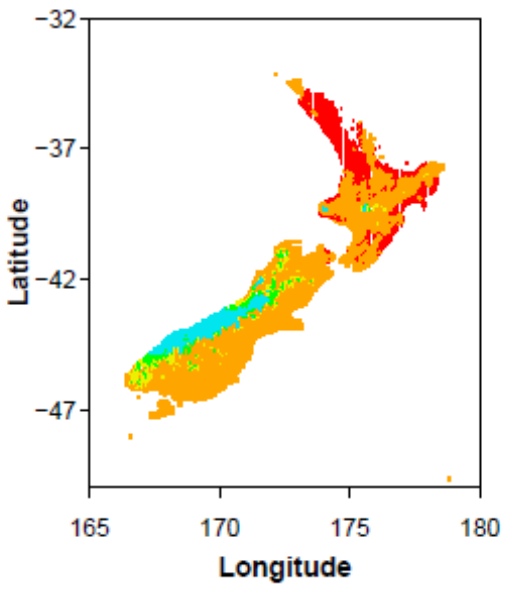


Supplementary Table 4: Summary table comparing both the conservative and liberal datasets for Trachemys scripta elegans with regards to New Zealand (NZ) suitability score based on weighted multimodel average, $90 \%$ Confidence Interval (CI), and proportion of NZ with a suitability $>0.1$.

\begin{tabular}{|c|c|c|c|}
\hline $\begin{array}{c}\text { Dataset } \\
\text { incorporated into } \\
\text { model }\end{array}$ & $\begin{array}{l}\text { NZ Suitability } \\
\text { Score }\end{array}$ & 90\% CI range & $\begin{array}{c}\text { Proportion of } \\
\text { NZ with } \\
\text { suitability > } \\
\text { 0.1 } \\
\end{array}$ \\
\hline $\begin{array}{l}\text { Conservative } \\
\text { (confirmed breeding) }\end{array}$ & 0.197 & $0.072-1$ & 0.25 \\
\hline $\begin{array}{l}\text { Liberal } \\
\text { (includes } \\
\text { unconfirmed } \\
\text { breeding) }\end{array}$ & 0.612 & $0.47-1$ & 0.81 \\
\hline
\end{tabular}


Appendix 11: Supplementary Information for Chapter 5

(Developmental degree-day models to assess the establishment potential of red-eared slider turtles and other exotic reptiles in New Zealand)

Supplementary Figure 1: Mean development time (days) vs. Temperature $\left({ }^{\circ} \mathrm{C}\right)$ for snake-neck turtles (Chelodina longicollis), Reeves turtles (Chinemys reevesii), Greek

tortoises (Testudo graeca), bearded dragons (Pogona vitticeps $(\bullet)$ and P. barbata $(\mathbf{\bullet})$ ), leopard geckos (Eublepharis macularius), and waterdragons (Physignathus lesueurii

$(\bullet)$ and $P$. cocincinus $(\mathbf{\square}))$.

Snakeneck turtles

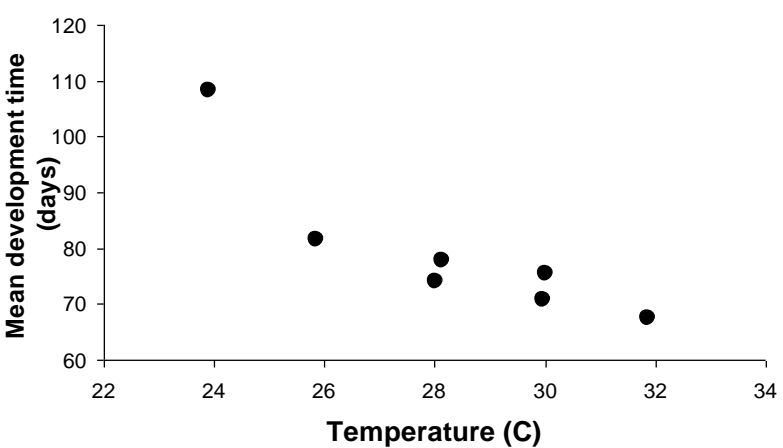

Bearded dragons

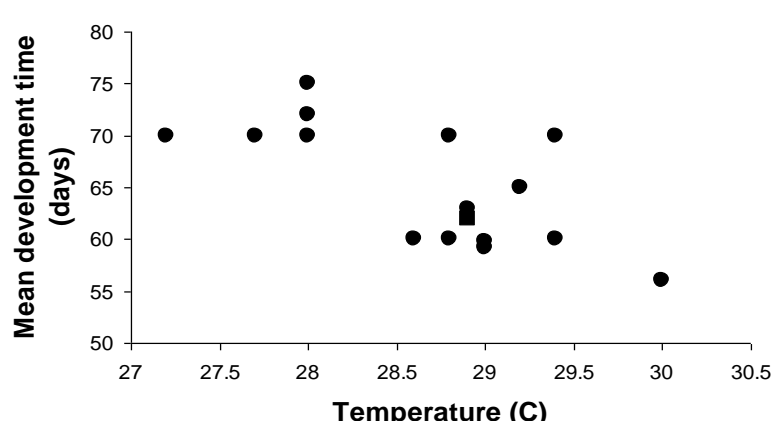

Reeves turtles

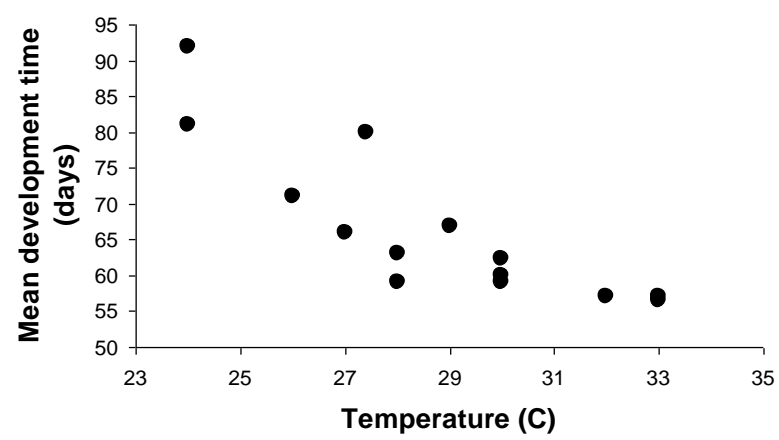

Leopard geckos

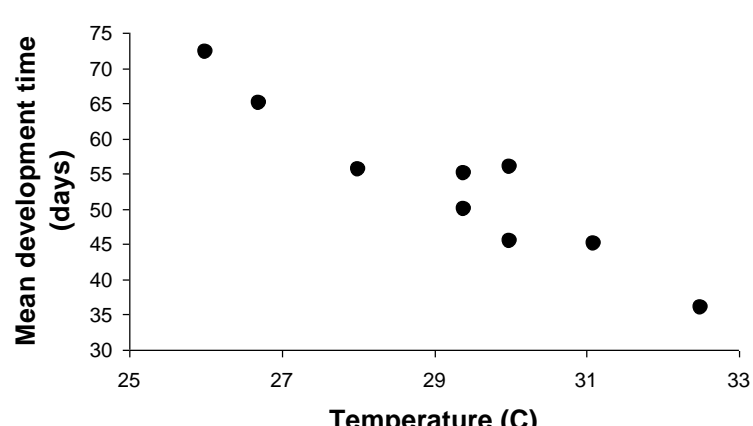

Greek tortoises

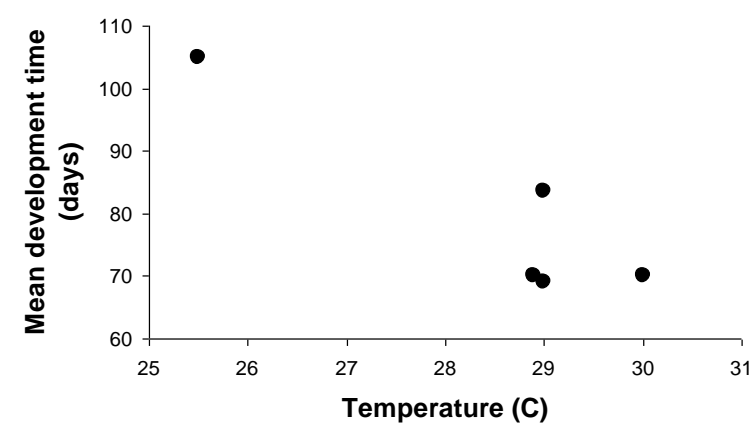

Waterdragons

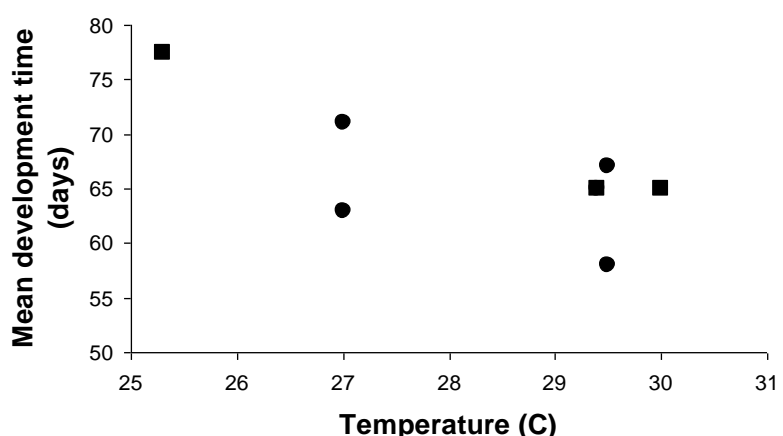


Supplementary Figure 2: Reduced Major Axis Regression plotting mean development time (days) * temperature $\left({ }^{\circ} \mathrm{C}\right)$ against mean development time (days) for snake-neck turtles (Chelodina longicollis), Reeves turtles (Chinemys reevesii), Greek tortoises (Testudo graeca), bearded dragons (Pogona vitticeps ( $\bigcirc)$ and P. barbata ( $\square)$ ), leopard geckos (Eublepharis macularius), and waterdragons (Physignathus lesueurii (०) and P. cocincinus ( $\square)$ ).

Snakeneck turtles

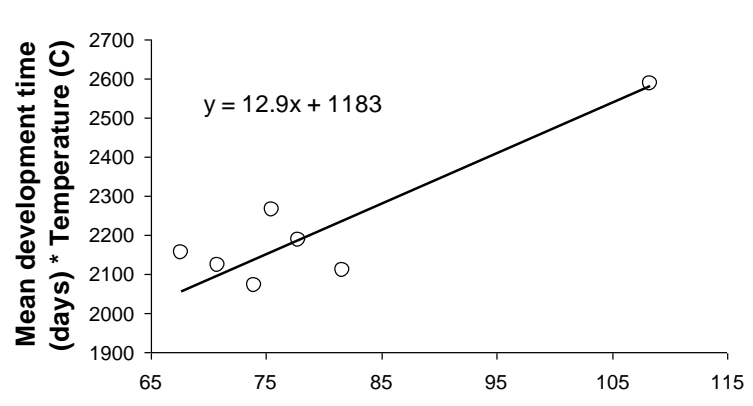

Mean development time (days)

\section{Bearded dragons}

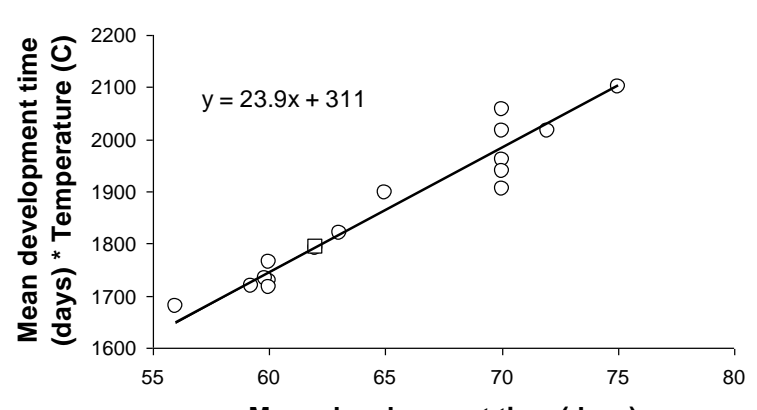

Mean development time (days)

\section{Reeves turtles}

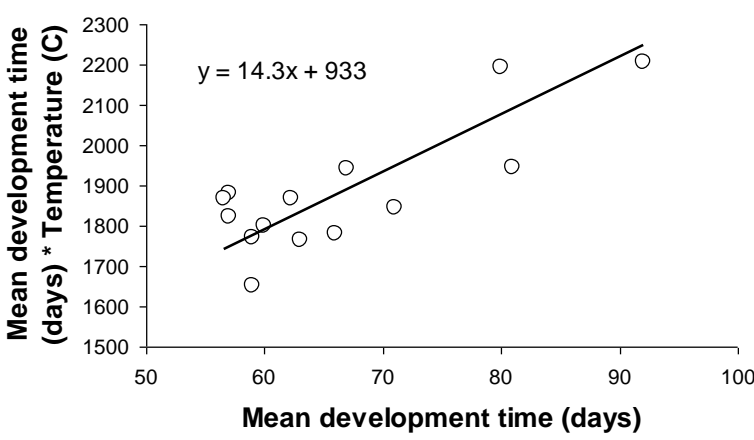

Leopard geckos

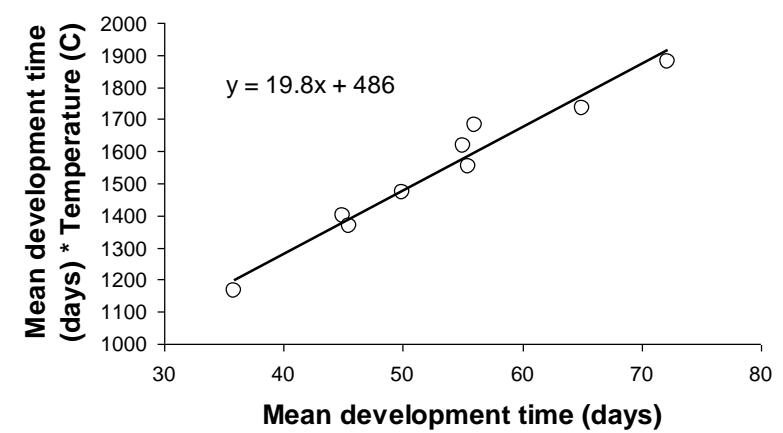

Greek tortoises

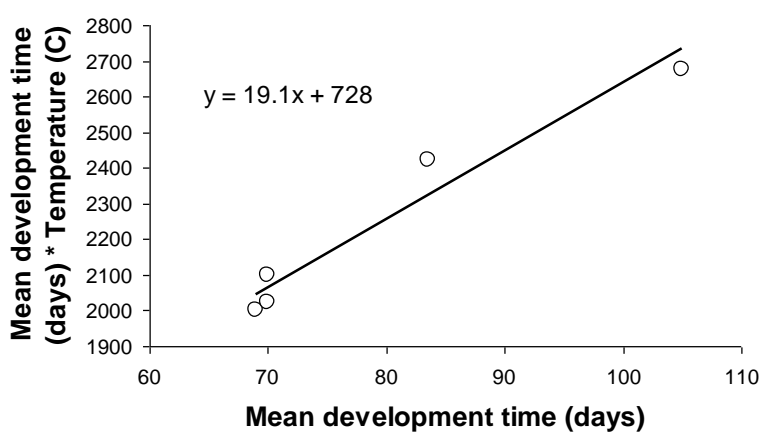

Waterdragons

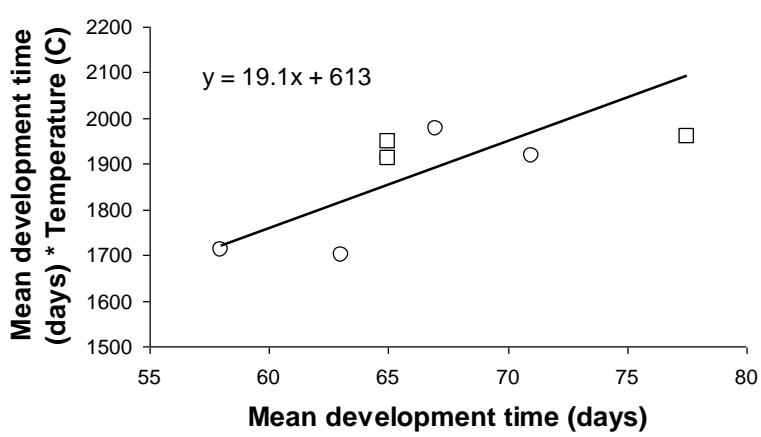


Supplementary Table 1: Data regarding developmental time and incubation length of exotic reptile eggs that were incorporated into the degree-day models.

\begin{tabular}{|c|c|c|c|c|}
\hline $\begin{array}{l}\text { Common } \\
\text { name }\end{array}$ & $\begin{array}{l}\text { Scientific } \\
\text { name }\end{array}$ & $\begin{array}{c}\text { Mean } \\
\text { incubation } \\
\text { temperature } \\
\left({ }^{\circ} \mathrm{C}\right)\end{array}$ & $\begin{array}{c}\text { Mean } \\
\text { development } \\
\text { time (days) }\end{array}$ & Reference \\
\hline $\begin{array}{l}\text { Red-eared } \\
\text { slider }\end{array}$ & $\begin{array}{c}\text { Trachemys } \\
\text { scripta elegans }\end{array}$ & 25 & 112.5 & $\begin{array}{l}\text { (Ernst and } \\
\text { Lovich 2009) }\end{array}$ \\
\hline $\begin{array}{l}\text { Red-eared } \\
\text { slider }\end{array}$ & $\begin{array}{c}\text { Trachemys } \\
\text { scripta elegans }\end{array}$ & 25 & 86 & $\begin{array}{c}\text { (Tucker and } \\
\text { Paukstis 1999) }\end{array}$ \\
\hline $\begin{array}{l}\text { Red-eared } \\
\text { slider }\end{array}$ & $\begin{array}{l}\text { Trachemys } \\
\text { scripta elegans }\end{array}$ & 25.2 & 96.9 & $\begin{array}{c}\text { (Ernst and } \\
\text { Lovich 2009) }\end{array}$ \\
\hline $\begin{array}{l}\text { Red-eared } \\
\text { slider }\end{array}$ & $\begin{array}{c}\text { Trachemys } \\
\text { scripta elegans }\end{array}$ & 26 & 67.5 & $\begin{array}{c}\text { (Invasive Species } \\
\text { Specialist Group } \\
\text { (ISSG) 2006) }\end{array}$ \\
\hline $\begin{array}{l}\text { Red-eared } \\
\text { slider }\end{array}$ & $\begin{array}{c}\text { Trachemys } \\
\text { scripta elegans }\end{array}$ & 27.5 & 68.9 & $\begin{array}{l}\text { (Ernst and } \\
\text { Lovich 2009) }\end{array}$ \\
\hline $\begin{array}{l}\text { Red-eared } \\
\text { slider }\end{array}$ & $\begin{array}{l}\text { Trachemys } \\
\text { scripta elegans }\end{array}$ & 28 & 61.1 & $\begin{array}{c}\text { (Tucker and } \\
\text { Warner 1999) }\end{array}$ \\
\hline $\begin{array}{l}\text { Red-eared } \\
\text { slider }\end{array}$ & $\begin{array}{l}\text { Trachemys } \\
\text { scripta elegans }\end{array}$ & 28 & 62.6 & $\begin{array}{c}\text { (Tucker and } \\
\text { Warner 1999) }\end{array}$ \\
\hline $\begin{array}{l}\text { Red-eared } \\
\text { slider }\end{array}$ & $\begin{array}{c}\text { Trachemys } \\
\text { scripta elegans }\end{array}$ & 28 & 62.3 & $\begin{array}{c}\text { (Tucker and } \\
\text { Warner 1999) }\end{array}$ \\
\hline $\begin{array}{l}\text { Red-eared } \\
\text { slider }\end{array}$ & $\begin{array}{c}\text { Trachemys } \\
\text { scripta elegans }\end{array}$ & 28 & 63.4 & $\begin{array}{c}\text { (Tucker and } \\
\text { Warner 1999) }\end{array}$ \\
\hline $\begin{array}{l}\text { Red-eared } \\
\text { slider }\end{array}$ & $\begin{array}{c}\text { Trachemys } \\
\text { scripta elegans }\end{array}$ & 28 & 65.1 & $\begin{array}{c}\text { (Tucker and } \\
\text { Paukstis 2000) }\end{array}$ \\
\hline $\begin{array}{l}\text { Red-eared } \\
\text { slider }\end{array}$ & $\begin{array}{c}\text { Trachemys } \\
\text { scripta elegans }\end{array}$ & 28 & 67.1 & $\begin{array}{c}\text { (Tucker and } \\
\text { Paukstis 2000) }\end{array}$ \\
\hline $\begin{array}{l}\text { Red-eared } \\
\text { slider }\end{array}$ & $\begin{array}{c}\text { Trachemys } \\
\text { scripta elegans }\end{array}$ & 28.5 & 65.33 & $\begin{array}{l}\text { (Filoramo and } \\
\text { Janzen 1999) }\end{array}$ \\
\hline $\begin{array}{l}\text { Red-eared } \\
\text { slider }\end{array}$ & $\begin{array}{l}\text { Trachemys } \\
\text { scripta elegans }\end{array}$ & 28.5 & 65.28 & $\begin{array}{c}\text { (Filoramo and } \\
\text { Janzen 1999) }\end{array}$ \\
\hline $\begin{array}{l}\text { Red-eared } \\
\text { slider }\end{array}$ & $\begin{array}{l}\text { Trachemys } \\
\text { scripta elegans }\end{array}$ & 28.5 & 61 & $\begin{array}{l}\text { (Les, Paitz et al. } \\
\text { 2007) }\end{array}$ \\
\hline $\begin{array}{l}\text { Red-eared } \\
\text { slider }\end{array}$ & $\begin{array}{l}\text { Trachemys } \\
\text { scripta elegans }\end{array}$ & 28.7 & 60.9 & $\begin{array}{c}\text { (Tucker, } \\
\text { Filoramo et al. } \\
\text { 1998) }\end{array}$ \\
\hline $\begin{array}{l}\text { Red-eared } \\
\text { slider }\end{array}$ & $\begin{array}{c}\text { Trachemys } \\
\text { scripta elegans }\end{array}$ & 28.7 & 62.8 & $\begin{array}{c}\text { (Tucker, } \\
\text { Filoramo et al. } \\
\text { 1998) }\end{array}$ \\
\hline $\begin{array}{l}\text { Red-eared } \\
\text { slider }\end{array}$ & $\begin{array}{c}\text { Trachemys } \\
\text { scripta elegans }\end{array}$ & 29.8 & 63.85 & $\begin{array}{c}\text { (Ernst and } \\
\text { Lovich 2009) }\end{array}$ \\
\hline $\begin{array}{l}\text { Snake-neck } \\
\text { turtle }\end{array}$ & $\begin{array}{l}\text { Chelodina } \\
\text { longicollis }\end{array}$ & 23.89 & 108.3 & (Georges 1988) \\
\hline $\begin{array}{l}\text { Snake-neck } \\
\text { turtle }\end{array}$ & $\begin{array}{l}\text { Chelodina } \\
\text { longicollis }\end{array}$ & 25.86 & 81.6 & (Georges 1988) \\
\hline $\begin{array}{l}\text { Snake-neck } \\
\text { turtle }\end{array}$ & $\begin{array}{l}\text { Chelodina } \\
\text { longicollis }\end{array}$ & 28.12 & 77.8 & (Georges 1988) \\
\hline
\end{tabular}




\begin{tabular}{|c|c|c|c|c|}
\hline $\begin{array}{l}\text { Snake-neck } \\
\text { turtle }\end{array}$ & $\begin{array}{l}\text { Chelodina } \\
\text { longicollis }\end{array}$ & 29.97 & 70.8 & (Georges 1988) \\
\hline $\begin{array}{l}\text { Snake-neck } \\
\text { turtle }\end{array}$ & $\begin{array}{l}\text { Chelodina } \\
\text { longicollis }\end{array}$ & 31.86 & 67.6 & (Georges 1988) \\
\hline $\begin{array}{l}\text { Snake-neck } \\
\text { turtle }\end{array}$ & $\begin{array}{l}\text { Chelodina } \\
\text { longicollis }\end{array}$ & 30 & 75.5 & $\begin{array}{l}\text { (Goode and } \\
\text { Russell 1968) }\end{array}$ \\
\hline $\begin{array}{l}\text { Snake-neck } \\
\text { turtle }\end{array}$ & $\begin{array}{l}\text { Chelodina } \\
\text { longicollis }\end{array}$ & 28 & 74 & (Johnson 2006) \\
\hline Reeves turtle & $\begin{array}{l}\text { Chinemys } \\
\text { reevesii }\end{array}$ & 28 & 59 & $\begin{array}{l}\text { (Du, Shen et al. } \\
\text { 2009) }\end{array}$ \\
\hline Reeves turtle & $\begin{array}{l}\text { Chinemys } \\
\text { reevesii }\end{array}$ & 24 & 81 & $\begin{array}{l}\text { (Du, Hu et al. } \\
\text { 2007) }\end{array}$ \\
\hline Reeves turtle & $\begin{array}{l}\text { Chinemys } \\
\text { reevesii }\end{array}$ & 26 & 71 & $\begin{array}{l}\text { (Du, Hu et al. } \\
\text { 2007) }\end{array}$ \\
\hline Reeves turtle & $\begin{array}{l}\text { Chinemys } \\
\text { reevesii }\end{array}$ & 28 & 63 & $\begin{array}{l}\text { (Du, Hu et al. } \\
\text { 2007) }\end{array}$ \\
\hline Reeves turtle & $\begin{array}{l}\text { Chinemys } \\
\text { reevesii }\end{array}$ & 30 & 59 & $\begin{array}{l}\text { (Du, Hu et al. } \\
\text { 2007) }\end{array}$ \\
\hline Reeves turtle & $\begin{array}{l}\text { Chinemys } \\
\text { reevesii }\end{array}$ & 32 & 57 & $\begin{array}{l}\text { (Du, Hu et al. } \\
\text { 2007) }\end{array}$ \\
\hline Reeves turtle & $\begin{array}{l}\text { Chinemys } \\
\text { reevesii }\end{array}$ & 24 & 92 & $\begin{array}{l}\text { (Du, Zheng et al. } \\
\text { 2006) }\end{array}$ \\
\hline Reeves turtle & $\begin{array}{l}\text { Chinemys } \\
\text { reevesii }\end{array}$ & 27 & 66 & $\begin{array}{l}\text { (Du, Zheng et al. } \\
\text { 2006) }\end{array}$ \\
\hline Reeves turtle & $\begin{array}{l}\text { Chinemys } \\
\text { reevesii }\end{array}$ & 30 & 60 & $\begin{array}{l}\text { (Du, Zheng et al. } \\
\text { 2006) }\end{array}$ \\
\hline Reeves turtle & $\begin{array}{l}\text { Chinemys } \\
\text { reevesii }\end{array}$ & 33 & 57 & $\begin{array}{l}\text { (Du, Zheng et al. } \\
\text { 2006) }\end{array}$ \\
\hline Reeves turtle & $\begin{array}{l}\text { Chinemys } \\
\text { reevesii }\end{array}$ & 29 & 66.91 & $\begin{array}{l}\text { (Wang, Ma et al. } \\
\text { 1995) }\end{array}$ \\
\hline Reeves turtle & $\begin{array}{l}\text { Chinemys } \\
\text { reevesii }\end{array}$ & 30 & 62.29 & $\begin{array}{l}\text { (Wang, Ma et al. } \\
\text { 1995) }\end{array}$ \\
\hline Reeves turtle & $\begin{array}{l}\text { Chinemys } \\
\text { reevesii }\end{array}$ & 33 & 56.57 & $\begin{array}{l}\text { (Wang, Ma et al. } \\
\text { 1995) }\end{array}$ \\
\hline Reeves turtle & $\begin{array}{l}\text { Chinemys } \\
\text { reevesii }\end{array}$ & 27.4 & 80 & $\begin{array}{l}\text { (Kirkpatrick } \\
\text { 1991) }\end{array}$ \\
\hline Greek tortoise & $\begin{array}{c}\text { Testudo } \\
\text { graeca }\end{array}$ & 25.5 & 105 & (Wiltshier 2000) \\
\hline Greek tortoise & $\begin{array}{c}\text { Testudo } \\
\text { graeca }\end{array}$ & 29 & 83.5 & $\begin{array}{l}\text { (Lapid, Nir et al. } \\
\text { 2004) }\end{array}$ \\
\hline Greek tortoise & $\begin{array}{l}\text { Testudo } \\
\text { graeca }\end{array}$ & 29 & 69 & $\begin{array}{l}\text { (Soler, Silvestre } \\
\text { et al. 2009) }\end{array}$ \\
\hline Greek tortoise & $\begin{array}{l}\text { Testudo } \\
\text { graeca }\end{array}$ & 30 & 70 & (Dix 2009) \\
\hline Greek tortoise & $\begin{array}{l}\text { Testudo } \\
\text { graeca }\end{array}$ & 28.9 & 70 & $\begin{array}{l}\text { (Pet Care Gt } \\
\text { 2010) }\end{array}$ \\
\hline $\begin{array}{c}\text { Bearded } \\
\text { dragon }\end{array}$ & $\begin{array}{l}\text { Pogona } \\
\text { barbata }\end{array}$ & 28.9 & 62 & $\begin{array}{l}\text { (Abell-Davis } \\
\text { 2000) }\end{array}$ \\
\hline $\begin{array}{l}\text { Bearded } \\
\text { dragon }\end{array}$ & $\begin{array}{l}\text { Pogona } \\
\text { vitticeps }\end{array}$ & 28.8 & 60 & $\begin{array}{l}\text { (Sundial Reptile } \\
\text { 2010) }\end{array}$ \\
\hline
\end{tabular}




\begin{tabular}{|c|c|c|c|c|}
\hline $\begin{array}{l}\text { Bearded } \\
\text { dragon }\end{array}$ & $\begin{array}{l}\text { Pogona } \\
\text { vitticeps }\end{array}$ & 27.2 & 70 & (Tosney 2004) \\
\hline $\begin{array}{l}\text { Bearded } \\
\text { dragon }\end{array}$ & $\begin{array}{l}\text { Pogona } \\
\text { vitticeps }\end{array}$ & 29.4 & 60 & $\begin{array}{l}\text { (A-1 Reptiles } \\
\text { 2010) }\end{array}$ \\
\hline $\begin{array}{l}\text { Bearded } \\
\text { dragon }\end{array}$ & $\begin{array}{l}\text { Pogona } \\
\text { vitticeps }\end{array}$ & 28 & 75 & $\begin{array}{l}\text { (Federation of } \\
\text { New Zealand } \\
\text { Aquatic Societies } \\
\text { 2009) }\end{array}$ \\
\hline $\begin{array}{c}\text { Bearded } \\
\text { dragon }\end{array}$ & $\begin{array}{l}\text { Pogona } \\
\text { vitticeps }\end{array}$ & 29 & 59.8 & $\begin{array}{l}\text { (Sullivan, Orgeig } \\
\text { et al. 2002) }\end{array}$ \\
\hline $\begin{array}{l}\text { Bearded } \\
\text { dragon }\end{array}$ & $\begin{array}{l}\text { Pogona } \\
\text { vitticeps }\end{array}$ & 29 & 59.25 & $\begin{array}{l}\text { (Johnston, Orgeig } \\
\text { et al. 2000) }\end{array}$ \\
\hline $\begin{array}{l}\text { Bearded } \\
\text { dragon }\end{array}$ & $\begin{array}{l}\text { Pogona } \\
\text { vitticeps }\end{array}$ & 28 & 72 & $\begin{array}{l}\text { (My bearded } \\
\text { dragons 2010) }\end{array}$ \\
\hline $\begin{array}{l}\text { Bearded } \\
\text { dragon }\end{array}$ & $\begin{array}{l}\text { Pogona } \\
\text { vitticeps }\end{array}$ & 28 & 70 & (McGleish 2010) \\
\hline $\begin{array}{l}\text { Bearded } \\
\text { dragon }\end{array}$ & $\begin{array}{l}\text { Pogona } \\
\text { vitticeps }\end{array}$ & 29.2 & 65 & $\begin{array}{l}\text { (Bearded dragon } \\
\text { guide 2010) }\end{array}$ \\
\hline $\begin{array}{l}\text { Bearded } \\
\text { dragon }\end{array}$ & $\begin{array}{l}\text { Pogona } \\
\text { vitticeps }\end{array}$ & 29.4 & 70 & (Pollock 2010) \\
\hline $\begin{array}{l}\text { Bearded } \\
\text { dragon }\end{array}$ & $\begin{array}{l}\text { Pogona } \\
\text { vitticeps }\end{array}$ & 28.8 & 70 & $\begin{array}{l}\text { (Anonymous } \\
\text { 2010a) }\end{array}$ \\
\hline $\begin{array}{l}\text { Bearded } \\
\text { dragon }\end{array}$ & $\begin{array}{l}\text { Pogona } \\
\text { vitticeps }\end{array}$ & 28.9 & 63 & (Hitch 2010) \\
\hline $\begin{array}{l}\text { Bearded } \\
\text { dragon }\end{array}$ & $\begin{array}{l}\text { Pogona } \\
\text { vitticeps }\end{array}$ & 27.7 & 70 & $\begin{array}{l}\text { (Anonymous } \\
2010 \mathrm{~b} \text { ) }\end{array}$ \\
\hline $\begin{array}{l}\text { Bearded } \\
\text { dragon }\end{array}$ & $\begin{array}{l}\text { Pogona } \\
\text { vitticeps }\end{array}$ & 28.6 & 60 & $\begin{array}{l}\text { (RepticZone } \\
\text { 2010) }\end{array}$ \\
\hline $\begin{array}{c}\text { Bearded } \\
\text { dragon }\end{array}$ & $\begin{array}{l}\text { Pogona } \\
\text { vitticeps }\end{array}$ & 30 & 56 & $\begin{array}{l}\text { (Handrigan and } \\
\text { Richman 2010) }\end{array}$ \\
\hline Leopard gecko & $\begin{array}{l}\text { Eublepharis } \\
\text { macularius }\end{array}$ & 29.4 & 50 & (Kirby 2005) \\
\hline Leopard gecko & $\begin{array}{l}\text { Eublepharis } \\
\text { macularius }\end{array}$ & 26.7 & 65 & $\begin{array}{l}\text { (Anonymous } \\
\text { 2010c) }\end{array}$ \\
\hline Leopard gecko & $\begin{array}{l}\text { Eublepharis } \\
\text { macularius }\end{array}$ & 29.4 & 55 & $\begin{array}{l}\text { (Anonymous } \\
\text { 2010c) }\end{array}$ \\
\hline Leopard gecko & $\begin{array}{l}\text { Eublepharis } \\
\text { macularius }\end{array}$ & 31.1 & 45 & $\begin{array}{l}\text { (Anonymous } \\
2010 \mathrm{c})\end{array}$ \\
\hline Leopard gecko & $\begin{array}{l}\text { Eublepharis } \\
\text { macularius }\end{array}$ & 30 & 56 & $\begin{array}{l}\text { (Handrigan and } \\
\text { Richman 2010) }\end{array}$ \\
\hline Leopard gecko & $\begin{array}{c}\text { Eublepharis } \\
\text { macularius }\end{array}$ & 26 & 72.2 & $\begin{array}{l}\text { (Viets, } \\
\text { Tousignant et al. } \\
\text { 1993) }\end{array}$ \\
\hline Leopard gecko & $\begin{array}{l}\text { Eublepharis } \\
\text { macularius }\end{array}$ & 28 & 55.5 & $\begin{array}{l}\text { (Viets, } \\
\text { Tousignant et al. } \\
\text { 1993) }\end{array}$ \\
\hline Leopard gecko & $\begin{array}{c}\text { Eublepharis } \\
\text { macularius }\end{array}$ & 30 & 45.5 & $\begin{array}{l}\text { (Viets, } \\
\text { Tousignant et al. } \\
\text { 1993) }\end{array}$ \\
\hline Leopard gecko & Eublepharis & 32.5 & 35.9 & (Viets, \\
\hline
\end{tabular}


macularius

\begin{tabular}{|c|c|}
\hline Waterdragon & $\begin{array}{c}\text { Physignathus } \\
\text { lesueurii }\end{array}$ \\
\hline Waterdragon & $\begin{array}{c}\text { Physignathus } \\
\text { lesueurii }\end{array}$ \\
\hline Waterdragon & $\begin{array}{c}\text { Physignathus } \\
\text { lesueurii }\end{array}$ \\
\hline Waterdragon & $\begin{array}{c}\text { Physignathus } \\
\text { lesueurii }\end{array}$ \\
\hline
\end{tabular}

Waterdragon Physignathus cocincinus

Waterdragon Physignathus cocincinus

Waterdragon Physignathus cocincinus

Waterdragon Physignathus cocincinus
Tousignant et al. 1993) (Anonymous 2010d) (Langerwerf 2006) (Langerwerf 2006) (Mark (NZ reptile breeder) 2010)

65 (Langerwerf 2006)

(Power 2010)

(Hillman 2010)

25.3
65

65

77.5
(Anonymous 2004)

\section{References}

A-1 Reptiles (2010). "Bearded dragon care: Pogona vitticeps." Retrieved February 13, 2010, from http://www.a1reptiles.net/BeardedDragonCareSheet.html.

Abell-Davis, S. (2000). "Pogona barbata." Retrieved June 2, 2008, from http://www.jcu.edu.au/school/tbiol/zoology/herp/Pogonabarbata.PDF.

Anonymous (2004). "Reptile Forums." Retrieved March 8, 2010, from http://www.reptileforums.com/forums/showthread.php?t=6245.

Anonymous (2010a). "How to breed bearded dragons." Retrieved March 2, 2010, from http://www.videojug.com/article/how-to-breed-bearded-dragons.

Anonymous (2010b). "How to breed bearded dragons." Retrieved March 3, 2010, from http://www.ehow.com/how_2268018_breed-bearded-dragons.html.

Anonymous (2010c). "Breeding leopard geckos the right way." Retrieved March 2, 2010, from http://ezinearticles.com/?Breeding-Leopard-Geckos-the-RIGHTWay\&id=563028.

Anonymous (2010d). "Australian waterdragon: Physignathus lesueurii." Retrieved March 4, 2010, from http://www.reptilia.org/Lizards20.aspx.

Bearded dragon guide (2010). Retrieved March 2, 2010, from http://www.beardeddragonguide.com/breeding-sexing-bearded-dragon-lizards/.

Dix, D. (2009). Good as gold: Breeding golden Greek tortoises. Reptiles. July 2009. 
Du, W., L. Hu, et al. (2007). "Effects of incubation temperature on embryonic development rate, sex ratio and post-hatching growth in the Chinese three-keeled pond turtle, Chinemys reevesii." Aquaculture 272: 747-753.

Du, W., J. Shen, et al. (2009). "Embryonic development rate and hatchling phenotypes in the Chinese three-keeled pond turtle (Chinemys reevesii): The influence of fluctuating temperature versus constant temperature." Journal of thermal biology 34: 250-255.

Du, W., R. Zheng, et al. (2006). "The influence of incubation temperature on morphology, locomotor performance, and cold tolerance of hatchling Chinese threekeeled pond turtles, Chinemys reevesii." Chelonian Conservation and Biology 5(2): 294-299.

Ernst, C. and J. Lovich (2009). Turtles of the United States and Canada. Baltimore, Maryland, USA, The Johns Hopkins University Press.

Federation of New Zealand Aquatic Societies (2009). Retrieved November 20, 2009, from http://fnzas.org.nz/fishroom/viewtopic.php?f=40\&t=42546\&sid=0a593ad5baf 6b62eec8239fd00a2b847\&start $=0$.

Filoramo, N. and F. Janzen (1999). "Effects of hydric conditions during incubation on overwintering hatchlings of the red-eared slider turtle (Trachemys scripta elegans)." Journal of Herpetology 33(1): 29-35.

Georges, A. (1988). "Sex determination is independent of incubation temperature in another Chelid turtle, Chelodina longicollis." Copeia 1988(1): 248-254.

Goode, J. and J. Russell (1968). "Incubation of eggs of three species of chelid tortoises, and notes on their embryological development." Australian Journal of Zoology 16: 749-761.

Handrigan, G. and J. Richman (2010). "Autocrine and paracrine Shh signaling are necessary for tooth morphogenesis, but not tooth replacement in snakes and lizards (Squamata)." Developmental Biology 337: 171-186.

Hillman, S. (2010). "Chinese Water Dragon." Retrieved March 7, 2010, from http://www.reptileguides.com/water_dragon_breeding.html.

Hitch, R. (2010). "Breeding bearded dragons (Pogona vitticeps)." Retrieved March 2, 2010, from http://www.reptileuv.com/reptile-caresheets/bearded-dragon-breeding.php.

Invasive Species Specialist Group (ISSG) (2006). Retrieved July 12, 2006, from www.issg.org/database/species/ecology.asp?si=71\&ver=print

Johnson, R. (2006). "Dystocia in an injured common Eastern long-necked turtle (Chelodina longicollis)." Veterinary Clinics Exotic Animal Practice 9: 575-581. 
Johnston, S., S. Orgeig, et al. (2000). "Development of the pulmonary surfactant system in two oviparous vertebrates." American Journal of Physiology: Regulatory, Integrative and Comparative Physiology 278: R486-R493.

Kirby, S. (2005). "Breeding and incubating." Retrieved March 5, 2010, from http://www.leopardgecko.co.uk/documents/caresheet/breeding.htm.

Kirkpatrick, D. (1991). The Reeves turtle, Chinemys reevesii: An alternative to sliders and painted turtles. Reptile and Amphibian Magazine. Nov./ Dec. 1991: 2-7.

Langerwerf, B. (2006). Water Dragons. Neptune City, New Jersey, USA, T.F.H. Publications, Inc.

Lapid, R., I. Nir, et al. (2004). "Reproductive traits in the spur-thighed tortoise (Testudo graeca terrestris): New tools for the enhancement of reproductive success and survivorship." Theriogenology 61(6): 1147-1162.

Les, H., R. Paitz, et al. (2007). "Experimental test of the effects of fluctuating incubation temperatures on hatchling phenotype." Journal of Experimental Zoology 307A: 274-280.

Mark (NZ reptile breeder) (2010). Personal Communication: May 8, 2010. Manawatu, TradeMe.

McGleish, T. (2010). "Bearded dragon care and breeding." Retrieved 8 January, 2010, from http://www.kingsnake.com/gladescs/bearded/.

My bearded dragons (2010). "Breeding bearded dragons." Retrieved February 6, 2010, from http://www.mybeardeddragons.co.uk/breeding.html.

Pet Care Gt (2010). "Greek tortoise breeding." Retrieved March 7, 2010, from http://www.petcaregt.com/Turtle/Greek-Tortoise-Breeding.html.

Pollock, A. (2010). "Bearded dragon: Breeding and egg care." Retrieved February 6, 2010, from http://www.helium.com/items/1095445-breeding-bearded-dragons.

Power, T. (2010). "Breeding Chinese water dragons." Retrieved March 7, 2010, from http://www.triciaswaterdragon.com/breeding.htm.

RepticZone (2010). "Care sheet for bearded dragons breeding." Retrieved February 5, 2010, from http://repticzone.com/caresheets/1285.html.

Soler, J., A. Silvestre, et al. (2009). "Testudo graeca iberia: The Eurasian spurthighed tortoise in Romania." Reptilia 64: 39-44.

Sullivan, L., S. Orgeig, et al. (2002). "Regulation of pulmonary surfactant secretion in the developing lizard, Pogona vitticeps." Comparative Biochemistry and Physiology, Part A 133: 539-546. 
Sundial Reptile (2010). "Bearded dragon care sheet." Retrieved March 5, 2010, from http://www.sundialreptile.com/care\%20sheet--bearded\%20dragon.htm.

Tosney, K. (2004). "Bearded dragon eggs: Laying and incubation." Retrieved March 2, 2010, from http://www.bio.miami.edu/ktosney/file/eggs.pdf.

Tucker, J., N. Filoramo, et al. (1998). "Response of red-eared slider, Trachemys scripta elegans, eggs to slightly differing water potentials." Journal of Herpetology 32(1): 124-128.

Tucker, J. and G. Paukstis (1999). "Post-hatching substrate moisture and overwintering hatchling turtles." Journal of Herpetology 33(4): 608-615.

Tucker, J. and G. Paukstis (2000). "Hatching success of turtle eggs exposed to dry incubation environment." Journal of Herpetology 34(4): 529-534.

Tucker, J. and D. Warner (1999). "Microgeographic variation in response of redeared slider (Trachemys scripta elegans) embryos to similar incubation environments." Journal of Herpetology 33(4): 549-557.

Viets, B., A. Tousignant, et al. (1993). "Temperature-dependent sex determination in the leopard gecko, Eublepharis macularius." The Journal of Experimental Zoology 265: 679-683.

Wang, P., W. Ma, et al. (1995). "Studies on the physiological ecology of incubation in Chinemys reevesii." Asiatic Herpetological Research 6: 151-156.

Wiltshier, B. (2000). The Greek spur-thighed tortoise (Testudo graeca): Its care and management. Auckland, New Zealand, Premier Print Services Ltd. 